\title{
Biogeography and ecology in a pantropical family, the Meliaceae
}

\author{
M. Heads \\ Buffalo Museum of Science, 1020 Humboldt Parkway, \\ Buffalo, NY 14211-1293, USA. \\ m.j.heads@gmail.com
}

\begin{abstract}
This paper reviews the biogeography and ecology of the family Meliaceae and maps many of the clades. Recently published molecular phylogenies are used as a framework to interpret distributional and ecological data. The sections on distribution concentrate on allopatry, on areas of overlap among clades, and on centres of diversity. The sections on ecology focus on populations of the family that are not in typical, dry-ground, lowland rain forest, for example, in and around mangrove forest, in peat swamp and other kinds of freshwater swamp forest, on limestone, and in open vegetation such as savanna woodland. Information on the altitudinal range of the genera is presented, and brief notes on architecture are also given. The paper considers the relationship between the distribution and ecology of the taxa, and the interpretation of the fossil record of the family, along with its significance for biogeographic studies. Finally, the paper discusses whether the evolution of Meliaceae can be attributed to 'radiations' from restricted centres of origin into new morphological, geographical and ecological space, or whether it is better explained by phases of vicariance in widespread ancestors, alternating with phases of range expansion.
\end{abstract}

Keywords. Altitude, limestone, mangrove, rain forest, savanna, swamp forest, tropics, vicariance

\section{Introduction}

The family Meliaceae is well known for its high-quality timbers, especially mahogany (Swietenia Jacq.). The family also has a diverse phytochemistry with many bioactive compounds, and different species are used in the production of cosmetics, medicines (antifungal, antiviral, and antibacterial), and poisons (such as insecticides). Some are important for their edible fruit. Most Meliaceae species are tropical trees with compound leaves, and the family includes the largest-known tree in Africa - an Entandrophragma excelsum Sprague, $81.5 \mathrm{~m}$ high on Mt Kilimanjaro (Hemp et al., 2017).

Meliaceae comprise about 48 genera and 700 species. The family is widespread through the tropics and also occurs in some temperate areas. Most members occupy lowland tropical rain forest on dry ground (termed 'terra firme' forest in Brazil), but the family is also present in mangrove swamp, freshwater swamp forest, montane forest, drier forest, woodland, and open savanna. It is often present in secondary vegetation, and several species are invasive weeds. The family occurs up to subalpine forest at the tree line (some members are frost-tolerant), but it is absent from true alpine vegetation. 


\section{Previous models of Meliaceae biogeography}

\section{Spatial analysis}

It has long been assumed that taxa originate in a restricted area and attain their distribution by moving out from there. Many different criteria have been proposed in order to locate a group's centre of origin. For example, it has been placed at the site of a group's centre of diversity, of its oldest fossil, or of its phylogenetically 'basal' group. (A 'basal' group is simply the smaller of the two main groups at the basal phylogenetic node; both clades are equally basal in the phylogeny, and strictly speaking it is the node, not either one of the clades, that is basal).

Previous studies on the biogeography of Meliaceae have proposed a localised centre of origin for the group. Using 'ancestral area' programmes, these studies have calculated an Old World centre of origin, either in Africa (Koenen et al., 2015) or in Madagascar-India (Koenen, 2011). However, the programmes used will often calculate centres of origin, even in cases where this is unlikely or at least questionable. For example, if members of a basal paraphyletic grade occur in the same region, the programmes will always find a centre of origin there. However, a group with a phylogeny Old World (Old World (Old World (New World))) has a basal paraphyletic grade in the Old World, but may not have had a centre of origin there. In the example shown here (Fig. 1), differentiation has taken place entirely by vicariance. The ancestor was cosmopolitan, as is the modern group.

In the case of subfamily Melioideae, for example, the phylogeny is: Old World (Old World (Old World (Old World (Old World and New World)))). The paraphyletic group in the Old World means that ancestral area programmes will calculate a centre of origin there. However, there is no need for any trans-Atlantic dispersal in the Melioideae if Meliaceae were already global before the origin of the two modern subfamilies (cf. Fig. 1).

Likewise, for the family as a whole, Koenen et al. (2015) wrote that: "The topology indicates an Old World origin for the family, as the Palaeotropical taxa in the family are paraphyletic with respect to Neotropical lineages (figs 1, S1)". The phylogeny shows that New World Meliaceae are secondary in a sense, but this does not necessarily mean they are the result of trans-Atlantic dispersal.

\section{Chronological analysis}

Establishing the time tree of phylogeny of a group is traditionally based on the fossil record of the group and its relatives. Muellner et al. (2006) wrote that "Fossils supporting a Gondwanan range are available for only few of the many pantropical eudicot families. Some workers have therefore taken the absence of Cretaceous fossils to attribute tropical range disjunctions to long-distance dispersal...". An alternative possibility is that the fossil record is very incomplete. Previous studies on the biogeography of Meliaceae have all calibrated the phylogeny with the fossil record alone, although Koenen et al. (2015) admitted that the fossil record of Meliaceae is "sparse". 

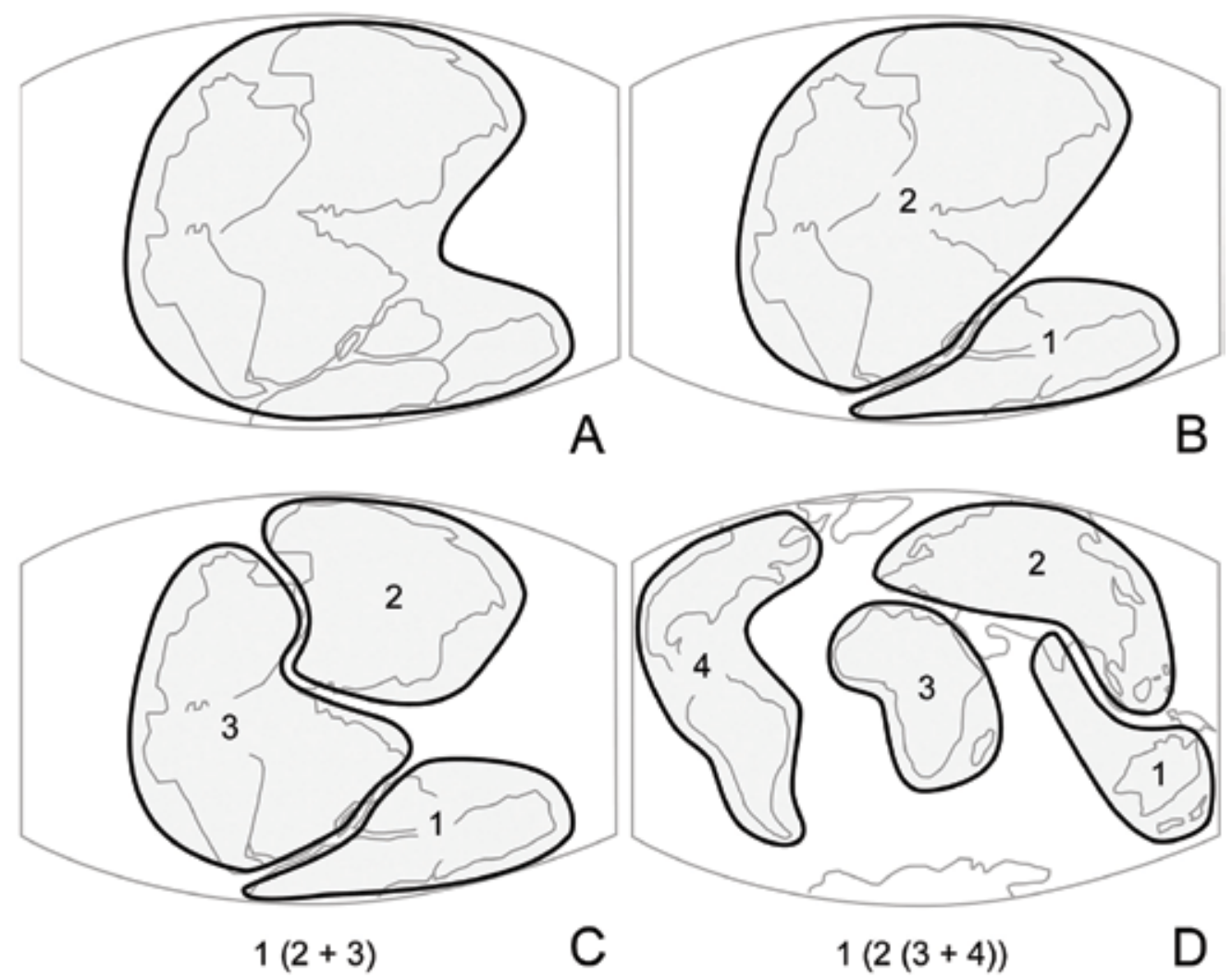

Fig. 1. Differentiation of a hypothetical, global group by vicariance, not by radiation from a centre of origin. A. A cosmopolitan ancestor of the group. B. Division into two groups. C. A second division gives three groups, one in what will become Africa and America. D. With the opening of the Atlantic, the America-Africa group is divided. The phylogeny is: Old World (Old World (Old World + New World)). There is a basal, paraphyletic grade in the Old World, but there was not a centre of origin there.

Individual fossils provide a fabulous wealth of data on extinct organic form, but the fossil record itself, and the stratigraphic sequence of taxa in it, cannot be taken at face value. Even at high taxonomic levels there are large gaps. For example, Grande (2016) highlighted three orders of fishes. In lampreys (order Petromyzontiformes; 38 living species), the youngest fossil is 120 million years old. In hagfishes (order Myxiniformes; 20 living species), the only fossil is 300 million years old. In coelacanths (order Coelacanthiformes; two living species, 150 extinct fossil species), the youngest fossil is 65 million years old. These marine animals live in conditions that are much more conducive to fossilisation than land plants such as Meliaceae.

Fossils (assuming palaeontologists agree on their identification) can provide a very useful minimum age for a clade, while actual clade ages can be estimated on the basis of biogeography and tectonics. If the boundary between clades correlates spatially with a tectonic feature, the age of the clades can be equated with the age 
of activity on that feature. If a coherent synthesis can be obtained using many such correlations, the argument for a causative relationship is strengthened.

Muellner et al. (2006) wrote that reliable age estimates depend on "completeness of the fossil record of a plant group... uncontroversial geology and age of the fossils... unambiguous assignment of the fossil taxa to extant taxa... and unambiguous, wellsupported positions of the corresponding extant taxa in the phylogenetic trees". In the Meliaceae alliance, the authors proposed that two taxa fulfilled all these requirements, Ailanthus Desf. (Simaroubaceae) and Toona (Endl.) M.Roem. (Meliaceae). However, the oldest Ailanthus fossils are "virtually identical" (Pfeil \& Crisp, 2008) to modern plants, and they appear in the fossil record without any obvious precursors. The simplest explanation is that the record is very incomplete.

Fossil fruit from the Early Eocene London Clay comprise capsules with winged seeds, typical of Meliaceae subfamily Cedreloideae, and they have been described as Toona sulcata (Bowerb.) E.Reid \& M.Chandler (Reid \& Chandler, 1933; Collinson, 1983). Other authors have interpreted the fossils as intermediate between Toona and Cedrela P.Browne and have placed them on the crown node of tribe Cedreleae (Toona and Cedrela) (Muellner et al., 2010). However, Koenen et al. (2015) wrote that the fruits of extant species of Toona and Cedrela are more elongate than the globose fossil fruits, "making the placement in Cedreleae [Toona and Cedrela] doubtful". Pigg et al. (2014) wrote that the generic assignment of the London Clay fossils "is in need of reevaluation".

Fossils from the Late Cretaceous of Wyoming have been identified as an extant genus of Meliaceae, Guarea L., that is widespread in tropical America. Muellner et al. (2006) described the identification as 'controversial'. Nevertheless, both the experts that they consulted (T.D. Pennington and K.B. Pigg) gave personal communications that the identification "may be correct". Muellner et al. did not use the fossil in their analysis, as this calibration produced "unrealistically old ages" for clades.

Fruits and seeds described from the Late Cretaceous (Campanian/Maastrichtian boundary) of Senegal were assigned to Meliaceae and considered to be similar to the genera Carapa Aubl. and Trichilia P.Browne (Monteillet \& Lappartient, 1981). However, Pigg et al. (2014) considered that the specimens need to be reevaluated.

Based on a fossil-calibrated phylogeny of the family, Muellner et al.(2006) argued that Meliaceae originated in Africa and dispersed from there to Eurasia, then North America, and finally South America (see discussion in Heads, 2012). Vicariance was ruled out because the family was thought to be too young: fossil-calibrated divergence estimates "indicate that Meliaceae originated after the last known connection between Africa and South America" (Muellner et al., 2006; italics added).

However, fossils can only indicate that a clade evolved before, not after, a particular date. Muellner et al. (2006) eliminated trans-Atlantic vicariance, but only by treating the minimum (fossil-calibrated) clade ages as maximum clade ages. Interpreting the clade ages in this way is not logical, and so the idea of dispersal that is based on these interpretations is dubious.

Muellner et al. (2006: 246) wrote: “Although we are aware that our calculated values are minimum estimates our fossil calibration points would have to be at least 
30-40 million years older to make the oldest Old-New World divergence events within the Meliaceae consistent with a continental break-up scenario". There is no reason why there should not be at least 30-40 million years of sampling error in a group's fossil record (see the three orders of fishes cited above), and so vicariance in Meliaceae with continental breakup is not falsified by the fossil record.

Muellner et al. (2006: 247) concluded: "Investigations employing new tools... have shown that long-distance, transoceanic dispersal may have played a major role in shaping the distribution of many taxa...". But the new data from sequencing studies, fossils, and geology all need to be interpreted. The studies that Muellner et al. (2006) cited have indeed supported traditional, centre of origin/dispersal theory, but only by treating fossil-calibrated, minimum clade ages as maximum ages.

Muellner-Riehl et al. (2016) referred to "the only direct (primary) information that the fossils provided, namely the minimum age of the respective clade...". To obtain actual clade ages with fossil calibrations "generally requires setting a maximum constraint [for at least one clade] that, in a strict form, does not exist as fossils only provide minimum ages". This is correct. However, the authors neglected their own advice, as they continued: "Using the absence of fossils for a maximum age constraint can only be justified in cases of a dense fossil record of multiple groups appearing in a sequence reflecting their evolutionary relationship. This applies to the eudicotyledons (eudicots), where the succession of the appearance and geographical spread of early angiosperm pollen (monosulcate, Hauterivian-Valanginian), early eudicot pollen (tricolpate, Barremian-Aptian), and derived eudicot pollen (tricolporate, late Albian) justifies the assumption that eudicots originated not much earlier than the appearance of their fossil pollen record...". Koenen et al. (2015) agreed with this: tricolpate pollen "is perhaps the only angiosperm fossil that can be used as a hard maximum age constraint as it is a plant part that is produced in abundance, fossilises easily and appears all over the fossil record shortly after its [putative] first appearance... Consequently, it seems unlikely that eudicots will be much older".

However, there are several problems with this, as discussed elsewhere (Heads, 2014: 67). Smith et al. (2010: 5897) concluded instead: "Using the first appearance of tricolpate pollen as a fixed calibration may underestimate the origin of eudicots and, by extension, other age estimates that have relied on this constraint. Tricolpate grains first appear in separated geographical areas and the grains themselves are not uniform in morphology..., both observations implying that the tricolpate clade originated some time before its appearance in the fossil record...".

Although the oldest tricolpate (eudicot-type) pollen is dated as about $125 \mathrm{Ma}$, excellent macrofossil material from 123 to $126 \mathrm{Ma}$ shows closest affinities with the eudicot family Ranunculaceae (Sun et al., 2011), suggesting that modern eudicot families, or their immediate precursors, already existed by then. This indicates a prior history for eudicots as a whole.

A further problem with the dating of eudicots from fossils is the fact that while most eudicots have tricolpate or 'tricolpate-derived' pollen, some do not. One example is Duparquetia Baill., a liane from West Africa that is near-basal in the phylogeny of legumes. It has bizarre pollen that in some features is "unique in the Fabales and 
eudicot clades, resembling more closely the monosulcate pollen found in monocots and basal angiosperms" (Banks et al., 2006: 107). It is doubtful that this pollen, if known only from fossils, would be identified as a eudicot.

In their clock study of eudicots, Anderson et al. (2005) noted that the tricolpate pollen of eudicots may have evolved after the split of eudicots from their sister group, for example, by parallel evolution in the main eudicot lineages. In another clock study, Smith et al. (2010) estimated that eudicots evolved in the Late Jurassic. They wrote: "our results suggest that the first appearance of tricolpate grains at ca. $125 \mathrm{Myr}$ underestimates the origin of the tricolpate clade by perhaps 3 to $22 \mathrm{Myr}$. This finding is problematic because the record of fossil pollen is judged to be very good through this time period...". But the pollen record is very good only in relation to the fossil record of other plant parts, not in an absolute sense. Smith et al. concluded (p. 5900): "we favour the use of $125 \mathrm{Myr}$ as a minimum age for the origin of the eudicot crown clade".

The study by Smith et al. (2010) was fossil-calibrated, and the age of eudicots they suggested is still only a minimum. Yet their extension of the age of eudicots from Early Cretaceous to Late Jurassic means that eudicot groups would have been exposed to critical, tectonic and paleogeographic events in Earth history.

Modern Bayesian dating studies (e.g. Muellner-Riehl et al., 2016) often acknowledge that, in theory, fossils can give only minimum clade ages. However, in practice they stipulate just how much older a clade can be than its oldest fossil, in the 'priors' (stipulated prior to any analysis). The problem is that the priors are subjectively chosen and are usually very narrow, that is, a clade is assumed to be not much older than its oldest fossil. With priors that are too narrow, the analysis will often produce clade ages that are much too young, and this is especially likely in a group with such a sparse fossil record as Meliaceae.

Priors are crucial. As Hauenschild et al. (2018) observed, vicariance is often ruled out for clades in which reconstructed age estimates are younger than continental breakup. However, they noted that the young ages estimated "may also be due to overly small highest posterior density intervals of the time estimated based on too narrowly set priors, and vicariance thereby may be erroneously ruled out (Beaulieu et al., 2013). If the importance of vicariance in the course of the Gondwanan breakup is to be evaluated via the pragmatic criterion of mismatch between age estimates and geological history, the priors defining the molecular dating analyses have to be solid" (italics added). Yet the priors used in practice are both subjective and narrow, an inheritance from the earlier, simplistic idea that a group's age is the age of its oldest fossil.

Biologists setting priors often do not appreciate that there is a secular trend to fossil preservation, as younger periods of time are represented by larger volumes of sedimentary rock. In addition, the quality of younger rocks for fossil preservation increases, as older rocks are more likely to be deformed. Finally, younger fossils are more similar to modern groups and are more likely to have been identified correctly.

Holland (2016) discussed 'the pull of the recent', whereby the quality of the fossil record declines with geological age. He concluded: "Although minimum ages of clades are given by the oldest preserved fossil, these underestimate the true age, 
which must be bracketed by probabilistic methods... Although most of these methods assume uniform preservation rates, this assumption is unsupported over geological timescales...".

Bromham (2019) suggested that molecular clock dating "requires us to believe six impossible things before breakfast". Many of the assumptions "are based on statistical tractability rather than being informed by improved understanding of molecular evolution, yet changing the assumptions can influence molecular dates. ... If our assumptions are wrong, then our inference could be misleading, however much data we have.... All molecular dating analyses require us to make statements of belief, irrespective of whether we call them models, assumptions, or priors. We need to recognise that while some disagreements between molecular dates are due to differences in data or method, many are due to different beliefs codified in the analyses...".

To summarise, a fossil gives a minimum age for its clade, and we do not know how much older than this date the actual clade age is. Biogeographic calibrations suggest that many clades are much older than their oldest fossil (Heads, 2014).

Koenen et al. (2015) used four fossils to calibrate a phylogeny of Meliaceae, including Toona sulcata from the London Clay. All four fossil calibration points were assigned uniform priors with the fossil ages as a minimum age and the maximum age constrained to the same age as the root height prior. But how old is the root? Koenen et al. (2015) wrote: "the shape of the chosen prior distribution is often subjective. Choosing an informed prior distribution based on palaeobiological evidence... would be better, but this is not possible given the sparse fossil record of Meliaceae...".

Koenen et al. (2015) ran three analyses with different maximum age priors, as follows: 1. Using a fossil-calibrated crown age for Sapindales (c. $71 \mathrm{Ma}$ ) as a hard maximum bound; 2. Using a fossil-calibrated stem age of Sapindales (98 Ma) as a hard maximum bound; 3. Using the age of the first tricolpate pollen (127 Ma) as a hard maximum bound for the age of eudicots.

The authors regarded the third method as most likely. Nevertheless, the authors found that in scenarios 2 and 3, the crown age of the Sapindales becomes 'unrealistically old', especially when the tricolpate pollen age is used. (Using tricolpate pollen, the authors calculated that Sapindales originated at $120 \mathrm{Ma}$ and Meliaceae at $80 \mathrm{Ma}$, but biogeography indicates that this last date is still much too young).

By stipulating such narrow priors and thus calculating such young clade ages, the authors were able to support traditional chance dispersal over vicariance: “... Old World/New World disjunctions are indeed substantially too young (Oligocene or younger) for vicariant explanations... [Thus] Our results indicate [Oligocene or younger] trans-Atlantic dispersal from Africa to the New World..." (Koenen et al., 2015). Again, this simply reflects the very narrow priors that were imposed. The time and place of origin of Meliaceae can be regarded as open questions.

Twenty years ago, most authors argued that species had their origin in the Pleistocene (since 2.6 Ma). The argument that species could ever be Cretaceous (before $65 \mathrm{Ma}$ ), made on the basis of treating fossils as minimum clade ages and on biogeography (Craw et al., 1999), was controversial. Now, most authors accept that 
species may be as old as Miocene (5-20 Ma). However, recent molecular studies have proposed that species of plants, such as Gunnera herteri Osten (Bacon et al., 2018), and animals, such as petalurid dragonfly species and the frog Leiopelma hochstetteri (Ware et al., 2014; Carr et al., 2015), date back to the Cretaceous (65 Ma).

\section{Global distribution of Meliaceae and allied families}

The family Meliaceae is widespread in tropical Africa, Asia and America (Fig. 2), and so it can be described loosely as 'pantropical'. However, it also has significant representation outside the tropics in South Africa, Australia, New Zealand, Pakistan, northern India, Nepal, and central China (north to Gansu). The highest latitude reached by the family is about $43^{\circ} \mathrm{S}$ (Dysoxylum spectabile Hook.f. at the Hurunui River in New Zealand; see www.NZPCN).

In addition to their presence in some temperate forests, native Meliaceae are absent in a large part of the wet tropics, as they do not occur in the central Pacific (Hawaii and southeastern Polynesia). The reason for this curious anomaly is discussed further below.

As already mentioned, fossils suggest that Meliaceae were formerly distributed further north, in Europe, Japan, and North America. However, because of problems with the identifications, the putative fossil Meliaceae are not shown in Fig. 2. Also missing from Fig. 2 are the many naturalised species of Meliaceae, including invasive weed trees. In modern times, species of Meliaceae have naturalised far beyond the indigenous limits of the family, especially in North America, Eurasia, and the central Pacific islands.

Most Meliaceae inhabit 'lowland tropical rain forest' of some kind (540 species), but 162 species are in drier, deciduous forest and savanna (Koenen et al., 2015). Also, many occur at higher elevations, in distinctly montane forest. Together with the extratropical species, this shows that the group does not require the hot, wet conditions of lowland tropical rain forest, and the distribution of these conditions does not explain the distribution of the family.

\section{Distribution of Meliaceae and related families in the Pacific}

Meliaceae have maximum species numbers in tropical Asia and Malesia (303 species), with fewer in the Neotropics (189 species), Madagascar (107 species), and tropical Africa (102 species). However, despite their abundance in Malesia and parts of the south-west Pacific, such as Fiji, Meliaceae are absent from a vast area of the central Pacific (Fig. 2). This area of absence includes Hawaii (where there are five naturalised species), the Galapagos (with one naturalised, invasive species), Juan Fernandez Islands, the Marquesas Islands (one naturalised species), the Society Islands and the Cook Islands. This absence exists despite the fact that the family includes mangroves (Xylocarpus J.Koenig, which ranges east to Tonga) and many weedy species.

When explaining absences in groups it is often useful to consider the distribution of the groups' relatives. Meliaceae (48 genera, 700 species) form a well-supported 


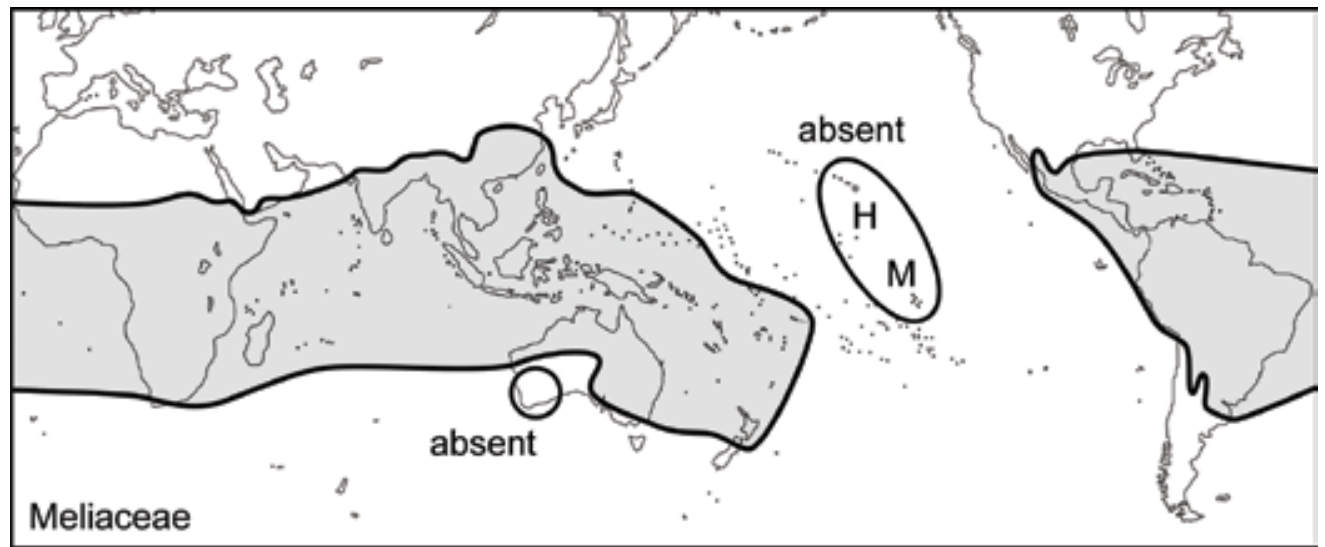

Fig. 2. Global distribution of Meliaceae (grey fill), and large regions where Meliaceae are absent (unfilled) (Stevens, 2001 onwards). $\mathrm{H}=$ Hawaiian Islands; $\mathrm{M}=$ Marquesas Islands. Extralimital fossils occur in the northern hemisphere but are not shown. Anthropogenic introductions are also not shown.

clade with the smaller, pantropical family Simaroubaceae (22 genera, 100 species) (Koenen et al., 2015; Muellner-Riehl et al., 2016). This pair is closest to Rutaceae (153 genera, 1975 species). Simaroubaceae are 'pantropical', as they are present in Africa, Asia and America. However, as with Meliaceae, they are absent from Hawaii, the Galapagos, Juan Fernandez Islands, and SE Polynesia. In contrast, native Rutaceae are present in all four of these areas, and are notably diverse in Hawaii (58 species) and the Marquesas ( 7 species) (the Marquesas have only 4\% of the land area of Hawaii). The absence of Meliaceae from many very small islands in the central Pacific, such as Rapa or Rarotonga, might be the result of regional extinction with continuing subsidence (as the plate moves away from the central Pacific spreading ridge and cools). However, the absence from Hawaii and the Marquesas seems more significant, as the closely related Rutaceae are so diverse there.

The central Pacific allopatry between the two clades, Meliaceae + Simaroubaceae, vs Rutaceae, especially on the Hawaii-Marquesas sector, can be explained as a trace of the original allopatry caused by vicariance between the two clades. If this is correct, similar patterns should occur in other groups.

The Hawaiian biota is well known for the high diversity of groups such as honeycreepers, drosophilids and lobeliads. However, there are also many conspicuous absences (Heads, 2012). In the Hawaiian flora, many tropical plants, including mangroves, are absent, despite having very efficient means of dispersal. Other plants that characterise tropical shorelines and small islands, either globally (such as Calophyllum L., Terminalia L., Hernandia L., Salicornia L., and Atriplex L.) or through the Old World and Pacific (such as Barringtonia J.R.Forst. \& G.Forst.), are also absent from the Hawaiian indigenous flora. Nevertheless, species of most of these genera thrive in Hawaii as introduced weeds. 
Transport to Hawaii in mud on birds' feet is often proposed to explain groups' presence on the islands. Yet some of the most characteristic marsh plants, such as Eriocaulaceae and Juncus L., are absent from the indigenous flora (although several introduced Juncus species are now widespread). In the same way, many diverse, pantropical groups that are abundant in rain forest elsewhere are absent from the indigenous flora of Hawaii. These include Cyatheaceae, Araceae sensu stricto, Zingiberales (Zingiberaceae, Marantaceae etc.), Melastomataceae, Ficus L. (figs), and Piper L. (members of all these groups are naturalised). Thus, although the absence of Meliaceae, including the mangrove Xylocarpus, from Hawaii seems strange, it conforms to a standard pattern that requires a general explanation, and regional vicariance is suggested here. Meliaceae are also absent from southwestern Australia (as native plants), again, in a region where Rutaceae have high diversity.

\section{Phylogeny and biogeography in Meliaceae}

Koenen et al. (2015) sequenced all the genera of Meliaceae and 254 (c. 34\%) of the species. The phylogeny that they proposed (Fig. 3) is adopted here, with the single exception of the Xylocarpus-Carapa group, discussed below.

Two subfamilies are now accepted for Meliaceae: Cedreloideae (previously known as Swietenioideae) with 14 genera, and Melioideae with 34 genera. The xylem anatomy in each of the two subfamilies is distinctive (Pennington \& Styles, 1975), and the genera that are most highly rated for their timber, some of the most sought after in the world, are mainly in subfamily Cedreloideae. These include true mahogany (Swietenia in America), African mahogany (Khaya A.Juss. and Entandrophragma C.DC.), Spanish cedar (Cedrela) and toon (Toona).

\section{Subfamily Cedreloideae}

Subfamily Cedreloideae comprises three primary clades (Fig. 3). The first is a transPacific pair, Chukrasia A.Juss. and Schmardaea H.Karst. The second and third groups are pantropical. The second main clade comprises another trans-Pacific pair (Toona and Cedrela) and genera of Africa and Madagascar. In the third main clade (Soymida A.Juss. etc.), the phylogenetic/geographic sequence is distinctive: India - Madagascar - Africa - America - widespread. This could represent either a series of dispersal events or a sequence of vicariance events in an already widespread ancestor.

Each of the three main groups in Cedreloideae includes both Old World and New World members, suggesting early differentiation of the three, followed by their range expansion (by normal dispersal) and widespread overlap around the globe. These two phases are obscure, and their geography is 'buried' beneath the last round of differentiation, within each of the three clades. The biogeography at that level is much clearer. 


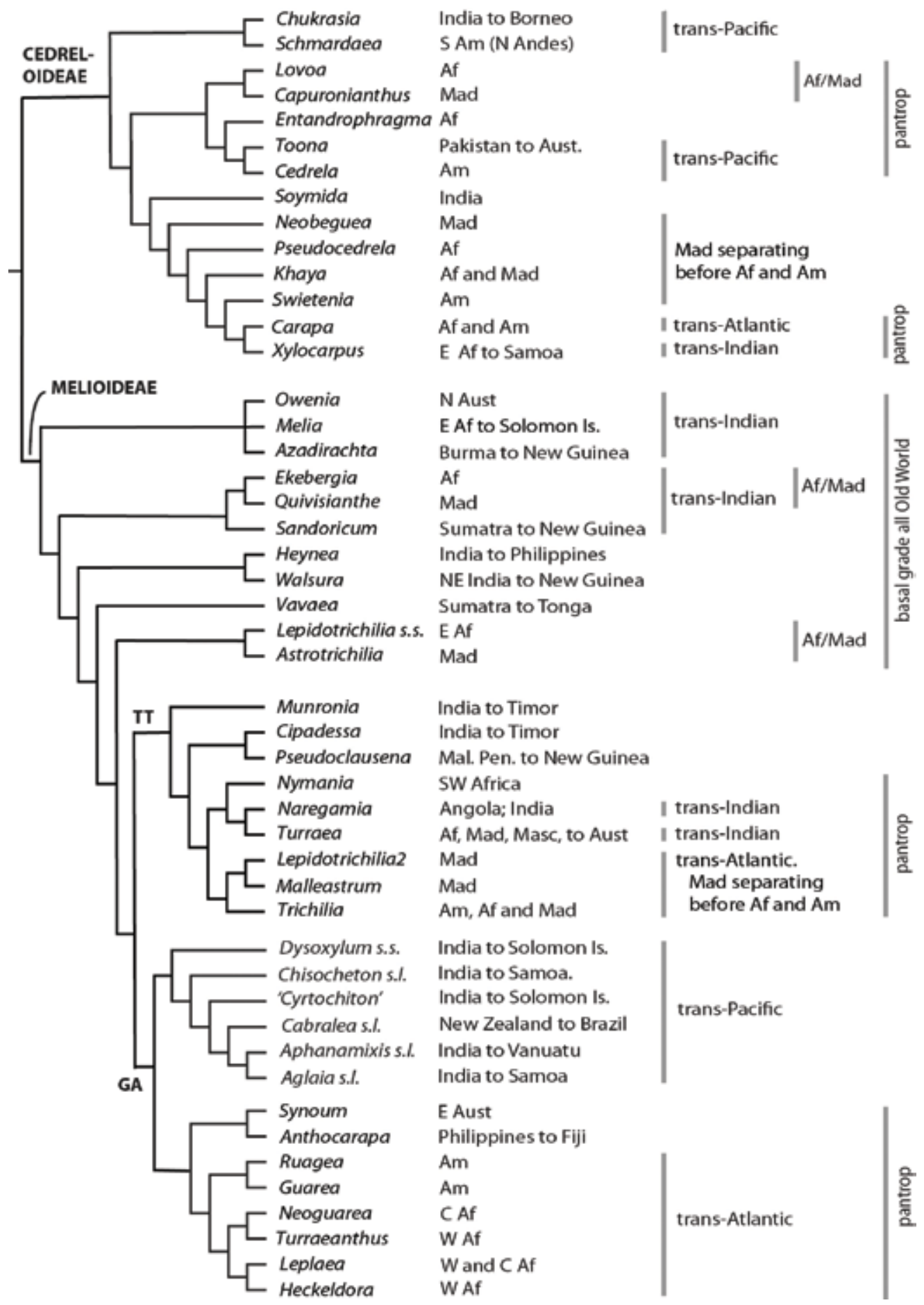

Fig. 3. Phylogeny and distribution of Meliaceae. TT $=$ Turraea-Trichilia clade; $\mathrm{GA}=$ GuareaAglaia clade. 


\section{Subfamily Melioideae}

Subfamily Melioideae comprises a basal, paraphyletic grade made up of five clades (all restricted to the Old World) and two large, Old World-New World sister groups, the TT and GA clades.

In the basal grade, the two basal clades (the Owenia F.Muell. group and the Ekebergia Sparrm. group) both have trans-Indian Ocean disjunctions; in the first it appears to be East Africa - India, in the second: Madagascar - Sumatra. Of the next three clades, two are around the eastern Indian Ocean (India to the Philippines and New Guinea), and one is around the western Indian Ocean (East Africa and Madagascar).

The remainder of Melioideae comprises the Turraea-Trichilia (TT) clade and its sister, the Guarea-Aglaia (GA) clade. Both are distinct in the family because of the large numbers of species in each. Both could be described as 'pantropical', but there are significant differences between them. The geographic differences are of special interest, and it is suggested that they represent traces of the original allopatry that existed between the two at the time of their origin.

\section{Pantropical groups in Meliaceae}

Meliaceae are not simply a pantropical group, as the family includes four, separate pantropical groups, two in each subfamily. Thus Meliaceae, a complex of several pantropical groups, stand in contrast with other 'pantropical' groups, such as primates, in which there is only one pantropical clade, the group itself, and the primary subclades are geographically restricted.

As suggested above, the fact that there are multiple pantropical clades in Meliaceae implies early phases of diversification followed by large-scale range expansion leading to clade overlap. The range expansion was not necessarily the result of rare, chance dispersal, and is more likely to have involved normal dispersal, as part of a community, mediated by geological changes which affected many different groups in similar ways. For example, the last, very large-scale marine transgressions, in the Cretaceous, would have meant that any groups with a maritime or tidal ecology and a tendency to weediness would have expanded their range considerably.

\section{Trans-Atlantic distributions}

Within the pantropical clades of Meliaceae (Fig. 3), several groups each straddle one of the major ocean basins. Trans-Atlantic disjunctions are evident in three clades: Khaya-Carapa; Lepidotrichilia2-Malleastrum-Trichilia (with Lepidotrichilia2 being a segregate of Lepidotrichilia T.D.Penn. \& Styles sensu stricto); and RuageaGuarea-Neoguarea-Turraeanthus-Leplaea-Heckeldora. Likewise, in the sister group of Meliaceae, the Simaroubaceae, trans-Atlantic groups include Quassia L. of West Africa and tropical America, and also Pierreodendron Engl. of West Africa + Simarouba Aubl. of tropical America (Clayton et al., 2009).

\section{Trans-Indian Ocean distributions}

These occur in five clades of Meliaceae: Xylocarpus; Owenia-Melia-Azadirachta; Ekebergia-Quivisianthe-Sandoricum; Naregamia; and Turraea. In Simaroubaceae, 
similar patterns occur in Samadera Gaertn. (Madagascar, India, Sri Lanka, and Burma to the Solomon Islands) and Soulamea Lam. (Seychelles, and Borneo to Fiji).

\section{Trans-Pacific distributions}

Trans-Pacific affinities in tropical groups are common, but they are much less well known than trans-Atlantic and trans-Indian Ocean affinities. In Meliaceae they occur in three clades: Chukrasia-Schmardaea; Toona-Cedrela; and DysoxylumChisocheton-Cabralea-Aphanamixis-Aglaia. These trans-Pacific affinities include the 'basal' clade of the 'basal' subfamily (Chukrasia-Schmardaea). Likewise, in the Simaroubaceae, the 'basal' clade comprises Picrasma Blume: India to the Solomon Islands, also in tropical America, plus Castela Turpin + Holacantha A.Gray of tropical and subtropical America (including the Galapagos; Clayton et al., 2009). Other transPacific groups include the family Heliconiaceae (Sulawesi to Fiji and widespread in tropical America) and the tribe Moutabeeae (Polygalaceae) (Heads, 2014: 271-274). A recently documented example is the tribe Anomospermeae (Menispermaceae) (Lian et al., 2019).

The biogeographic connections across the tropical Pacific can be accounted for by tectonic change. As Mabberley (1992: 17) noted: “... much of the land accreted along the western coast of the Americas since the Middle Jurassic comprises various fragments, some from far away in the Pacific". There is now good evidence that parts of the large igneous plateaux that formed in the West Pacific (Ontong Java, Hikurangi and Manihiki Plateaux) were subaerial (Heads, 2014: 205; Buchs et al., 2018; Hochmuth et al., 2019), and that components of the Manihiki Plateau collided with western Colombia (Hochmuth \& Gohl, 2017).

\section{Madagascar}

Madagascar has long been known for its high levels of endemism in Meliaceae, and six of the eight genera present are endemic. The morphology-based taxonomy of Pennington \& Styles (1975) proposed that two of the Madagascar endemics, Capuronianthus J.-F.Leroy and Quivisianthe Baill., represent monotypic subfamilies (the only subfamilies that were accepted apart from Cedreloideae and Melioideae). The molecular phylogeny of Koenen et al. (2015) does not support this, but the earlier classification does indicate the great morphological distinction of these Madagascar genera.

Three clades display an Africa-Madagascar sister group relationship: LovoaCapuronianthus, Ekebergia-Quivisianthe, and Lepidotrichilia sensu strictoAstrotrichilia. Rather than the Madagascar group being nested in an otherwise African group, perhaps sister to a form in Mozambique, the Madagascar group is sister to Africa as a whole, consistent with an early differentiation.

In two cases, a Madagascar clade separates from a widespread, intercontinental group before Africa and America separate from each other (Lepidotrichilia2 and Malleastrum (Baill.) J.-F.Leroy in Madagascar vs. Trichilia in America, Africa, Madagascar and Asia; and Neobeguea J.-F.Leroy in Madagascar vs. Pseudocedrela Harms in Africa, Swietenia in America, and others). Again, this suggests an early differentiation. 


\section{India}

India appears as a boundary or centre of endemism in 13 clades, especially in the Dysoxylum Blume group. A boundary at NE India (Assam in the broad sense) occurs in Walsura Roxb. and Chisocheton Blume, and in the widespread species Dysoxylum mollissimum Blume.

\section{Phylogeny and ecology of Meliaceae}

Meliaceae are often abundant and conspicuous. In the lowland primary forests of Malesia they make up to $17 \%$ of all trees with trunks over $10 \mathrm{~cm}$ diameter (Mabberley et al., 1995). In West Africa they can dominate forests in the same way that legumes dominate some South American rain forests, and dipterocarps dominate some in Malesia. Meliaceae are poorly represented at higher altitudes, but they are sometimes conspicuous in lower montane forest and a few species occur near the tree line in the Andes and East Africa. Many species inhabit secondary forest, and drier, more open vegetation, with a few in semidesert. As White (1986) commented, "In its ecology the Meliaceae is more diverse than most tropical families of comparable size...".

Apart from rain forest giants, the family also includes understorey treelets (with a single trunk) and shrubs with varied architecture. Subfamily Melioideae also includes a few straggling, scandent and climbing shrubs, a liane (Turraea laurentii De Wild. in the Congo basin), rhizomatous subshrubs, and geoxylic subshrubs with more or less herbaceous sucker shoots that resprout annually from a woody rootstock.

\section{Reconstructions of ancestral ecology}

Most Meliaceae are evergreen trees and treelets in lowland rain forests. However, an analysis using BAYESTRAITS reconstructions (Pagel \& Meade, 2007) concluded that the most recent common ancestor of Meliaceae was a deciduous species that inhabited either savannas, dry forest, or montane forest (Koenen et al., 2015). The programmes that reconstruct ancestral morphology and ecology, as with the ancestral area programmes (see above), assume that a paraphyletic basal grade displays the primitive condition. However, the idea that the ancestor was geographically, morphologically and ecologically restricted and uniform in this way (as an ideal, Platonic entity) is rejected here. The biogeography of the family instead indicates widespread ancestors, and widespread groups are much more likely to be heterogeneous genetically, morphologically and ecologically. There is no reason to assume that the direct ancestor of Meliaceae was a uniform species, or that it was restricted to a single area or habitat type.

\section{Have Meliaceae evolved by radiation?}

It is sometimes suggested that the evolutionary history of Meliaceae has been one of radiation. Koenen et al. (2015) concluded that the family as a whole evolved by "recent radiations", while Pennington \& Clarkson (2013) proposed recent radiation in Guarea, Clarkson et al. (2016) proposed "recent rapid radiation" in Trichilia, and 
Grudinski et al. (2014a) discussed the "major radiation" in Aglaia Lour.

The idea of 'evolutionary radiation' implies a restricted morphological, ecological and geographical centre, and, as noted, Koenen et al. (2015) proposed that the Meliaceae radiated from 'a deciduous species that inhabited seasonal habitats... in the Old World'. Their paper was a contribution in a volume dedicated to 'adaptive radiations' (Hetherington, 2015). This concept was popularised by the authors of the Modern Synthesis (Simpson, 1953), and it proposes that groups originate at a centre and radiate out from there, invading new morphological, ecological and geographic space. However, the acceptance of vicariance as a mode of speciation means there is another mode of differentiation, one that does not involve radiation. Hence authors now make a clear distinction between adaptive radiation and geographic speciation (Givnish, 2015), and accept non-ecological, allopatric speciation as well as nonadaptive radiations (Czekanski-Moir \& Rundell, 2019).

The process that has resulted in many 'adaptive radiations' is not only not adaptive, it is also not a radiation. In a vicariance event, there is not necessarily any ecological difference between the descendants, and there is no radiation from a centre; rather, there is a break at the centre, in a widespread ancestor. Thus examples of 'adaptive radiations', such as Meliaceae, are probably neither adaptive nor radiations, but are more likely to be the result of alternating phases of differentiation by allopatric vicariance, and range expansion by dispersal. The latter is not the result of chance, but is mediated by tectonics and climatic change.

Givnish (2015) pointed out that there is much confusion about 'adaptive radiation'. Soulebeau et al. (2015) described it as a 'pivotal concept' in evolutionary biology, but found that it is 'hazy', and "usually used in a misleading way, implying a range of hypotheses and corollaries in the best case and serving as an 'empty bag' in many others". One thing that 'radiation' must imply is a central point of origin (morphological, ecological and geographic), from which the radiation takes place. As Givnish (2015) recognised, the core issue in adaptive radiation has always been: “... the invasion of additional volumes of morphospace and ecospace [the 'adaptive zones' of Simpson (1953)]". Volume of ecospace is, in large part, 'kind of habitat'.

The key point here is that a clade invades one or more new ecospaces from a centre of origin in another. This differs from a vicariance model, in which different habitats are inherited, not invaded, by descendant clades, from a widespread ancestor that already occupied a range of habitats before the new clades diverged.

Adaptive radiation is a component in a process termed the CODA model (Lomolino \& Brown, 2009), as it is based on centre of origin, dispersal and adaptation. In this model, a clade moves out from its centre of origin by dispersal to a new locality and habitat. Here it faces new extrinsic needs and changes its morphology and physiology in response to these, bringing about adaptation. It is usually taken for granted that adaptation is the main factor in structural evolution, although this has been questioned by some tropical botanists (e.g. Corner, 1952; Van Steenis, 1981; Hay \& Mabberley, 1991), and instead of structure being determined by function and extrinsic needs, structure may determine function. For example, the morphology of an animal's teeth determines many aspects of its diet; the diet does not determine the 
teeth. If the teeth evolve (or fall out), the diet changes. In this model, morphological evolution is driven not by adaptation (which is the result, not the cause), but by nonrandom mutation (Nei, 2013). In mutation-driven evolution, selection may prune some of the products of mutation, but it is a secondary process, not an all-powerful mechanism that can produce whatever new morphology is required. Modern studies are now questioning even classical examples of adaptation, such as bill morphology in birds (Navalón et al., 2019) and body size in squamates (Slavenko et al., 2019).

In the model of ecological evolution suggested here, the ancestor of Meliaceae was already widespread globally, morphologically diverse, and ecologically diverse before the modern groups began to differentiate. Differentiation of such a global group by vicariance does not require a centre of origin, or a radiation, and the trajectory of morphological evolution is primarily the result of non-random mutation, not selection.

\section{Habitats occupied by Meliaceae}

Meliaceae are in 'lowland rain forest', but this is difficult to define and grades off into other types of forest in cooler, drier, wetter, and more saline sites. Many Meliaceae occur in typical lowland forest, but are also present in one or more of the other forest types, and several are restricted to these. Niche studies often concentrate on the ecological relationships of species, but the focus in this paper is on the distributional and ecological range of genera. Within the genera, the species often occur in different habitats and form ecophyletic series. Aspects of the ecology of Meliaceae genera are shown in Fig. 4.

\section{Mangrove and associated vegetation}

In Meliaceae, Xylocarpus is recognised as a true mangrove, and mangrove associates occur in 10 other genera, scattered through the different clades. Likewise, in a phylogenetic study of halophytes, Bromham (2015) was “....surprised to find that, rather than clustering in groups of related species, salt-tolerant grass species [200 spp.] were scattered throughout the phylogeny... Many of the other families tested showed a similar (non-significant) pattern of many independent origins [of salt tolerance]". However, the scattering of salt-tolerance through the phylogeny would not be surprising if the feature were a primitive one and the present-day occurrences relictual.

Mangrove plants are characterised by their intertidal habitat and a high frequency of certain morphological features, such as stilt roots, pneumatophores, and vivipary. However, these are far from constant, even in classic mangroves. For example, Rhizophora L. does not have pneumatophores, Bruguiera Lam. does not have stilt roots, and Sonneratia L.f. is not viviparous (even though it is often a pioneer mangrove; Van Steenis, 1958). This suggests that the features are not new adaptations to new needs, but relictual features of early seed plant architecture, and that mangroves did not invade the shore but originated there.

Stilt roots are recorded in two Meliaceae, both species of lowland forest in Malesia: Chisocheton tomentosus Mabb. of the Malay Peninsula and Sumatra (lowland and hill dipterocarp forest, to $400 \mathrm{~m}$ altitude), and C. polyandrus Merr. of Borneo (lowland and hill dipterocarp forest, 150-300 m altitude) (Mabberley et al., 1995). 


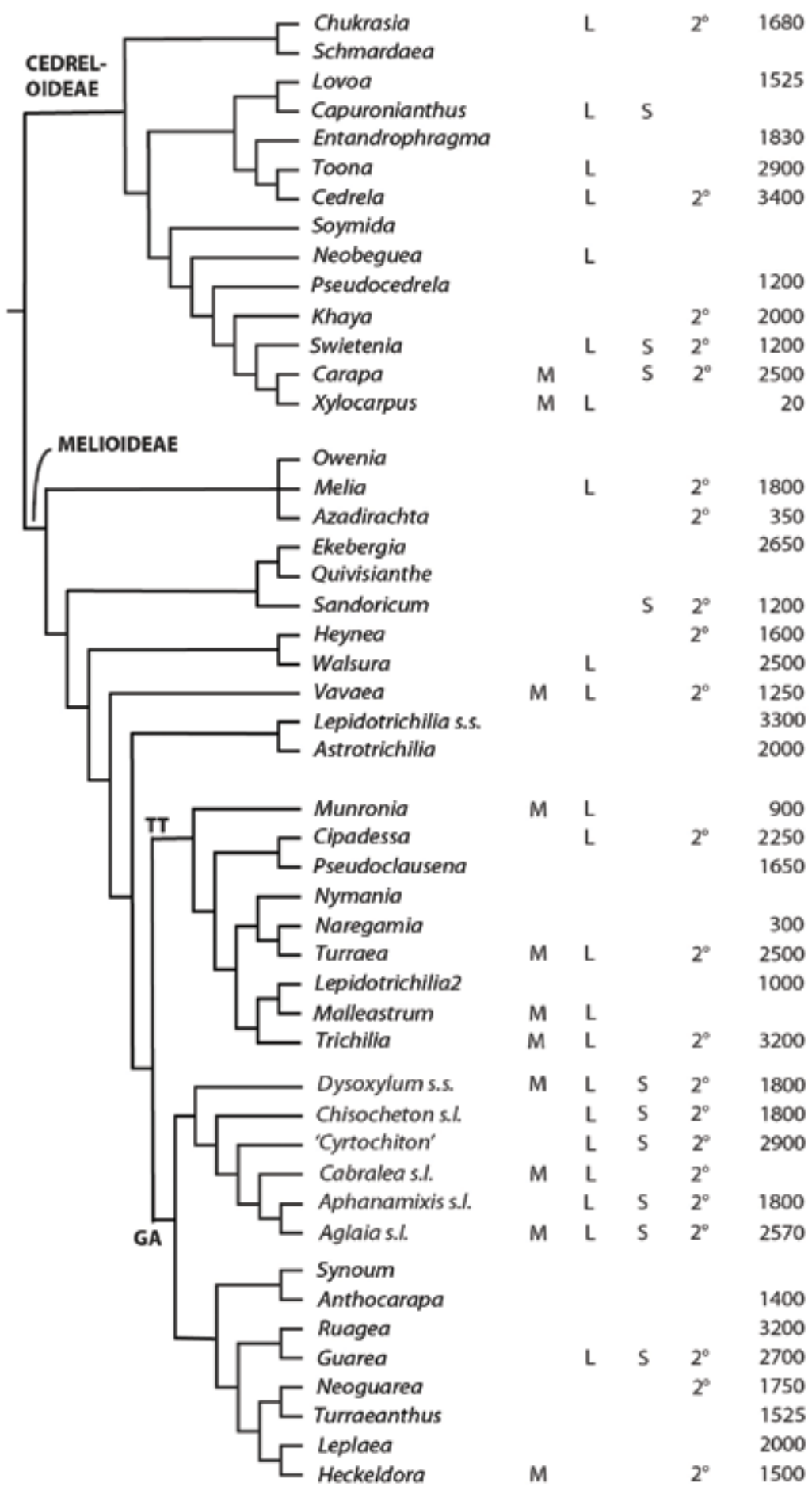

Fig. 4. Phylogeny and ecology of Meliaceae. $\mathrm{M}=$ in or near mangrove; $\mathrm{L}=$ on limestone; $\mathrm{S}$ $=$ in swampy forest; $2^{\circ}=$ in secondary forest; upper elevational limit given (in metres) where documented. Most genera are also in the lowlands. The figure does not include all species in Dysoxylum Blume sensu lato, including the 2580 and $3000 \mathrm{~m}$ records, as their precise clade is not known. 
Pneumatophores and extended, ribbon-like buttresses occur in the mangrove Xylocarpus. Another member of Meliaceae, Aglaia cucullata Pellegr., is a tree with plank buttresses up to $3 \mathrm{~m}$ high; it also has pneumatophores up to $60 \mathrm{~cm}$ high and up to $7 \mathrm{~m}$ away from the bole. The species ranges from the Ganges delta in Bangladesh to New Guinea, and inhabits mangrove, back-mangrove, tidal estuaries, Nypa Steck palm swamp, riverine forest, and lowland evergreen forest, at 0-50 m altitude (Mabberley et al., 1995).

A third morphological feature seen in many mangroves is vivipary. In most angiosperm seeds, growth is suppressed for some time and can involve a lengthy phase of dormancy. This suppression does not occur in viviparous seeds. Tomlinson (1986: 26) suggested that "vivipary among seed plants... is well-developed only in mangroves". However, it occurs in many species other than those given in the latest list (Farnsworth, 2000), such as 53 species of Cactaceae (Cota-Sánchez et al., 2011) and a spectacular, stilt-rooted member of Asteraceae, Fitchia speciosa Cheeseman (pers. obs, in Rarotonga, Cook Islands). Lloyd (1902) described vivipary in Podocarpus Pers. and other groups, and concluded that vivipary "... is by no means the unusual condition it is often supposed to be".

Another plant missing from Farnsworth's (2000) list is a viviparous member of Meliaceae, Dysoxylum mollissimum Blume. This large tree (up to $58 \mathrm{~m}$ high) inhabits primary and secondary forests, including coastal forests behind mangrove, up to 1900 $m$ altitude, and Mabberley et al. (1995) wrote that "the seeds may germinate before the fruits are dispersed from the tree". In contrast, the 'true mangrove' member of Meliaceae, Xylocarpus, is not truly viviparous, but the embryos, like those of the mangroves Avicennia L. and Laguncularia C.F.Gaertn., are well developed when they fall and emerge as seedlings soon afterwards (Mabberley et al., 1995).

A poorly known aspect of architecture in mangroves is the development of runners. In mangroves such as Avicennia, Rhizophora and Sonneratia, the lower branches may recline under their own weight and root distally; in Sonneratia alba Sm., individual axes have been traced to a length of $37 \mathrm{~m}$ (Tomlinson, 1986). These runners or stolons are similar morphologically to rhizomes, which are present in Meliaceae such as Naregamia Wight \& Arn., Trichilia, and possibly Turraea L. Likewise, rooting of reclining branches is observed in Carapa. Runner development here, as in the mangroves, is interpreted as archaic. Thus the construction of the trees and treelets of most Meliaceae has involved the suppression of the horizontal system of runners in favour of a single, main, erect axis. Adventitious rooting in many trees is suppressed, but it has been found to be more common in tree branches (under epiphyte mats) than was realised (Nadkarni, 1981). Fully developed stilt roots also occur in mossy montane forest, in groups such as Pandanus Parkinson.

A critical feature of mangroves is their tolerance of frequent physical disturbance by the tides. Tomlinson (1986: 24) noted that mangroves display "clearly pronounced characteristics of pioneer species in their reproductive biology..." and "we might characterise mangroves as pioneer species...". Likewise, many genera and species of Meliaceae occur in secondary vegetation (see 'Secondary forest', below), and some species are gregarious. 


\section{Back-mangrove}

The inner, landward edge of the mangrove (the 'back-mangrove') is one of the more diverse communities in the tropics, but it is seldom discussed. There are many kinds of adjacent terrestrial communities, and a large number of 'mangrove-associate' species.

Guppy (1906: 43) described Fijian shore plants under three headings, 'beach formation', 'mangrove formation', and 'intermediate formation'. He observed that "The mangrove formation comprises . . . many plants other than mangroves", and that "It is not possible to draw a definite line between the plants of the mangrove swamp and those of the tracts around" (p. 551). Whitmore (1984) agreed: "there is no sharp demarcation between beach vegetation of sandy and rocky coasts, mangrove forest of muddy coasts, and brackish water forests . ..". In Queensland, Dowling \& McDonald (1982) wrote: "In some instances it is difficult to decide which species are 'true' mangroves and which are not. The problem mainly exists for marginal species that occur in brackish areas and which may occasionally behave as a 'true' mangrove in some situations and as land based plants in others".

The back-mangrove may grade into beach forest or thicket, to periodically or permanently inundated freshwater swamp forest and peat swamp forest, to lowland rain forest, to "a particularly rank and luxuriant vegetation where the Scitamineae [Zingiberaceae, Marantaceae, etc.] often take a leading part" (Guppy, 1906: 485), to open, arid salinas occupied by halophytic herbs or shrubs (Chapman, 1976), or to other kinds of open habitat and secondary vegetation. There is often no sharp line between mangrove and these communities, or, rather, there is often a small-scale mosaic of species typical of the different communities in different microhabitats. A small area in inner mangrove vegetation that is raised by just a few centimetres can bear typical dry land species, even if it is only a few square metres in extent (cf. Van Steenis, 1958: 432). The situation is much more complex than the zonation patterns illustrated in textbook accounts of the outer mangrove.

It is usually assumed that angiosperms 'invaded' the mangrove habitat (and the morphology) rather than inheriting it. However, "the oldest coniferoid gymnosperms [Cordaitales] had stilt-roots and a combination of anatomical features today seen only in some mangrove trees" (Mabberley, 1992: 18). In order to provide a coherent explanation for angiosperm evolution, it was suggested that the ancestral forms were mangroves or mangrove associates that could tolerate high levels of disturbance (Heads, 2003, 2006). Because of these pre-adaptations, the main clades became widespread with the marine transgressions of the Mesozoic. Following the retreat of the seas, many mangroves and mangrove associates were left stranded inland, for example in the Amazon and Congo basins, and in central Australia. In regions that underwent mountain-building (orogeny), populations were subject to passive uplift (Heads, 2019). This model recalls Church's (1919) ideas on land plant evolution: “... a continental area could not have been lifted out of the sea in the first place without taking some life with it [p. 8]... The discussion of any theory of 'migration' should be preceded by the examination of the probabilities of a mechanism of 'transition in situ' (= transmigration) [p. 12]". 
The 'stranding' model predicts that Meliaceae may retain some characters associated with mangroves or mangrove associates on carbonate platforms and limestone. Limestone and mangrove floras, especially those with a 'weedy' tendency, would have provided widespread, genetically diverse, ancestral species from which modern species of freshwater swamp forest, lowland rain forest, dry forest, secondary forest, thicket, and montane forest could have been derived.

In Meliaceae, an ecophyletic series spanning mangrove and dry land forest is seen in the sister genera Xylocarpus (in mangrove, or at least maritime) and Carapa (on the edge of mangrove to montane). A similar range is seen in many other angiosperms. For example, it is well known that Rhizophoraceae inhabit the outer belt of mangrove (i.e. mangrove in the strict sense), but the family also includes large trees of dry land rain forest, such as Anopyxis Engl. of West Africa, and Carallia Roxb. of Madagascar, tropical Asia and Australia. In another example, Combretaceae include Conocarpus L. and Laguncularia of mangroves and saline swamps, but the family is also a major component of African savannah woodland and rain forest. One of the genera, Terminalia L., inhabits mangrove, freshwater swamp forest, dry land rain forest, and savanna-woodland. In another family, Chrysobalanaceae, Chrysobalanus icaco L. subsp. icaco is one of the most characteristic members of coastal thicket and the landward side of mangrove swamps on both sides of the Atlantic. However, it also occurs in open vegetation on waterlogged soils up to $200 \mathrm{~km}$ inland in Africa and $600 \mathrm{~km}$ inland in South America, and the inland populations can be attributed to the advance and recession of inland seas. The second subspecies, Chrysobalanus icaco subsp. atacorensis (A.Chev.) F.White, is widely distributed on river banks in tropical Africa and can be explained in the same way.

Distinguishing 'true mangroves' from plants that are 'not true mangroves' is simply a matter of academic definition. Many species occur in mangrove but are not restricted to it; likewise, there is often no real difference between the 'inner' or 'back mangrove' and 'forest immediately behind the mangrove'. Rather than trying to define discrete ecological entities, the aim here is to trace the ecophyletic connections of plants in the mangrove.

For example, the trees of Sabah and Sarawak in northwestern Borneo include many species in mangrove or closely associated with it, and eight of these illustrate the main links between this vegetation and various others (Soepadmo et al., 19952014): 1. Cerbera odollam Gaertn. (Apocynaceae). In, or on the edge of, mangrove and riverine forest; 2. Cynometra elmeri Merr. (Leguminosae). Back mangrove and freshwater swamp forest, up to $300 \mathrm{~m}$; 3. Cynometra ramiflora L. var. ramiflora (Leguminosae). Forest just behind mangrove, also in inland forest up to $400 \mathrm{~m} ; 4$. Ilex cymosa Blume (Aquifoliaceae). Mangrove, peat swamp forest, coastal padang shrubland on white sands, riverine forest, and dipterocarp forest, up to $1200 \mathrm{~m} ; 5$. Pouteria obovata (R.Br.) Baehni (Sapotaceae). Mangrove, kerangas (heath forest), hill forest on limestone; 6. Cordia dichotoma G.Forst. (Boraginaceae). At the back of mangroves, coastal hills below $100 \mathrm{~m}$, inland forest along rivers and on limestone. Both Pouteria obovata and Cordia dichotoma have 'invaded' the hinterland by normal dispersal along the shores of earlier seas in which the limestones were deposited. Some 
of the regions were later uplifted; 7. Ganophyllum falcatum Blume (Sapindaceae). Inner edge of mangroves, river banks, primary and secondary forest on well-drained or periodically inundated level-lands, on slopes, clay and limestone, to $1200 \mathrm{~m}$; 8. Guioa bijuga Radlk. (Sapindaceae). Mangroves, peat swamp forest, riverbanks, primary and secondary kerangas, mixed dipterocarp forest, roadsides (i.e. highly disturbed sites); sometimes on ultramafics.

In Sabah and Sarawak a complete sequence from mangrove to montane occurs in many tree genera. Examples include Barringtonia (Lecythidaceae), known from mangrove, beach forest and swamp forest at sea level, and dipterocarp forest, up to $2000 \mathrm{~m}$. Outside the region the complete mangrove-to-montane sequence occurs in individual species, including four members of Meliaceae. These are: 1. Munronia pinnata (Wall.) W.Theob. Just behind the mangrove, up to $900 \mathrm{~m}$ in Malesia and 1800 $\mathrm{m}$ in China; 2. Trichilia emetica Vahl. Combretum forest on coral limestone, up to 1850 m; 3. Dysoxylum mollissimum. Forests behind mangrove (sometimes viviparous), up to $1900 \mathrm{~m}$; and 4. Trichilia dregeana Harv. \& Sond. Behind mangrove, up to $2100 \mathrm{~m}$.

Munronia pinnata, with higher altitude populations at higher, rather than lower, latitudes (in China), displays an 'anti-ecological' trend. The same phenomenon is also seen in other groups such as the odd-nosed primates (mangrove of Borneo to mountains of China; Heads, 2019). The trend can be explained by passive uplift of populations in southern China.

In standard 'ancestral area' algorithms, a large family with all genera in Africa and one, deeply nested, in Madagascar will always indicate that the group dispersed from Africa to Madagascar. But this overlooks the possibility of widespread ancestral biogeography (cf. Fig. 1). Likewise, in a large family with only one mangrove, deeply nested in the phylogeny, the mangrove habitat is assumed to be derived. However, this overlooks the possibility of ancestral polymorphism ('incomplete lineage sorting').

The idea that ancestral angiosperms and Meliaceae were mangroves and mangrove associates is not derived from standard ancestral habitat algorithms. These are flawed, as they assume that the ancestral condition is that held by a paraphyletic basal 'group', and this cannot be justified (cf. Fig. 1). Instead, a mangrove ancestry is suggested in order to group and explain many different aspects of the plants' biogeography, morphology and ecology, as well as their phylogeny.

\section{Freshwater swamp forest}

The best description of freshwater swamp forest is Corner's (1978) account for the southern Malay Peninsula, which includes 40 spectacular plates. Corner described the tidal flooding: "Salt water from the estuary banks up the brackish water to a depth of several feet and the effect is carried upstream... The water would rise in the creeks and spill over into the swamp-forest with a slight gurgling and hissing as the air was driven out" (Corner 1978: 9). As well as the tidal flooding (which varies through the year), there is also seasonal flooding with the annual rains. At Jason Bay, "For 2-3 miles inland from the coast there was a confusion of brackish and freshwater swamp-forest and remains of former coastal dunes" (Corner 1978: 49). 
Corner (1978: 8) noted that while stilt roots are well known in the mangrove family Rhizophoraceae, “...even now few botanists realise that stilt-rooted trees of many genera of other families abound in freshwater swamp-forest". The swamp forest at Sedili contained 75 species with stilt roots, 75 with prominent buttresses, and 36 with pneumatophores. Eighteen species had both stilt roots and pneumatophores. One of the formations in the freshwater swamp forest is the mempisang (Polyalthia sclerophylla Hook.f. \& Thomson) belt, "distinguished by the variety of trees and shrubs and by the presence of erect pneumatophores, which in places were so dense that passage was impossible..." (Corner 1978: 16). Thus freshwater swamp forest and mangrove are closely related in their flooding regime, in the structure of their trees, and in their floras.

Ten genera of Meliaceae are recorded in freshwater forest that is either permanently or periodically flooded (Fig. 4). In the Sedili region of the Malay Peninsula, Corner (1978) recorded 40 species of Meliaceae, and as many as 26 of these $(65 \%)$ occurred in freshwater swamp forest. Corner compared this forest with a distinct type of swamp forest in Borneo and Sumatra that is built on peat.

\section{Peat swamp forest}

Peat soils are formed by the build-up of partially decomposed organic matter under waterlogged, anoxic conditions. Corner (1978: 85) wrote: "Peat swamp-forest is considered to be an outcome of freshwater swamp-forest, behind the mangrove and nipa, where for some reason the water-logged soil is no longer subject to tidal inundation or disturbed by the passage of streams". Thus there is no enrichment of the soil with silt. Peat swamp can also develop from old mangrove cut off from the sea, and in some ways peat swamp forest is the acidic-soil equivalent of alkaline-soil mangrove. Corner continued: "The forest debris accumulates into peat which raises the soil into a convex mound or dome, even up to $16 \mathrm{~m}$ in depth in Sarawak and Brunei, and becomes eventually so poor for plant-growth that a rather low forest of small trees... survives, along with a little undergrowth and Sphagnum".

In Malesia, two species of Meliaceae are more or less restricted to peat swamp forest. These are Sandoricum beccarianum Baill. (Thailand, Malay Peninsula, Sumatra and Borneo) and Chisocheton amabilis Miq. (Malay Peninsula, Sumatra and Borneo; also in riparian forest) (Mabberley et al., 1995). Six other Malesian Meliaceae are recorded in peat swamp but are not restricted to it (Chisocheton lansiifolius Mabb., Dysoxylum cyrtobotryum Miq., Aglaia rubiginosa (Hiern) Pannell, A. lawii (Wight) C.J.Saldanha, A. korthalsii Miq. and A. glabriflora Hiern).

In the central part of the Congo basin, the Cuvette Centrale, peat does not occur beneath terra firme forest, seasonally flooded forest or savanna (Dargie et al., 2017). However, peat does underlie swamp forest that covers about $145,500 \mathrm{~km}^{2}$ in the basin, and this is the most extensive area of peatland in the tropics. Dargie et al. (2017) described two main types of peat swamp forest in this basin; one is dominated by the hardwoods Carapa procera DC. (Meliaceae), Uapaca paludosa Aubrév. \& Leandri (Phyllanthaceae) and Xylopia rubescens Oliv. (Annonaceae), and one by a palm, Raphia laurentii De Wild. 


\section{Riverbank communities and rheophytes}

Riverine or riparian forest is intermediate between freshwater flooded forest and dry land forest. In the tropics, riparian forest often includes rheophytes, plants distinguished by their long, narrow, willow-like leaves, tough, flexible stems, and their habitat, in or by rivers. Their morphology enables them to withstand heavy floods, and herbarium specimens often include debris left after floods. On river banks the branches of rheophytes typically project horizontally over the water.

Worldwide, Borneo has by far the highest diversity of rheophyte species (Van Steenis, 1981). In Meliaceae, Van Steenis listed five rheophytes, all in Malesia. More recent taxonomy recognised the following (Mabberley et al., 1995; Pannell, 2007): Aglaia yzermannii Boerl. \& Koord. (Sumatra and Malay Peninsula), A. rivularis Merr. (Borneo), A. lancifolia Harms (Borneo), Dysoxylum angustifolium King (Malay Peninsula) and Sandoricum borneense Miq. (Borneo). Dysoxylum angustifolium is a common component of the neram (Dipterocarpus oblongifolius Blume) vegetation of rivers, growing amongst the rocks and on the banks, and overhanging the water. Sandoricum borneense inhabits riparian forest, subject to inundation down to just above tidal influence, overhanging the water like Dipterocarpus oblongifolius.

\section{Heath forest in Malesia - kerangas}

A distinctive, open heath forest called kerangas (or kerengas) occurs in coastal and lowland Borneo and other parts of Malesia. In Borneo, it can occur between peatswamp forest and lowland dipterocarp forest. It is found on acidic, nutrient-poor, white sands that are strongly podzolised or even seasonally waterlogged, often on raised beach terraces and sandstone plateaux that are periodically inundated. On increasingly poor sites, kerangas is replaced by open shrubland (padang), but this is not inhabited by Meliaceae. Seventeen Meliaceae species are recorded from kerangas: Sandoricum dasyneuron Baill., S. caudatum Mabb., Dysoxylum crassum Mabb., and 14 species of Aglaia sensu lato.

There is a close relationship between kerangas and peat swamp; for example, of the four species of Aglaia sensu lato recorded in peat swamp forest, three are also in kerangas. Another example is the tree Combretocarpus Hook.f. (Anisophylleaceae), distributed from Sumatra to Borneo and restricted to coastal peat swamp forest and kerangas (Ding Hou, 1958). There is also a close link between these two forest types and montane forest. For example, Castanopsis foxworthyi Schottky (Fagaceae) inhabits peat swamp forest, kerangas, and montane forest up to $2400 \mathrm{~m}$ (Soepadmo, 1972).

\section{Savanna woodland}

The floristic affinities between lowland rain forest and open savanna woodland are closer than might be expected based on their very different appearance. In the lowland tropics, the same families of trees characterise both rain forest (closed forest with evergreen trees) and savanna woodland (open vegetation with deciduous trees). These families include Meliaceae, along with Anacardiaceae, Sapindaceae, Burseraceae, Leguminosae, Rubiaceae, Myrtaceae, Annonaceae, Chrysobalanaceae, Moraceae, Combretaceae, and Ebenaceae. 


\section{High altitude forest}

Five genera of Meliaceae are recorded at or above $3000 \mathrm{~m}$ altitude, 13 others at or above $2000 \mathrm{~m}$, and 11 others above $1500 \mathrm{~m}$ (the approximate upper limit of lowland rain forest). Thus 29 genera, more than half the genera in the family, extend above the lowlands. The genera of Meliaceae that reach the highest altitudes are: 1. Cedrela at $3400 \mathrm{~m}$ (C. lilloi C.DC. of SW Peru, NW Argentina and SE Brazil. Cedrela montana Turcz., is recorded at $3100 \mathrm{~m}$ and in subpáramo, in the Andes north of C. lilloi); 2. Trichilia at $3300 \mathrm{~m}$ (T. multifoliola C.DC. of Bolivia); 3. Lepidotrichilia sensu stricto at $3300 \mathrm{~m}$ (L. volkensii Styles \& F. White of East Africa); Ruagea H.Karst. at $3200 \mathrm{~m}$ (R. hirsuta (C.DC.) Harms of Bolivia to Ecuador); and Schmardaea at $3000 \mathrm{~m}$ (Andes), a monotypic genus known only above $1500 \mathrm{~m}$ and the only genus of Meliaceae that does not occur in the lowlands.

\section{Secondary forest}

Meliaceae are often thought of as trees of primary rain forest, but as many as 22 genera are recorded from secondary vegetation. Six of these (Cedrela, Swietenia, Chukrasia, Melia L., Azadirachta A.Juss. and Trichilia) include species regarded in places as troublesome weeds and invasives. In the largest genus in the family, Aglaia sensu lato, 52 of the 127 species (41\%), are recorded in secondary forest (Pannell, 1992, 2004; Mabberley et al., 1995).

Weeds are the plants of the future. The plants of 20 million years from now will be descended from today's widespread weeds of secondary forest, not today's restricted endemics of 'climax' vegetation. Weediness is an archaic feature, a relic ecology and not a recently derived one, but it is not necessarily preserved in an old clade. If evolution works largely by recombination of older features rather than evolution of new characters (as suggested for many Meliaceae), old features can be preserved in younger taxa.

\section{Limestone}

In the genera of Meliaceae, 22 out of 48, or 46\%, have been reported from limestone. In the largest genus of the family, Aglaia sensu lato, 44 of the 127 species, or $35 \%$, are recorded on it. The close connection between Meliaceae and limestone is probably an ancient one. Epicontinental limestone formed during past marine incursions, and as the seas receded (with either uplift or climatic change) it would have been colonised by the local coastal flora.

In Meliaceae, the genus Xylocarpus is present in mangrove and also on limestone rocks just above the mangrove. This close link between mangrove forest and limestone vegetation occurs in many other groups. For example, in Fiji, 39 indigenous plant species are recorded in or around mangrove and also on limestone (Heads, 2006). The presence of calcium ions in the soil water dramatically reduces the damage that would otherwise be done to a plant by an excess of sodium ions (see references in Heads, 2006). The evidence from biogeography, ecology and physiology suggests that the mangrove-limestone connection is an old one. 
Mangroves are often most conspicuous growing in mud. It has been suggested that "Rocky coasts or coasts with exposed coral are unsuited to mangroves except where plants can root in silt-filled depressions" (Tomlinson, 1986: 5), and even that coral reefs are an 'extreme' habitat for mangroves (Tomlinson, 1986: 333). However, Van Steenis (1958) described the habitat of mangroves as "muddy shores,... along sandy or rocky beaches, and on old coral reefs covered with a thin sheet of sand or mud". Mangroves such as Rhizophora stylosa Griff. often occur in pure white coral sand (e.g. on Vanua Mbalavu Island in Fiji; pers. obs.). In Malesia, the species is recorded "Exclusively along sandy shores and coral terraces, facing the open sea, obviously resisting the surf better than the other species" (Ding Hou, 1958). The mangrove Sonneratia alba (cited above for its runners) occurs in: "Shallow parts of calm seas, seashores, along the mouth of tidal creeks... [and] grows as well on a sandy or rocky as on a muddy soil, not rarely on coral terraces. Often gregarious..." (Backer \& Van Steenis, 1951; italics added).

\section{Ultramafic substrate}

Cedrela, Walsura, Dysoxylum and Aglaia are recorded in soil developed on ultramafic parent material (including weathered ultramafic rock, serpentine). Walsura monophylla Merr. of the Philippines (Palawan) and Dysoxylum minutiflorum C.DC. of New Caledonia are restricted to it. Four species occur on both limestone and ultramafics: 1 . Cedrela cubensis Bisse. Cuba. On serpentine and limestone sites (Puentes, 2005); 2. Dysoxylum nutans (Blume) Miq. Sumatra to Moluccas. Primary and secondary forest, very common especially near streams, parent material of the sites includes ultrabasics and limestone; to $1600 \mathrm{~m}$ (Mabberley et al., 1995); 3. Aglaia grandis Korth. Indochina to Sulawesi. Primary forest, sometimes on ultrabasic rock and limestone; sea level to 1700 m (Mabberley et al., 1995); 4. Aglaia elaeagnoidea Benth. India to Samoa. In New Caledonia on beaches, and on calcareous and serpentine soil (Mabberley, 1988).

The affinity between limestone and ultramafics is also seen within genera, such as Walsura: W. monophylla is largely restricted to ultrabasic soils, while $W$. grandifolia Ridl. is apparently restricted to limestone. The relationship is also evident in other families. For example, in the Alocasia (Schott) G.Don species (Araceae) of west Malesia, A. melo A.Hay et al. is confined to ultramafics, six other species are restricted to limestone, and A. cuprea (K.Koch \& Bouché) K.Koch of Sabah is found on sandstone, limestone and ultramafics (Hay, 1998). West Indian Euphorbiaceae (Jestrow et al., 2012) include the sister pair Lasiocroton Griseb. (7 species) in coastal Cuba, Bahamas, western Hispaniola and Jamaica on limestone, and Leucocroton Griseb. (26 species) in inland Cuba, on serpentine soils.

Soils on both ultramafics and limestone are characterised by being droughtprone and showing high base saturation (in limestone soils the exchange complex is dominated by calcium, in ultramafic habitats by magnesium). However, the physiological, ecological and phylogenetic affinity between limestone and ultramafic floras also reflects the tectonic relationship between the two types of rock. Both characterise belts of subduction and accretion (plate margins), where taxa of uplifted 
coral reefs and carbonate platforms are pre-adapted for life on the basic soils of obducted ultramafic terranes (Heads, 2014). Taxa that are able to survive on ultramafics and limestone will thrive around active plate margins and persist around extinct ones.

\section{Habitat restriction}

Most Meliaceae species inhabit lowland tropical forest, but within this some species have a specific habitat type and also a localised geographic distribution. In Malesia, for example, certain species are restricted to flooded sites by rivers (Dysoxylum angustifolium of the Malay Peninsula), peat swamp forest (Sandoricum beccarianum of Thailand, Malay Peninsula, Sumatra and Borneo), peat swamp forest and riparian forest (Chisocheton amabilis in Sumatra, Malay Peninsula, and Borneo), limestone (Chisocheton ruber Ridl. of Borneo) and ultramafic rocks (Walsura monophylla in the Philippines) (Mabberley et al., 1995). It might be assumed that what appear to be specific habitat requirements have determined the distribution. However, limestone and ultramafics are widespread, and other species with very localised distributions have no obvious ecological restrictions, e.g. Dysoxylum boridianum Mabb. from Boridi, Papua New Guinea. In practice, many individual species occur in many habitat types.

\section{Generic Treatment}

Information has been compiled from the general treatments and floras of Harms (1940), Keay (1958), Staner \& Gilbert (1958), White \& Styles (1963), Van Balgooy (1971), Pennington \& Styles (1975), Pennington et al. (1981), White \& Styles (1986), Styles \& White (1991), Mabberley (1988, 1995, 2011, 2013, 2017), Mabberley et al. (1995), Peng et al. (2008), Wongprasert et al. (2011), and African Plant Database (2019). These are cited explicitly only in particular cases. Other sources of information are listed under individual genera.

The first two genera, Chukrasia and Schmardaea, form a clade that straddles the Pacific basin.

\section{Chukrasia A.Juss.}

Distribution. One species in India and Sri Lanka to southern China, Indochina, Malay Peninsula, northern Sumatra and SW Borneo (Fig. 5; Kalinganire \& Pinyopusarerk, 2000). Three allopatric forms have been proposed, based on bark and leaf morphology: one in Sri Lanka, one in Myanmar and Thailand, and one in China, Laos, Vietnam, and Malaysia (Kalinganire et al., 2002).

Ecology. Trees in evergreen rain forest, semi-deciduous forest, and deciduous forest, sparse forests in hilly regions (China); occasionally as a colonist of bare ground, including road cuttings; recorded on limestone. Up to $1680 \mathrm{~m}$ altitude (in Thailand; 


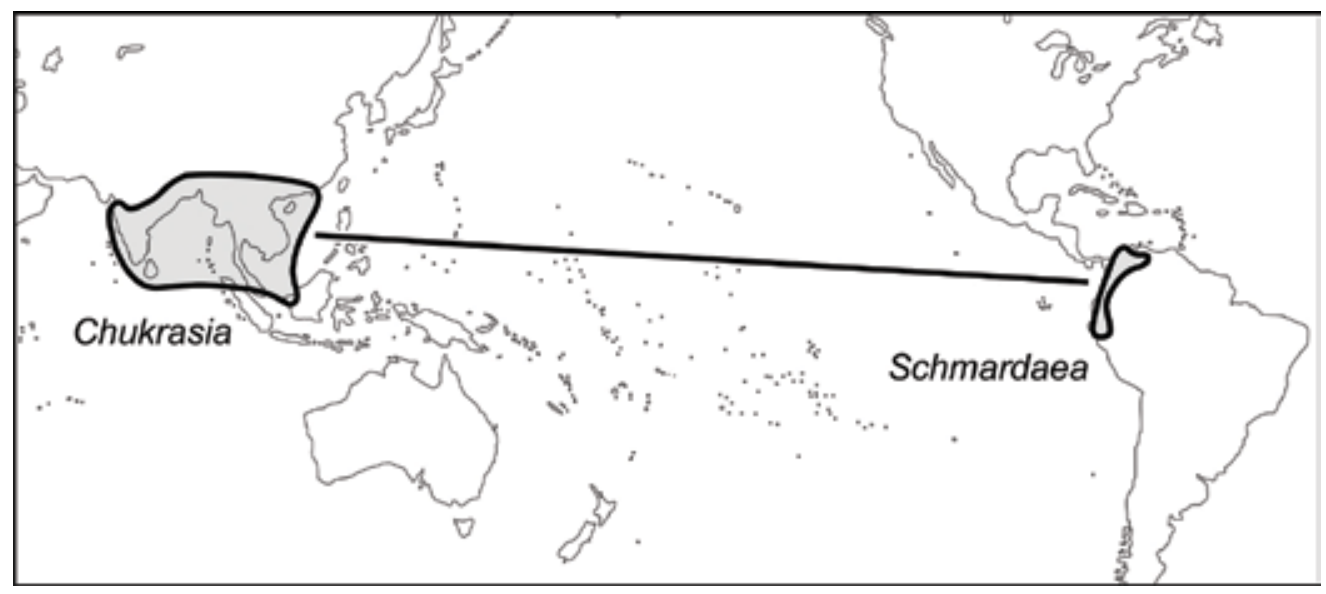

Fig. 5. Distribution of Chukrasia A.Juss. and Schmardaea H.Karst.

Wongprasert et al., 2011). Chukrasia tabularis A.Juss. is capable of invading gaps in the forest and is often gregarious. It is common in former shifting cultivation areas (Kalinganire \& Pinyopusarerk, 2000). In Australia, it is an aggressive species that produces large seed crops and may form pure stands in disturbed forest. It has become naturalised on parts of the Atherton Tablelands where it was initially established in plantations (Kalinganire \& Pinyopusarerk, 2000).

\section{Schmardaea H.Karst.}

Distribution. One species in the Andes of NW Peru, W Ecuador, NW Colombia, and NW Venezuela (Fig. 5).

Ecology. A small tree or multistemmed shrub which coppices readily (Styles \& Bennett, 1992). Confined to evergreen montane and submontane cloud forest; 1500-3000 m (Pennington et al., 1981).

The next clade comprises five genera (Fig. 6): Lovoa Harms (Africa), Capuronianthus J.-F.Leroy (Madagascar), Entandrophragma (Africa), Toona (India to Australasia) and Cedrela (America). The five genera are all allopatric except for Lovoa and Entandrophagma, which overlap in Africa. The overall pattern is consistent with vicariance of a pantropical ancestor, followed by dispersal of Lovoa or Entandrophragma, or both, within Africa.

In the clade of five genera as a whole, Lovoa and Capuronianthus form the sister group to the other three genera, and so geographically the initial vicariance event took place between Lovoa (absent in parts of western Africa where Entandrophragma is 


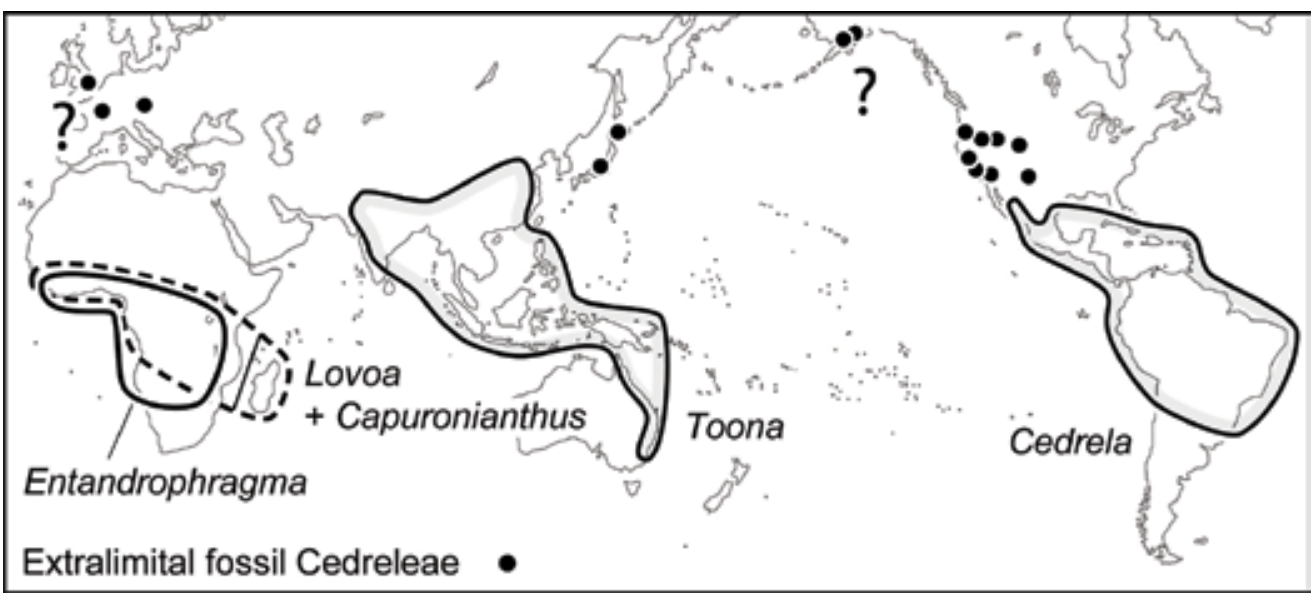

Fig. 6. Distribution of five genera with the phylogeny: Lovoa + Capuronianthus (Entandrophragma $($ Toona + Cedrela $))$.

present) and Entandrophragma (absent in parts of East Afria where Lovoa is present). The break took place between western and eastern Africa, and occurred before Lovoa separated from its sister Capuronianthus in Madagascar. (The break between Lovoa and Entandrophragma also took place before Entandrophragma was separated by the Atlantic and Indian Ocean basins from Toona + Cedrela). Overall, the break corresponds in space and time with activity on the Lebombo monocline (see below), a precursor to the Mozambique Channel rifting. In southern Africa this monocline marks the eastern limit of Entandrophragma (and its sisters) and the western limit of Lovoa (and its sister).

\section{Lovoa Harms}

Distribution. Two species in Africa. One species is western and one eastern (Fig. 7). In East Africa, the genus is present in several areas where Entandrophragma is absent, notably central Kenya, coastal Kenya, eastern Tanzania (Uluguru Mountains) and coastal Tanzamia.

Ecology. Trees, restricted to evergreen rain forest, including riverine forest and lake shore forest where the species can be very common; $180-1525 \mathrm{~m}$.

\section{Capuronianthus J.-F.Leroy}

Distribution. Two species in Madagascar; one species in the far north, one in the far south (Fig. 7; Leroy, 1976). 


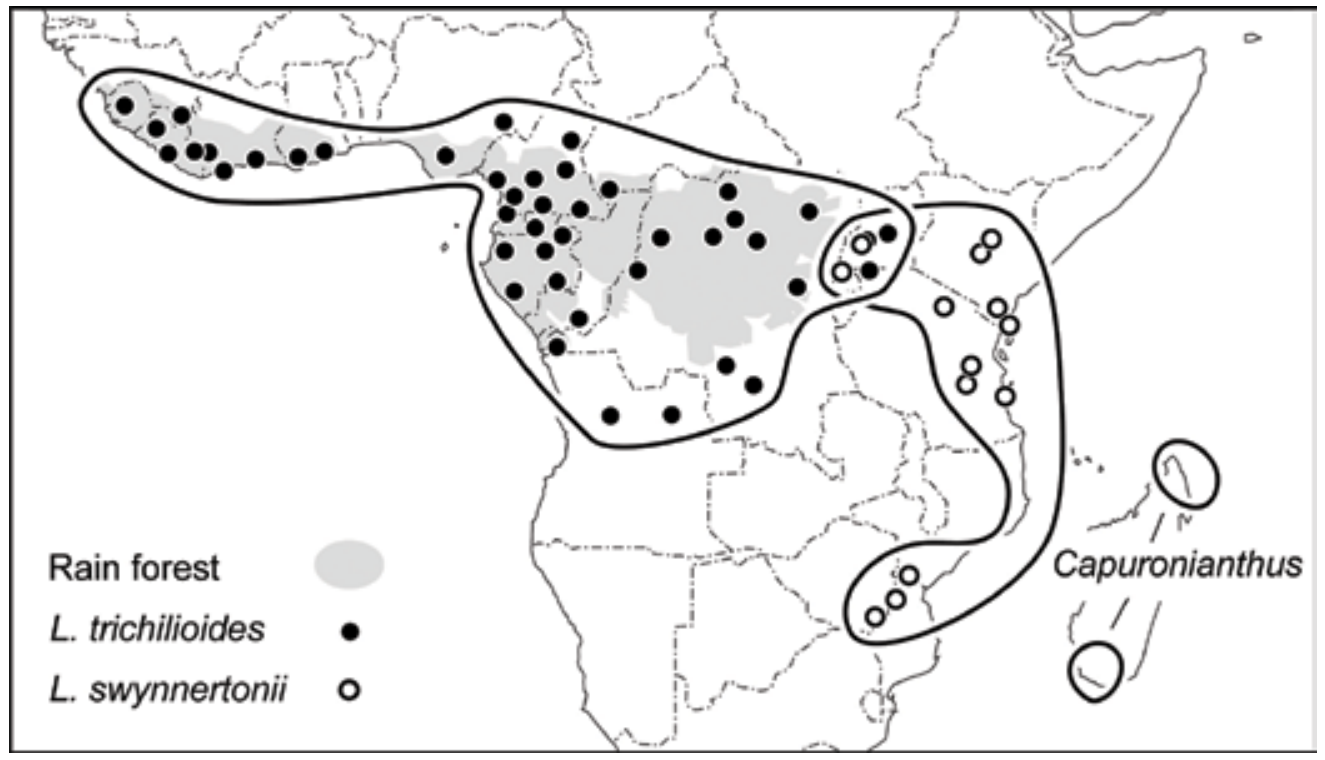

Fig. 7. Distribution of Lovoa Harms and Capuronianthus J.-F.Leroy.

Ecology. Xeromorphic trees in open, xerophilous forest, bush with Euphorbia L. and Didierea Baill., and coastal and subcoastal forest; on sand and limestone plateaux (Leroy, 1958c).

\section{Entandrophragma C.DC.}

Distribution. A genus of 11 species in Africa (Sierra Leone to South Africa) (Fig. 8).

Ecology. Trees of swamp forest, riverine forest, terra firme rain forest, dry, open, semi-deciduous forest, savanna woodland, and deciduous thicket; from the lowlands to $2220 \mathrm{~m}$ (Entandrophragma excelsum in East Africa). In 2016 a specimen of Entandrophragma excelsum $81.5 \mathrm{~m}$ high was discovered on Mt Kilimanjaro, and this is Africa's tallest recorded tree (Hemp et al., 2017).

Notes. A molecular study (Monthe et al., 2019) showed five clades in the genus, and these are mapped here (Fig. 8). The phylogeny of the clades is: $1(2(3(4+5)))$. Clade 1 comprises Entandrophragma utile (Dawe \& Sprague) Sprague of western and central Africa (in both rain forest and dry forest), and its sister group in eastern and southern Africa. As with the break between the two species of Lovoa (Fig. 7), the break in Clade 1 (at a line: SW Angola - Uganda) does not coincide with the boundary between rain forest and savanna woodland. Overall, Clade 1 encircles a large region of eastern Angola, southern DRC, and much of Zambia, where it, Entandrophragma as a whole, and in fact the whole subfamily are absent. This area of absence is also 


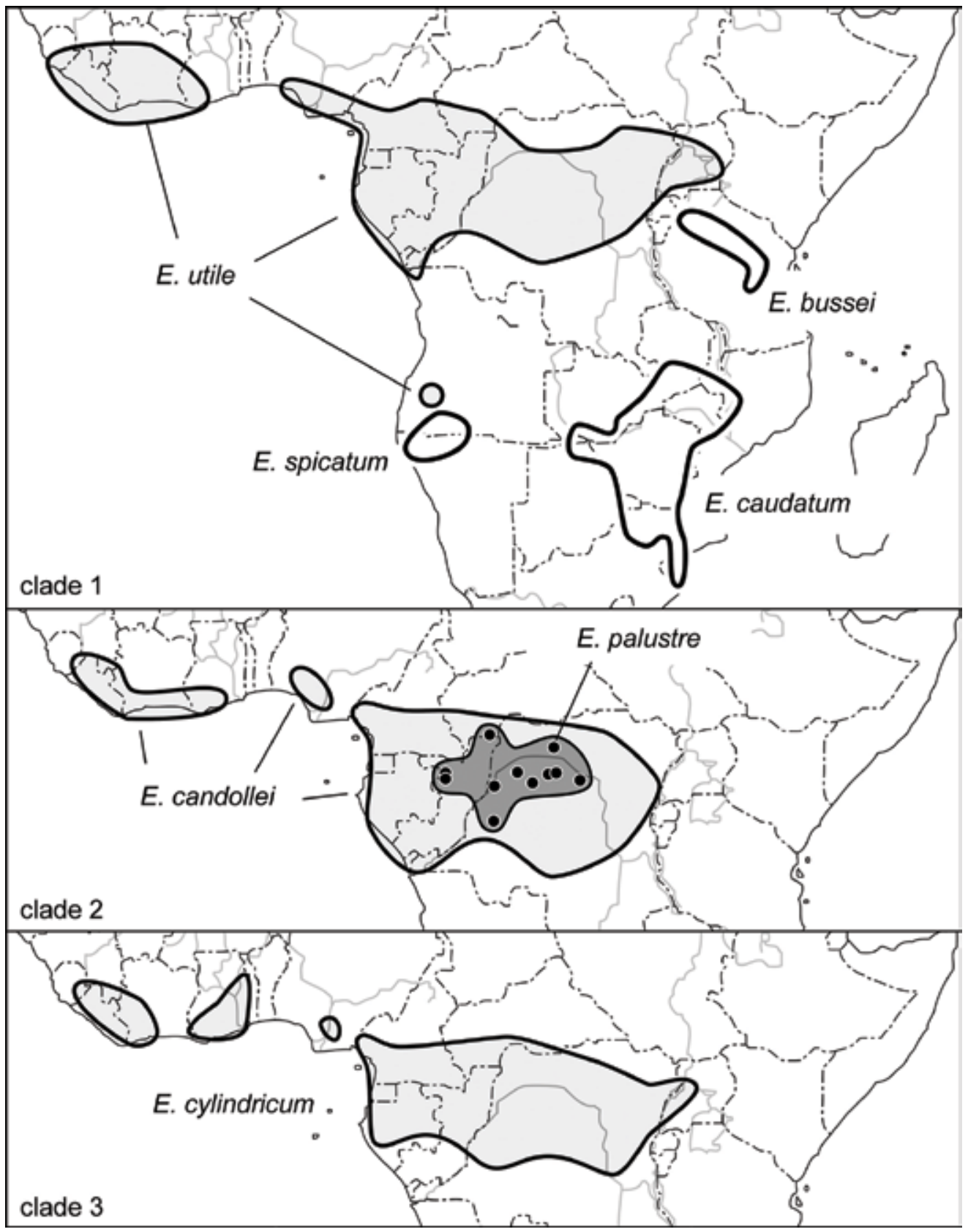

Fig 8. Distribution of Entandrophragma C.DC. (Data from Monthe et al., 2019, and African Plant Database, 2019). The five maps (continued on the next page) show the five clades; these have the phylogeny: $1(2(3(4+5)))$. 


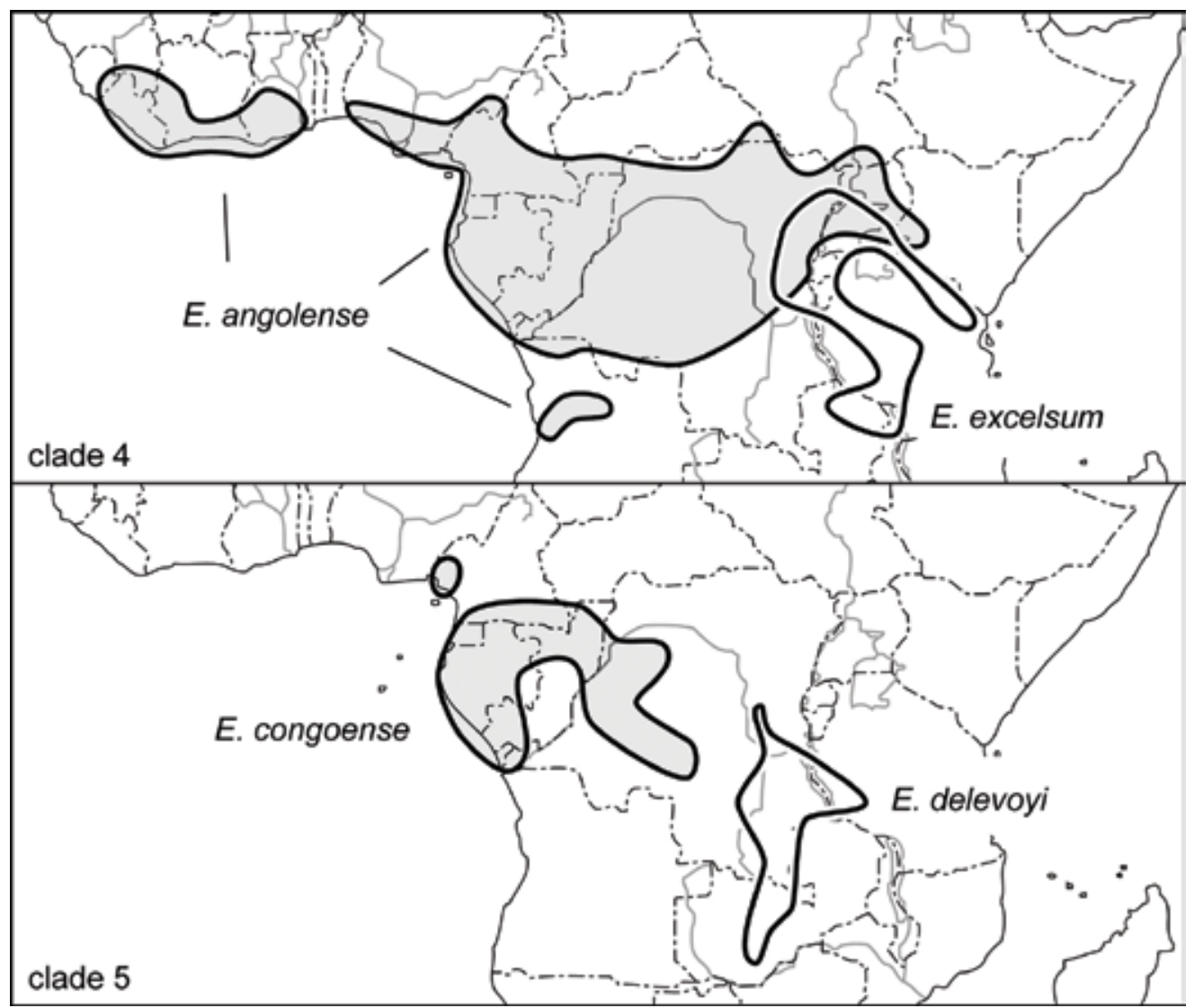

Fig 8. (Continuation). Distribution of Entandrophragma C.DC. (Data from Monthe et al., 2019, and African Plant Database, 2019).

a standard centre of endemism for groups in subfam. Melioideae, for example, the rhizomatous subshrub Trichilia quadrivalvis C.DC. discussed below; see also Ekebergia benguelensis C.DC. The pattern suggests that the absence of Clade 1 is not caused by ecological factors, but is the result of phylogeny; Cedreloideae are replaced there by forms of Melioideae, and this allopatry is a regional trace of the original vicariance between the two subfamilies. Thus while clade 1 as such is absent in eastern Angola and neighbouring regions, it is represented there by close relatives, and so the absence is not absolute.

Clade 2 is Entandrophragma candollei Harms, widespread in western and central Africa, and its sister, E. palustre, restricted to the Congo Cuvette Centrale. Clade 3 is Entandrophragma cylindricum (Sprague) Sprague only, with a Guineo-Congolian distribution that duplicates that of E. utile and E. candollei. Clade 4 is Entandrophragma angolense (C.DC.) C.DC. in the west, and E. excelsum in the east. The break between the two is in eastern DRC. Yakusu et al. (2018) wrote that Entandrophragma excelsum is in both 'Zambezian' and 'Afromontane' phytogeographic regions. Thus it can be 
regarded as a 'transgressor species' (of the English authors) or a 'liaison species' (French authors) - the regions are not cut and dried. The underlying idea is that species distribution should conform to regional phytochoria, themselves largely determined by vegetation structure. Physiognomic 'units', such as the 'Guineo-Congolian forest' and 'Amazon forest', often prove not to be biogeographic entities, but composites. Clade 5 is Entandrophragma congoense (De Wild.) A.Chev. in west-central Africa and $E$. delevoyi De Wild. in the east, divided at a break in eastern DRC, as in Clade 4.

The main difference between the last two clades is the presence of clade 4 through West Africa, west of Cameroon, where clade 5 is completely absent. Clade 5 has its western boundary at the Cameroon/Nigeria border, an area that corresponds to the Cameroon Volcanic Line (CVL). This originated in the Cretaceous and is one of the main tectonic features in Africa (Fig. 9). Other Cretaceous features shown in Fig. 9 include rifts (the Benue Trough, the Central African Shear Zone, and smaller rifts in Tanzania).

The volcanoes along the CVL do not show a linear age sequence, and so the line is probably controlled structurally rather than by plate movement over a hotspot. It has been active in episodes since the end of the Cretaceous. The CVL abuts a major rift, the Benue Trough, that was active from the early Cretaceous and was associated with the opening of the Atlantic basin. [For more on the geology and biogeography of the CVL/Benue Trough region, see Heads (2015)].

Distributional boundaries and phylogenetic breaks at the CVL occur in several clades of Meliaceae that are discussed in this paper. In addition, at least four species are endemic there: Trichilia grandifolia Oliv. on São Tomé Island, and Heckeldora ledermannii, Carapa oreophila Kenfack and C. littoralis Kenfack on the on-land part of the CVL. The CVL also features in many other groups as a centre of endemism, a boundary, and a site of ecological anomalies. For example, Xylopia africana (Benth.) Oliv. (Annonaceae) is endemic to the area (Fig. 10), and is unusual in African Xylopia species, as it inhabits mossy, montane forest; most species are in the lowlands (Johnson \& Murray, 2018).

While the species of Entandrophragma in West and central Africa overlap widely, the five species present in southern and East Africa (in clades 1, 4 and 5) are all completely allopatric (Fig. 11). This suggests that the clades were initially allopatric, and that this has been maintained in eastern and southern Africa. In contrast, in the west, the initial allopatry has been obliterated almost entirely by range expansion. Any apparently minor differences among these species may represent traces of the original allopatry. The means of dispersal that facilitated the range expansions in West Africa were the same as those that facilitated in-situ survival in the east.

Entandrophragma (Fig. 11) and Lovoa (Fig. 7) overlap widely in Africa. However, the former is present in parts of the west (southern Angola and Namibia) where Lovoa is absent, and Lovoa is present in parts of the east (Kenya and southeastern Tanzania) where Entandrophragma is absent.

In the Congo, Entandrophragma palustre is restricted to swamp forest in the Cuvette Centrale, while the other species in the genus inhabit dense moist evergreen forest and semi-deciduous forest. Entandrophragma palustre is evergreen, the others 


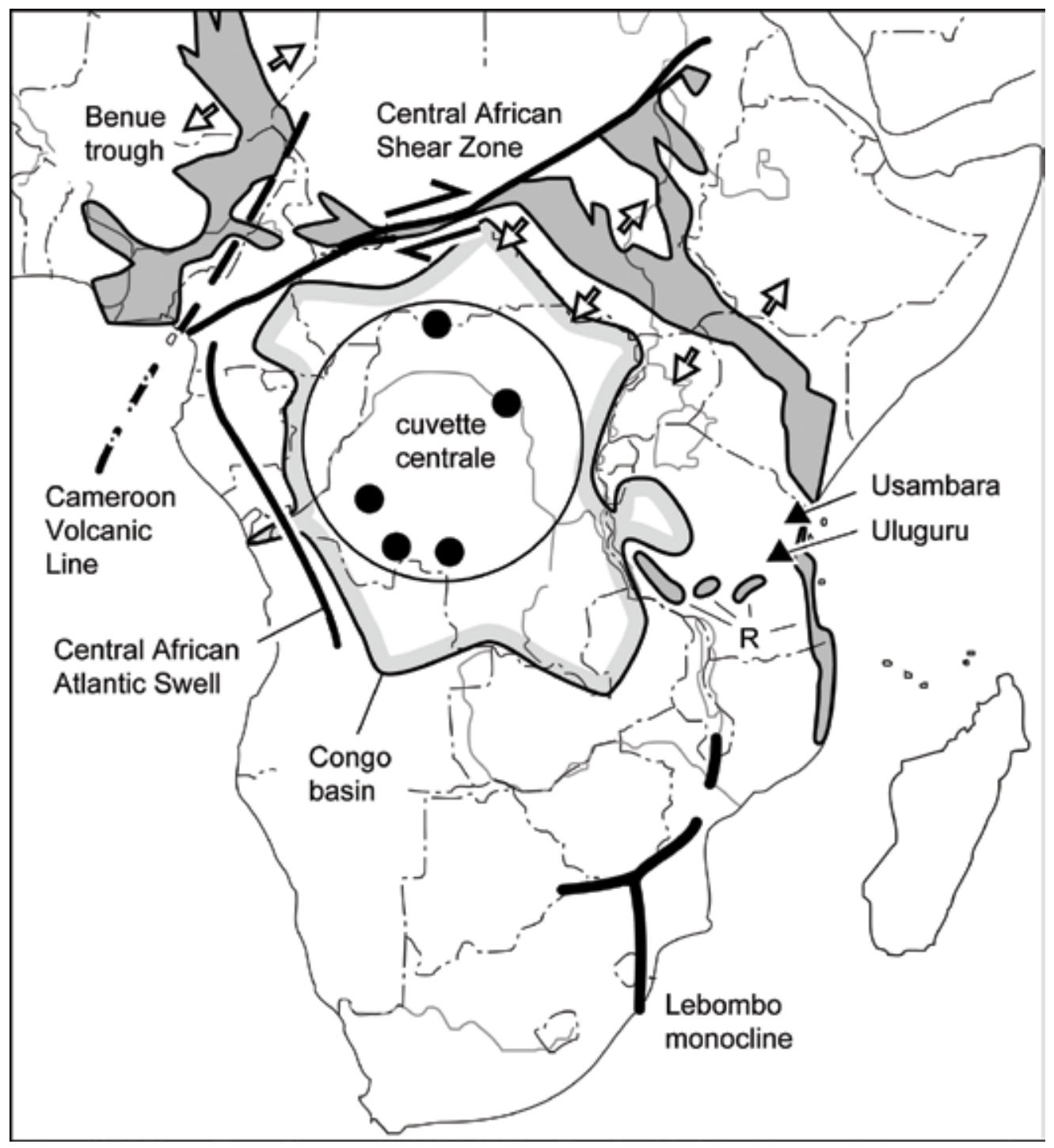

Fig. 9. Some main tectonic features in Africa. Black dots = late Jurassic-Cretaceous fossiliferous marine beds in the Congo basin. R = Rukwa, Usangu, Kilosa and Ruvumal rift basins (Heads, 2012).

deciduous. In the Congo basin, Richards et al. (1996) considered that there are two main types of forest on the hydromorphic (flooded) soils. One is permanently swampy forest, and this is dominated by Entandrophragma palustre and Coelocaryon botryoides Vermoesen (Myristicaceae). The other is seasonally flooded forest dominated by Oubanguia africana Baill. (Scytopetalaceae) and Guibourtia demeusei (Harms Léonard (Leguminosae). The Entandrophragma-Coelocaryon forest is comparable to the igapó (black water forest) of the Amazon and occupies wet depressions, often covering very large areas. The soil never dries out and contains $50-70 \%$ of organic 


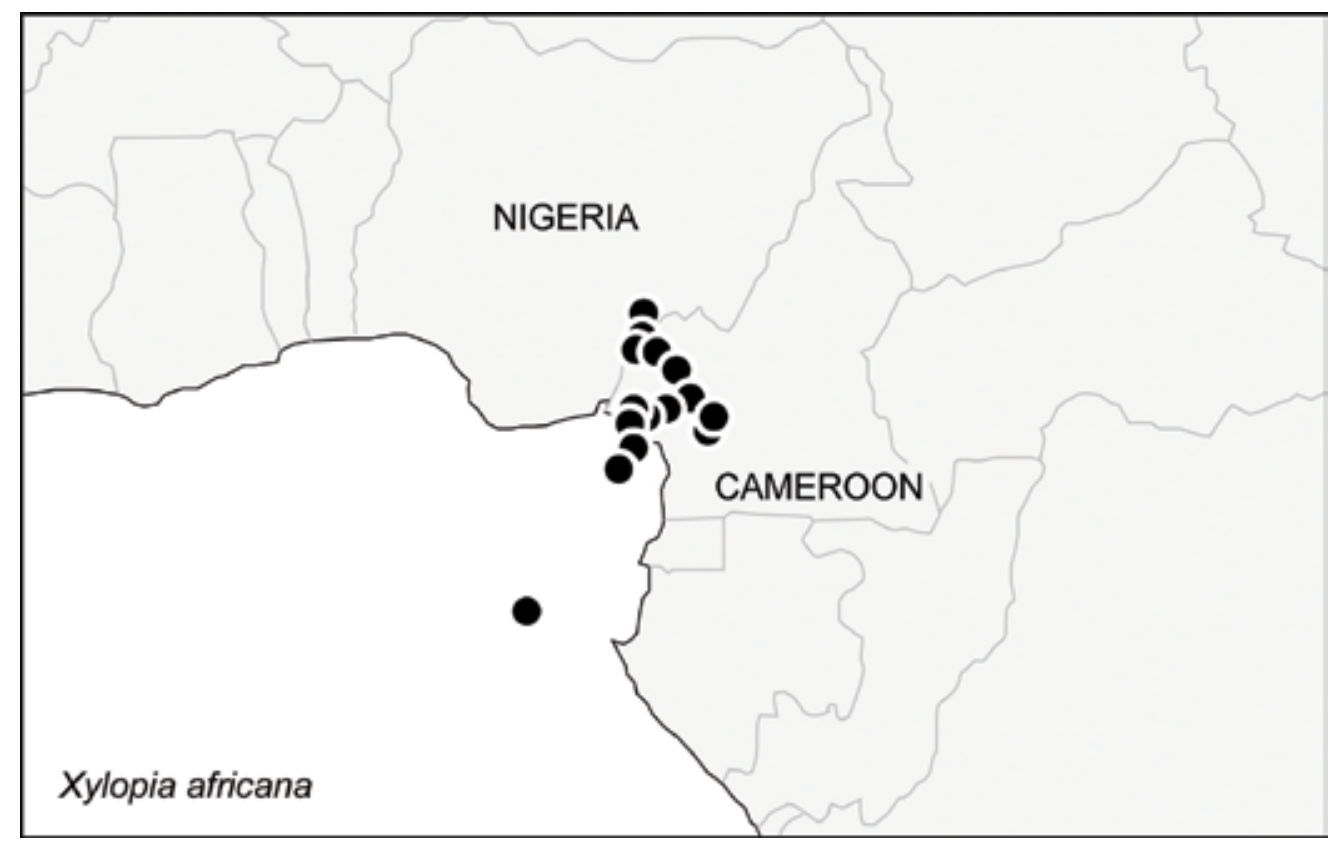

Fig. 10. Distribution of Xylopia africana (Benth.) Oliv. (Annonaceae) (Johnson \& Murray, 2018).

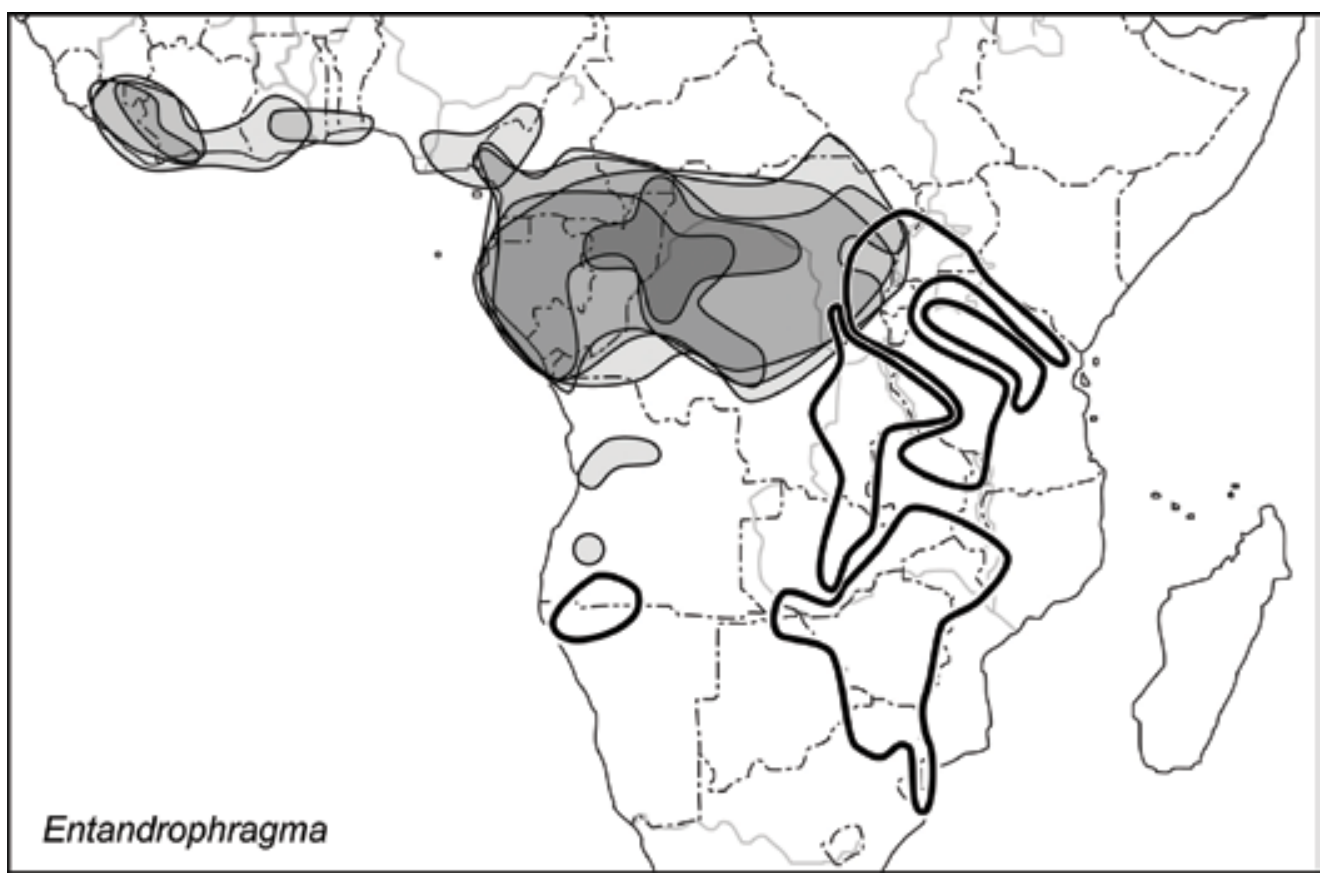

Fig. 11. Distribution of Entandrophragma C.DC. Clades show massive overlap from Liberia to eastern DRC, with highest levels of sympatry in the Cuvette Centrale, but east and south of there all species are allopatric. 
material. Two subassociations occur, one on peaty soils and one on organic soils with some sand. The Oubanguia-Guibourtia association, on the other hand, is comparable to the várzea (white water forests) of the Amazon; the soil is sandy to silty in texture and not particularly rich in organic material.

The next two genera, Toona and Cedrela, make up the tribe Cedreleae (mapped in Fig. 6 with its African sister group, Entandrophragma). Fossil members of Cedreleae from Japan and the contiguous United States do not significantly alter the 'trans-Pacific' nature of the tribe's extant distribution, and the identity of the fossils from Europe and Alaska has been questioned (see above).

In their study of Cedrela, Muellner et al. (2010) wrote: "The root node of our data set (i.e., the [most recent common ancestor] of Melioideae and Cedreloideae) was constrained maximally to $90 \mathrm{Myr}$, based on previous estimates (Muellner et al., 2006, 2007, 2008b), and fruit and seed fossils from Senegal 'similar to living Meliaceae' that date back to the Campanian/Maastrichtian boundary [72 Ma]... [T] his date may be regarded as a minimum estimate" (italics added). Muellner et al. (2010) proposed that Toona and Cedrela split at $48 \mathrm{Ma}$ on the basis of "Fossil fruits intermediate between extant Cedrela and Toona, such as the London Clay [Eocene] Toona sulcata (Reid \& Chandler, 1933; T.D. Pennington, pers. obs.)...". Nevertheless, the identification of the fossils has been queried (see above). In another study of Cedrela (Koecke et al., 2013), "The stem age of the most recent common ancestor (MRCA) of Cedreleae was set to 50 mya based on the minimum age of the oldest known fossils... with a lognormal distribution and a standard deviation of 1.1". But the reason for choosing these priors, including the very low value for the standard deviation, was not explained. Stipulating such a narrow prior means that clade age is assumed to be only a little older than the fossil age, and in this way the traditional belief that the fossil record is accurate is incorporated in the analysis.

Interpretations of the fossil record have suggested that Cedreleae (Cedrela and Toona) were widespread in the northern hemisphere during the Eocene, with occurrences in Europe, North America and Japan. Fossil material of Cedrela is distributed widely through the western United States (Oligocene to Miocene), while there is Pliocene material (and extant populations) in Central America and Peru. Muellner et al. (2010) suggested that these oldest fossils of Cedreleae "support a centre of origin scenario in which the ancestor of Cedreleae moved from Africa to Europe or, alternatively, originated in Europe, and then separated into two lineages, one moving westward into North America (Cedrela), the other into Asia (Toona)". However, it is difficult to understand why the location of a group's oldest fossils should represent a centre of origin. It is also difficult to see why one lineage would migrate west and the other migrate east, and simple vicariance would explain the pattern more easily.

The complete absence of Toona and Cedrela from Africa would traditionally be explained by extinction there, perhaps caused by aridification. However, while the group as such is absent from Africa, it is represented there by its sister group, 
Entandrophragma, and so the simplest explanation accounting for both groups is allopatric differentiation of a widespread ancestor by vicariance. This group of three genera is, in turn, absent from Madagascar and parts of East Africa. However, its sister group comprises Capuronianthus, endemic to Madagascar, and Lovoa of mainland Africa.

\section{Toona (Endl.) M.Roem.}

Distribution. Four or five species in eastern Pakistan to China (north to southern Gansu), SE Asia, Malesia, New Britain and eastern Australia (Fig. 6; Muellner et al., 2010).

Ecology. Trees. Primary, secondary, riparian, and disturbed forest. Sea level to $2900 \mathrm{~m}$ (Toona sinensis (A.Juss.) M.Roem. in China; in Malesia recorded only up to $2000 \mathrm{~m}$ ). Toona calcicola Rueangr. et al. of NE Thailand is apparently restricted to limestone (Rueangruea et al., 2015). Toona sureni (Blume) Merr. in Malesia is often present in logged or disturbed areas; both the other species in Malesia are also recorded in disturbed forest. Toona ciliata M.Roem. has become extensively naturalised in countries such as Malawi (Styles \& White, 1991).

\section{Cedrela L.}

Distribution. Nineteen species (Pennington \& Muellner, 2010; Koecke et al., 2013; Köcke et al., 2015; Palacios et al., 2019) throughout tropical America (northern Mexico to Paraguay, including the West Indies) (Fig. 6, from Muellner et al., 2010).

The genus has its highest species diversity in the northern Andes. As mentioned already, it is thought to have had a North American origin, as the fossil record of the genus there (Oligocene-Miocene) is older than the record in Central and South America (Pliocene) (Muellner et al., 2010; Pennington \& Muellner, 2010). Koecke et al. (2013) interpreted this age sequence as an accurate depiction of spatial evolution, referring to "the southward migration of species, as shown by the fossil record". Based on the idea, the authors argued that "the extant South American species are most likely descendants from Central American taxa...". Cavers et al. (2013) reached similar conclusions: "From Europe [the centre of origin], Cedrela moved westwards on a boreotropical dispersal path and occurs in North American fossil records from 51 Ma until 15-13 Ma..., finally retreating south in the mid-Miocene... The start of diversification in Cedrela is estimated at between 33 and $22 \mathrm{Ma}$ (Muellner et al., 2010) when separate Central and South American clades formed... This suggests that the genus entered South America from North America during the mid-Oligocene (c. 25 Ma), potentially making use of islands... [Following this,] diversification proceeded in the South American branch of Cedrela and, from here, recolonisation of Central America and the Antilles occurred...". 
However, none of these inferred dispersal events among North, Central and South America would be required if Cedrela originated in situ, as an American vicariant of Toona. In a vicariance model, the north-to-south geographic sequence in oldest to youngest fossils is an artefact of the record, and there was no centre of origin in North America. Likewise, there is no reason why the centre of Cedrela species diversity in the northern Andes should represent the centre of origin of the genus. As discussed below, with the exception of a single, widespread species, the two main clades in Cedrela are allopatric around a break in Panama/Costa Rica. This also provides no support for a northern centre of origin.

Ecology. Trees in evergreen rain forest, seasonally dry, deciduous forest, pine-oak forest, cerrado savanna in eastern Brazil, and secondary vegetation; on acidic soils on volcanics and alkaline soils on limestone; from the lowlands to $3400 \mathrm{~m}$ (Pennington et al., 1981; Muellner et al., 2010). Cedrela lilloi C.DC. of SW Peru, NW Argentina, and SE Brazil extends from (800-)1000-3400 m (the upper limit of the family) and is able to withstand considerable frost. Cedrela montana $(1400-3100 \mathrm{~m})$ is in montane forest, cloud forest and subpáramo. Cedrela odorata sensu lato is a strong light demander and appears frequently as a fast-growing pioneer species in secondary forest (Pennington et al., 1981).

Muellner et al. (2010) wrote that: "Most Cedrela species have restricted distributions in seasonally dry, deciduous forests... but several species occur in wet rain forest, such as $C$. tonduzii C.DC., which is distributed throughout the mountain ranges of Central America...". Several are in the lowlands, but most species are restricted to montane regions.

Cedrela species are found almost exclusively in well-drained habitats and attain a good size even on the poorest of rocky soils. Most are intolerant of poorly drained situations. Cedrela 'odorata I' is often found on limestone, as in Jamaica (Kelly et al., 1988). In Cuba, serpentine and limestone sites are inhabited by Cedrela cubensis, whereas $C$. odorata sensu lato occurs at wetter sites (Puentes, 2005).

Cedrela fissilis Vell. is distributed from Colombia to southern Brazil and shows a wide ecological range. In the western part of its distribution it is in lowland, evergreen, seasonal forest (Peru) or evergreen, nonseasonal forest (Ecuador, Colombia), while in the east it occurs in semideciduous forest, gallery forest and cerrado vegetation. In southern Brazil (Paraná), it is a component of Araucaria forest (Muellner et al., 2010). This variation is consistent with the idea that distribution determines ecology, rather than ecology determining distribution.

Cedrela trees may occur as scattered individuals in undisturbed forest where their crowns are in the canopy, but they are far more numerous in areas of second growth forest (Earle Smith, 1960): "Here, mature trees with their crowns in the canopy and seedlings with their crowns in the understory may occur in groups". Cedrela odorata sensu lato is an important invasive species in the Galapagos Islands (RivasTorres \& Rivas, 2018) and also in South Africa.

Cedrela lilloi is able to regenerate in mature forest stands without large scale disturbances, but is dependent on fine-scale canopy openings (Grau, 2000). The species 
has a gap-phase regeneration mode, and its growth rate is rapid compared with many neotropical tree species.

Cedrela occurs in both wet forest and dry forest, and so ecological 'centre of origin' theory suggests that the genus originated in either one or the other. From this, the genus subsequently colonised, at least once, the other forest type. Pennington \& Muellner (2010) argued that Cedrela originated in seasonal dry forests. However, Muellner et al. (2010) wrote: "On the ML and Bayesian trees, the habitat preferences of the MRCA of Cedrela remained ambiguous... The optimisation on the MP strict consensus tree suggested an ancestral preference for a dry forest habitat; that on the MP majority rule consensus suggested wet forest....". The authors concluded that "... the ancestral habitat preference of Cedrela could not be inferred (probably in part because of the crude binary coding of habitats)...". If Cedrela originated by vicariance with Toona, in situ and over much of America, it is likely that ancestral Cedrela already occupied both forest types when it began to differentiate into the modern groups.

Notes. The phylogeny for Cedrela presented by Koecke et al. (2013) (and, with slight variants, Cavers et al., 2013) supports two main clades, as follows (distributions from www.tropicos.org). (Cedrela odorata L. proved to be polyphyletic, and the different components were referred to as $C$. odorata I, II and III): 1. five species in Mexico to Panama ('Central American 2' of Cavers et al., 2013); and 2. fourteen species in Mexico to Panama, West Indies, and South America.

Clade 1 ranges through Mesoamerica (from Mexico to Panama), while Clade 2 is in Mesoamerica, the West Indies and South America. Thus the only overlap is within Mesoamerica, and in fact most of the species in Clade 2 (11/14) are restricted to South America and the West Indies (where Clade 1 is absent).

The only members of Clade 2 in Mesoamerica are Cedrela 'odorata I' (north to Mexico; this is the only species of clade 2 present from Mexico to Costa Rica), $C$. 'odorata II' (north to Panama and Costa Rica), and C. ngobe Köcke et al. (endemic to Costa Rica and Panama). Thus, with the single exception of the northern populations of one widespread species, C. 'odorata I', the two main clades of Cedrela are allopatric: Clade 1 ranges south to Panama, and Clade 2 (apart from $C$. 'odorata I') ranges north to Costa Rica. The two have a boundary at, and overlap at, Panama and Costa Rica. The northern populations of Cedrela 'odorata I' can be explained as the result of range expansion (dispersal), but the direction of the dispersal (north to south? Pacific to Atlantic versant of Central America?) is unclear.

In the model proposed here, the two main clades of Cedrela originated by in situ vicariance around a boundary in Panama-Costa Rica, with range expansion in a single species, $C$. 'odorata I'. This is much simpler than the 'northern centre of origin/ invasion of South America' model presented in earlier studies.

While Panama and Costa Rica form the main boundary in Cedrela, the locality is not simply a boundary. It is also a zone of localised overlap, where the two main Cedrela clades occur together. Likewise, the total number of plant species, relative to area, is much higher in Costa Rica and Panama than in any South American country (Prance, 1994). These features could, perhaps, be explained by dispersal into the area 
from the north and south. However, the area is also a centre of endemism, with a great many examples, including Cedrela ngobe restricted to Panama and southern Costa Rica. (Several other Meliaceae endemic there are discussed below, under Guarea). Finally, Panama-Costa Rica is a locality where taxa display large-scale disjunctions and also anomalous absences, and these are difficult to account for in the centre of origin-dispersal models.

In Costa Rica, studies on seedling traits in Cedrela odorata sensu lato (Navarro et al., 2002) showed two groups, one in northwestern Costa Rica, including Nicoya Peninsula (C. 'odorata I' of Koecke et al., 2013) and one in eastern Costa Rica $(C$. 'odorata II'). The Nicoya Peninsula and other areas in Costa Rica and Panama comprise accreted oceanic terranes, including island arcs and ophiolite sequences associated with island arcs (Fig. 12). The area is discussed in more detail below.

Subsequent molecular studies showed that Cedrela 'odorata I' extends from northwestern Costa Rica to Mexico and the West Indies, and also has disjunct populations far to the south, in Ecuador (Cavers et al., 2013; Koecke et al., 2013). The disjunction from Nicoya Peninsula, across Panama and Colombia, to Ecuador, is impressive. However, similar breaks occur in many clades, including several other Meliaceae cited below, and so a general explanation is needed. Climatic or tectonic factors are possibilities.

Cedrela 'odorata I' populations from the Nicoya Peninsula have similar seedlings to populations from dry Pacific sites, but are located in an area of higher rainfall. Thus while the boundary between Cedrela 'odorata I' and C. 'odorata II' is geographic, it is not related to climate, and Navarro et al. (2002) proposed a vicariance model: "Differentiation may have occurred when the cordilleras Volcanica Central and Guanacaste raised a barrier within the range of the species in Costa Rica...". A tectonic explanation does seem to be the most likely explanation, but uplift on its own does not account for the Nicoya Peninsula-Ecuador disjunction.

The following seven genera form a clade (Koenen et al., 2015; Muellner-Riehl et al., 2016; Guo et al., 2018). The first three break off from the others in sequence: India Madagascar - Africa, although the statistical support here was not strong.

\section{Soymida A.Juss.}

Distribution. One species in India and Sri Lanka. Widespread in India from Rajasthan in the north-west and the Varanasi region (Uttar Pradesh) in the north-east, through central India (Deccan Plateau, Western Ghats) south to Travancore and the Carnatic (Harms, 1940).

Ecology. Trees in low mountain ranges on laterite, in dry forests, together with Chloroxylon (Rutaceae) (Harms, 1940). In Sri Lanka (where it is now thought to be 


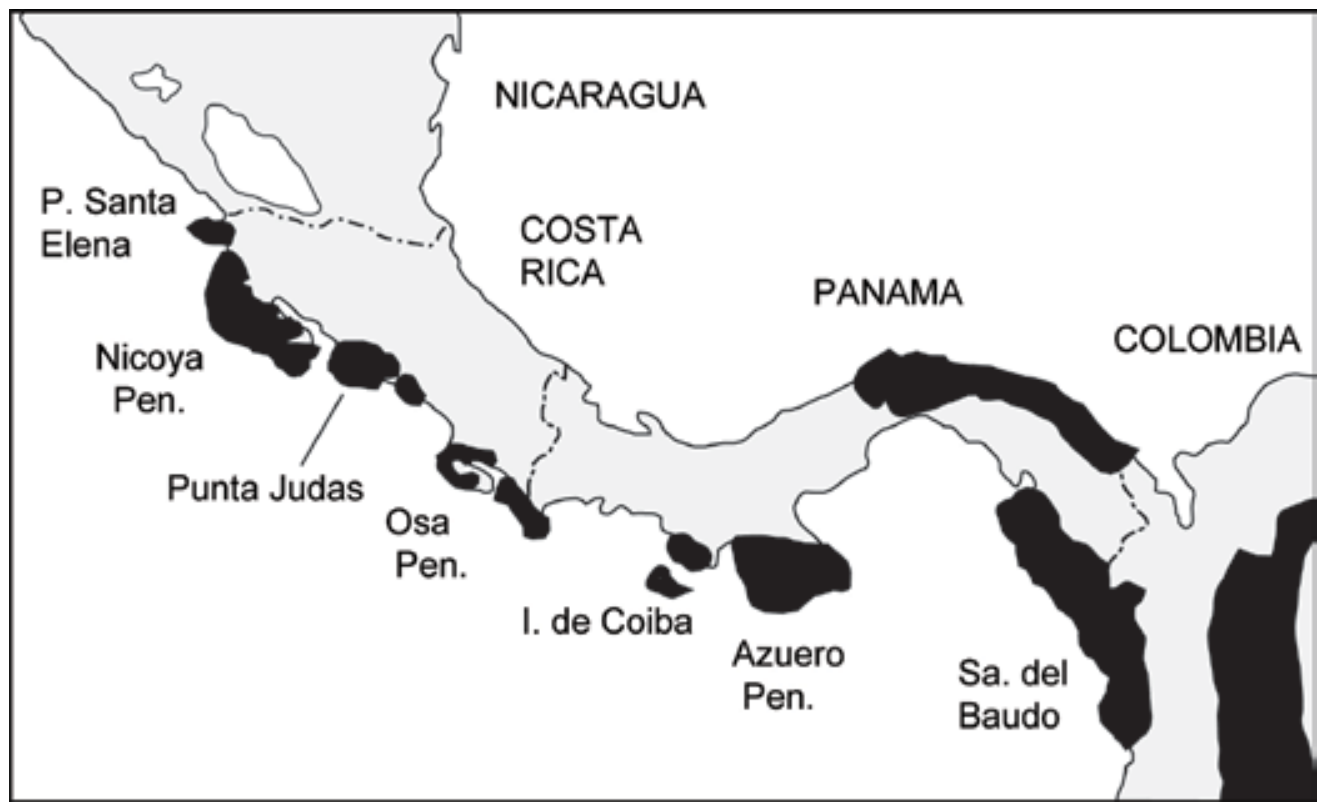

Fig. 12. Locality map of southern Central America (with Nicoya, Osa and Azuero Peninsulas, Punta Santa Elena and Punta Judas, and Serranía del Baudó), showing accreted oceanic terranes (island arcs, ophiolites) in black.

indigenous), Soymida inhabits fire-savannas (talawas) in the dry and intermediate zones up to about $1000 \mathrm{ft}$. [305 m] (Meijer, 1970).

\section{Neobeguea J.-F.Leroy}

Distribution. Three species in Madagascar.

Ecology. Trees in xerophilous vegetation in the west and south (maps in Leroy, 1976). The species inhabit sandy coastal areas and maritime forest, and also present on karst and calcareous plateau. Neobeguea leandriana J.-F.Leroy seems restricted to calcareous substrates (Leroy, 1958a, 1970, 1976).

\section{Pseudocedrela Harms}

Distribution. One species in Africa (Senegal to Ethiopia and Uganda) (Fig. 13).

Ecology. Tree, bole often crooked and branched from near the base, often coppicing and regenerating mainly by root-suckers. In gallery forest, savanna woodland, and on terraces along streams, in hollows and on deep sands, often gregarious on moist, heavy soil of valleys or swampy areas; 120-1200 m. 


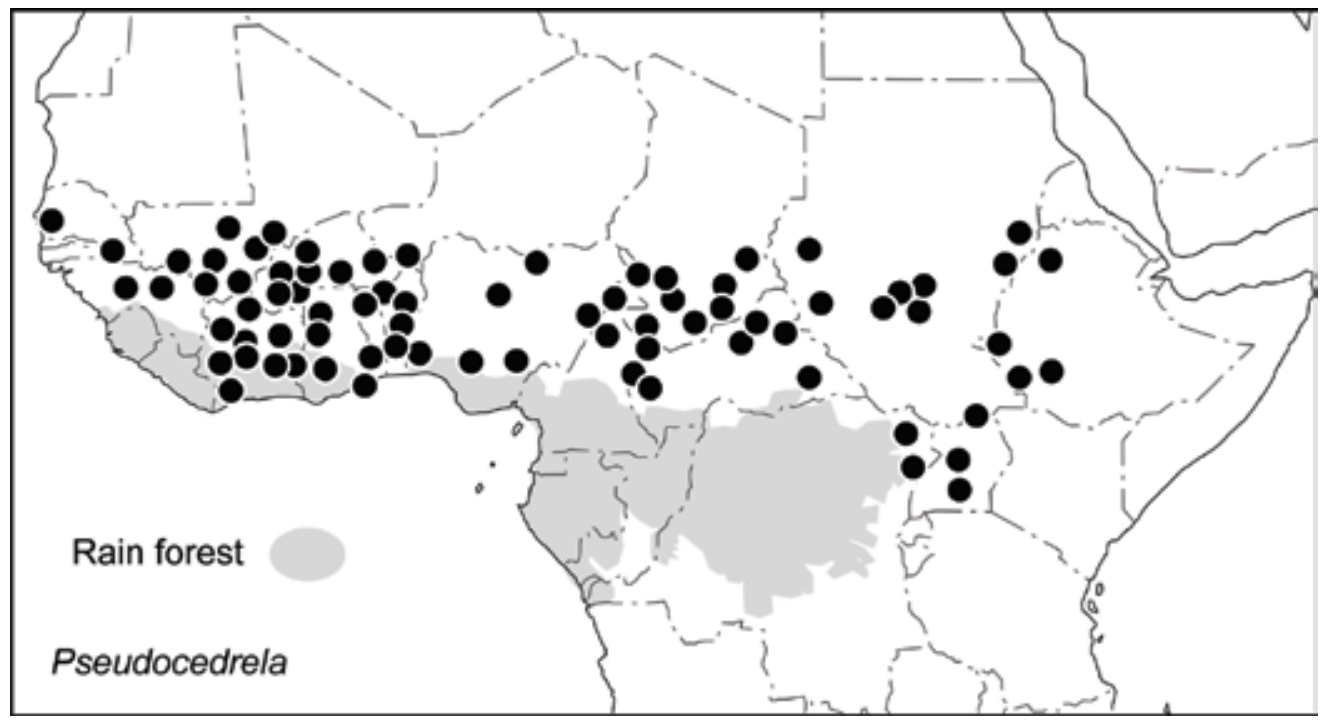

Fig. 13. Distribution of Pseudocedrela Harms (African Plant Database, 2019).

\section{Khaya A.Juss.}

Distribution. Eight species in Tropical Africa (7 species), Madagascar and Comoro Islands (1 species) (Fig. 14A). A molecular phylogeny (Monthe et al., 2019) arranged the species in two main clades, and these display a high level of allopatry (Fig. 14A). One is in the north and west, the other lies further south and east, including Bioko and Madagascar. The two clades overlap only in Ivory Coast/Ghana, and in SW Cameroon. Both clades are in rain forest and savanna woodland.

In the northwestern clade, Khaya senegalensis (Desr.) A.Juss., K. grandifoliola C.DC. and the pair K. agboensis A.Chev. + K. euryphylla Harms form three, allopatric latitudinal bands, but this is disrupted at the Cameroon Volcanic Line (Fig. 9), where there is a break between $K$. agboensis and K. euryphylla.

In the south-eastern clade of Khaya, K. ivorensis A.Chev. (Ivory Coast to the Congo mouth) is sister to $K$. madagascariensis Jum. \& H.Perrier of Madagascar. This disjunction appears to skirt the large area of central Africa occupied by its sistergroup, Khaya anthotheca (Welw.) C.DC. $+K$. sp. nov., and probably also the area of the unsequenced $K$. nyasica Baker f. (often included in $K$. anthotheca). The disjunct affinity is of special interest, as it repeats a standard west-east disjunction across Africa, but in this case the gap is filled by an allopatric sister group. Thus the disjunction can be explained by simple vicariance, and there is no need to invoke extinction to account for the 'gap'. The break between Khaya ivorensis and K. anthotheca runs in a northsouth line from Gabon to northern Angola, and this corresponds with the belt of uplift at the Central African Atlantic Swell (Fig. 9). 


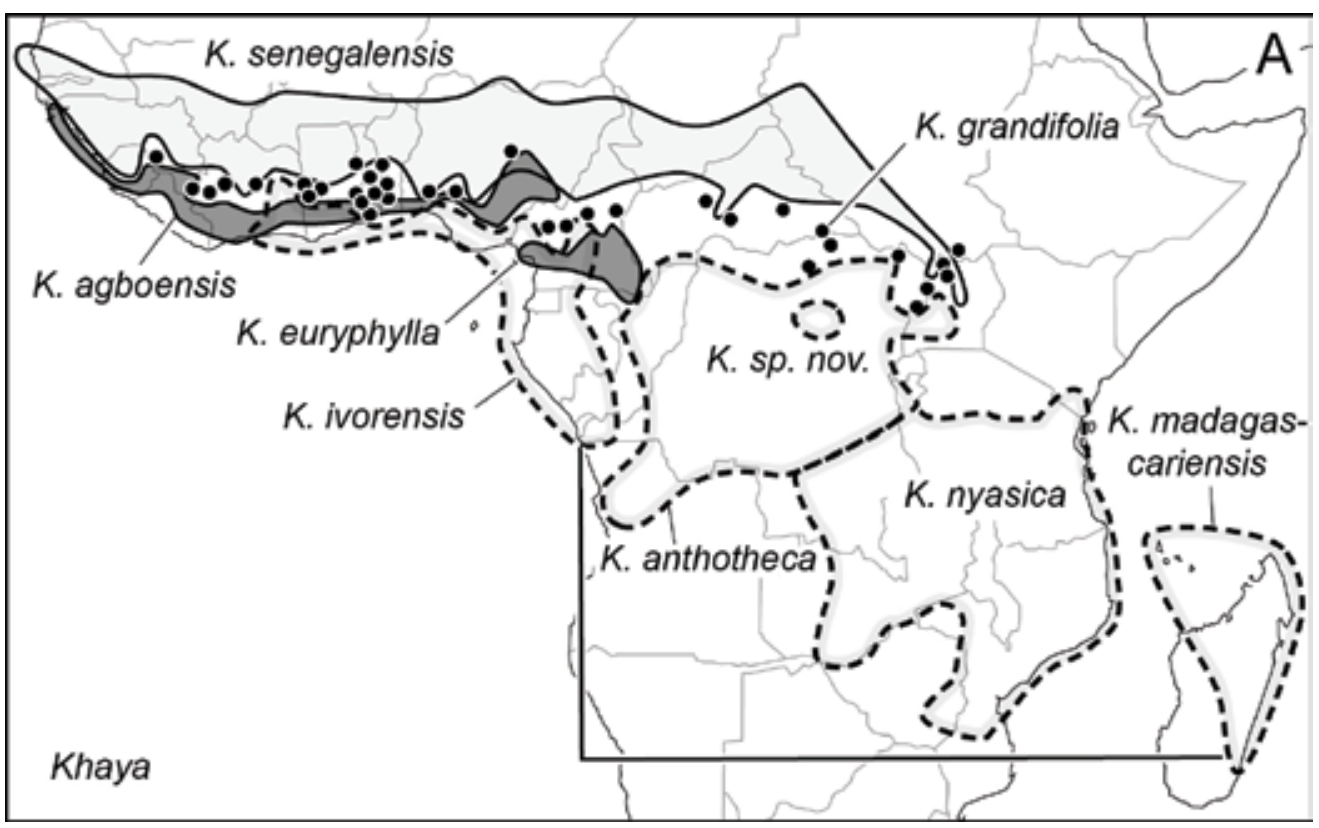

Fig. 14 . Distribution of Khaya A.Juss. A. One clade in light and dark grey fill and black dots, the other clade in broken lines. (Data from Monthe et al., 2019).

Ecology. Large trees in sandy ground by lagoons (Khaya ivorensis), riparian forest, rain forest of lowlands and hills, and savanna woodland, often in rocky places; 10-2000 m. The first main clade of Khaya, in the north-west (Fig. 14B), is mainly in savanna, but it also occurs in rain forest in Liberia, Ivory Coast, Ghana and Cameroon. The second clade (Fig. 14C) is mainly in rain forest, but there are savanna-woodland populations in Angola, southern DRC and Madagascar.

\section{Swietenia Jacq.}

Distribution. Three species. Widely cultivated. One species in Mesoamerica, one in the West Indies, and one widespread from Mexico to the Amazon basin (Fig. 15):

Swietenia humilis Zucc. (Fig. 15A). On the Pacific versant of Mexico and south, mainly on the Pacific side, to Costa Rica. In Mexico it is widespread on the allochthonous terranes (Guerrero terrane etc.); these were accreted in Cretaceous time onto the Pacific margin of the craton. In Guatemala the species occurs along the Motagua fault, almost reaching the Atlantic coast.

Swietenia macrophylla King. (Fig. 15B). SE Mexico and through Central America (mainly on the Caribbean side) to the Amazon basin. In Mexico it is absent on the accreted terranes. 


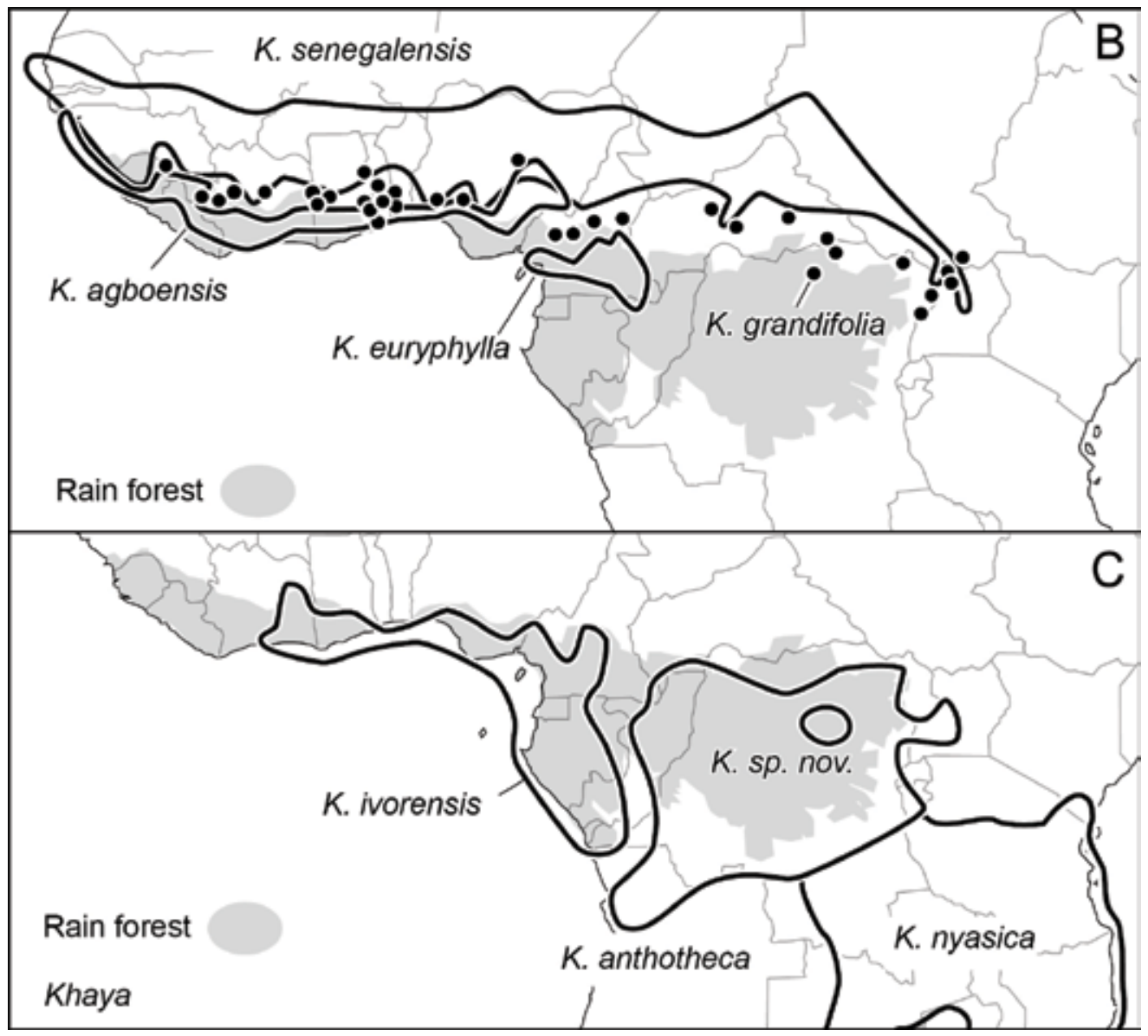

Fig. 14. (Continuation). Distribution of Khaya A.Juss. B. Distribution of the northern clade in relation to the rain forest. C. Distribution of the southern clade in relation to the rain forest. (Data from Monthe et al., 2019).

Swietenia mahagoni (L.) Jacq. (Fig. 15B). West Indies (Cayman Islands, Cuba, Bahamas, Jamaica, Hispaniola) and southern Florida. Often on limestone. It is widely planted and often escaped from cultivation, and so its original area of distribution is difficult to ascertain.

Novick et al. (2003) discussed whether Swietenia had a centre of origin in Mesoamerica or in Amazonia. They suggested that "we lack fossil evidence establishing the geographical origin". However, they thought that the northern distribution of all three Swietenia species supports an origin of S. macrophylla there as well, with later dispersal to the Amazon. Yet the three species are almost completely allopatric, consistent with an origin by simple vicariance, and so there is no need for any range expansion in any of them. 


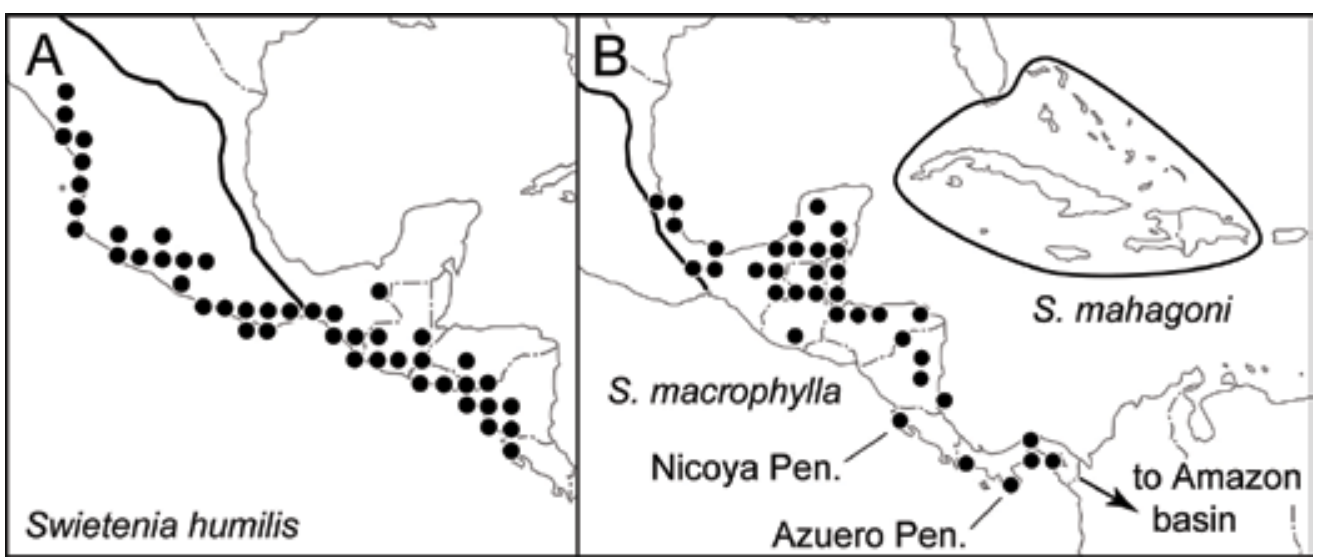

Fig. 15. Distribution of Swietenia Jacq. A. Swietenia humilis Zucc. Solid line = boundary between accreted terranes in the west and craton in the east (Umhoefer, 2003). B. Swietenia macrophylla King and Swietenia mahagoni (L.) Jacq.

Ecology. Trees in moist or dry forest, rocky areas, often on limestone (Swietenia mahagoni); sea level-1200 m. Swietenia mahagoni regenerates well within unlogged and logged forest, is a good coloniser of abandoned farm land, and "thrives on disturbance..." (Pennington, 2002). On some islands it is regarded as a weed.

Notes. Swietenia macrophylla displays "strong phylogeographic structure" in Mesoamerica, and greater genetic differentiation there than in Amazonian populations (Novick et al., 2003). In Mesoamerica, the two populations on the Pacific coasts of Costa Rica (Santa Rosa, by the Nicoya Peninsula) and Panama (Azuero Peninsula) (see Fig. 12) were genetically distant from all the others. Novick et al. (2003) wrote that the split of these populations from the rest "may have occurred early in the Mesoamerican expansion of mahogany, perhaps prior to the late Miocene development of the Talamanca mountain range".

Novick et al. (2003) pointed out that the pattern in Swietenia macrophylla, in which the Nicoya and Azuero populations are distinct from all the others, is similar to that seen in other groups. For example, Perdices et al. (2002) found that vicariance has played a strong role in the diversification of the catfish genus Rhamdia, and they identified cis- and trans-Andean clades. One of the species, Rhamdia guatemalensis, ranges from southern Mexico to northern Colombia. The basal split within the species is between a population at Cañas, by the Nicoya Peninsula, and all the rest.

The 21 species of Poeciliopsis (Poeciliidae) are small topminnows distributed mostly in Pacific-slope drainages from Arizona to western Colombia. The basal break is between subgen. Aulophallus, found along the Pacific coast between the Nicoya and Azuero Peninsulas, and the remaining 18 species, making up subgen. Poeciliopsis (Mateos et al., 2002).

Other endemics in the region include the mangrove hummingbird, Amazilia boucardi, restricted to the sector between the Nicoya and Osa Peninsulas, and the 
frog Craugastor rugosus, distributed between Punta Judas (= Punta Mala) and the Osa Peninsula and its hinterland. The Osa Peninsula in particular is known for its high diversity and endemism.

The mayfly Tikuna atramentum is only known from Santa Elena Peninsula, Nicoya Peninsula, Punta Judas, and Osa Peninsula (Fig. 12; Flowers \& Ávila A., 2006). In another mayfly genus, Choroterpes, both the Costa Rican species show a similar pattern to that of Tikuna, with C. maireana restricted to Santa Elena Peninsula, and C. gregoryi at Nicoya Peninsula, Punta Judas and opposite Osa Peninsula (Ávila A. \& Flowers, 2006). Flowers \& Ávila A. (2006) made the critical observation that the localities of Tikuna atramentum show a 'tight spatial correlation with ophiolitic terranes' in the 'Nicoya Complex' in the broad sense. Ávila A. \& Flowers (2006) mapped a similar correlation in Choroterpes. The Nicoya Complex includes a Jurassic-Paleogene ophiolite sequence, comprising ultramafic rocks, epiclastic material indicating a Cretaceous volcanic island arc, and a Campanian-Eocene arcrelated complex. Flowers \& Ávila A. (2006) noted that a similar, close association of hemipterans, plants, and birds with ophiolite terranes has been reported in New Guinea. They wrote that these taxa seem to have arrived in New Guinea by accretion of the terranes on which they occur, and that a similar accretion process may be responsible for the distribution of Tikuna atramentum in Costa Rica.

Many marine rocks on land were deposited as sediments during marine transgressions. However, ophiolite suites, like those in the Nicoya Complex, are of special interest as they did not form in situ, but have been tectonically emplaced from elsewhere. They represent slices of oceanic crust and upper mantle that have been ramped up onto land during obduction (the opposite of subduction), a process that occurs at plate margins when an island arc collides with a continent.

Ophiolites often include ultramafic rocks, and botanists have inferred that the endemism typical of them is due to soil chemistry. However, this is unlikely to be the real explanation, as there is usually striking endemism in animals as well as plants, and ophiolite terranes can harbour both ultramafic and non-ultramafic endemics. Thus ophiolites are probably so significant for biogeography, not because of their chemistry, but because they are arc terrane markers. The most mature phase of arc collision is seen in old arc fragments now deeply embedded in modern mainlands, as in Borneo, the Philippines, New Guinea, and New Zealand. The remnants of these Mesozoic arc systems have been crushed between arcs or continents, but they have left a biological signature in the distributions of living taxa.

The biogeographic problem in Costa Rica and Panama requires several features to be explained together: endemism on the Nicoya, Osa and Azuero peninsulas in Swietenia and others; endemism along the rest of the Costa Rica-Panama biogeographic centre; anomalous absences in the same area; and major disjunctions in the area (such as the Nicoya-Ecuador disjunction in Cedrela 'odorata I').

These phenomena can all be explained, not as the result of dispersal from north to south or from south to north, but with reference to the Nicoya Complex of island arcs, seamounts, and associated ocean floor that formed in the Pacific, and were translated eastward. Parts ended up being 'smeared' onto the west coast of America 
and are now embedded in the mainland of Costa Rica (at the peninsulas discussed above), Panama (Azuero Península and the Serranía del Sapo) and Colombian Chocó (Serranía de Baudó, continuous with the Serranía del Sapo; see Fig. 12).

As North and South America moved apart, the Caribbean trench and its associated active island arc moved east into the Caribbean (Fig. 16). The process resulted in the accretion of oceanic terranes, including arcs and seamounts, onto the mainland (Fig. 17). Movement of the trench into the Caribbean took place on strike slip faults to the north (Motagua fault system) and south (Romeral fault system). The process explains the geometry of distribution patterns seen in several Meliaceae described below, and also in parrots (Fig. 18), passerines (Fig. 19), and frogs (Fig. 20) (for other examples, see Heads, 2016).

Savage et al. (2005) wrote that "Theories about the origin of the biota of Costa Rica have generally assumed dispersal across a Central American land bridge that was formed by volcanic and tectonic activity sometime during the Pliocene". Biota are thought to have crossed the bridge from the north and from the south in a great 'interchange'. However, Savage et al. (2005) noted that the correlation of mayfly distributions with the Nicoya Complex suggested "the intriguing possibility that Costa Rica acquired some of its biodiversity eons before the Great American Interchange". Accretion of Cretaceous-Cenozoic island arc/s in the region would account for many aspects of the diversity there, including both endemism and disjunction.

The idea of a Great American Biotic Interchange was derived from a literal reading of the mammalian fossil record, and it remains a central tenet of dispersal biogeography. Nevertheless, it would seem unlikely that the only groups arriving in southern Central America/Chocó on island arcs formed in the Pacific were the mayflies described by the authors cited above; probably entire rain forest communities were involved.

An 'interchange' across a Costa Rica-Panama landbridge might explain the overlap of distributions and the high diversity there, but it does not account for the abrupt boundaries in the area, the high endemism, the strange absences, the large-scale disjunctions, or the precise correlations of distributions with allochthonous terranes. These, together with the diversity, can all be explained if a large part of the regional biota, rather than forming in situ, instead represents tectonic introduction from the Pacific plate. The Costa Rica-Panama region is an important biogeographic centre in its own right, with its own endemics and anomalous absences; it is not simply a 'bridge' (or a 'barrier' or 'filter') between North and South America.

\section{Carapa Aubl.}

Distribution. Four, 12 or 27 species have been recognised in different treatments. America, São Tomé Island, mainland Africa (Fig. 21A, B). The genus was earlier treated with four species (three in America and one in Africa). Kenfack (2011a) carried out morphometric and molecular analyses, and referred to numbered morphospecies. Nine of these were later named as new species (Kenfack, 2011b), and overall Kenfack 


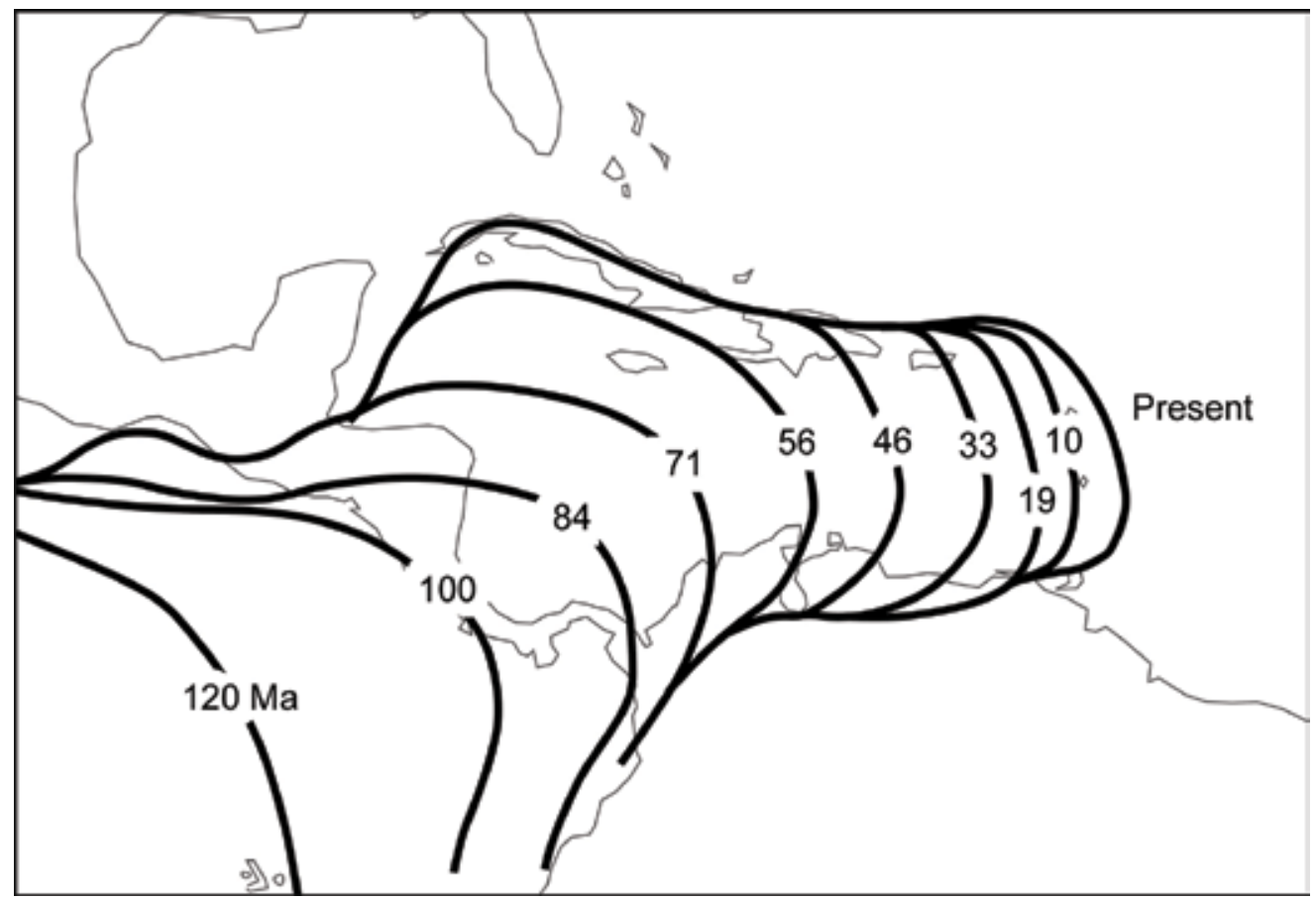

Fig. 16. Former relative positions of the Caribbean Trench from $120 \mathrm{Ma}$ to the Present (Pindell \& Kennan, 2009). The base map has no palaeogeographical significance; over the time period shown, North and South America have drifted apart.

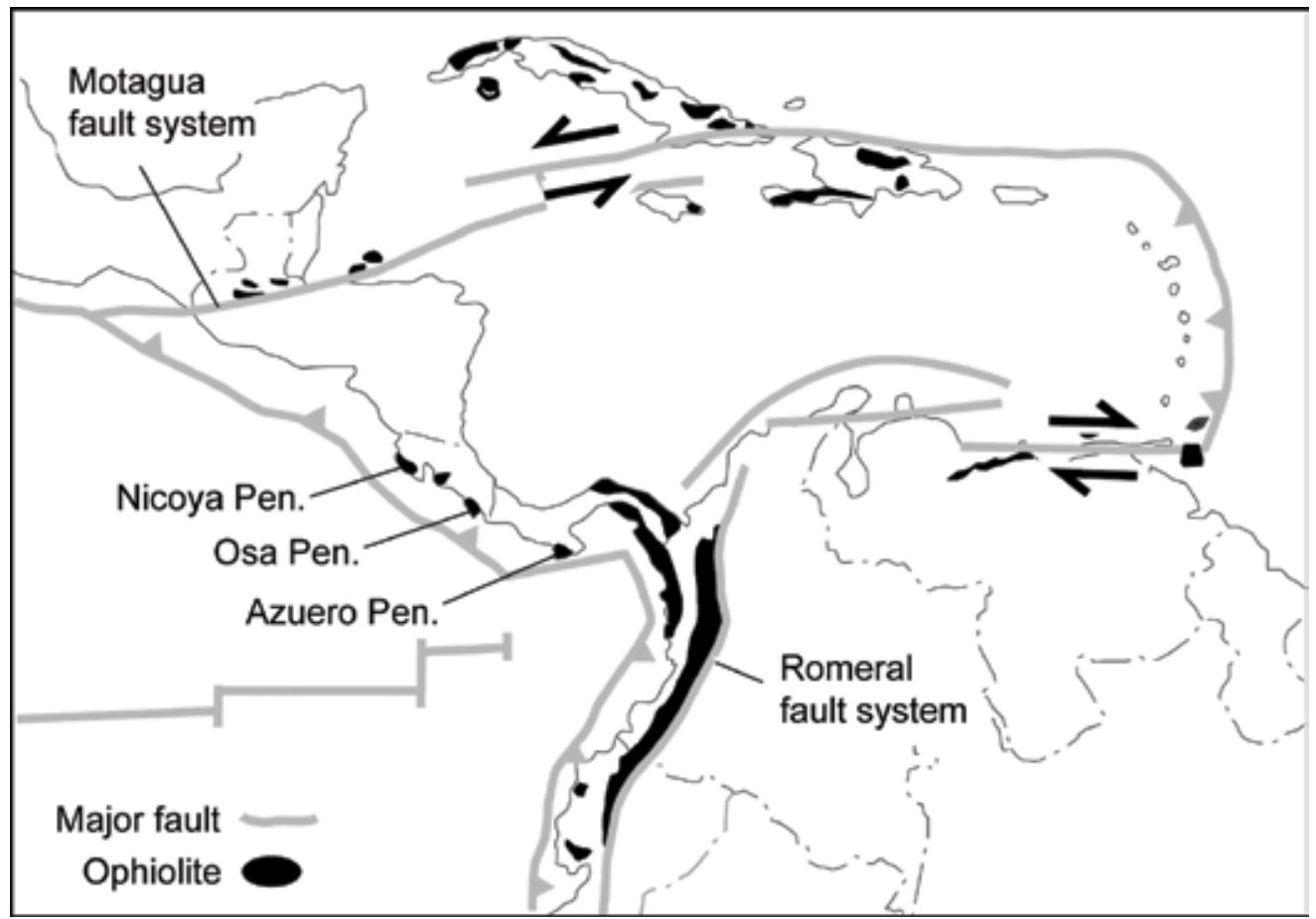

Fig. 17. Outline of Caribbean tectonics (Denyer \& Baumgartner, 2006; Weber et al., 2009). 


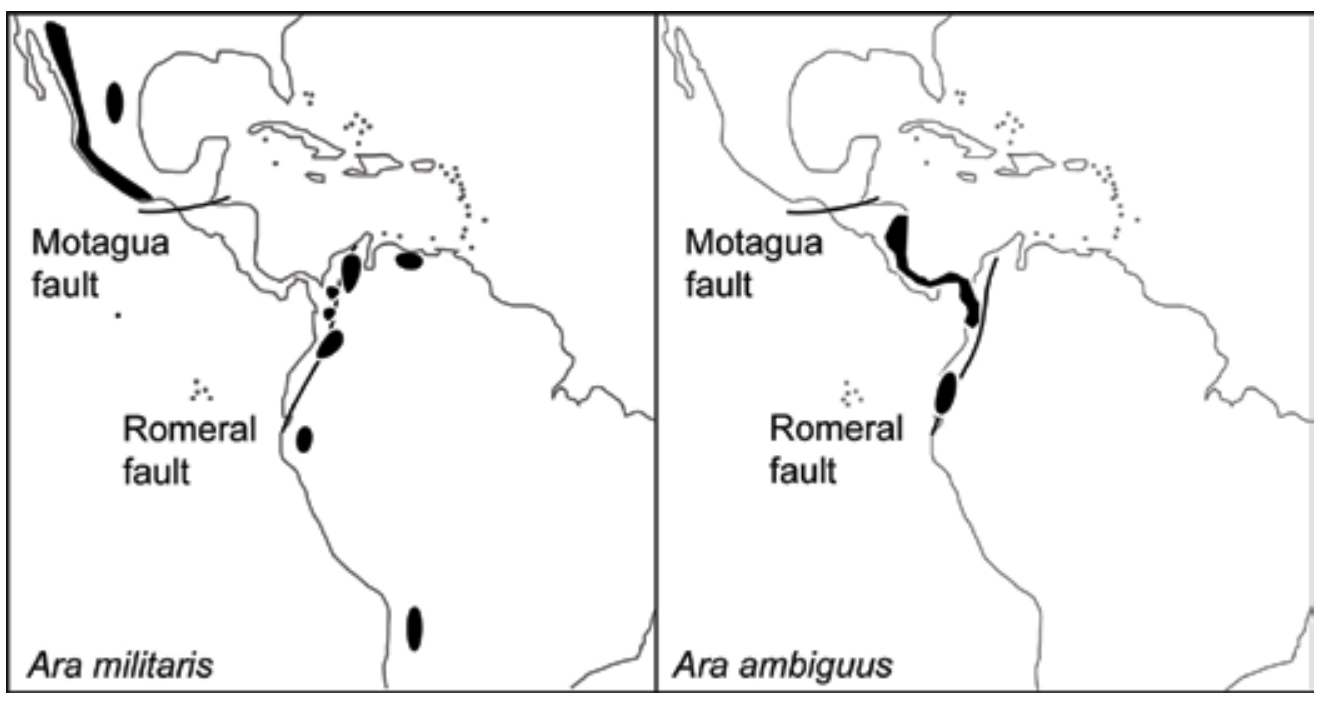

Fig. 18. Distribution of the parrots Ara militaris (L.) and Ara ambiguus (Bechstein) (Psittacidae) (Heads, 2016).

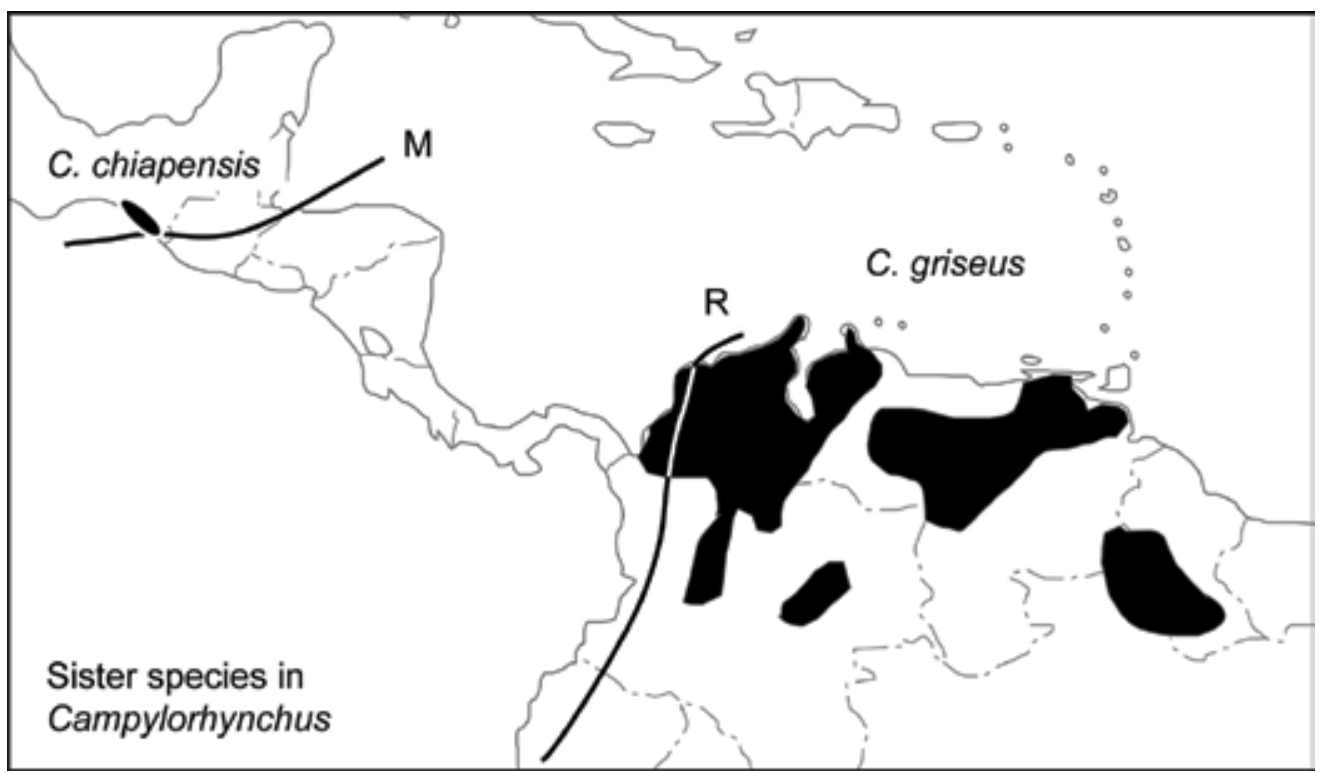

Fig. 19. Distribution of two sister species in the passerine bird Campylorhynchus Spix (Troglodytidae) (Heads, 2016). 


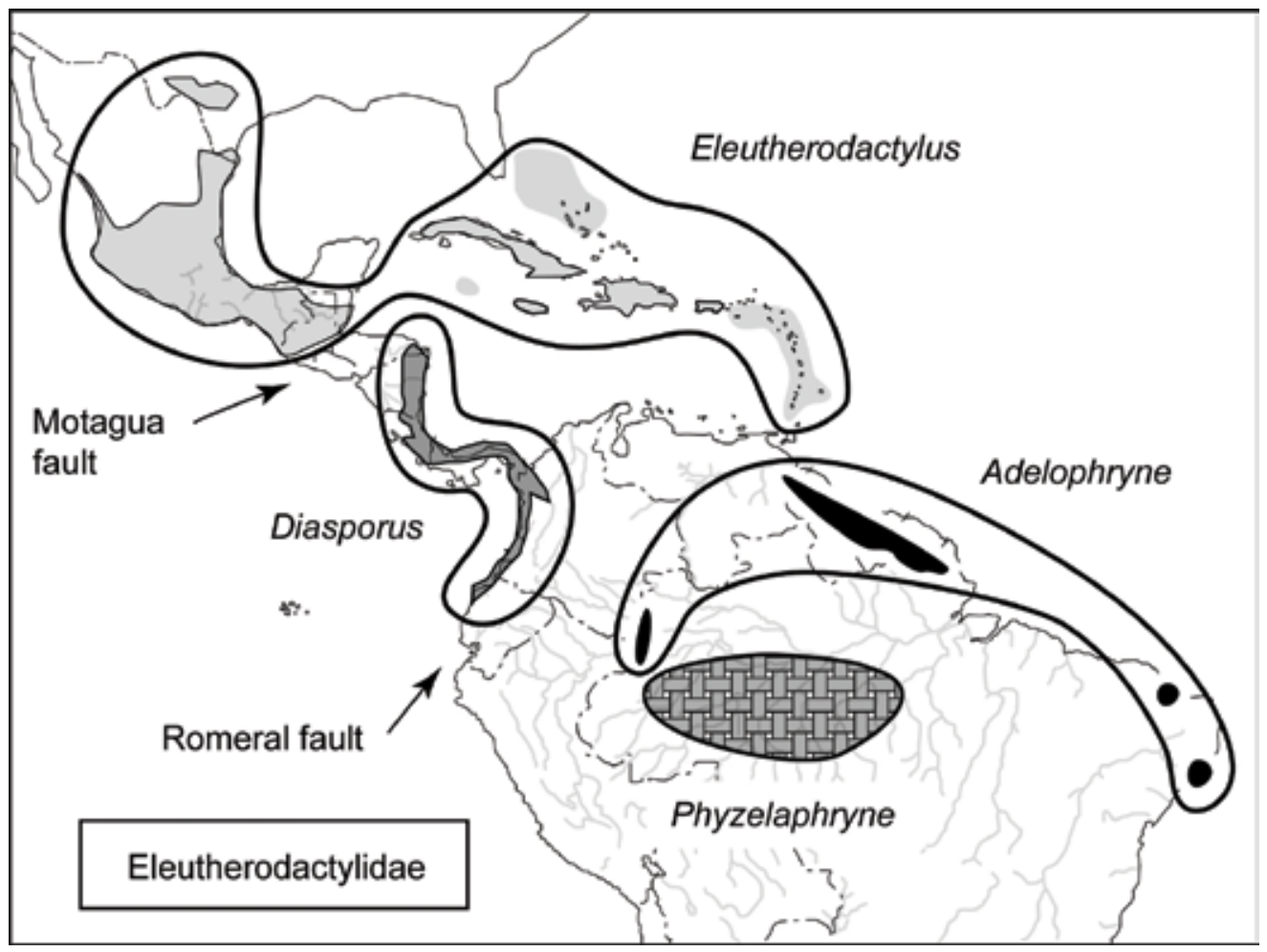

Fig. 20. Distribution of the frog family Eleutherodactylidae (Heads, 2016).

recognised 27 species (11 in America and 16 in Africa). Koenen et al. (2015) accepted 12 species (two in America, 10 in Africa).

Ecology. Trees present at the inland limits of mangroves (in Gabon and Panama) and often in saline soil, flood plains and marshy conditions, periodically inundated forest, streams in wet forests, lowland rain forest, gallery forest in savannas, disturbed forest, and montane forest; gregarious in rocky mountains in Ivory Coast (Aubréville, 1936); up to $2300 \mathrm{~m}$ in America and $2500 \mathrm{~m}$ in Africa. The sister pair Xylocarpus and Carapa shows the transition from mangrove (Xylocarpus, some Carapa species) to higher montane forest (some Carapa).

In America, Carapa ranges from the mangrove up to $2300 \mathrm{~m}$. In Clade I, the widespread Carapa guianensis sensu stricto is of special interest. Throughout most of its range it grows in flood plains and marshy conditions (Kenfack, 2011a). In the north of Guyana, for example, it is a small, basally branched tree that grows in forest that is subject to tidal inundation. However, further inland, in the Brazilian Amazon and in Peru, it grows in terra firme forest and is a large tree to $40 \mathrm{~m}$ tall (Kenfack, 2011b). It generally occurs between sea level and $300 \mathrm{~m}$ altitude but reaches $400 \mathrm{~m}$ in the Dominican Republic and $500 \mathrm{~m}$ in Venezuela. 


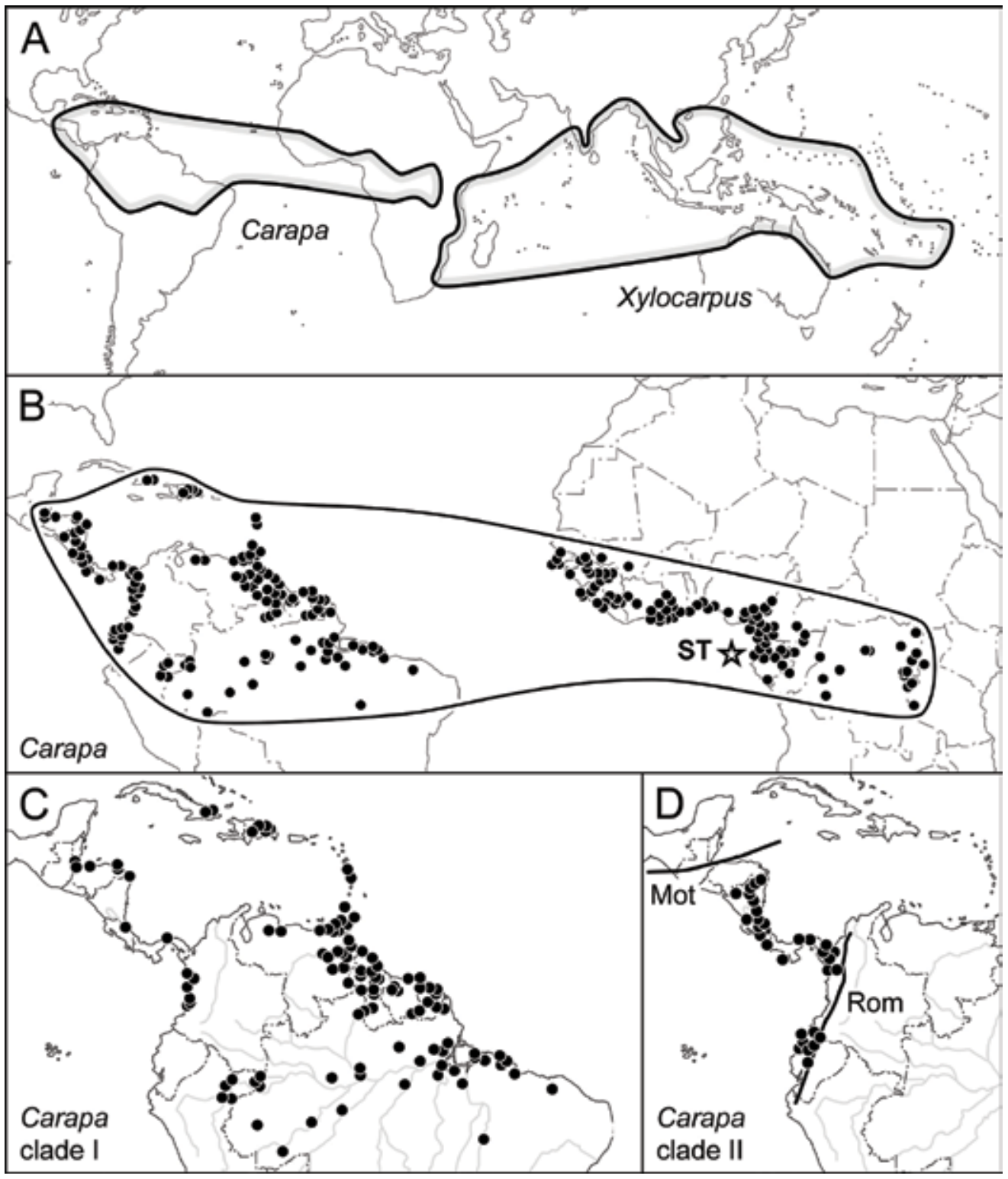

Fig. 21. A. Distribution of Xylocarpus J.Koenig and Carapa Aubl. B. Distribution of Carapa. $\mathrm{ST}=$ Carapa gogo Kenfack (possibly not a distinct species) on São Tomé Island. C. Distribution of Carapa clade I. D. Distribution of Carapa clade II. Mot = Motagua fault system, Rom = Romeral fault system.

In the floodplain forests (várzea) of the Amazon estuary, at $5 \mathrm{~m}$ elevation, Londres et al. (2017) studied the population structure of Carapa guianensis sensu lato in three types of várzea differentiated by tidal influence, species dominance and composition, and edaphic conditions. In all three, densities of Carapa guianensis were much higher than in terra firme forests 
Carapa nicaraguensis C.DC. (morphospecies 4 in Kenfack, 2011a) is recorded from periodically inundated forest and, on Coiba Island off the south coast of Panama, from riverbanks in an area of mangrove.

In mainland Africa, Carapa inhabits mangrove, coastal and lowland forest, including gallery forest in savanna, and extends up to montane forest at $2500 \mathrm{~m}(C$. grandiflora Sprague in East Africa and C. oreophila in SW Cameroon and SE Nigeria). In West Africa, Carapa procera DC. sensu lato has been reported as "Forest tree; habit varies from a sprawling tree with arching branches up to about 50' high in swamp forest to a tall tree with clear bole in lowland rain forest" (Keay, 1958).

Asuk et al. (2018) recorded Carapa procera sensu lato from mangrove swamp at Calabar, Nigeria. In East Africa, Carapa procera sensu lato is recorded "in lake-shore, riparian and mid-altitude forest (especially where drainage is impeded); 1140-1830 m" (Styles \& White, 1991). The mangrove associates recognised by Kenfack (2011b) in African Carapa are as follows: Carapa dinklagei Harms (= morphospecies 17 of Kenfack, 2011a) in SW Nigeria to Gabon, edge of mangrove swamp (Rio del Rey, SW Cameroon), low depressions in coastal forest, wet valleys along rivers and streams; sea level to $800 \mathrm{~m}$; Carapa mangarevensis Kenfack \& Issembe (= morphospecies 24 of Kenfack, 2011a) in Gabon, mostly along the inland edge of mangroves, often under saline conditions; Carapa littoralis (= morphospecies 22 of Kenfack, 2011a) in Cameroon, coastal sites, sometimes more or less associated with mangrove forests. These species record an ecophyletic transition between mangrove and dry ground. Another species of special interest is Carapa microcarpa A.Chev. (= morphospecies 13 of Kenfack, 2011a). It occurs from Ivory Coast to Benin in periodically inundated terrains and along streams in wet forests, in contrast to morphospecies 12 [Carapa procera] and 14 [C. velutina C.DC.], which grow in gallery forest in savanna or dry forest. In Ghana, Carapa microcarpa grows along streams in montane rain forest, with branches that arch downwards and occasionally take root where they touch the ground (pers. obs., Atewa Range).

Notes. The trans-Atlantic Carapa and the trans-Indian Ocean mangrove Xylocarpus were long thought to be sisters. The phylogeny in Koenen et al. (2015) instead proposed a phylogeny: Soymida (Neobeguea (Pseudocedrela (Swietenia (Xylocarpus $($ Khaya + Carapa $))))$ ), but without strong support. However, recent studies support the traditional status of Carapa and Xylocarpus as sisters. Muellner-Riehl et al. (2016) presented a phylogeny mainly similar to that of Koenen et al. (2015), but with a clade: (Khaya of Africa + Swietenia of America) (Carapa + Xylocarpus). Guo et al. (2018) proposed the arrangement used here: Khaya (Swietenia (Carapa + Xylocarpus)).

The American species of Carapa fell in two molecular clades showing distinct allopatry (Fig. 21C, D) (Kenfack, 2011a). In Clade I, the northern limit corresponds closely with the Motagua fault system. Clade I includes the most widespread species in the genus, Carapa guianensis Aubl. sensu stricto (morphospecies 1 of Kenfack, 2011a). In Central America Carapa guianensis is present only on the Caribbean coast, while in the West Indies (where it is the only Carapa present), it occurs in Cuba (Oriente only), Hispaniola, and the central Lesser Antilles (Grenada, Dominica, and 
Martinique) (Kenfack, 2011b). The species (and genus) is notably absent from Puerto Rico and Jamaica, and is disjunct between Dominica/Martinique and Hispaniola/ eastern Cuba.

Carapa clade II is restricted to the area between the Motagua and Romeral fault systems, consistent with its accretion, with the oceanic terranes, to the mainland. It displays a notable gap in Chocó, and this is filled by members of Clade I. In Central America, Clade I is restricted to the Caribbean coast, while clade II is widespread.

Carapa gogo Kenfack (= morphospecies 18 in Kenfack, 2011a) was treated as endemic to the island of São Tomé (Kenfack, 2011b) but is probably not a distinct species (Koenen et al., 2015). Whatever the exact taxonomic status of the population might be, the locality is significant.

\section{Xylocarpus J.Koenig}

Distribution. Two species in East Africa (Somalia to Mozambique), Madagascar, Mascarene Islands, India and east to Tonga and Samoa (Fig. 21A). Xylocarpus is distributed in East Africa and around the Indian Ocean, and it is allopatric with its sister group, the trans-Atlantic Carapa of America and West and Central Africa. The two genera are "geographic vicariants with different ecology" (Mabberley, 1988); Xylocarpus is usually in mangrove and other maritime sites, while Carapa usually occurs in forest on dry land.

Ecology. Xylocarpus granatum J.Koenig is in mangrove, usually estuarine and often associated with Nypa palm and Sonneratia (Lythraceae). Xylocarpus moluccensis (Lam.) M.Roem. sensu lato is also in mangrove, but usually in the upper reaches and often in only slightly brackish water; it also occurs ('X. rumphii'-type populations) above high water mark in scrub, woodland and forest, on cliffs, rocks (including limestone) and sandy substrates, often near surf, up to $20 \mathrm{~m}$ alt.

Notes. Three species of Xylocarpus have often been recognised, but a molecular study did not support the traditional distinction between $X$. moluccensis and X. rumphii (Kostel.) Mabb. (Guo et al., 2018), and these are treated here as a single species (moluccensis is the earlier epithet). Guo et al. (2018) proposed the following phylogeny: Xylocarpus granatum (X. moluccensis [samples BG1, MW4] (X. moluccensis [all other samples] $+X$. rumphii)). The two samples of Xylocarpus moluccensis sensu stricto from the Indian Ocean that were sequenced (BG1 from Bangladesh and MW4 from the western Malay Peninsula) form the sister to the rest of $X$. moluccensis sensu lato.

Despite the overall sympatry of the two species from East Africa to Tonga, allopatry does occur at more local scales. For example, around East Africa and around New Caledonia the distributions differ as follows (White \& Styles, 1963; Styles \& White, 1991; Mabberley 1988):

Xylocarpus granatum is present in Somalia and India, in the north, but not in the Mascarenes, and is present in New Caledonia on Grande Terre only. 
Xylocarpus moluccensis sensu lato (incl. X. rumphii) is absent from Somalia and India, but present in the Mascarenes, and is present in New Caledonia on the Loyalty Islands only.

In the New Caledonian archipelago, the break between Grande Terre (Xylocarpus granatum) and the Loyalty Islands ( $X$. moluccensis sensu lato) is a standard biogeographic division (Heads, 2012). The break has been attributed to the late Cretaceous opening of the South Loyalty basin (at $85 \mathrm{Ma}$ ); subsequently, in the Paleocene, the basin closed, almost completely.

With respect to their morphology, the two species differ as follows: Xylocarpus granatum has buttresses extended, flattened and ribbon-like, spreading across the mud, pneumatophores absent; Xylocarpus moluccensis sensu lato has buttresses not extended or ribbon-like, pneumatophores present, peg-like and erect, pointed. (Xylocarpus rumphii-type populations of $X$. moluccensis occur above the mangrove and have neither buttresses nor pneumatophores).

The morphological distinction between 'pneumatophores' and 'ribbon-like buttresses' may not be as great as it appears, but the Grande Terre-Loyalty Islands break between the species suggests it is an old one.

The next three genera form a trans-Indian Ocean clade that is sister to the rest of subfam. Melioideae. In the phylogeny of Koenen et al. (2015) the three genera formed an unresolved tritomy; Melia has usually been placed close to Azadirachta.

\section{Owenia F.Muell.}

Distribution. Five species in Northern Australia (north of a line: Carnavon-Alice Springs-Sydney) (Fig. 22). The genus is allopatric with Azadirachta. Within Owenia the distributions of the species scarcely overlap. Owenia cepiodora F.Muell. is locally endemic at the McPherson-Macleay Overlap, an important area of endemism located where the border of Queensland and New South Wales meets the coast (Heads, 2012)

Ecology. Trees in dry rain forest, woodland, grassland, disturbed vegetation, and on sandy plains, often locally dominant. Sucker shoots can develop in Owenia venosa F.Muell. and $O$. acidula F.Muell.

\section{Melia L.}

Distribution. Two species. Tropical East Africa (Melia volkensii Gürke); India to Australia and the Solomon Islands (M. azedarach L.). (Fig. 22). Melia azedarach is widely naturalised. In Australia it is widespread, but the original distribution, somewhere north-east of a line: Kimberley-Alice Springs-southern New South Wales, is completely obscured by cultivated and naturalised forms (Mabberley, 2013). 


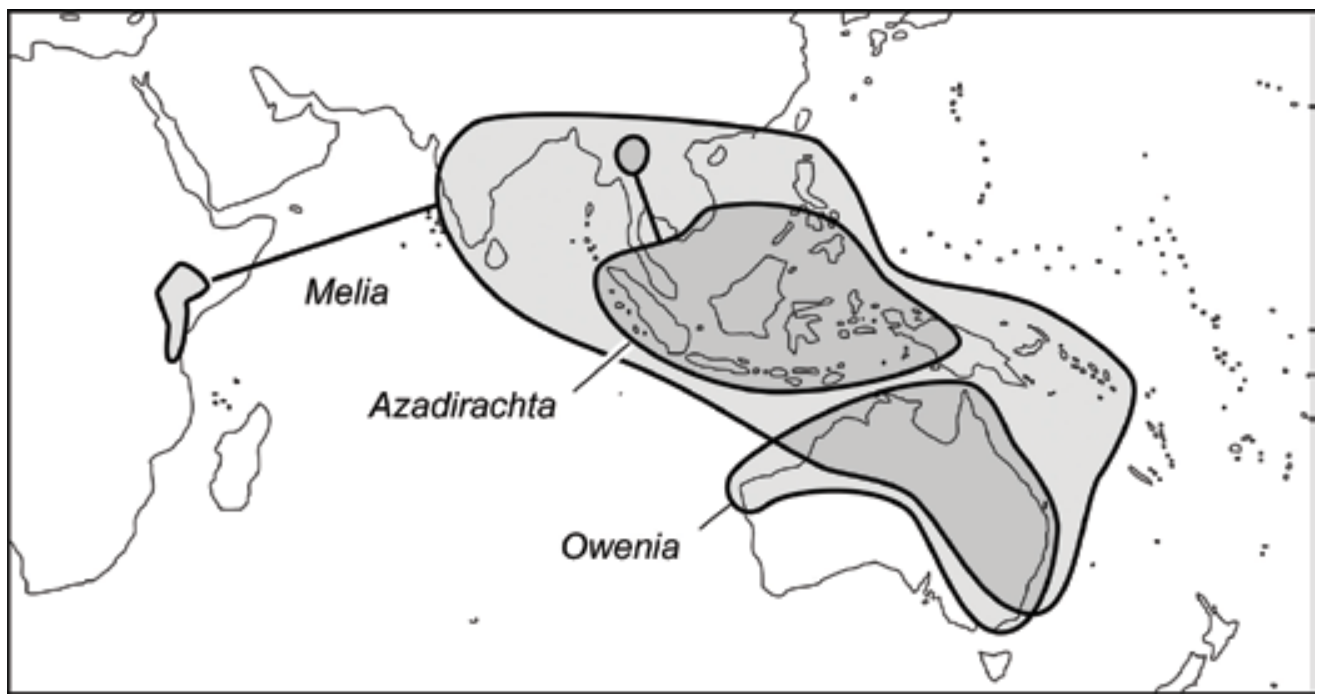

Fig. 22. Distribution of Owenia F.Muell., Melia L., and Azadirachta A.Juss.

Ecology. Both species are trees. Melia volkensii is in deciduous bushland, sometimes fringing seasonal watercourses and on rock outcrops, in reddish soils over limestone; 350-1675 m. Melia azedarach inhabits rain forest, seasonal forest, bamboo thickets, woodland and savanna, where it may coppice; recorded on limestone; up to $1800 \mathrm{~m}$ (in the Himalayas). In Australia it is in "subtropical and dry rain forest and in EucalyptusAcacia forest where smaller, often in regrowth" (Mabberley, 2013). Melia azedarach is widely cultivated and often invasive (Tilney et al., 2018). In parts of South Africa, "... it is naturalised and has become a pest. As early as 1906 it was established near Barberton, and now, in the Transvaal, it is the most widespread and aggressive of the invasive introduced trees" (White \& Styles, 1986).

\section{Azadirachta A.Juss.}

Distribution. Two species. Azadirachta indica A.Juss., the Neem tree, is now widespread globally but is probably native in Burma. Azadirachta excelsa Jacobs ranges from Sumatra to New Guinea (Fig. 22).

Ecology. Both species are trees. Azadirachta excelsa is in rain forest, to $350 \mathrm{~m}$ altitude, $A$. indica is naturalised in savanna and thicket, up to $225 \mathrm{~m}$. It is considered a weed in parts of the Middle East and sub-Saharan Africa where it dominates large areas of savanna. In West Africa it is one of the main sources of fuel (as charcoal). In the Northern Territory, Australia, it is invasive along waterways and is classified as a class $\mathrm{B}$ and $\mathrm{C}$ weed (https://nt.gov.au/environment/weeds). 
The following three genera form a trans-Indian Ocean group disjunct between Madagascar and Sumatra.

\section{Sandoricum Cav.}

Distribution. Five species in Sumatra, Thailand and Malay Peninsula to the Philippines and New Guinea (East Sepik, Madang and Morobe; www.IUCNredlist.org; W. Takeuchi pers. comm. 12 May 2019) (Fig. 23). All five species occur in Borneo, and three are endemic there, including Sandoricum caudatum Mabb. restricted to the Kuching area.

Ecology. The species are all trees. Their respective habitats form a sequence from tidal level up to $1200 \mathrm{~m}$ altitude, consistent with an interpretation of the group as a series of uplifted mangrove associates: 1. Sandoricum borneense. Riverbank forest subject to inundation down to just above tidal influence; 2. Sandoricum beccarianum. Peat swamp forest, codominant locally, up to $30 \mathrm{~m}$; 3. Sandoricum caudatum. Dipterocarp forest and kerangas, up to $350 \mathrm{~m}$; 4. Sandoricum dasyneuron . Dipterocarp forest and ecotone to kerangas, also Agathis forest on acid sands, 50-600 m; 5. Sandoricum koetjape (Burm.f.) Merr. Periodically inundated swamp forest (W. Takeuchi pers. comm., 12 May 2019) and primary and secondary forest, 40-1200 m.

19. Quivisianthe Baill.

Distribution. Two species in Madagascar (Fig. 23).

Ecology. Trees in dry deciduous forest, Acacia scrub forest, and gallery forest.

\section{Ekebergia Sparrm.}

Distribution. Three species in Africa (Senegal to South Africa) (Fig. 23).

Ecology. Trees in rain forest, riparian forest, montane forest, savanna woodland, savanna, rocky places; near sea level to 2650 m (Ekebergia capensis Sparrm. in East Africa).

Notes. Ekebergia capensis is widespread through much of sub-Saharan Africa, and largely overlaps the range of E. benguelensis (southern central Africa) and $E$. pterophylla (C.DC.) Hofmeyr (South Africa). From West Africa to Uganda Ekebergia capensis occurs in savanna woodland and drier parts of the rain forest region, while in east and southern Africa it is mostly in montane forest, riparian forest, and temperate forest (as at Knysna in South Africa). White (1986) wrote: "Because it occurs in more 


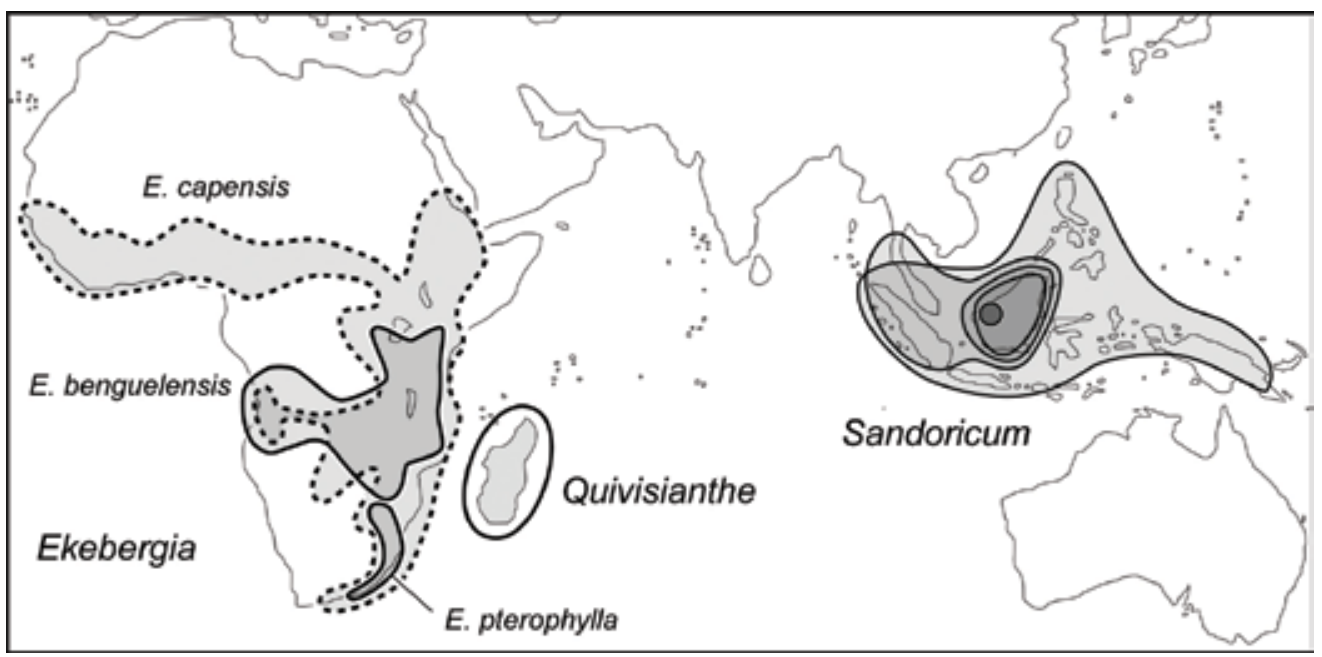

Fig. 23. Distribution of Ekebergia Sparrm., Quivisianthe Baill. and Sandoricum Cav.

than one major vegetation type and more than one regional phytochorion, it is an ecological and chorological transgressor...",

The neat allopatry among Ekebergia, Quivisianthe and Sandoricum (Fig. 23) suggests that none of the genera have spread very far. In contrast, the overlap between Ekebergia capensis and each of the two other species, which are themselves neatly allopatric, can be explained by vicariance of the three followed by range expansion of E. capensis. In this model the original area of Ekebergia capensis, the area that does not overlap with either of the other species, is still very large and would likely have included both closed rain forest and open savanna. Thus there is no need for the species itself to have ever migrated from one to the other.

The following two genera, Walsura and Heynea, range from India to New Guinea and form the sister group to a large, pantropical clade (Fig. 3). The pair is mapped here (Fig. 24) with Vavaea, but the three genera do not form a clade; instead, Walsura + Heynea broke off first from a pantropical clade, then Vavaea separated from the remainder of the pantropical clade. The distributions of Walsura + Heynea and of Vavaea thus represent the approximate locations of two successive breaks in a widespread ancestor.

\section{Walsura Roxb.}

Distribution. Sixteen species in NE India (Assam), Sri Lanka, Andaman Islands to western New Guinea (Vogelkop Peninsula); not naturally in Sumatra or Java (Clark, 1994; Mabberley, 2003). Borneo is a major centre of diversity, with seven species, six endemic (cf. Sandoricum). 


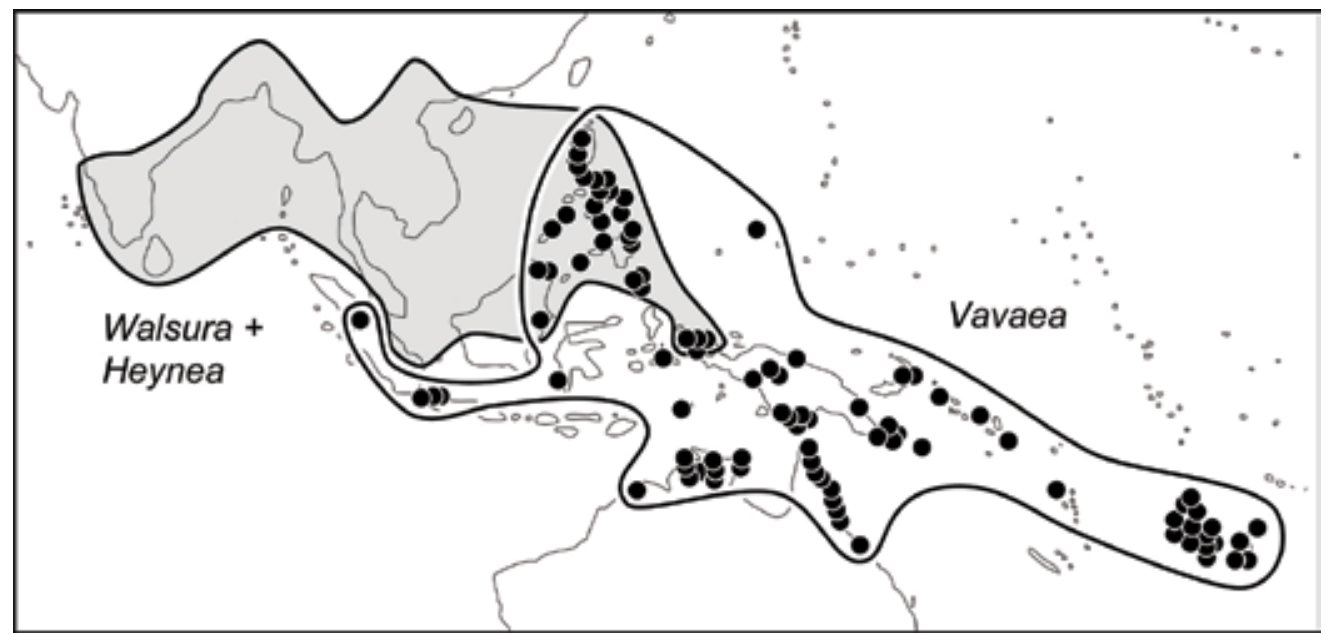

Fig. 24. Distribution of Walsura Roxb. + Heynea Roxb. (Clark, 1990, 1994) and Vavaea Benth. (Van Balgooy, 1966; Mabberley, 2013).

Ecology. Trees. In Malesia usually in wet evergreen forest, in China usually in sparse or dense forests in hilly regions. Walsura monophylla Merr. of Palawan (Philippines) is largely restricted to ultrabasic soils, while $W$. grandifolia Ridl. of Kuching (Borneo) is only known from limestone (Mabberley, 2003). From $5 \mathrm{~m}$ up to $2500 \mathrm{~m}$ (highest records in Thailand).

\section{Heynea Roxb.}

Distribution. Two species in Southern India (not Sri Lanka), Sikkim to Nicobars, southern China, Indochina, Malay Peninsula, Sumatra, Borneo and the Philippines (map in Clark, 1990: 283).

Ecology. Trees. In Malesia in rain forest, especially at forest edges, in regenerating clearings and along roadsides. In China in forests, sparse forests and thickets at low elevations and in hilly regions. Up to $1600 \mathrm{~m}$ (in Thailand).

\section{Vavaea Benth.}

Distribution. Four species from Sumatra to Tonga, including Yap in Micronesia (Fig. 24). One widespread species, Vavaea amicorum Benth., has the range of the genus. Two other species are endemic to Papua New Guinea, and one is endemic to Fiji. 
Ecology. Trees with Terminalia-branching. Inner edge of mangrove swamps, beach thickets, primary and secondary forests, often on limestone (throughout the generic range), including limestone just above high tide level (Vavaea amicorum in Fiji; Heads, 2006) and limestone cliffs; up to $1250 \mathrm{~m}$.

Notes. The previous two genera, Heynea + Walsura, range from India to western New Guinea, and are largely allopatric with Vavaea, ranging from Sumatra to Tonga. Overlap is restricted to north-eastern Borneo, the Philippines, and Vogelkop Peninsula of New Guinea. This suggests that three clades, Heynea + Walsura, Vavaea, and the pantropical sister of Vavaea, formed in allopatry, and that the third clade later underwent largescale range expansion. The allopatry between the first two has remained largely intact, although local overlap has developed in eastern Borneo, Philippines and Vogelkop Peninsula. The single Sumatra record of Vavaea is based on a Junghuhn collection discussed by Van Steenis (1950).

The eastern boundary of Vavaea at Tonga corresponds with the eastern limit of the mangrove Xylocarpus (Fig. 21A) and also the mutual boundary of the Australia and Pacific plates. Smith (1985) wrote: "It is of some significance, in a biogeographical consideration, that Vavaea, an abundant component of forest vegetation in Fiji and Tonga, has apparently been unable to cross the water barriers to the Horne and Wallis Islands or Samoa; this fact does not suggest ease of dispersibility...".

In the widespread Vavaea amicorum, Pennington (1969) recognised four main centres of variation: Philippines, New Guinea, Solomon Islands and Fiji. (Specimens with a spreading indumentum, i.e. ' $V$. pilosa Merr.', occur in the Philippines, New Guinea, and the Solomon Islands). These localities mark a common distribution and also the south-western margin of the Philippine and Pacific plates. Vavaea is sister to a large pantropical complex (the following two genera and the diverse TT and GA clades) that comprises more than half the family, and so its close distributional alignment with the plate margins is of special interest.

The next two genera, Lepidotrichilia + Astrotrichilia, form an East Africa-Madagascar pair that is sister to the pantropical group: TT clade + GA clade.

24. Lepidotrichilia T.D.Penn. \& Styles, sensu stricto

Distribution. One species, Lepidotrichilia volkensii (Gürke) J.-F.Leroy, in East Africa (Ethiopia to Malawi) (Fig. 25). In mountains around the East African Rift, and almost reaching the coastline in southernmost Kenya. The other species currently placed in this genus are treated here under Lepidotrichilia2 of Madagascar.

Ecology. A tree of mid-altitude and montane forest; 1050-3300 m. (African Plant Database, 2019). 


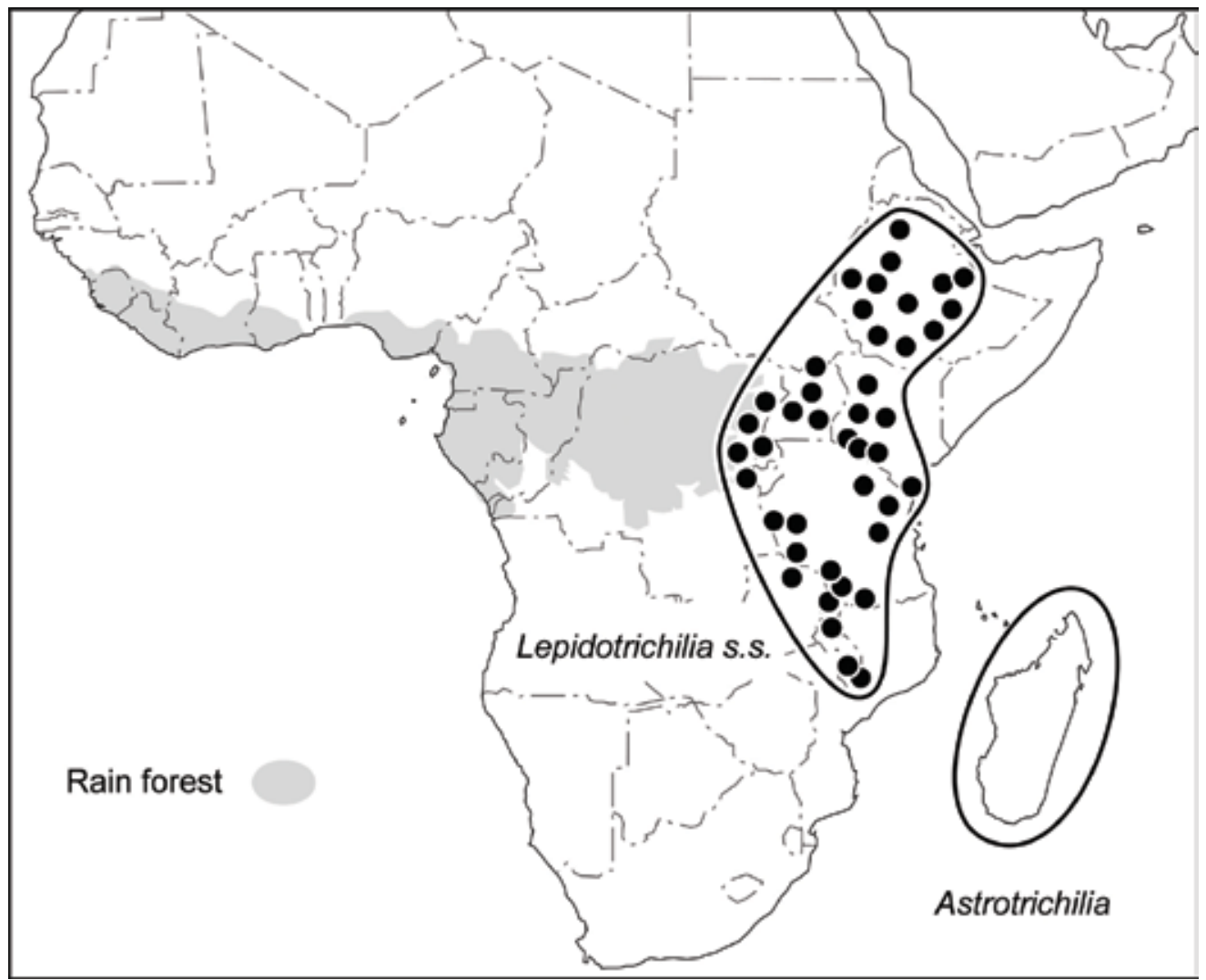

Fig. 25. Distribution of Lepidotrichilia T.D.Penn. \& Styles sensu stricto and Astrotrichilia T.D.Penn. \& Styles.

\section{Astrotrichilia T.D.Penn. \& Styles}

Distribution. Twelve species in Madagascar. Ten of the species were described by Leroy \& Lescot (1996).

Ecology. Trees and shrubs in littoral forest, damp depressions on sandy soil (Astrotrichilia voamatata J.-F.Leroy), dense forest, xerophilous bush and montane forest; sea level-2000 m (Leroy, 1958d; Leroy \& Lescot, 1996).

The remaining genera of Meliaceae make up a large, pantropical group comprising the TT (Trichilia-Turraea) clade and its sister the GA (Guarea-Aglaia) clade (Fig. 26). The group as a whole includes all seven Meliaceae genera with more than 20 species, three in the TT clade (Trichilia, Turraea and Malleastrum), and four in the GA clade (Aglaia, Guarea, Dysoxylum and Chisocheton). Trichilia (America, Africa, Madagascar) and Aglaia (Asia, Pacific) are the only genera in the family with more than 100 species. 


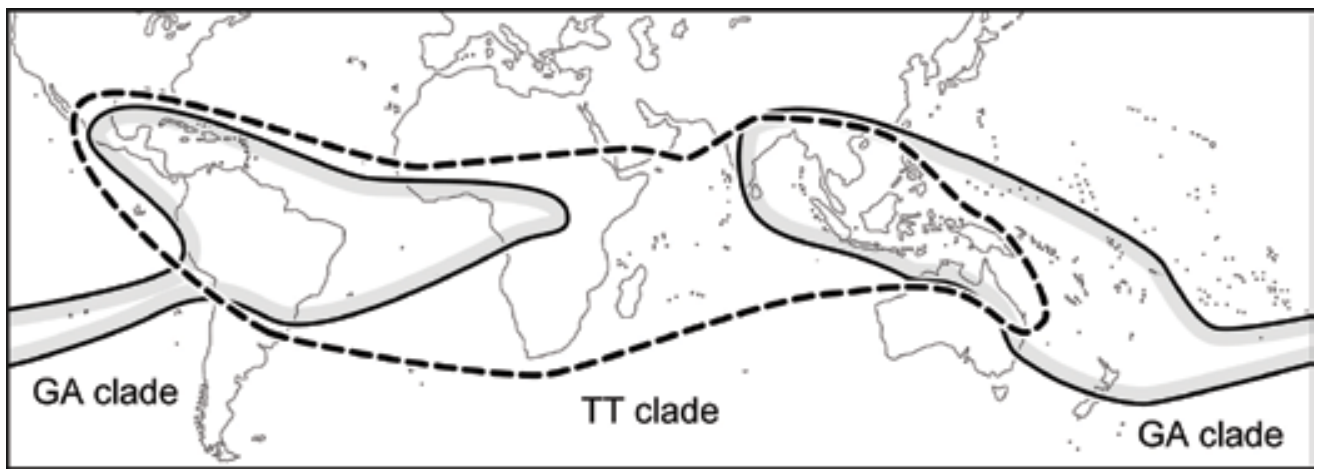

Fig. 26. Distribution of the Trichilia-Turraea clade and the Guarea-Aglaia clade.

The TT clade is diverse in southern Africa and East Africa, and reaches Yemen. It is also widespread on the islands in the western Indian Ocean: Socotra, Aldabra, Madagascar, and the Mascarenes. It is absent east of Australia and New Guinea, and while the TT clade displays trans-Atlantic affinities (in Trichilia) and trans-Indian Ocean affinities (in Turraea and Naregamia), there is no direct trans-Pacific affinity.

The GA clade, in contrast with the TT clade, is absent from southern Africa, East Africa (except for a single possible record of Leplaea Vermoesen from Tanzania), Yemen and the islands in the western Indian Ocean. It is diverse in Australia and New Guinea, and present in the Pacific islands east to Tonga. While there are no direct trans-Indian Ocean connections, there is a trans-Pacific affinity in Cabralea sensu lato.

The TT and GA clades overlap only in America-West Africa, and in India-New Guinea; in much of the western Indian Ocean region the TT clade occurs alone, and in much of the west Pacific only the GA clade is present. This allopatry can be interpreted as a trace of the original allopatry, and the areas of overlap as secondary developments.

\section{Munronia Wight}

Distribution. Five species (incl. the long misunderstood 'Turraea' breviflora Ridl., now Munronia breviflora (Ridl.) Mabb. \& Muellner; Muellner \& Mabberley, 2008; Cuong et al., 2014). India and Sri Lanka, east to Timor. In the widespread Munronia pinnata (Wall.) W.Theob. (India to Timor), some specimens from Java "resemble the Indian plants...", (Mabberley et al., 1995), suggesting possible disjunctions across the Bay of Bengal.

Ecology. Shrublets, sometimes suckering with apparently short-lived shoots. Just behind the mangrove, drier, open and seasonal forest, bamboo forest thicket; sea level to $1800 \mathrm{~m}$ (in China). Munronia pinnata occupies the whole generic range from mangrove to $1800 \mathrm{~m}$. Four of the five species are recorded from limestone rocks, cliffs, and crevices. 
The next two genera, Cipadessa and Pseudoclausena, are sisters and together range from India to Timor and New Guinea (Fig. 27), repeating the India-New Guinea pattern of Walsura + Heynea, and the India-Timor distribution of Munronia. There is a high level of allopatry between Cipadessa, which is western, and Pseudoclausena, which is eastern. The two overlap only in a small part of eastern Sumatra, Sulawesi, and SW Philippines (Mindanao etc.). In the Malay Peninsula the two appear to be neatly allopatric, with Cipadessa present in Kedah only (Mabberley et al., 1995), while Pseudoclausena occurs east of there and through the rest of the Peninsula (Clark, 1994).

\section{Cipadessa Blume}

Distribution. One species in India and Sri Lanka, to Timor (Fig. 27).

Ecology. Small trees or shrubs, sometimes subscandent, in sparse forests, forest edge, thicket, early successional forest, ravines and crevices in rocks, hilly regions on limestone; 200-2250 $\mathrm{m}$ (in Thailand).

\section{Pseudoclausena T.P.Clark}

Distribution. One species in the Malay Peninsula, Sumatra, Borneo, Philippines, Sulawesi, Moluccas, western New Guinea (Fig. 27; Clark, 1994).

Ecology. A tree of wet forest; 500-1650 m (in Thailand).

The next six genera form a clade (making up the rest of the TT clade), and their overall distribution is mapped in Fig. 28. Trichilia and allies form a trans-Atlantic clade, while Turraea and allies form a trans-Indian Ocean group, and the two overlap only in Africa and Madagascar. The high level of allopatry suggests original vicariance at a break somewhere in Africa, followed by widespread overlap there (although not in SW Africa, where the Turraea group occurs alone).

The next three genera make up the distinctive Turraea group, part of the TT clade. The plants are small trees or shrubs, sometimes scrambling or climbing, and the leaves are nearly always simple (pinnate only in Turraea streyi F. White \& Styles of SE South Africa). 


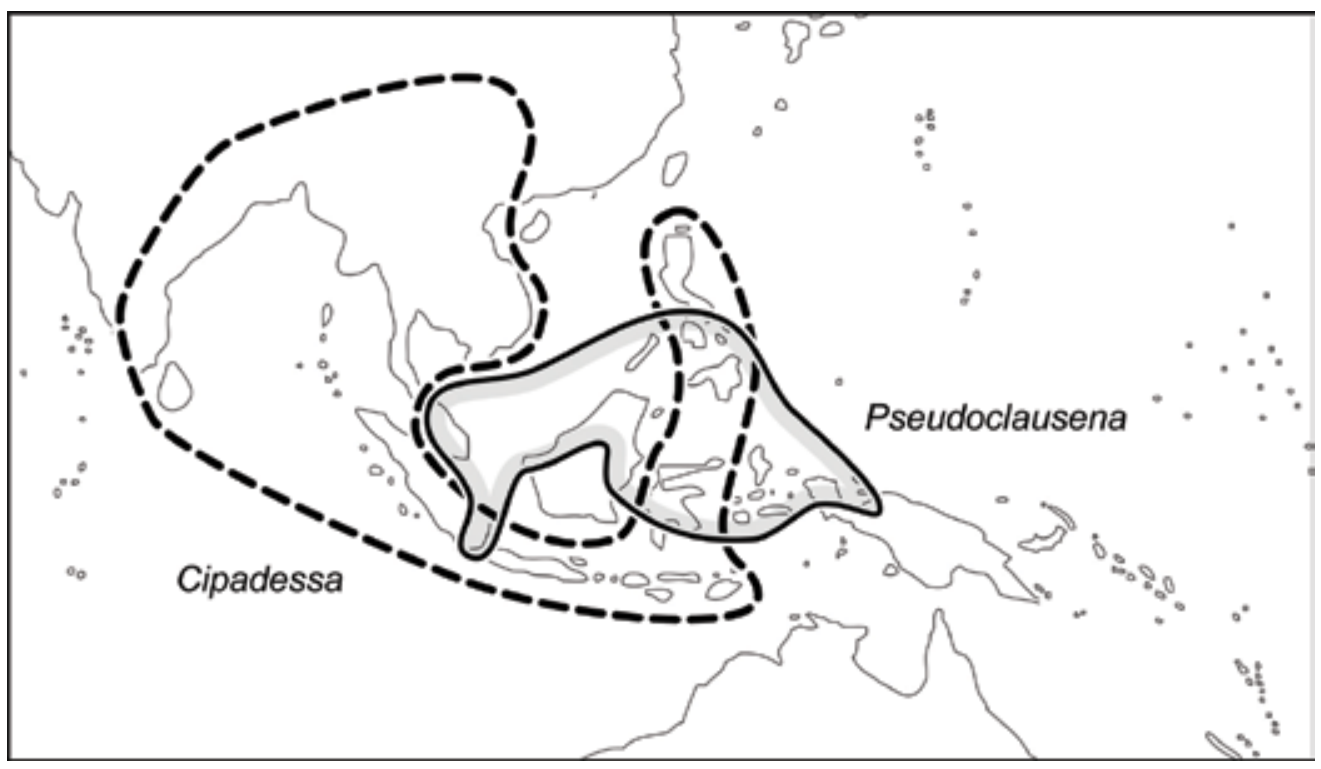

Fig. 27. Distribution of Cipadessa Blume and Pseudoclausena T.P.Clark.

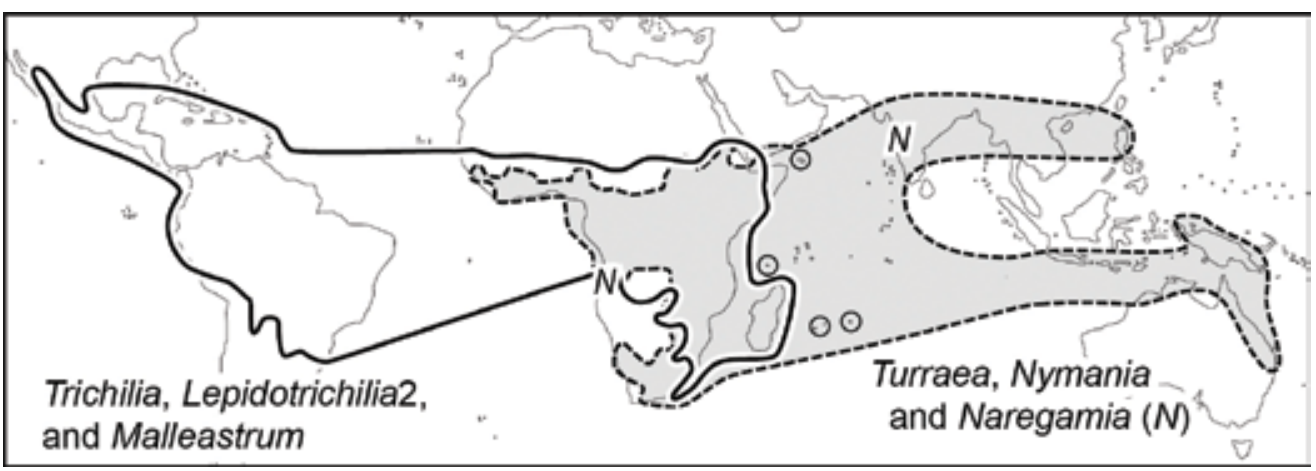

Fig. 28. Distribution of the Trichilia group (Trichilia P.Browne, Lepidotrichilia2 and Malleastrum (Baill.) J.-F.Leroy) and the Turraea group (Nymania Lindb., Turraea L., and Naregamia Wight \& Arn.).

\section{Nymania Lindb.}

Distribution. One species in South Africa and Namibia (Fig. 29, from White, 1986). Semi-desert areas in the Karoo-Namib region, also in the Cape Floristic Region in enclaves of karoid vegetation (absent from typical Cape vegetation) (White, 1986). There is significant local differentiation in the species, and different catchments contain genetically distinct lineages (Potts, 2017).

Nymania capensis (Thunb.) Lindb. is located west of the Lebombo monocline (Fig. 9), an important biogeographic boundary (Heads, 2012). In the eastern part of its 


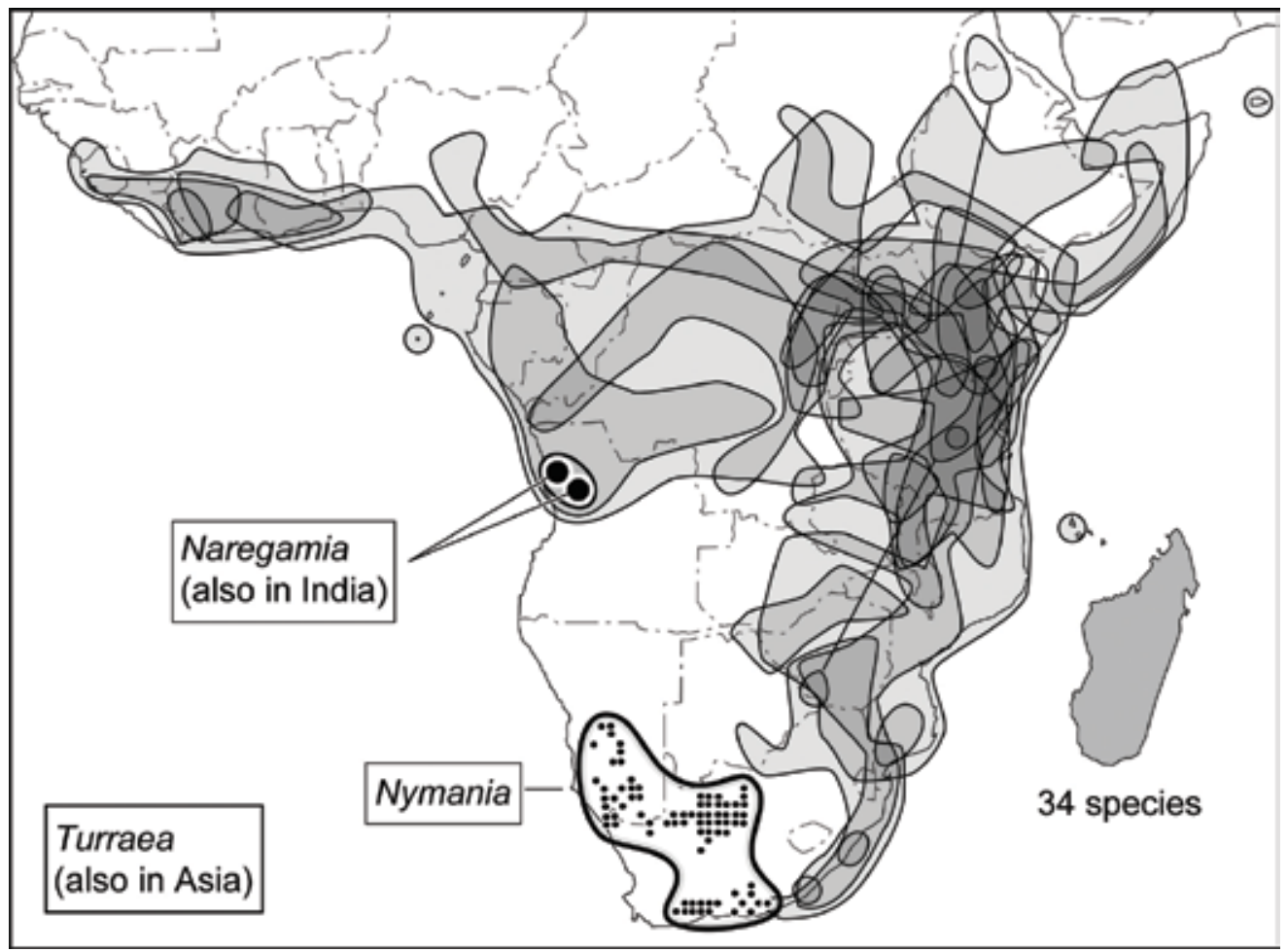

Fig. 29. Distribution of Nymania Lindb., and the African species of Turraea L. and Naregamia Wight \& Arn.

range, its distribution overlaps that of Ekebergia capensis (Fig. 23), but in the western part of its area, Nymania is the only Meliaceae present. It is allopatric with its sister clade, Turraea + Naregamia, with the two meeting at the Albany node (where the mountain ranges of the Cape Fold Belt intersect the coast).

Ecology. Shrub in semi-desert, karoid vegetation (dense, woody, and thorny thicket, often with succulents), and in bushland peripheral to the main area of the Karoo desert (Potts, 2017; White \& Styles, 1986). Not in true desert or in the fynbos heathland of south-western South Africa.

Notes. The present paper does not consider the architecture of Meliaceae in any detail (notes on rhizomes were given above, in the section 'Mangrove and associated vegetation'). However, Nymania is so unusual that it warrants some brief discussion. The morphology of a plant helps determine its ecology, and the following paragraphs propose a mechanism of generating small-leaved plants, such as Nymania, that can survive in arid areas.

In most Meliaceae, shoot growth conforms to the architectural models of Corner, Aubréville, Champagnat, Rauh and Attims (Mabberley et al., 1995; African 
Plant Database, 2019). Even Meliaceae found in drier, open vegetation, such as Pseudocedrela and Ekebergia, are more or less 'normal', large-leaved members of the family. However, architecture in Nymania is radically different, and the plant has been described as "un-meliaceous-looking" (Penningon \& Styles, 1975). The architecture (Fig. 30; see also the many photographs at www.GBIF.org), together with its distinctive flower and fruit, has meant that the genus has been placed in as many as six families, including its own.

Nymania capensis is a shrub 1-5 $\mathrm{m}$ high, and the shoots are differentiated into brachyblasts (short shoots) with abortive internodes, and long shoots with abortive apices. The leaves are small, just $1-2(-4) \mathrm{cm} \times 3-5 \mathrm{~mm}$, and form tufts or fascicles on the brachyblasts. The same shoot differentiation seen in Nymania also occurs in many other plants of southern and eastern Africa, Madagascar, Australia, New Zealand and warmer parts of America. The species are often described as 'divaricate' or 'divaricately branched', as in, for example, Melicope simplex A.Cunn. (Rutaceae) of New Zealand (Allan, 1961) and Boronia acanthoclada Paul G.Wilson (Rutaceae) of south-western Australia (Duretto et al., 2013). However, many other plants described with 'divaricate' branching (such as Aglaia odoratissima Blume in Mabberley et al., 1995) do not have the distinctive shoot differentiation discussed here.

In their epochal treatment of tree architecture, Hallé et al. (1978: 59) did not consider 'divaricate' growth, as they treated brachyblasts as "ephemeral units equivalent to leaves". However, 'divaricate' architecture (long shoots with abortive apices, short shoots with abortive internodes) was described accurately by Philipson (1978), and so it is referred to here as Philipson's model. Apart from Nymania, other Meliaceae with shoot architecture conforming to Philipson's model include species of northeast Africa species such as Turraea parvifolia Deflers and T. retusa Styles \& F.White, discussed below, and Malagasy species such as Turraea rhombifolia Baker.

Interpreting the morphology of plants with Philipson's model is challenging. The brachyblasts, abortive long shoots, and several other features mean that the plants are not simply small versions of typical Meliaceae. The latter have large, compound leaves (up to $240 \mathrm{~cm}$ long in Chisocheton macrophyllus King), large, branched inflorescences (up to $7 \mathrm{~m}$ long in Chisocheton penduliflorus Hiern), and bracts that are small (two or three orders of magnitude smaller than the leaves), simple and linear. In contrast, the leaves in Nymania are small, simple, and linear, the flowers are solitary, and there are no inflorescence bracts - the flowers are borne in the axils of leaves.

If the vegetative shoot system of a normal, large-leaved Meliaceae were suppressed, leaving only the inflorescence, and if most of the flowers in the inflorescence were then also suppressed, leaving bracts as the only foliage, the result would be something like Nymania. In this interpretation, the Nymania shoot system is not homologous with a Chisocheton plant, but with its inflorescence, largely sterilised. The foliage in Nymania is made up, not of reduced leaves, but of sterilised inflorescence bracts. There appear to be no bracts because all the leaves are bracts, and the flowers appear to be solitary because the whole plant is an inflorescence.

The morphogenetic changes required to produce Philipson's model in a 'normal' plant are quite simple and may require only a small number of minor genetic changes; 


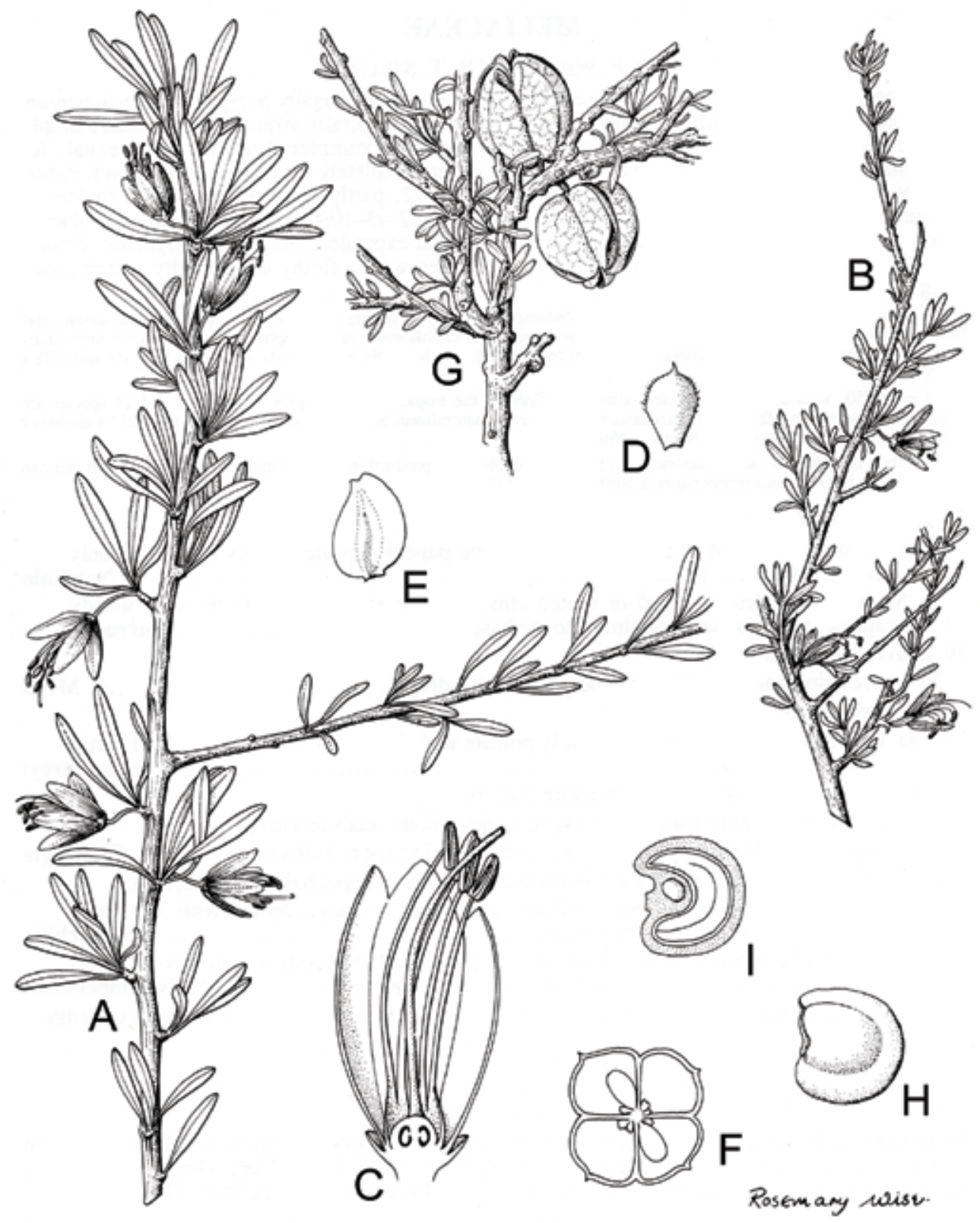

Fig. 30. Nymania capensis (Thunb.) Lindb. A \& B. Flowering twigs $(\times 0.7)$. C. Flower $(\times 3)$. D. Calyx lobe $(\times 3)$. E. Lateral petal $(\times 1)$. F. Cross section of fruit $(\times 1)$. G. Fruiting twigs $(\times 0.7)$; H. Seed $(\times 2.7)$. I. Seed in longitudinal section $(\times 2.7)$. (Drawing by Rosemary Wise, reproduced with permission from the South African National Biodiversity Institute.) 
no new structures are required, only reduction and sterilisation of parts already present. Other plants with shoot systems interpreted as largely sterilised inflorescences are discussed elsewhere (Heads, 2012: 16, 79, 250, 257; 2017: 440).

\section{Naregamia Wight \& Arn.}

Distribution. Two species. Naregamia alata Wight \& Arn. is in India (Western Ghats, from Konkan southwards to Travancore), and N. africana is in Angola (Figs. 27 and 28). Cheek (1996) sank Naregamia in Turraea; Koenen et al. (2015) sequenced $N$. alata only, and so the composition of the genus still requires testing. The disjunction between southern Africa and India displayed in Naregamia is also seen in other groups. Jeffrey (1988) noted the "astonishing geographical disjunction" of Dactyliandra welwitschii Hook.f. (Cucurbitaceae), found in deserts of the Namib (SW Africa) and Rajasthan (India).

Ecology. Small, barely woody, rhizomatous shrublets or herbs with a woody rootstock. The ecology is poorly known. The type of Naregamia africana (Welw.) Exell is recorded from thin woods at forest edges with Leguminosae at stream bank; $300 \mathrm{~m}$.

31. Turraea L. sensu lato

(Incl. Humbertioturraea J.-F.Leroy and Calodecaryia J.-F.Leroy, both of Madagascar; Koenen et al., 2015).

Distribution. 73 species (Turraea sensu stricto with 66 spp., Humbertioturraea with five, and Calodecaryia with two) in Africa, Socotra, and Yemen (30 species), Madagascar and Mascarenes (c. 43 species), and Asia-Australasia (1 species) (Fig. 28).

Turraea species are concentrated in tropical East Africa, Madagascar, and the Mascarenes (Fig. 29). Species numbers rapidly diminish to the east and to the west: the Zambesi region has nine species, DRC seven, west tropical Africa five or six, southern Africa four. Turraea ranges east to mainland New Guinea and north-eastern Australia, but it is notably absent from Sumatra, Borneo, Sulawesi and the Moluccas, and along the chain: Bismarck Archipelago, Solomon Islands, Vanuatu, New Caledonia, Fiji, and Tonga.

Although Turraea is widespread through most of sub-Saharan Africa, including all the islands in the Gulf of Guinea, it is absent in the southwest (Angola, Namibia, western South Africa). This is precisely the region where its allies, Naregamia and Nymania, are concentrated (Naregamia is also in India). In north-eastern Africa, Turraea parvifolia is in northern Kenya, Ethiopia, Djibouti, Somalia and Yemen, often on limestone. The only other Meliaceae in the Arabian Peninsula is Trichilia emetica Vahl, which also extends from mainland Africa to Yemen. Disjunction across the Gulf of Aden also occurs in other groups, such as Rhigozum somalense Hallier $\mathrm{f}$. 
(Bignoniaceae; Philipson's model), and Kilian et al. (2004) mapped several other transGulf of Aden endemics. During the early Miocene (c. $25 \mathrm{Ma}$ ), Arabia and Africa were rifted apart when the Red Sea and Gulf of Aden were formed by seafloor spreading. This process would explain the disjunction evident in the Meliaceae, Bignoniaceae, and many others that straddle the plate boundary.

Turraea socotrana Styles \& F.White is endemic to Socotra, where it is the only member of Meliaceae. It inhabits limestone cliffs at medium elevations and also granite in the mountains (Brown \& Mies, 2012: 211).

In Turraea mombassana C.DC. (Ethiopia to Malawi) and T. robusta Gürke (Uganda and Kenya to Malawi and Zambia) the distributions intersect the current coastline near the Tanzania/Kenya border. This repeats the pattern seen in Lovoa swynnertonii Baker f. (Fig. 7), Melia volkensii (Fig. 22) and Lepidotrichilia volkensii (Fig. 25).

In Madagascar, 31 species of Turraea sensu stricto were accepted in an unpublished manuscript by Leroy, but 16 of these remain undescribed (Callmander et al., 2012). Callmander et al. (2012) described two new species from Madagascar, and Randrianarivony et al. (2017) described another.

In the Mascarenes, Turraea is the only genus of Meliaceae present. It is notably diverse on the islands, with nine species, all endemic (Baider \& Florens, 2016). Mauritius and Réunion have two species each, four others are shared between Mauritius and Réunion, and Rodrigues has one.

The single Asian species of Turraea, T. pubescens Hell., is closely related to some of the East African species (Mabberley et al., 1995). A similar transoceanic distribution is seen in the allied Naregamia (the previous genus), in Angola and India.

Ecology. Small trees, shrubs (sometimes scrambling or climbing), subshrubs, possibly rhizomatous (Turraea streyi F.White \& Styles of South Africa), and one liane ( $T$. laurentii De Wild. of the Congo basin). Behind mangrove, in forest and thicket on coastal dunes, wet, swampy and riverine rain forest, drier and deciduous forest, savanna woodland, bushland, thicket, banks of wadis (dry, gently sloping valleys or depressions in desert that are periodically flooded), secondary forest and areas of abandoned cultivation, on and around rocks, including limestone. From sea level to $2500 \mathrm{~m}$ altitude (Turraea holstii Gürke in the East African mountains). Turraea pellegriniana Keay and T. vogelii Benth. each occur in both rain forest and savanna.

Termitaria create an important heterogeneity in the landscape, soil and vegetation of African forest and savanna woodland (Craw et al., 1999), and comprise mounds often $10 \mathrm{~m}$ across and several metres high. They are composed of soils with a higher $\mathrm{pH}$ and higher levels of clay, nutrients (N, P, K, Ca and $\mathrm{Na}$ ), and water retention than the surrounding acidic, sandy soils. Not surprisingly, they host a distinctive flora and fauna. Turraea robusta, Turraea nilotica Kotschy \& Peyr., Trichilia emetica and Trichilia capitata Klotzsch are all recorded on termite mounds.

In southern tropical Africa, a lower altitude flora of basic soils (dominated by the legumes Colophospermum J.Léonard and Acacia Mill.) can be distinguished from a flora of acidic soils at higher altitude (dominated by another legume, Brachystegia 
Benth.). However, in some ways the former is always present in the latter, for example in the flora of termite mounds. On the plateaux of southern and eastern Africa, a high proportion of the angiosperm species found on termitaria (e.g. Capparaceae) are important components of deciduous woodlands at lower altitudes. It is suggested that the basic soils of the termitaria have allowed many coastal elements to survive uplift, more or less in situ.

The nine species of Turraea in the Mascarenes extend from dry coastal areas to about $800 \mathrm{~m}$ elevation in the wet vegetation of the highest mountain peaks (Baider \& Florens, 2016).

The single species of Turraea in Asia-Australasia is Turraea pubescens, a deciduous shrub found behind mangrove and in other coastal vegetation, in semievergreen forest, deciduous forest, thicket, savanna, secondary vegetation at forest edges, on dunes and rocks including limestone and basalt; sea level-1000 m.

Notes. Turraea has one main concentration of diversity in Madagascar (34 species) and another in Tanzania, Kenya, and Uganda (18 species). In the latter area the plants range from sea level (Turraea nilotica, T. mombassana, T. wakefieldii Oliv.) up to $2500 \mathrm{~m}$ (T. holstii) (Styles \& White, 1991). In a key to the species of the region, the first couplet separates 'species with leaves, flowers and fruits borne on short lateral shoots of slow and limited growth' from 'species with leaves borne mostly on long shoots, usually widely spaced' (Styles \& White, 1991). The two groups may well not be clades, but they provide a useful summary of architecture in the genus. In the first group, both long and short shoots are present. One example is Turraea parvifolia, cited above with reference to its presence in Yemen. The species is a rigidly branched shrub or small tree to $4 \mathrm{~m}$ tall. The short shoots have very short internodes, and so the leaves are borne in fascicles, while the long shoots undergo apical abortion. Thus the growth in these plants conforms to Philipson's model, as in Nymania. One of the synonyms of Turraea parvifolia is T. lycioides Baill., and Lycium L. (Solanaceae) does have very similar architecture.

Another Turraea with Philipson's model is T. retusa (syn. T. pevelingii Cheek) of Somalia (outside the East African region covered by Styles \& White, 1991). The species is a shrub 1-2.5 m tall, bearing 'spur shoots' (brachyblasts) with numerous, very short internodes, and 'extension shoots' (long shoots), the latter 'sometimes with spiny tips developing from main axes when leafless' (Cheek, 1991). Leaves are extremely variable in size and shape. Cheek (1991) wrote that the species displays a tendency to spininess that has not been observed previously in the genus, although apical abortion of long shoots is also seen in Turraea parvifolia, described above. Whether the aborted apex is simply parenchymatised (as in most New Zealand 'divaricates') or indurated as a spine (as in most African 'divaricates') is a secondary aspect of the morphology. Turraea retusa grows in Acacia-Commiphora bushland, usually on stabilised sand dunes, sometimes on limestone, and often in areas of heavy agricultural disturbance.

There are close architectural and ecological parallels between Turraea and other plants, such as Terminalia (Combretaceae). The last revision of African Terminalia recognised two main groups (Griffiths, 1959). In Group 1, the 'spinosa' group, leaves 
are borne in fascicles on short spur shoots of very slow growth, while branchlets and branches (long shoots) often abort apically. Growth thus conforms to Philipson's model. The species in Group 1 include Terminalia fatraea DC., known from shore thicket and closed bush on coral rocks and sandbanks in mangrove (coastal Kenya to Mozambique and Madagascar). Members of Group 2 are non-divaricates. They grow in savanna woodland, sometimes by the coast, in seasonally saturated soils and by the edge of dambos (seasonally flooded, grassy depressions), some on Kalahari Sand. The group includes Terminalia scutifera M.A.Lawson (Guinea to Sierra Leone), found in the "mangrove zone" or "knotted and gnarled by seashore", or in freshwater swamp forest (Griffiths, 1959). It is "extremely closely related" to Terminalia nyssifolia Britton of the Americas, a species that inhabits similar vegetation.

If a plant's stems are not strong enough to form an erect trunk a decumbent or climbing habit can result, as seen in several Turraea species recorded as sometimes scrambling: Turraea mombassana subsp. mombassana, T. robusta, T. wakefieldii, $T$. floribunda Hochst. and T. obtusifolia Hochst. Turraea vogelii ranges from Ghana to Uganda and Angola, including Bioko ('near the sea'; Keay, 1958), Príncipe, and São Tomé. The species is a climbing shrub 5-12 m tall, rarely an erect shrub to $2 \mathrm{~m}$. It inhabits forest and savanna at the edge of gallery forest, from 10-1375 m. In contrast, its close ally Turraea vogelioides Bagsh. \& Baker f. (eastern DRC to Kenya) is an erect shrub; it inhabits the understorey of riparian forest and well-drained and swampy rain forest, from 1150-1800 m. Of special interest is Turraea laurentii of rain forest and forest edge in DRC and Republic of Congo, recorded as a "sarmentous shrub or large liane" (African Plant Database, 2019). This seems to be the only known liane in the family.

The two Turraea species endemic in South Africa are distinctive through their architecture. Turraea streyi (SE coast of Natal, South Africa, from 50-200 m) is a subshrub or suffrutex up to $0.75 \mathrm{~m}$ high. It occurs in grassland, and inside and at the edges of scrub forest. Turraea pulchella T.D.Penn. (SE coast of Transkei, South Africa; $305-365 \mathrm{~m}$ ) is a second suffrutex. The plant is up to $0.2 \mathrm{~m}$ high with tufted, herbaceous stems arising from a short $(50 \mathrm{~mm})$, branched, woody base, and with a strong, woody, possibly rhizomatous rootstock. Cheek (1991) grouped this species with Turraea streyi.

The next three genera, Trichilia and allies, form a trans-Atlantic clade that, overall, shows a high level of allopatry with the last three genera, a trans-Indian Ocean group (Fig. 28).

\section{Lepidotrichilia2}

Distribution. Three species in Madagascar. Leroy (1958b) and Leroy \& Lescot (1996) placed the species in Lepidotrichilia of East Africa, but molecular evidence indicates 
that they form a new genus, sister to Malleastrum (Koenen et al., 2015). Pending further revision, the new genus is referred to here as Lepidotrichilia2.

Ecology. Small trees in forest; 800-1000 m (Leroy \& Lescot, 1996).

\section{Malleastrum (Baill.) J.-F.Leroy}

Distribution. A genus of 23 species in Madagascar, Comoro Islands, and Seychelles (Aldabra). Leroy (1964) treated 11 species (with maps), Leroy (1989) described three new species, and Leroy \& Lescot (1996) described six more. Fosberg (1974) described Malleastrum leroyi Fosberg from Aldabra.

Ecology. Small trees. Beach forest on maritime dune sand, evergreen forest, dry forest, gallery forest, on limestone, coastal sand and sandy-gritty terrain, dry ravines; sea level to 2000 m (Leroy, 1964, 1989; Leroy \& Lescot, 1996).

\section{Trichilia}

P.Browne

(Incl. Pterorhachis Harms and Pseudobersama Verdc.; Koenen et al., 2015).

Distribution. A genus of 107 species in Tropical America (81 species), Africa (20 species) and Madagascar (4 species).

Ecology. In America most species are trees of lowland rain forest, but a significant number are in seasonally dry deciduous forest and montane rain forest. Overall, the ecological range is: behind mangrove, flooded freshwater forest (including permanently and periodically inundated forest, várzea, igapó, rocks among cataracts; 16 species), dry seasonal forest, deciduous forest, secondary forest, savanna woodland, cerrado, limestone (12 species), montane forest (11 species); sea level to $3300 \mathrm{~m}$.

The only record of the genus associated with mangrove is Trichilia sp., inhabiting backswamp behind mangrove and also dry forest on San Andrés Island off Nicaragua (González et al., 2010). (The only Trichilia recorded on the island by Pennington, 2016, is T. martiana C.DC.).

Eleven species of American Trichilia inhabit montane forest. Trichilia multifoliola of Bolivia reaches a very high altitude for Meliaceae, $3300 \mathrm{~m}$ (Pennington, 2016: 44; although on p. 42 the upper limit was given as $3200 \mathrm{~m}$ ). The species occurs in high montane rain forest and cloud forest, including secondary formations. Trichilia pallida Sw. has a wide ecological range; it is usually in lowland rain forest, but in the Andes it inhabits montane forest and reaches $2000 \mathrm{~m}$ elevation.

In Africa, Trichilia ranges from sea level, on both west and east coasts, to $2100 \mathrm{~m}$ (T. dregeana) in Uganda. Most of the species (14 out of 18) are mainly confined to the Guineo-Congolian rain forest region, where they occupy rain forest (de Wilde, 1968). Two of the rain forest species are recorded from littoral forest: 
Trichilia prieureana A.Juss. Littoral forest (Ivory Coast), riparian forest, rain forest, moist semi-deciduous rain forest, deciduous forest, savanna woodland; coastal to $1500 \mathrm{~m}$; gregarious in forest, solitary in savanna; in Uganda it was formerly regarded as a weed tree and was poisoned locally by the Forest Department (White, 1986).

Trichilia monadelpha. Littoral forest (Audoin, Ivory Coast), often on river banks in evergreen and semi-deciduous forest, including gallery forest, common in secondary forest and sometimes abundant in very old secondary forest; 0-650 m.

Four other rain forest species are recorded in swamp forest or periodically inundated forest. Three of these are also in drier and secondary forest, and one of these, Trichilia rubescens, is another weed species, poisoned in managed forest. De Wilde (1968) wrote that "Many of the rain forest species favour secondary vegetation, and due to this habit, to some extent, their survival is enhanced by human interference in the original vegetation".

Two of the 'Guineo-Congolian' species of Trichilia species are recorded from both forest and savannah woodland: T. prieureana (also in littoral forest, see above; Senegal to Zambia) and T. retusa (Nigeria to eastern DRC).

Four other species of African Trichilia are unusual, as they mainly occur outside the 'Guineo-Congolian' rain forest region. The first, Trichilia dregeana, occurs in drier rain forest up to $2100 \mathrm{~m}$. On the coast of SE Africa it also occurs in seasonal swamp forest (near Maputo), and on sand flats behind mangrove (at Inhaca Island and at Isipingo, south of Durban). In West Africa it is found from 800-1600 m, but near the mouth of the Congo River it occurs near sea level, a feature which is "hard to explain" (de Wilde, 1968) and "puzzling" (White, 1986). However, White noted that Nuxia congesta Fresen. (Stilbaceae), an Afromontane near-endemic, also has small, local populations at low altitudes, including one near the mouth of the Congo River.

Of the three other species outside the Guineo-Congolian region, Trichilia emetica is recorded on coral limestone and the leeward side of dunes. Trichilia capitata, a scrambling shrub, is also recorded from sea level, and extends up to $300 \mathrm{~m}$. Trichilia quadrivalvis is unlike the others as it is restricted to inland sites (in southcentral Africa) and also has a distinctive architecture. It is a rhizomatous suffrutex, 10-40 $\mathrm{cm}$ high, that forms spreading clumps and carpets on the ground, with long, flexible rhizomes just below or on the soil surface. All other African species of Trichilia are erect trees or shrubs. Trichilia quadrivalvis is only known from miombo woodland with Brachystegia and Julbernardia (Leguminosae), on Kalahari Sands and from 1200-1250 m altitude. Evidence suggesting the origin of miombo as a back-mangrove community that has been stranded inland is discussed elsewhere (Craw et al., 1999).

Notes. An initial molecular phylogeny indicated that Trichilia sensu lato comprises three main clades (Clarkson et al., 2016): with a phylogeny Trichilia havanensis of America (35 American Trichilia species (6 African Trichilia species, Pseudobersama + Pterorrhachis, both from Africa, and T. trifolia of America)).

The phylogeny is: New World (New World (New World and Old World)), and so Clarkson et al. (2016) wrote that: "The African species of Trichilia are nested within the neotropical clade". However, strictly speaking, they are nested in an African + 
Neotropical clade. The paraphyletic basal grade in America would usually be taken as evidence of a centre of origin there, but as stressed above (Fig. 1), this is not necessarily correct.

In their study of Trichilia phylogeny, Clarkson et al. (2016) wrote that: "within the monophyletic crown group (sect. Moschoxylum) the majority of the species are on short branches with low sequence divergence between species, suggesting recent speciation... The causes of these recent rapid radiations within this seemingly stable and unchanging tropical environment are not immediately straightforward to understand". The reason for this problem could be that evolution in the group did not proceed by recent radiations, but by old divergences and juxtapositions.

The first clade in Trichilia comprises the American T. havanensis Jacq. This is widespread from Mexico (Sinaloa and Tamaulipas), through Central America to Colombia and northern Venezuela, also Cuba, Jamaica and Hispaniola (Pennington, 2016). (Absent from Puerto Rico, the Lesser Antilles and eastern Venezuela). The species inhabits a wide ecological range: lowland rain forest, wet montane forest, deciduous forest, and, often, disturbed areas; up to $2000 \mathrm{~m}$ elevation.

The 'American' clade of Trichilia includes all the sequenced American species except Trichilia havanensis (last section) and T. trifolia L. (in the African clade, below). It occurs throughout tropical America, from northern Mexico to northern Argentina, including the West Indies (Pennington, 2016).

In the American clade, Trichilia americana (Sessé \& Moc.) T.D.Penn. ranges from NW Mexico south, on the Pacific seaboard, to Panama (Fig. 31A). In Mexico, north of the Motagua fault, the distribution is restricted to the western terranes that were accreted from the Pacific side in the Cretaceous (cf. Swietenia humilis, Fig. 15A). The southern boundary is at Panama. As discussed already (see Swietenia), the 'landbridge' theory of Costa Rica-Panama biogeography would account for the high diversity in the region, but it does not explain the boundaries, endemism or disjunctions there.

Several Trichilia species show significant disjunctions. Trichilia moschata Sw. subsp. moschata (Fig. 31B) is disjunct across most of Central America, between the Motagua fault zone and the Romeral fault zone. This suggests that it was never present on the main Caribbean arc (Fig. 16), which would have had its own endemics. Several other species are disjunct across Panama and Chocó. Trichilia pittieri C.DC. (Fig. 31C) is disjunct across Panama and Colombia, and T. adolfi Harms, of Costa Rica, Colombia, Ecuador, and Peru, is disjunct across most of Panama (present in the far west). Trichilia poeppigii C.DC. (Fig. 31D) is disjunct across most of Chocó.

Trichilia quadrijuga Kunth subsp. quadrijuga (Fig. 32) is distributed from Panama to SE Brazil, but is disjunct across much of Panama and Chocó. The gap is filled by the other member of the species, Trichilia quadrijuga subsp. cinerascens (C.DC.) T.D.Penn., found west of the Romeral fault zone. Trichilia erythrocarpa Lundell (Fig. 32) is a close relative of T. quadrijuga (Pennington, 2016) and has a southern boundary at the Motagua fault zone. Another species with a southern boundary there is Trichilia minutiflora Standl.

Of the 15 Trichilia species in the West Indies, eight are also more or less widespread on mainland America but have restricted distributions in the West Indies, 


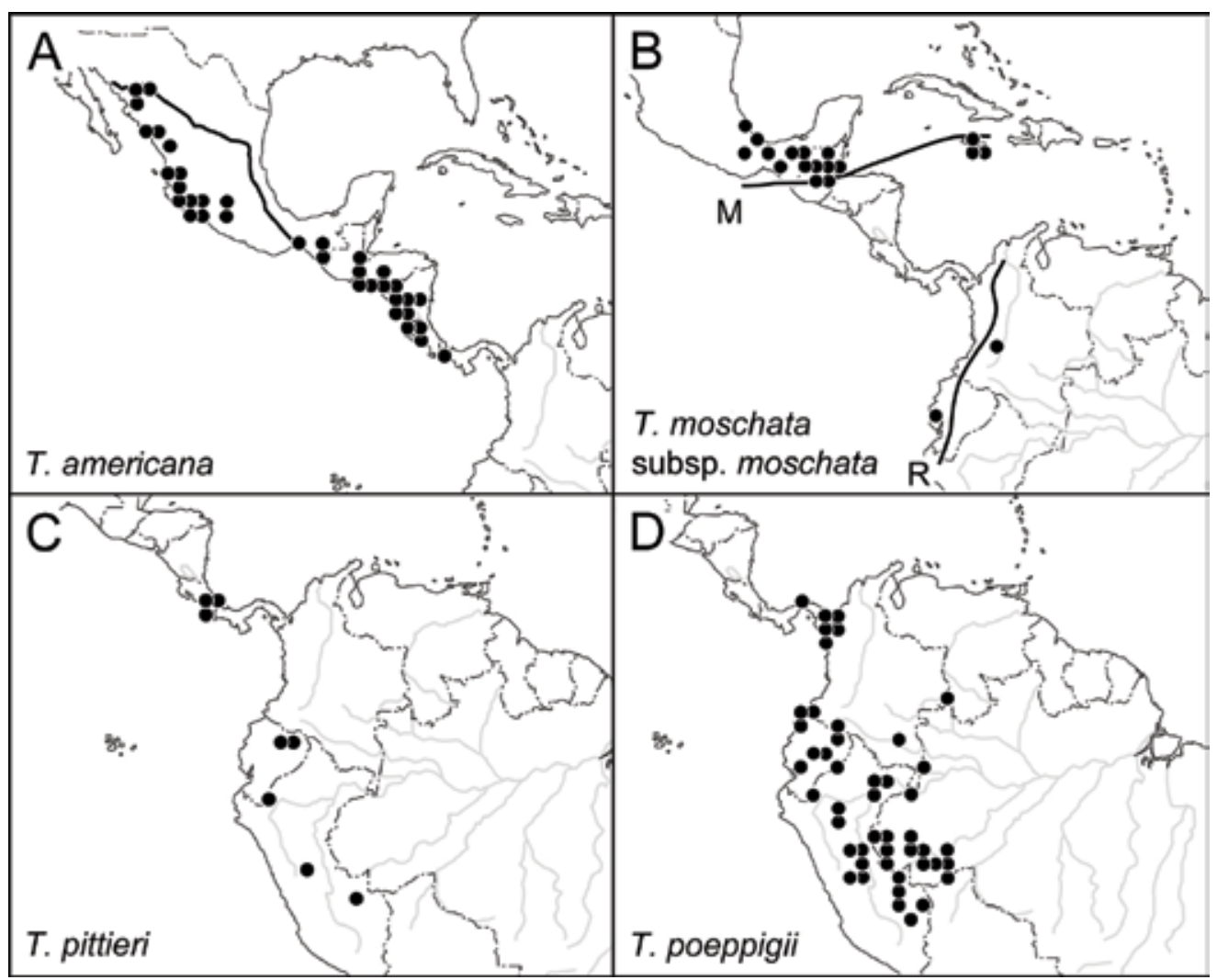

Fig. 31. Distribution of four Trichilia species. A. Trichilia americana (Sessé \& Moc.) T.D.Penn. Solid line $=$ boundary between accreted terranes in the west and craton in the east of Mexico. B. Trichilia moschata Sw. subsp. moschata. $\mathrm{M}=$ Motagua fault system; $\mathrm{R}=$ Romeral fault system. C. Trichilia pittieri C.DC. D. Trichilia poeppigii C.DC.

where they show a significant level of allopatry. The remaining seven species in the West Indies are endemic to the Greater Antilles and are all allopatric, apart from the overlap of two species in eastern Cuba: 1. Trichilia reticulata P.Wilson. Jamaica; 2. Trichilia trachyantha (Griesb.) C.DC. Cuba (widespread); 3. Trichilia pungens Urb. Eastern Cuba; 4. Trichilia stenophylla Urb. \& Ekman. NW tip of Haiti (Mole St. Nicolas); 5. Trichilia aquifolia P. Wilson. Northern Haiti (but not the NW tip) and southern Dominican Republic; 6. Trichilia monacantha Urb. Northern Dominican Republic; and 7. Trichilia triacantha Urb. Puerto Rico.

The seven species all inhabit drier forest and woodland on limestone. Trichilia reticulata and $T$. trachyantha have normal, non-spiny leaves, but the five other species all have distinctive, spiny leaves. The spiny-leaved species were regarded as a related group, but the molecular study by Clarkson et al. (2016) sampled two of the species, Trichilia aquifolia and T. triacantha, and these did not form a clade. (The non-spinyleaved species were not sampled). The relatives of the seven West Indian endemics 


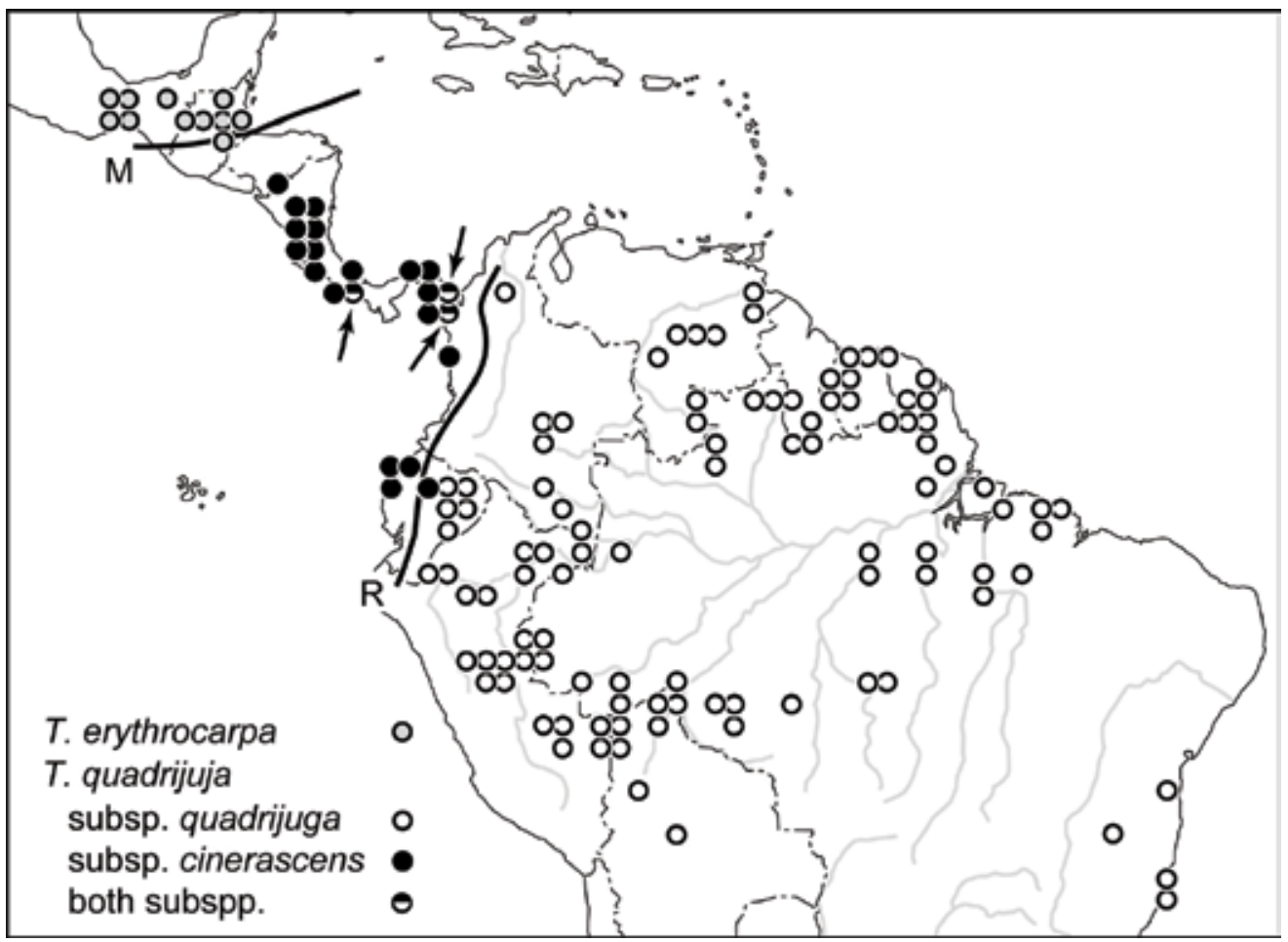

Fig. 32. Distribution of Trichilia quadrijuga Kunth and Trichilia erythrocarpa Lundell. $\mathrm{M}=$ Motagua fault system; $\mathrm{R}=$ Romeral fault system.

are unknown. Nevertheless, the striking allopatry among the seven can be explained by vicariance among their respective clades. If the phylogeny is clarified, any overlap among the other members of their respective clades would be explicable by subsequent range expansion.

The south-eastern seaboard of Brazil represents the other main centre of localised endemism in American Trichilia. Six of the endemics there form a molecular clade (Clarkson et al., 2016 Fig. 2): Trichilia congesta T.D.Penn., T. tetrapetala C.DC., T. magnifoliola T.D.Penn., T. florbranca T.D.Penn., T. blanchetii C.DC., and T. pseudostipularis (A.Juss.) C.DC. in part (the species in the broad sense, as mapped here, is polyphyletic) (Fig. 33). Five of the six species are in rain forest (up to 500 $\mathrm{m})$, while Trichilia blanchetii is in in the transition zone between wet rain forest and restinga, at 50-450 $\mathrm{m}$ altitude.

Endemism in SE Brazil can be accounted for by the uplift that took place there as the Atlantic opened. Subsidence along a rift, as in the Atlantic, can cause elastic rebound along its margins, or 'shoulders' (Ribeiro, 2006; Heads, 2012: 172). This same process of 'rift shoulder uplift' also occurred along the Atlantic coast of Africa (see the 'Atlantic Swell' in Fig. 9), and explains the high levels of endemism in the belt SW Cameroon-Gabon-Angola. 


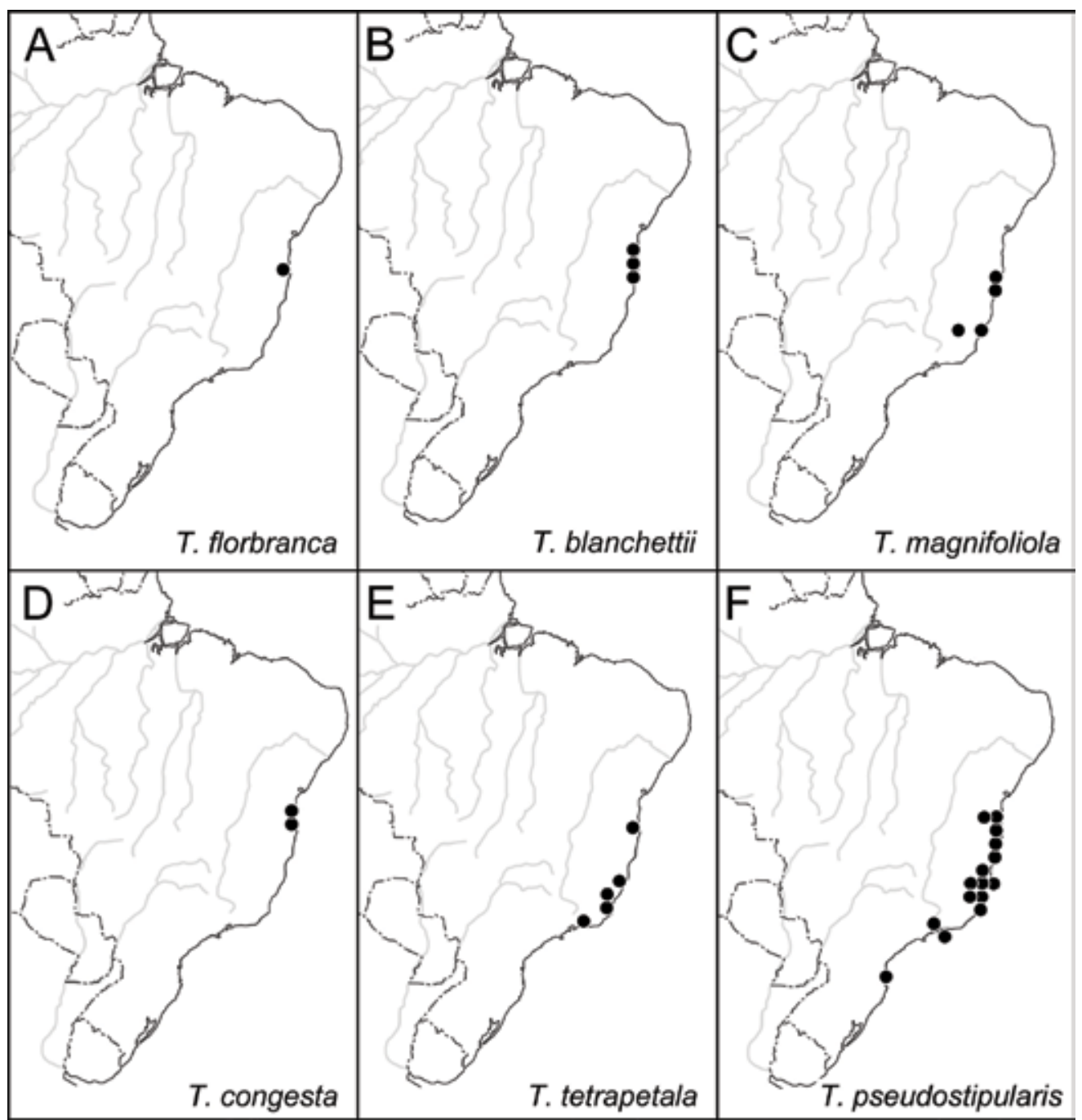

Fig. 33. Distribution of six Trichilia species endemic in SE Brazil. A. Trichilia florbranca T.D.Penn. B. Trichilia blanchetii C.DC. C. Trichilia magnifoliola T.D.Penn. D. Trichilia congesta T.D.Penn. E. Trichilia tetrapetala C.DC. F. Trichilia pseudostipularis (A.Juss.) C.DC.

Western Amazonia is well known as a centre of endemism and diversity, and 15 Trichilia taxa are endemic there: T. multifoliola, T. trimera T.D.Penn., T. hispida T.D.Penn., T. stipitata T.D.Penn., T. obovata W.Palacios, T. pachypoda (Rusby) C.DC., T. elsae Harms, T. ulei C.DC., T. tuberculata subsp. lanceolata (C.DC.) T.D. Penn., T. laxipaniculata Cuatrec., T. reynelii T.D.Penn., T. schomburgkii subsp. javariensis T.D. Penn., T. deminuta T.D.Penn., T. minima T.D.Penn., and T. vestigialis T.D.Penn.

In another common pattern, the Amazon river, which follows a Cretaceous rift, forms an important distributional break. It is displayed in members of Trichilia such as: Trichilia euneura C.DC., T. tenuifructa T.D.Penn. and T. surumuensis C.DC. along the 
Amazon River and north of there; and T. hispida, T. bullata T.D.Penn., T. fasciculata T.D.Penn., T. solitudinis Harms, and T. elegans subsp. richardiana (A.Juss.) T.D.Penn. along the Amazon River and south of there.

In the last revision, de Wilde (1968) recognised 18 species of Trichilia in mainland Africa, and there are also about four species in Madagascar. In a molecular phylogeny (Clarkson et al., 2016), the 'African clade' includes all six of the African species sampled so far, as well as Pterorhachis (2 species) and Pseudobersama (one species) of Africa, and a single American species, Trichilia trifolia L. The last species is known from Mexico to Venezuela, also Cuba, and, massively disjunct, on the coast of SE Brazil (Pennington, 2016).

In Trichilia there is a strong concentration of African species in the west (and the immediate allies, Malleastrum and Lepidotrichilia2, are in Madagascar) (Fig. 34). This is quite different from the arrangement in Turraea, in which the African species are concentrated in the east (and the allied plants, Naregamia and Nymania, are in the south-west) (Fig. 29). Trichilia is abundant in rain forest, but is not diverse in most of the Congo Cuvette Centrale. Instead, highest species diversity lies north and west of the Cuvette. Thus maximum diversity in the genus occurs around the margins of the Congo basin and also around the margins of the Atlantic basin, in West Africa and Brazil.

In Africa, Trichilia has disjunct centres of diversity in West Africa (western Ivory Coast: eight species), and in a central African belt that runs parallel with the Atlantic coast from central Gabon (10 species) to the Congo mouth region (nine species). Many other rain forest groups, such as Xylopia (Annonaceae), also show maximum levels of diversity along this Atlantic belt (Fig. 35; data from Johnson \& Murray, 2018). Xylopia has 45 species in tropical Africa, and maximum species diversity occurs in a zone extending from SW Cameroon to SW Republic of Congo (10-11 species per degree square). The diversity can be accounted for evolution mediated by uplift in the region.

The South Atlantic coast of Africa has three main relief elements: the South African Plateau, the Angola Mountains, and the Congo-Cameroon Atlantic Swell (Fig. 9). The belt, which corresponds with uplift in SE Brazil, reaches its maximum elevation of 1,575 $\mathrm{m}$ in south-central Gabon (Guillocheau et al., 2015). Geological data suggest two main uplift periods along the Atlantic Swell as a whole, one in the Late Cretaceous and one in the Oligo-Miocene (Colli et al., 2014). Late Cretaceous uplifts are documented by apatite fission track data in South Africa, Namibia, Gabon, and Equatorial Guinea. Significant vertical displacement is also confirmed by numerous lowstand wedges along the margins.

The Gulf of Guinea islands are located on the oceanic part of the Cameroon Volcanic Line. Trichilia is represented on the islands by the widespread T. rubescens Oliv. and T. monadelpha (Thonn.) J.J.de Wilde on Bioko, and T. grandifolia endemic to São Tomé Island (allopatric with the rest of the genus). Another Meliaceae on São Tomé is Carapa gogo (Fig. 21B) (perhaps not a distinct species), and it is interesting that both populations occur in trans-Atlantic genera. Trichilia grandifolia has beaked fruit, which are known elsewhere in African Trichilia only in T. zewaldae J.J.de Wilde of Cameroon and Gabon. This feature and the distribution "suggest that Trichilia 


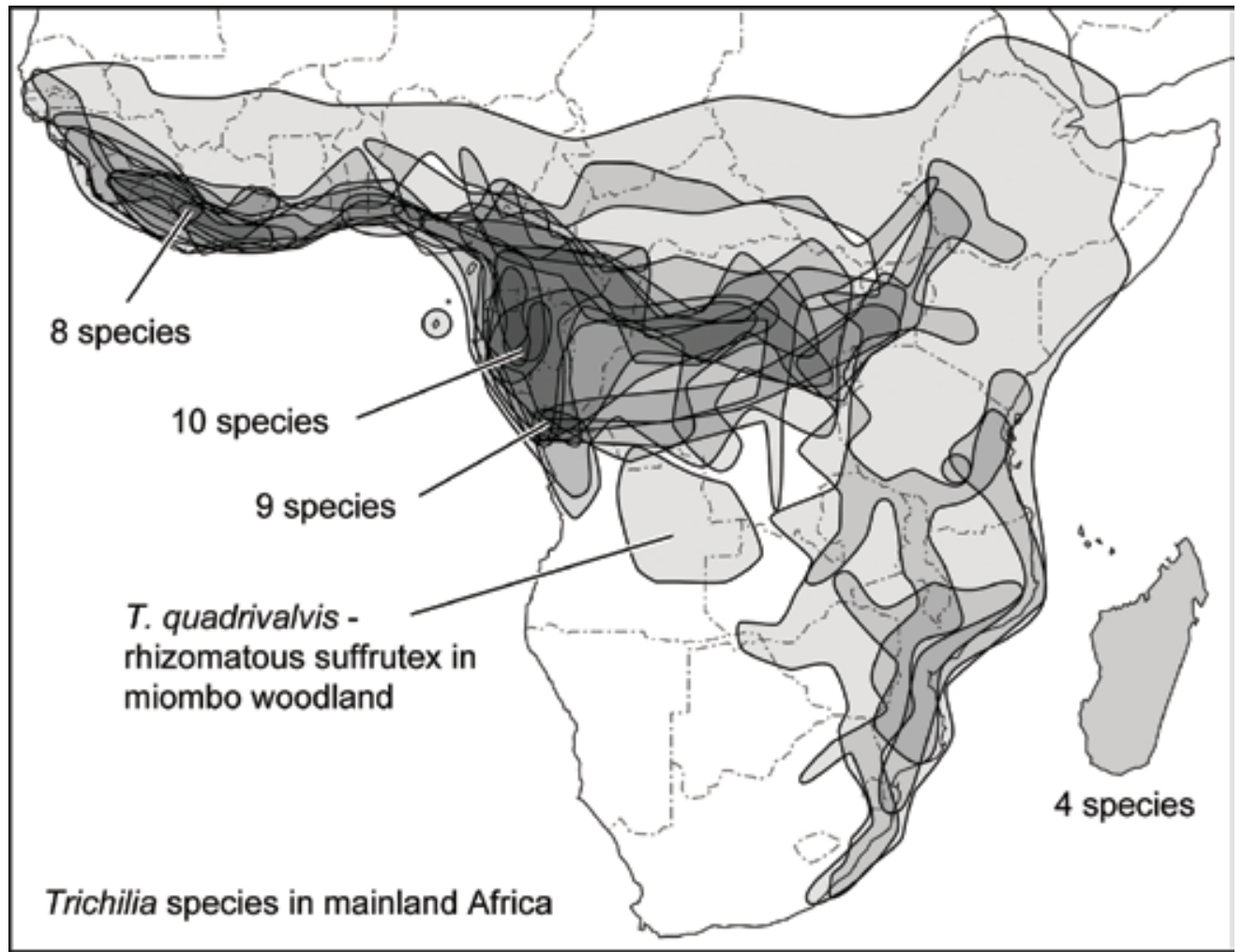

Fig. 34. Distribution of Trichilia species in Africa and Madagascar (individual species in Madagascar not shown).

zewaldae and T. grandifolia are descendants of a common ancestor" (de Wilde, 1968). This is more likely than one being derived from the other. The portion of the Cameroon Volcanic Line on the mainland is also important for Trichilia; a typical central African endemic, T. gilgiana Harms (Fig. 36), extends from the Benue Trough/CVL at the SE Nigeria/Cameroon border to eastern DRC.

'Pterorhachis' (two species, Cameroon and Gabon) and 'Pseudobersama' (one species, East African coast) form a sister pair within Trichilia (Clarkson et al., 2016) and show a massive disjunction across central Africa (Fig. 37). Trichilia dregeana shows a similar disjunction, with a gap of c. $1500 \mathrm{~km}$ between both areas (Fig. 38). The disjunction also occurs in Khaya (Fig. 13), and it can be attributed to connections skirting central Africa somewhere to the south.

Similar east-west disjunctions occur in many groups. For example, Sirdavidia Couvreur \& Sauquet (Annonaceae) of Gabon (Ivindo, Crystal Mountains) is sister to Mwasumbia Couvreur \& D.M. Johnson, of Tanzania, by the Uluguru Mountains (200 km west of Dar es Salaam), 2800 km away (Fig. 38). Couvreur et al. (2015) described the gap as "An incredible disjunction". However, they also observed that "East West/ Central disjunctions between rain forest restricted species are a common feature in African plants...". 


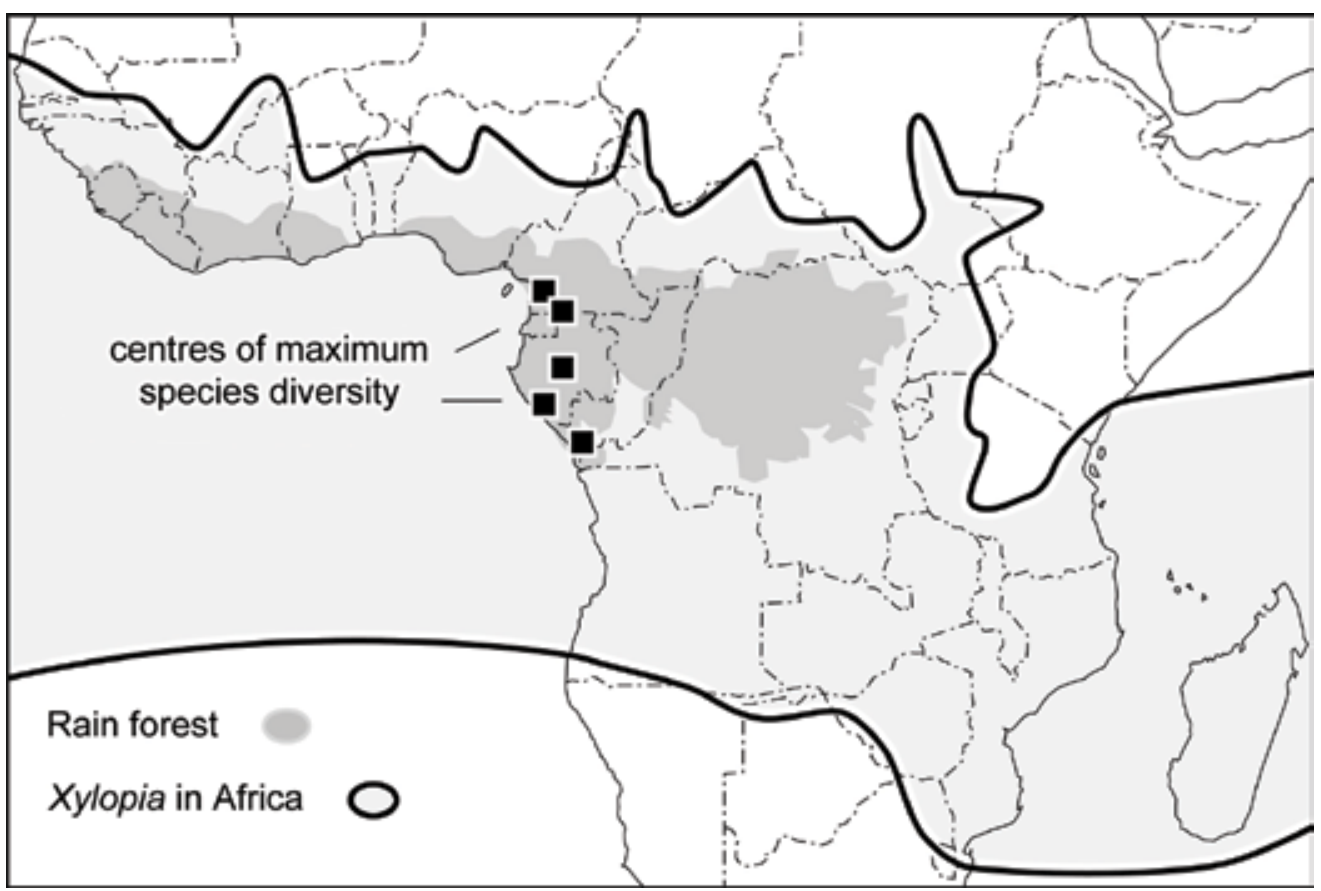

Fig. 35. Distribution of Xylopia L. (Annonaceae) in Africa, with areas of maximum species diversity (data from Johnson \& Murray, 2018).

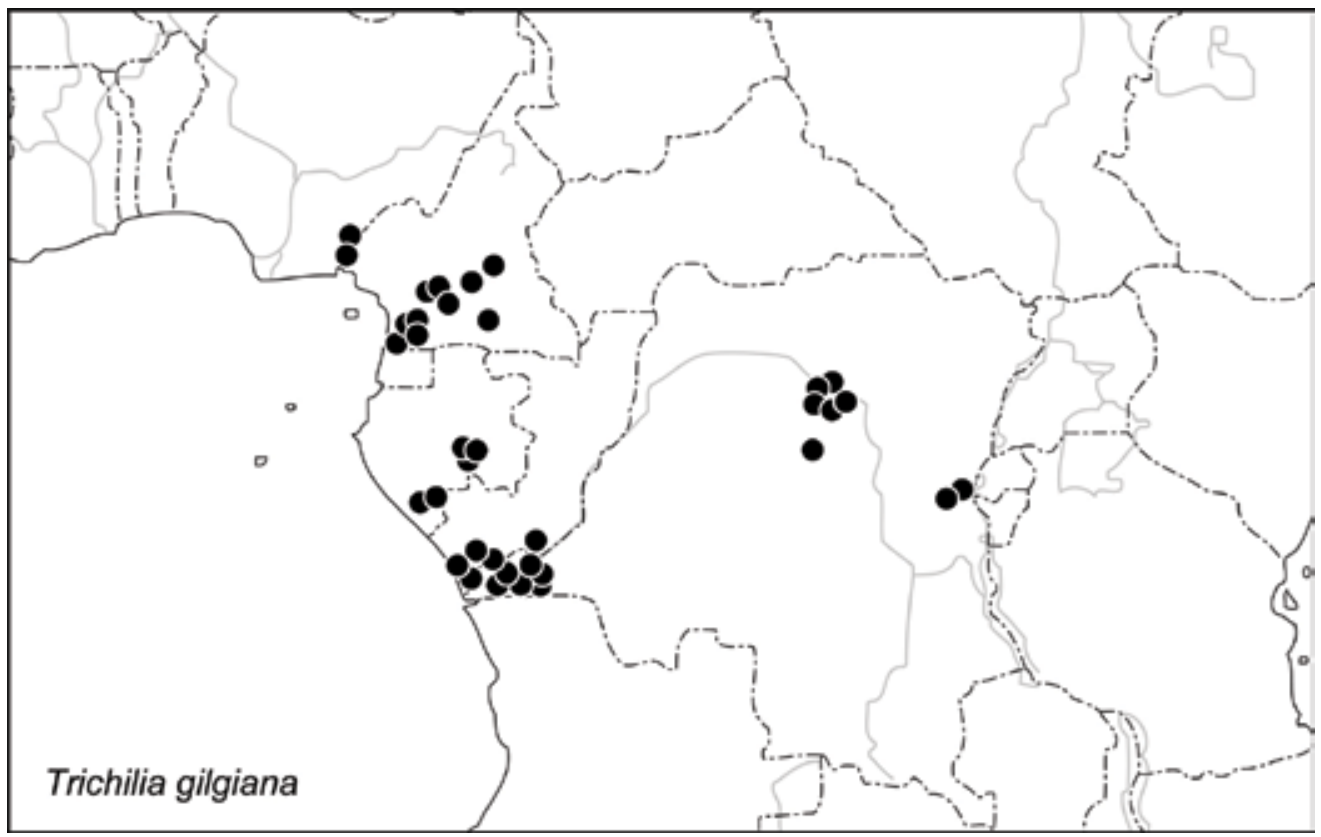

Fig. 36. Distribution of Trichilia gilgiana Harms. 


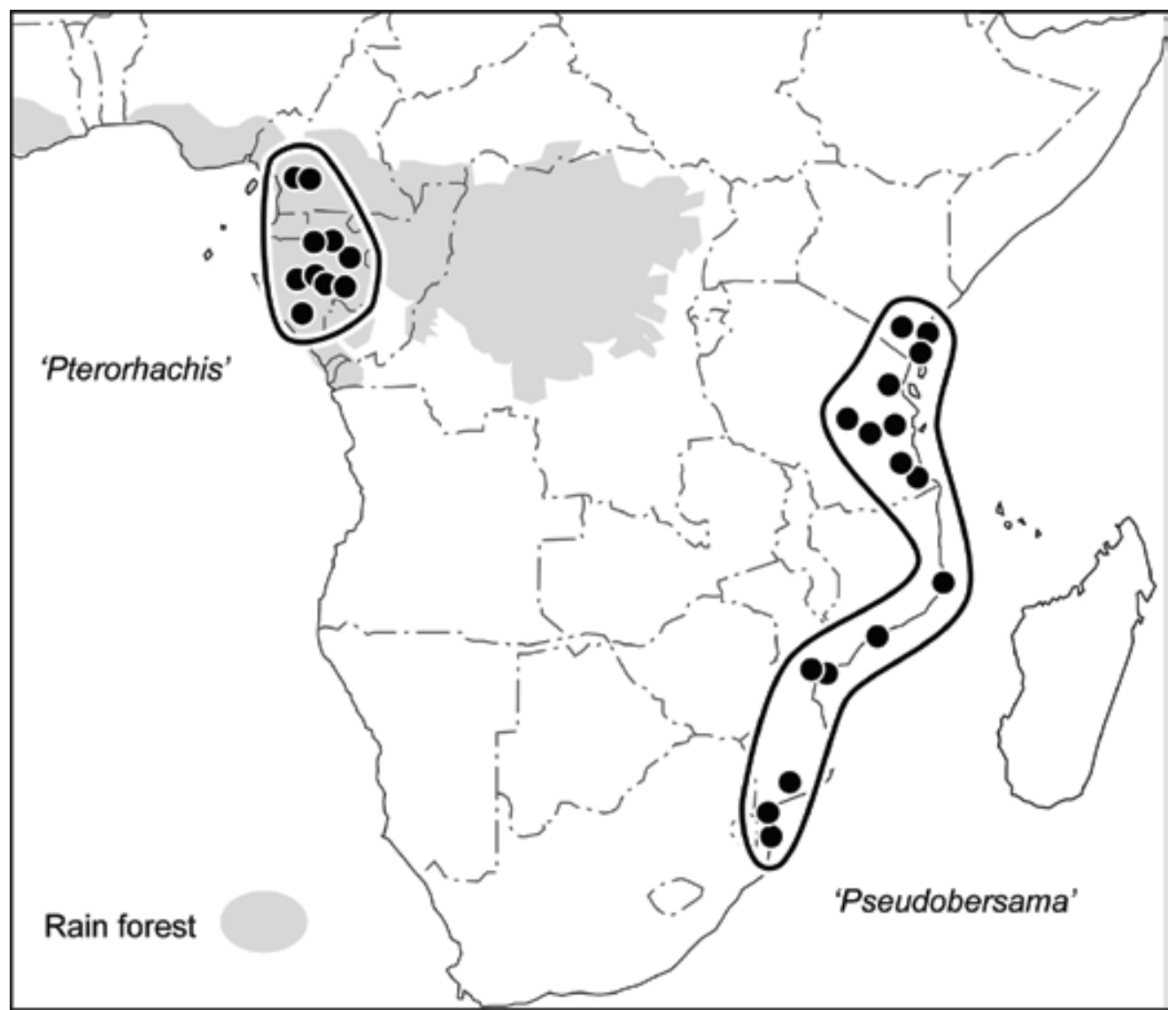

Fig. 37. Distribution of 'Pterorhachis' Harms and 'Pseudobersama' Verd., both treated here in Trichilia.

The 'eastern arc' mountain ranges of Tanzania are uplifted parts of the old African shield. They lie east of the East African Rift, which is a more recent structure. The ranges are well known for their biodiversity, and this reaches maximum levels in the Usambara and Uluguru Mountains (Fig. 9). These last ranges, as well as being a centre of diversity, also comprise an important centre of endemism, a biogeographic boundary (as in Lovoa; Fig. 7), a centre of disjunction (for example, to Madagascar), and a site of altitudinal anomalies in many groups (such as the low altitude giant lobelia, Lobelia longisepala Engl.) (WWF, 2019).

The uplift of the current 'eastern arc' mountains began in the Miocene, but the faults, and therefore perhaps also the biogeography, are considerably older than this the fault blocks of the Usambara and Uluguru Mountains developed along reactivated Mesozoic (Karoo) faults (Griffiths, 1993; Heads, 2012). 


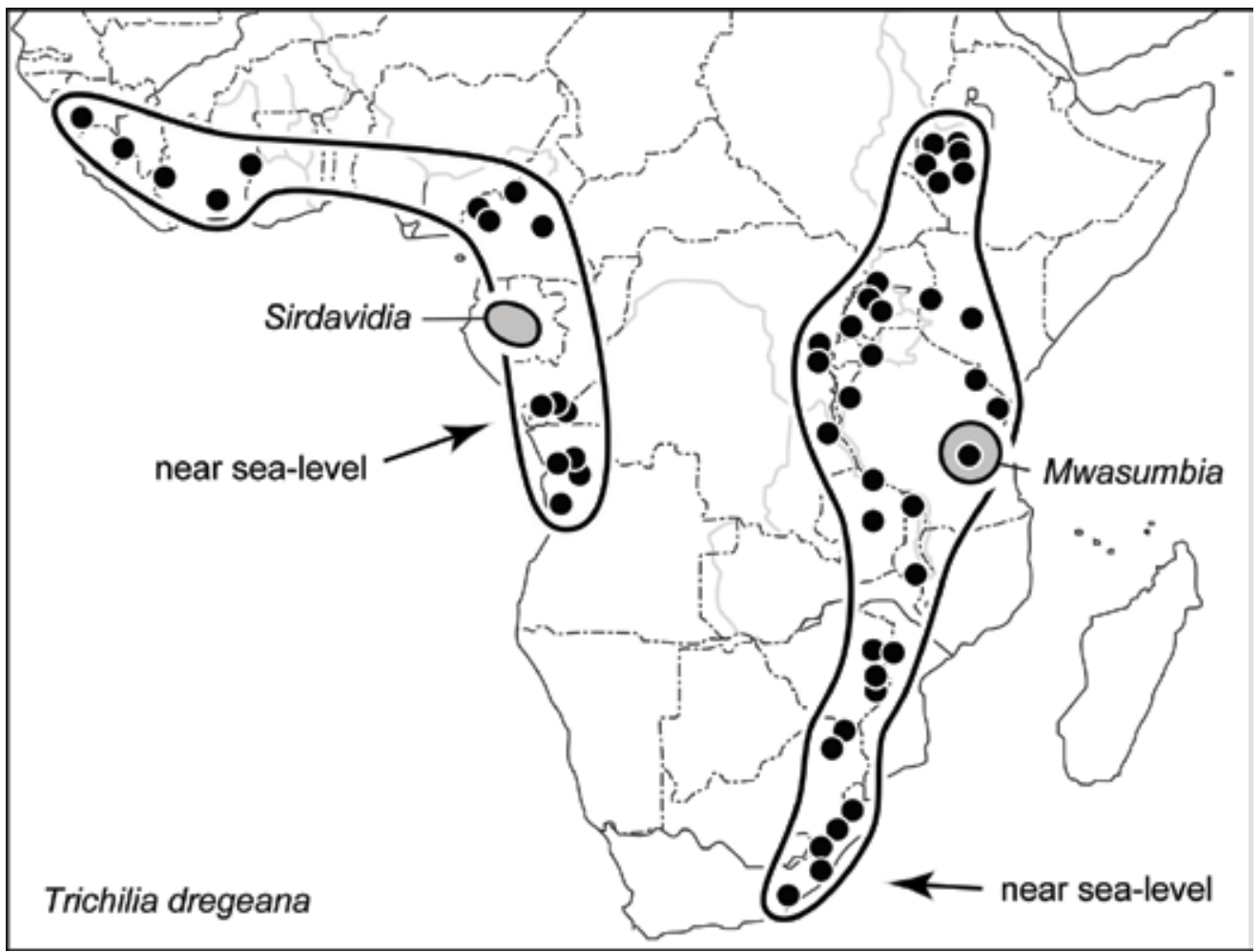

Fig. 38. Distribution of Trichilia dregeana Harv. \& Sond., and of two sister genera in Annonaceae, Sirdavidia Couvreur \& Sauquet in Gabon, and Mwasumbia Couvreur \& D.M.Johnson, by the Uluguru Mountains (Couvreur et al., 2015).

The African Plant Database (2019) accepted four species of Trichilia in Madagascar: T. tsaratanensis Lescot (forest at mid-altitude) and T. cauliflora J.-F. Leroy \& Lescot (both described in Leroy \& Lescot, 1996), T. mucronata (Cav.) Harms, and T. sambiranensis Callm. \& Philipson.

The remaining groups of Meliaceae comprise the diverse Guarea-Aglaia clade.

\section{Dysoxylum Blume sensu lato}

Dysoxylum, in the sense used by all modern authors, comprises about 80 species. However, a molecular phylogeny (Fig. 3; Koenen et al., 2015) indicates that it is polyphyletic, as suspected by Mabberley (1979: 313). In the molecular study, the eight sequenced species of Dysoxylum were dispersed among five clades that also include other accepted genera. These five clades are considered individually in more detail below, but it is difficult to assign most of the unsequenced Dysoxylum species 
to any one of the five clades. The delimitation of these clades is the most pressing phylogenetic problem in the family. The following notes concern Dysoxylum in the broad, polyphyletic sense, but see '35. Dysoxylum sensu stricto' below.

Distribution. Dysoxylum in the traditional, wide sense is distributed from India and Sri Lanka (three species) to southern China, through Indochina and Malesia (including Christmas Island) (50 species), south to the Solomon Islands (13), Australia (14), Lord Howe Island (1), Norfolk Island (1), New Caledonia (9), New Zealand (1), and east to Vanuatu (4), Fiji (9), Tonga (2), Samoa (3) and Niue (1) (Mabberley et al., 1995).

Dysoxylum sensu lato has its highest levels of endemism in New Caledonia (8 species of 9 total, $=89 \%)$, Fiji $(7$ of $9,78 \%)$ and New Guinea (16 of 28, 57\%). Further west, endemism is much lower (Borneo has 2 of 22 species, or $9 \%$, endemic, the Malay Peninsula has 2 of 17, or 11\%). Thus the genus demonstrates "a distinctly austral richness" by comparison with its allies Chisocheton and Aglaia; "Unlike those... Dysoxylum cannot be said to be essentially Malesian and has to be understood in a Pacific context" (Mabberley et al., 1995).

Ecology. In Malesia, Dysoxylum sensu lato is recorded from edges of mangrove swamps, back mangrove, freshwater (including tidal) swamp forest, peat swamp forest, riverine forest, primary forest, semi-deciduous forest, thicket (one species, Dysoxylum latifolium of "Rain forest and semi-deciduous thicket, Port Moresby region" (Mabberley et al., 1995), kerangas (heath forest), and secondary forest; substrates include ultramafics, limestone, coral, and sand. Sea level to $3000 \mathrm{~m}$.

Among the nine Dysoxylum species in New Caledonia, D. rufescens Sebert \& Pancher and $D$. minutiflorum are in maquis shrubland, where they are stunted and bushy with polymorphic foliage; D. minutiflorum is only on serpentine (Mabberley, 1988). In Fiji, the nine species range from sea level to $1150 \mathrm{~m}$. Two species are recorded on limestone, including Dysoxylum richii (A.Gray) C.DC. This last species inhabits the edges of mangrove swamps, forest and thickets, from near sea level to $1000 \mathrm{~m}$ (Smith, 1985). On Vanua Mbalavu Island it is restricted to the northern limestone section.

In Malesia, Dysoxylum sensu lato is well documented up to $2580 \mathrm{~m}$ (the highest altitudes are occupied by D. setosum (Span.) Miq. of Timor, New Guinea and Queensland). However, there is also an unidentifiable (juvenile) Dysoxylum specimen from $3000 \mathrm{~m}$ in the Wichmann Mountains, SW New Guinea (it is cited in Mabberley et al., 1995, under D. annae Mabb., to which it is possibly related).

Dysoxylum inopinatum of northern and central New Guinea occurs in forest, from just behind mangrove to mossy fagaceous forest at $1500 \mathrm{~m}$; it can be very common at low altitudes. The ecological range is consistent with that of a weedy form of back-mangrove, in which some populations have survived rapid uplift into the montane zone.

Notes. Several aspects of species biogeography in Dysoxylum sensu lato are of particular interest, and are not affected by the problems in delimiting the genus. The first involves the famous biogeographic break at Wallace's line. 
Wallace's line, between Borneo-Bali and Sulawesi-Flores, represents a classic problem in biogeography as there is no obvious ecological explanation for it; there is no apparent environmental difference either side of the line. Despite this, the biogeographic breaks in clades there are often very precise. A good example is Dysoxylum mollissimum, widespread from NE India to the SW Pacific. In this species, variation in the fruit wall is associated with geography "in that, uncannily following Wallace's Line, plants to the west [India to Bali; subsp. mollissimum] have smooth fruits, while those to the east [Sulawesi, Flores, Timor to Niue; subsp. molle (Miq.) Mabb.] have pustular lenticellate ones" (Mabberley et al., 1995).

Mabberley et al. (1995) pointed out several other examples in which related Dysoxylum taxa occur on each side of Wallace's Line: 1. Dysoxylum cyrtobotryum of SE Asia to the Andamans, Nicobars, Sumatra, Java, and Bali, and D. latifolium Benth. in New Guinea, northern Australia, and Solomon Islands. 2. Dysoxylum cauliflorum Hiern in Burma, Thailand, Cambodia, Malay Peninsula, Vietnam, Sumatra, Bangka, Borneo, and the Philippines (Palawan only), and D. cumingianum C.DC. in the Philippines (not Palawan), Taiwan (Lan Yu), Sulawesi, Bali, and the Moluccas. 3. Dysoxylum grande Hiern from continental Asia to Borneo, and D. oppositifolium F.Muell. from the Philippines to Queensland. 4. Dysoxylum pachyrhache Merr. in Borneo, and D. kaniense Harms in New Guinea. 5. Dysoxylum magnificum Mabb. in SE Sumatra and Sarawak, and D. brassii Merr. \& L.M.Perry in New Guinea. 6. Dysoxylum crassum in Borneo, and D. inopinatum (Harms) Mabb. in New Guinea (northern and central).

Lan Yu (or Lanyu) Island, also known as Orchid Island or Botel Tobago, lies off the southeastern coast of Taiwan. Despite its small size it is important for its endemism, and it is also a biogeographic-tectonic boundary (Heads, 2014: 375). Three species of Dysoxylum, Aglaia lawii, and the genus Aphanamixis Blume have northern limits there, and two Aglaia species have limits on the nearby Hengchun Peninsula (Mabberley et al., 1995; Peng et al., 2008): 1. Dysoxylum arborescens (Blume) Miq. Andaman and Nicobar Islands, Taiwan (Lan Yu), throughout Malesia, Solomon Islands, Queensland, and Vanuatu; 2. Dysoxylum parasiticum (Osbeck) Kosterm.: Taiwan (Lan Yu), Malesia, northern Queensland and Solomon Islands; 3. Dysoxylum cumingianum. Taiwan (Lan Yu), Philippines (but not in Palawan), Sulawesi, Bali, Moluccas; 4. Aphanamixis polystachya (Wall.) R.Parker (and the genus Aphanamixis). India, Indochina, Taiwan (Lan Yu) and through Malesia to the Solomon Islands; 5. Aglaia lawii Ramamoorthy. India to mainland China, Taiwan (Lan Yu), Indochina and Malesia to the Solomon Islands; 6. Aglaia rimosa (Blanco) Merr. Southernmost Taiwan (Hengchun Peninsula) and nearby islands including Lan Yu, Philippines, Sulawesi, Moluccas, New Guinea, New Britain and New Ireland; and 7. Aglaia elaeagnoidea (A.Juss.) Benth. India, Sri Lanka, Indochina, southernmost Taiwan (Hengchun Peninsula), Philippines and widespread through Malesia to Australia and Tonga. (The three species of Aglaia listed here are the only members of the genus in Taiwan).

Dysoxylum excelsum Blume ranges from India and Sri Lanka to the Solomon Islands, but so far it is unrecorded from the Bismarck Archipelago. A similar, anomalous absence there is recorded in a large number of other groups, such as birds 
of paradise and Aglaia elaeagnoidea, and a tectonic rather than ecological explanation seems most likely. In Fiji, Dysoxylum tenuiflorum A.C.Sm. is absent from the main islands (where it is replaced by other species) and is restricted to islands of Kandavu, Taveuni, Lakemba, and Kambara (on limestone).

In New Caledonia, Dysoxylum minutiflorum displays a classic case of disjunction along the West Caledonian fault zone (Fig. 39A, from Mabberley, 1988), a major strike-slip feature. This pattern is repeated in many groups (two examples are shown in Fig. 39B and C) and is discussed elsewhere (Heads, 2014).

The eight sequenced species of Dysoxylum are dispersed among five clades in the molecular phylogeny presented by Koenen et al. (2015). These five clades also include Chisocheton, Cabralea, and Aphanamixis (incl. Sphaerosacme). The five clades form a paraphyletic, basal grade in a clade that also includes Aglaia (incl. Lansium Corr. Serr. and Reinwardtiodendron Koord.). As yet the sampling is not sufficient to indicate the precise composition of the five clades. In the meantime they are treated here as five genera, Dysoxylum sensu stricto, Chisocheton sensu lato, 'Cyrtochiton' (= Dysoxlum sect. Cyrtochiton), Cabralea sensu lato and Aphanamixis sensu lato

\section{Dysoxylum Blume sensu stricto}

Distribution. Number of species unknown. ?India and Sri Lanka to the Solomon Islands (?Niue).

Ecology. Coastal forest behind mangrove (Dysoxylum mollissimum, sometimes viviparous), freshwater swamp forest, riverine forest, primary rain forest, montane forest, secondary forest; limestone; sea level to $1900 \mathrm{~m}$.

Notes. Dysoxylum alliaceum (Blume) Blume is widespread from the Andaman Islands to the Solomon Islands and is the type species of the genus. In the molecular phylogeny (Koenen et al., 2015) it appears in a clade of its own. It is distinct in Dysoxylum sensu lato through its overpowering garlic smell, but it is "intimately allied" with $D$. excelsum (NE India, Sri Lanka to Solomon Islands) (Mabberley et al., 1995). Both species are variable, but appear to have more or less distinct 'satellite taxa', namely Dysoxylum klanderi F.Muell. of Queensland and D. hongkongense (Tutcher) Merr. of China. Finally, Dysoxylum mollissimum, of India to Niue, has a slash in which the smell "is similar to that of $D$. alliaceum" (Mabberley et al., 1995), and it might also belong here.

\section{Chisocheton Blume sensu lato}

Distribution. Possibly 56 species (53 species in Chisocheton sensu stricto, plus three(?) in Dysoxylum (Didymocheton)) in NE India and tropical China through Malesia (46 species in Chisocheton sensu stricto) to NE Queensland and Vanuatu (Chisocheton sensu stricto) and Samoa. 


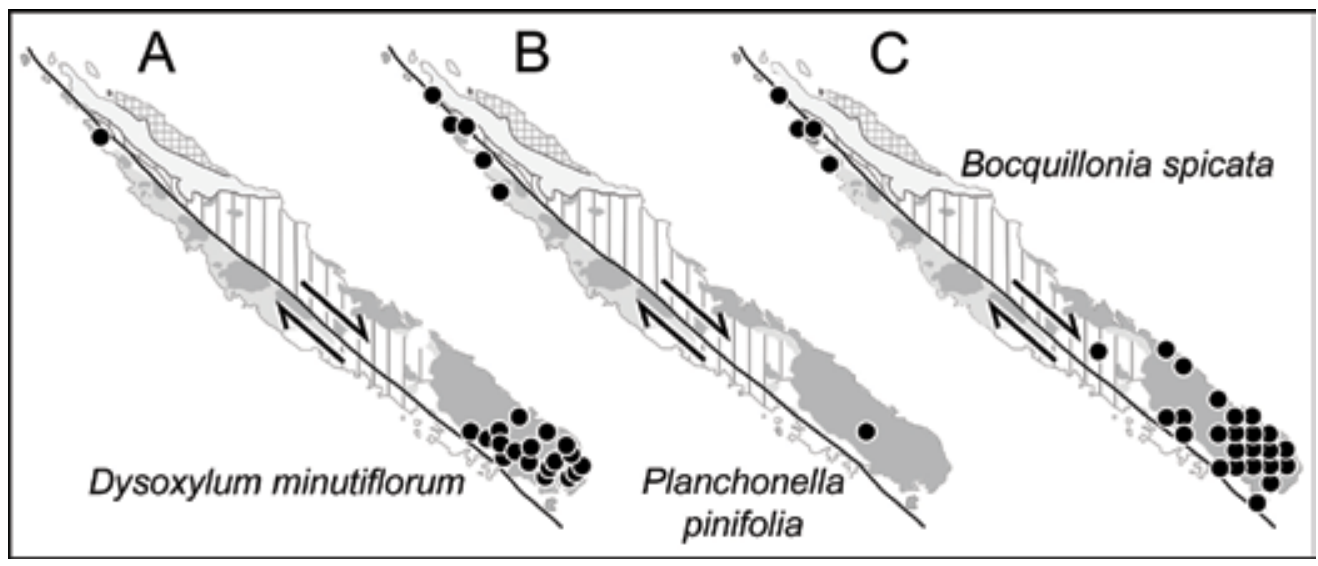

Fig. 39. Distribution of three species showing a dextral disjunction along the West Caledonian fault (solid line). Main terranes also shown (ultramafic terrane as dark grey). A. Dysoxylum minutiflorum C.DC. (Mabberley, 1988). B. Planchonella pinifolia (Baill.) Dubard (Sapotaceae) (www.endemia.nc). C. Bocquillonia spicata Baill. (Euphorbiaceae) (www.endemia.nc).

Ecology. Trees and treelets, often pachycaul. Stilt roots are recorded in Chisocheton tomentosus and C. polyandrus, both of which grow in lowland and hill dipterocarp forest. In Chisocheton macrophyllus the leaves are up to $240 \mathrm{~cm}$ long when shed and are the largest in the family (the leaves of Guarea cartaguenya Cuatrec. were described as $3 \mathrm{~m}$ long in Pennington, 1981, but this is probably a mistake. Apart from this record, the largest leaves that Pennington et al. (1981) and Pennington \& Clarkson (2013) documented in the genus are those of G. grandifolia DC., which are $140 \mathrm{~cm}$ long and were described by Pennington et al. (1981) as "enormous"). Mabberley (1979) listed seven other Chisocheton species in which leaves are at least $2 \mathrm{~m}$ long. The leaves in Chisocheton have a terminal bud and show indeterminate growth, as in many Guarea species. In Chisocheton pohlianus Harms and C. tenuis P.F.Stevens of New Guinea the leaves also bear epiphyllous inflorescences. Corner (1954) discussed the leaves in Chisocheton and argued that the indeterminate growth is more archaic than the determinate. One of the ways a modern seed plant leaf can be derived from a shoot is by suppression of both vegetative and reproductive buds.

Chisocheton sensu lato is recorded in Malesia from primary rain forest, riparian forest, freshwater and peat swamp forest, disturbed and secondary forest, montane forest, forest on limestone and ultramafics; from sea level to $1850 \mathrm{~m} \mathrm{(C.} \mathrm{montanus}$ P.F.Stevens in New Guinea). Five species are recorded on limestone, including Chisocheton ruber, restricted to limestone, 'Dysoxylum' nutans, on both limestone and ultramafics, and C.amabilis, restricted to peat swamp forest and riparian forest.

Notes. In the molecular phylogeny (Koenen et al., 2015), Chisocheton sensu lato includes a monophyletic Chisocheton sensu stricto, as well as Dysoxylum gaudichaudianum Miq. (Java to Samoa). The last species is allied morphologically with Dysoxylum sessile Miq. (Moluccas) and D. nutans (Java to Moluccas). (Dysoxylum nutans is the 
type species of Didymocheton Blume). These three species are distinct in Malesian Dysoxylum through their sepaloid bracteoles (see the key in Mabberley et al., 1995), and together they range from Java to Samoa. The placement of Dysoxylum nutans, at least, with Chisocheton makes some morphological sense, as it has "the appearance of a species of Chisocheton sect. Clemensia” (Mabberley et al., 1995).

The western limit of Chisocheton, in both narrow and wide senses, follows a line: Darjeeling and Rajabhatkhawa (West Bengal), Khasi Hills and Garo Hills (Meghalaya), and Cox's Bazar (Bangladesh, near the border with Burma) (these are localities for Chisocheton cumingianus Harms, as listed by Mabberley, 1979). Thus Chisocheton is present in India, but only in the northeast; its western distribution boundary follows the margin of the Indian plate.

In Chisocheton, the greatest concentrations of both endemic species and total number of species are in Borneo and New Guinea (Mabberley, 1979). Borneo has eight endemics out of 18 total, while New Guinea has nine endemics out of 13 total. Both islands are geological composites formed from many different terranes with independent histories.

Chisocheton ruber is a local endemic in Borneo, known only from limestone near Kuching (cf. Chukrasia, Fig. 5, Sandoricum caudatum, and Walsura grandifolia). As many as 57 species of dipterocarp have a distributional boundary at the Lupar River by Kuching (Corner, 1978), and the region is also significant in geology (Hall, 2017). The 'Lupar Line' of the geologists is a major strike-slip fault that was active during the latest Cretaceous and early Cenozoic. Chisocheton ruber, just south of the Lupar line, is keyed out in Mabberley et al. (1995) with the Borneo representative of C. cumingianus, subsp. kinabaluensis Mabb., which is found only in the north, in the Mount Kinabalu region.

Palawan in the SW Philippines is distinct biogeographically from the rest of the archipelago (Heads, 2014), and this is evident in two taxa of Chisocheton as well as six other Meliaceae: 1. Chisocheton pentandrus Merr. subsp. paucijugus Mabb. Peninsular Thailand, Malay Peninsula, Sumatra to Borneo and Philippines (Palawan); 2. Chisocheton pentandrus subsp. medius Mabb. Northern Borneo and Palawan; 3. Walsura monophylla. Palawan, restricted to ultramafics; 4. Dysoxylum cauliflorum. Burma, Indochina, Malay Peninsula, Vietnam, Sumatra, Bangka, Borneo, and Palawan (distinguished by its cauliflory, but closely allied to D. cumingianum of Taiwan (Lan Yu), Philippines (not Palawan), Sulawesi, Bali, and the Moluccas); 5. Dysoxylum acutangulum. ?Peninsular Thailand, Malay Peninsula, Sumatra, Java, Lesser Sunda Islands, Borneo, Palawan, Moluccas, New Guinea, Australia, Solomon Islands (not in Sulawesi); 6. Aphanamixis borneensis (Miq.) Harms. Borneo, Palawan, Moluccas (not in Sulawesi); 7. Aglaia macrocarpa (Miq.) Pannell. Vietnam, Peninsular Malaysia, Sumatra, Java, Borneo, Palawan, Sulawesi, ?Moluccas; and 8. Aglaia smithii Koord. Philippines (Palawan and Basilan), Lesser Sunda Islands, Moluccas and New Guinea (Adi I. off the south coast of the Vogelkop).

Dysoxylum gaudichaudianum, treated here in Chisocheton sensu lato, ranges from the Philippines, Java and Christmas Island to Australia, New Guinea, Bismarcks, Solomons, Vanuatu and Samoa. The species is one of the most widely distributed in 
the genus, "though its absence from Fiji is not readily explained" (Mabberley et al., 1995). The absence is all the more striking as Dysoxylum sensu lato is otherwise so diverse in Fiji, with nine species there, seven endemic (the only sequenced member belongs to Cabralea sensu lato).

\section{7. 'Cyrtochiton' \\ (三Dysoxylum sect. Cyrtochiton Miq.)}

Distribution. Possibly 14 species in India to Australia and Santa Cruz Island.

Ecology. Primary rain forest, riparian forest, peat swamp forest, secondary forest, semi-deciduous thicket; two of the four known species occur on limestone; up to 2900 m (New Guinea).

Notes. In the molecular phylogeny of Koenen et al. (2015), this clade comprises Dysoxylum binectariferum Hook.f. (India to Vietnam) and D. cyrtobotryum (Nicobars to Bali). The latter is the only sequenced member of Dysoxylum sect. Cyrtochiton (species 34-46 in Mabberley et al., 1995). In the molecular phylogeny, Dysoxylum sect. Dysoxylum is evidently polyphyletic, while the only other section in the genus, Dysoxylum sect. Cyrtochiton, may or may not be monophyletic. 'Cyrtochiton' may have a total range: India, southern China, Hainan, Vietnam, Thailand, Nicobars, Andamans, through Malesia to NE Australia, ?Bismarck Archipelago, and Solomon Islands (including the Santa Cruz Group).

38. Cabralea A.Juss. sensu lato

Distribution. Four to nine species in New Zealand, Norfolk Island, New Caledonia, Vanuatu, Fiji; Costa Rica to SE Brazil (Fig. 40A).

Notes. In the molecular phylogeny of Koenen et al. (2015), this group comprises Cabralea sensu stricto of America (Pennington et al., 1981), Dysoxylum rufescens of New Caledonia, D. bijugum (Labill.) Seem. of Norfolk Island, New Caledonia, Vanuatu, and Fiji (Mabberley, 1988), and D. spectabile of New Zealand. The clade has good statistical support $(\mathrm{PP}=1)$, but further sampling is needed to determine its precise composition.

Cabralea sensu stricto has a single, variable species recorded from Ecuador and southern Venezuela to SE Brazil (sparse records in the Amazon) and also, disjunct across Chocó and Panama, in Costa Rica (Cartago, near Turrialba) (Pennington, 1981). The disjunction between Ecuador and Costa Rica repeats the pattern seen in Cedrela 'odorata I' and Trichilia pittieri (Fig. 31C). The same disjunction often occurs in groups from the páramo, above the tree line, and so is attributed to the lack of suitable highlands in most of Panama. However, the members of Meliaceae cited here cannot 


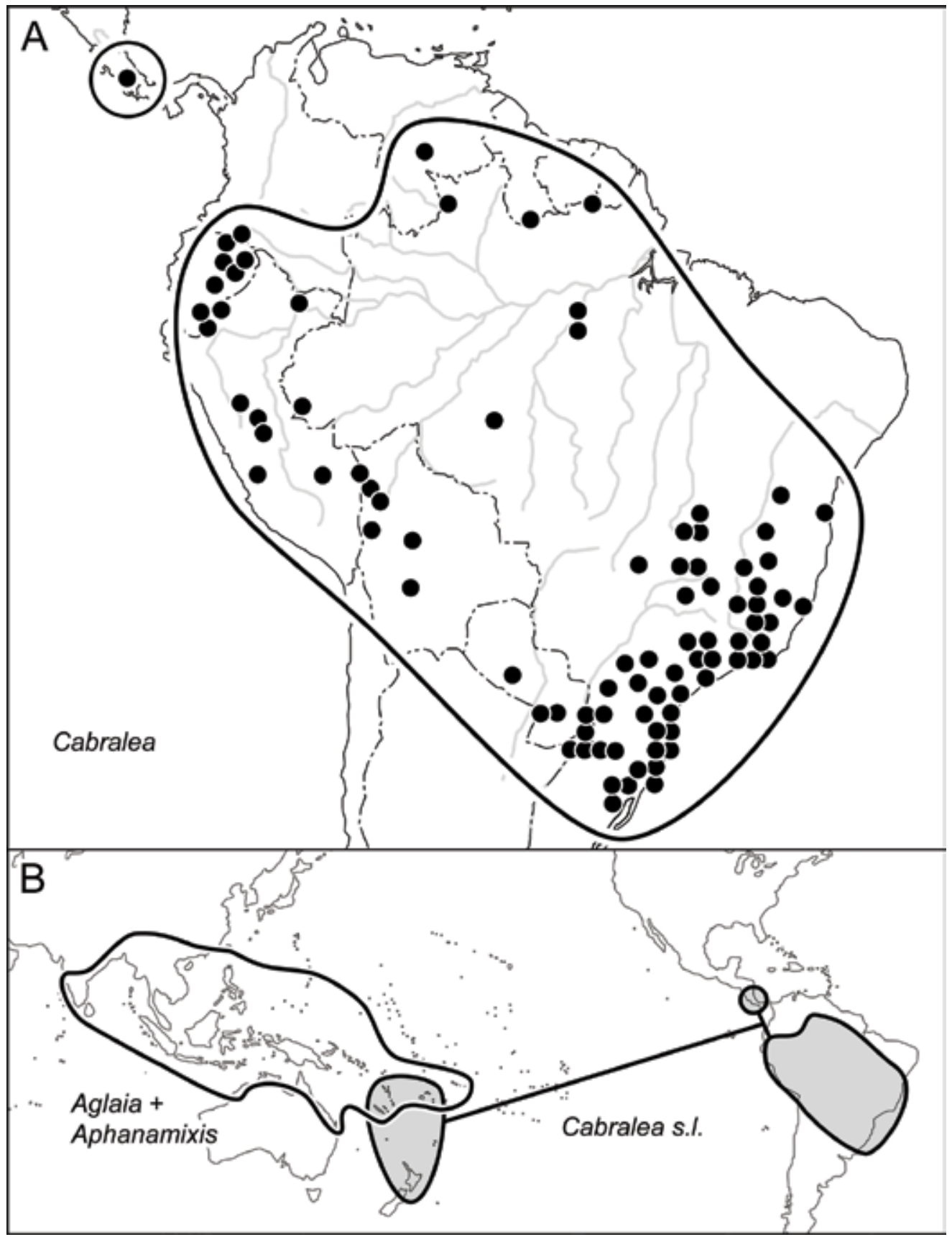

Fig. 40. A. Distribution of Cabralea A.Juss. sensu stricto (Pennington, 1981; www.tropicos. org). B. Distribution of Cabralea sensu lato and its sister group, Aglaia Lour. + Aphanamixis Blume. 
be explained in this way, and a general explanation for the pattern would be preferable. Koenen (2011) suggested that "dispersal to South America across the Pacific Ocean has also occurred as is evident from a sister-relationship between the Neotropical monotypic genus Cabralea and Dysoxylum spectabile native to New Zealand... [The affinity] suggests that New Zealand may have been the ancestral area of this clade". Instead, in the alternative model suggested here, Cabralea sensu lato originated by vicariance with its sister group. This is straightforward, as the two show a large degree of allopatry (Fig. 40B): Cabralea sensu lato ranges from New Zealand, north and east to New Caledonia, Vanuatu and Fiji, while its sister group, Aglaia + Aphanamixis, ranges south to the same three localities, which form the only area of overlap between the two clades.

Ecology. Trees and treelets. Dysoxylum spectabile (treated here in Cabralea sensu lato) is the only member of Meliaceae in New Zealand, where it inhabits "coastal forests... often in pure stands" (Moore \& Irwin, 1978: 90). In areas that are free of the introduced Australian possum, regeneration of Dysoxylum spectabile takes place even under a closed canopy, in microsites with deep leaf litter (Court \& Mitchell, 1988, 1989). As in other shade-tolerant species, the juveniles are slow-growing but can respond rapidly to an increase in available light.

In New Caledonia, Dysoxylum bijugum (Labill.) Seem. is recorded in backmangrove and littoral forests, and up to $400 \mathrm{~m}$. It is also very common in calcareous soil and sand.

In South America, the monotypic Cabralea sensu stricto is usually in lowland and coastal non-flooded, evergreen forest and lower montane rain forest. However, in eastern Brazil (Minas Gerais and Goiás) it inhabits areas with drier, strongly seasonal climate and is confined to gallery forest (Pennington et al., 1981).

39. Aphanamixis Blume sensu lato

(incl. Sphaerosacme decandra (Wall.) T.D.Penn. and Dysoxylum arborescens).

Distribution. Possibly five species in India, Sri Lanka, Nepal, tropical China, Indochina, throughout Malesia to the Solomon Islands (Peng et al., 2008).

Ecology. Trees of seasonally flooded forest, swamp forest (in Thailand), riverbanks, primary rain forest, heath forest, secondary forest, forest on limestone; up to $1800 \mathrm{~m}$ (Himalayas and Malesia).

Notes. In the molecular phylogeny (Koenen et al., 2015) this clade comprises Aphanamixis sensu stricto (3 species), Sphaerosacme (monotypic), and Dysoxylum arborescens. The distribution overlaps that of its sister, Aglaia, in the north, but Aglaia is the only member of the pair present in Australia, New Caledonia, Vanuatu, Fiji, Tonga and Samoa. 
40. Aglaia Lour. sensu lato

(incl. Lansium Corr. Serr. + Reinwardtiodendron Koord. as a clade)

Distribution. A genus of 127 species (including the 10 species of Lansium and Reinwardtiodendron), 95 in Malesia. Aglaia ranges from India (including the Western Ghats) and Sri Lanka to the central east coast of Australia (Gympie, $120 \mathrm{~km}$ north of Brisbane), Tonga and Samoa, including the Mariana Islands (Saipan, Roti and Guam) and Caroline Islands (Palau and Ponape). (It has also been introduced to Niue and the Cook Islands). The distribution encloses that of its sister, Apahanamixis (India to the Solomon Islands) (Fig. 40B).

Ecology. Aglaia species are trees and treelets. Habitats include mangrove, backmangrove, beach forest (including Barringtonia formation on sand), rocky seashore, tidal estuaries, Nypa palm swamp, freshwater swamp forest (including peat swamp forest), periodically inundated forest, riverine forest, primary terra firme forest, kerangas heath forest, deciduous forest, monsoon forest, thicket, and secondary forest.

The species inhabit various substrates, including limestone or coral (41 species), and ultramafics (two species), and range from sea level to $2570 \mathrm{~m}$ (Aglaia subcuprea Merr. \& L.M.Perry in New Guinea). [Aglaia sapindina Harms is recorded from 3800 $\mathrm{m}$ in Mabberley et al., 1995, and Pannell, 1992, but this is an error (Pannell, pers. comm. 22 April 2019)].

The following are recorded in, or associated with, mangrove and illustrate the ecophyletic series away from this habitat into dry land forest: 1. Aglaia cucullata (Roxb.) Pellegr. From the Ganges delta in Bangladesh to New Guinea. Tree with plank buttresses to $3 \mathrm{~m}$ high, sometimes with pneumatophores up to $7 \mathrm{~m}$ away from the bole and up to $60 \mathrm{~cm}$ high, mangrove, back-mangrove, tidal estuaries, Nypa palm swamp, riverine forest, lowland evergreen forest, 0-50 m (in Thailand). Aglaia cucullata is the only member of the genus with pneumatophores and the only species that grows in mangrove swamps; 2. Aglaia luzoniensis Merr. \& Rolfe. Borneo, Philippines, Sulawesi. Primary forest, secondary forest, near mangrove, on sand, sandy alluvium, sandstone, clay, volcanic clayey sand, limestone, 10-1400 m; 3. Aglaia brownii Pannell. New Guinea and Northern Territory of Australia. Semi-deciduous forest at edge of beach close to mangroves, on rocks and dunes near the sea, monsoon forest on coastal dunes, fringing coastal woods, Eucalyptus forest; 4. Aglaia rubiginosa. Sumatra, Peninsular Malaysia. Borneo. Upper reaches of mangrove (Mabberley, 2007: 18), peat swamp forest (often emergent), kerangas, and less frequently in primary lowland and hill forest, secondary forest and along roadsides; on granitic sand; 2-300 m.

Eight species of Aglaia sensu lato are recorded from seashore habitats other than mangrove, including beach forest (such as the Barringtonia formation), on sand, dunes, and rocks. All eight species are also recorded in secondary or disturbed forest, and four are on limestone or coral.

Eighteen species of Aglaia sensu lato are recorded in freshwater swamp forest 
of which 16 of these are also in primary (non-swampy) forest, 11 are also in secondary forest, and eight are also on limestone. Four species of Aglaia sensu lato are recorded in peat swamp forest. All of these sometimes occur in primary dryland forest, three are also in kerangas, three are also in secondary forest, and two are recorded on limestone.

Nine species in Aglaia sensu lato are recorded in forest that is periodically (but not tidally) flooded with freshwater. All nine occur at sea level (two are recorded down to $5 \mathrm{~m}$ elevation only), and from there extend to higher elevations, varying from 450 $2570 \mathrm{~m}$. Eight of the nine species also occur in secondary forest, and six of the nine are also recorded on limestone or coral. In addition 25 Aglaia species are recorded from riverine forest, including three specialist rheophytes. Eight of the species are also recorded in periodically inundated forest.

Fourteen species of Aglaia sensu lato are recorded from kerangas (heath forest) or semi-kerangas. Six of these are also in freshwater swamp forest (including peat swamp) and three are also in riverine forest.

Forty-four out of 127 (35\%) species of Aglaia sensu lato are recorded on limestone or coral, of which 20 of the limestone species are also found in secondary forest, five near mangrove or from other seashore habitat, five from swamp forest or periodically inundated forest, and two (A. grandis Korth. and A. elaeagnoidea) are also on ultramafics. Three of the species are found above $1500 \mathrm{~m}$; for example, Aglaia eximia Miq. ranges from sea level to $2000 \mathrm{~m}$, sometimes on limestone, consistent with uplift of a maritime ancestral population.

Of the 105 species of Aglaia sensu stricto accepted in the revision by Pannell (1992), 51 are recorded in secondary forest (Pannell, 1992; Mabberley et al., 1995). [Records from secondary forest are not given in Pannell (2007), so the status of nine of the ten new species there is not clear, but Aglaia stellatopilosa is recorded from secondary forest in Pannell (2004)]. None of the ten species of Lansium or Reinwardtiodendron are cited from secondary forest. Thus at least 52 species of 127 total in Aglaia sensu lato, or 41\%, are present in secondary forest.

The close ties of Aglaia with secondary vegetation, limestone, peat swamp forest and mangrove are explained here as relictual features. In this model, the ecology has been inherited from Mesozoic weeds that were associated with mangrove and coral reefs. These ancestral forms would have expanded their range inland with marine transgressions and survived uplift to different degrees in different areas.

Notes. Pannell (1992) accepted 105 species in Aglaia sensu stricto. Pannell (2004, 2007) reinstated six species from Borneo that were earlier treated as straight synonyms (Pannell, 1992) (Aglaia glabriflora, A. meliosmoides Craib, A. neotenica Kosterm., A. sterculioides Kosterm., A. lancifolia, and A. beccarii C.DC.), and also accepted three new species from Borneo: Aglaia bullata Pannell, A. sessilifolia Pannell and $A$. stellatopilosa Pannell. Other new species described after Pannell's (1992) revision are A. mackiana Pannell, A. soepadmoi Pannell, and A. pannelliana W.N.Takeuchi.

None of the three sections previously recognised in Aglaia (Sectt. Aglaia,Amoora and Neoaglaia) were recovered as monophyletic in molecular studies (Grudinski et al., 2014b). In addition, several widespread, variable species (e.g. Aglaia elaeagnoidea: India to Samoa; A. lawii: India to Solomon Islands; A. tomentosa Teijsm. \& Binn.: 
India to New Guinea) were not recovered as monophyletic. Despite the impressive revision by Pannell (1992), there is still much work needed on the systematics of Aglaia, at all levels.

The most diverse region for Aglaia is Borneo; there are 60 species there and often as many as 12 at a single forest site (Pannell, 2005). However, endemism in Borneo is less impressive. Instead, a maximum proportion of endemic species is found in Fiji, where $80 \%(8 / 10)$ of the species are endemic. Figures for other areas are: New Guinea 39\% (13/33), India 30\% (3/10), Australia 25\% (3/12), Borneo 20\% (12/60) and the Philippines $9 \%(3 / 35)$. It is notable that New Caledonia has only one, non-endemic species of Aglaia, namely, the widespread, eastern component of A. elaeagnoidea (the species itself appears to be polyphyletic).

Muellner et al. (2008a) studied ITS sequences in Aglaia (incl. Lansium and Reinwardtiodendron) and its small sister clade, Aphanamixis (incl. Sphaerosacme). Fossil-calibrated dates were treated as maximum ages for clades. The authors wrote: "The root node of our data set (i.e. the most recent common ancestor of Melioideae and Swietenioideae [= Cedreloideae]) was constrained to maximally $137 \mathrm{Ma}$, based on the onset of angiosperm radiation". However, this proposed date for the onset of angiosperm radiation is fossil-based and, logically, a minimum age. There are many reasons to think that the actual onset of angiosperm diversification was much earlier (Heads, 2014). The fossil-calibrated study by Li et al. (2019) found a Triassic age (about $209 \mathrm{Ma}$ ) for crown-group angiosperms, and this is probably a more realistic minimum age.

Muellner et al. (2008a) found that "The crown group of the tribe Aglaieae [Aglaia + Aphanamixis $]$ dates back at least to the Late Eocene", and this treatment of the fossil-calibrated date as a minimum age is justified. However, in their discussion they treated the date as a maximum age: "...the group is not old enough for major tectonic events to have influenced current distribution by vicariance. On the contrary, our data clearly indicate that long-distance dispersal has played a major role in the distribution and divergence of taxa within the Aglaieae... Divergence of living taxa from their closest living relatives took place during both the Miocene and the Pliocene, and peaked in the Pliocene. The present-day distribution of many species in the tribe must therefore have arisen as a result of dispersal rather than vicariance events" (italics added). Muellner et al. (2008a) concluded that "Our fossil calibrations would have to be at least 40-50 Myr older to make divergence events consistent with continental break-up scenarios...". The 40-50 Myr gap may be a more or less accurate estimate of the gap between the age of fossilisation of the clade used for calibration and its age of origin.

In another fossil-calibrated study, Grudinski et al (2014a) wrote that the crown group of Aglaia "dates back to the Oligocene/Miocene boundary...". But again, this is a minimum age. The authors used S-DIVA and DEC algorithms and located a centre of origin (in Sunda). Following its origin, the group started to disperse eastwards: "The directionality of dispersal events to or across Wallacea was predominantly eastwards... However, several reversal dispersal events occurred as well... there were long-distance dispersal events from the western Pacific islands back to Sundaland or the Philippines, which might have been facilitated by birds". 
Grudinski et al. (2014a) wrote that: "Only a few biogeographical studies employing phylogenetic methods are available for [Malesian] plants, most of them revealing a predominant west to east dispersal with diversification after the late Miocene...". However, this revelation is simply an artefact of the algorithms used these will guarantee a centre of origin at the location of a basal paraphyletic grade, even if this is not a centre of origin (Fig. 1). Grudinski et al. continued: "With at least 46 dispersal events across Wallace's and/or Lydekker's Line, our results clearly indicate that in the case of Aglaia, Wallacea acted as a transition zone..." (italics added). However, an alternative model explains the facts more simply, including several that are difficult to account for using chance, overseas dispersal. As stressed already, the pair Aglaia + Aphanamixis and its sister group, Cabralea sensu lato, display a high level of allopatry (Fig. 40B). The former pair ranges from India south to New Caledonia, Vanuatu and Fiji, while Cabralea sensu lato extends from New Zealand north to the same localities, which form a narrow belt of overlap. This is consistent with the origin of the two clades by vicariance, with local overlap subsequently developing around the break zone. This would account for the strange fact that Aglaia is represented in New Caledonia only by a single, widespread species. Cabralea sensu lato has at least one endemic there (Dysoxylum rufescens). Of the nine Dysoxylum species on New Caledonia, the only other species sequenced was D. bijugum, also on Norfolk Island, Vanuatu, and Fiji, and also in the Cabralea sensu lato clade.

In molecular studies of Aglaia (Grudinski et al., 2014b), the three main clades in the genus are: 1. Aglaia pannelliana of New Guinea; 2. Aglaia 'Clade 10', comprising 5 species of India, Sulawesi, and Moluccas; 3. All other Aglaia species. The three main clades form an unresolved tritomy. Aglaia pannelliana is easily distinguished by its large fruits and flowers, and has a special phylogenetic significance. It is known only from forest on limestone karst in the Strickland basin, in wet forest at $240 \mathrm{~m}$ (Fig. 41; Takeuchi, 2009a). The site is in a hydrocarbon production area, and hydrocarbon reserves often coincide with areas of high biodiversity as in this case. The eastern foothills of the Andes in Peru and Ecuador are another good example. In these areas both the hydrocarbons and the biodiversity can be explained by the peculiar tectonic history and distinctive styles of faulting (e.g. 'flower structures') (Heads, 2012).

The same area inhabited by Aglaia pannelliana (the square in Fig. 41) hosts several other local endemics, including Harpullia mabberleyana W.N.Takeuchi (Sapindaceae), Fittingia paniculata W.N.Takeuchi (Myrsinaceae), F. headsiana W.N.Takeuchi, Hypserpa calcicola W.N.Takeuchi (Menispermaceae), Kairoa endressiana W.N.Takeuchi \& S.S.Renner (Monimiaceae) and Dysoxylum middletonianum W.N.Takeuchi (Takeuchi, 2007, 2008, 2009a, 2009b, 2010, 2011). The last species, from $1430 \mathrm{~m}$ in moss forest, is the smallest Dysoxylum in eastern Malesia and is one of only two species with whip infructescences.

The species cited here all lie in the Papuan fold belt (Fig. 41), on the margin of the Australian craton that has been caught up in the New Guinea orogeny. The evolution of the species can be attributed to the dynamic tectonism of the region, rather than the stratigraphy. The species could predate the limestone, and would have colonised the strata as soon as these emerged from the sea, from other strata in the region. 


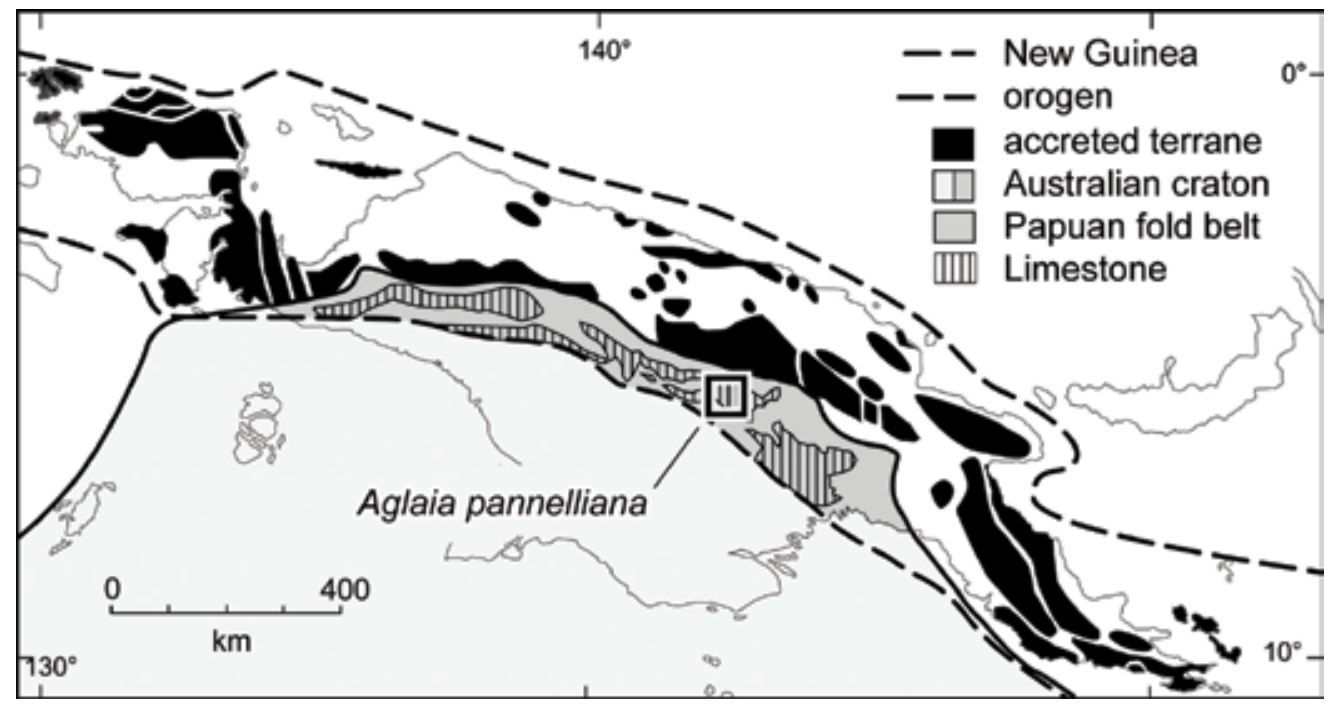

Fig. 41. Tectonic structure of New Guinea (Davies, 2012), with the location of Aglaia pannelliana W.N.Takeuchi and other endemics on the limestone of the Papuan fold belt.

In New Guinea, Aglaia species have their main diversity on the part of the island formed from accreted, allochthonous terranes, north of the part formed on the Australian craton (Fig. 42; Heads, 2001). In contrast, Aglaia pannelliana is located in southern New Guinea, on the deformed margin of the Australian craton. The boundary between the craton and the accreted terranes has been proposed as a major phylogenetic break in New Guinea (Heads, 2001, 2014).

Aglaia elaeagnoidea is distributed widely from India and Sri Lanka to Australia, New Caledonia, Vanuatu, and Samoa. Populations from Sulawesi to New Caledonia have been sampled and form a clade (Grudinski et al., 2014b). However, the species is not recorded in most of mainland New Guinea (apart from records near Port Moresby and Lae), the Bismarck Archipelago, the Solomon Islands and Fiji. This conspicuous gap in the range of the species corresponds with an area of endemism in other groups, including many species on mainland New Guinea, and Aglaia parksii A.C.Sm. of the Solomon Islands (including Bougainville) and Fiji.

Similar absences are seen in other groups. For example, Aglaia samoensis A.Gray is present on mainland Papua New Guinea, New Britain, New Ireland, Bougainville, Solomon Islands, Santa Cruz Islands, Vanuatu, Wallis Islands, and Samoa - but not Fiji. While the absence from Fiji seems as strange here as it does in Dysoxylum gaudichaudianum (cited above under Chisocheton), other species of Aglaia are endemic there, and so it is probably a case of simple vicariance.

Another disjunction in the SW Pacific is seen in the clade comprising Aglaia saltatorum A.C.Sm. and allies (Grudinski et al., 2014b). The group is recorded in the Philippines (Aglaia macrocarpa and A. costata Merr.), and, $5000 \mathrm{~km}$ away, in Santa Cruz Islands (between the main Solomon Islands and Vanuatu), Vanuatu, Fiji, Wallis 


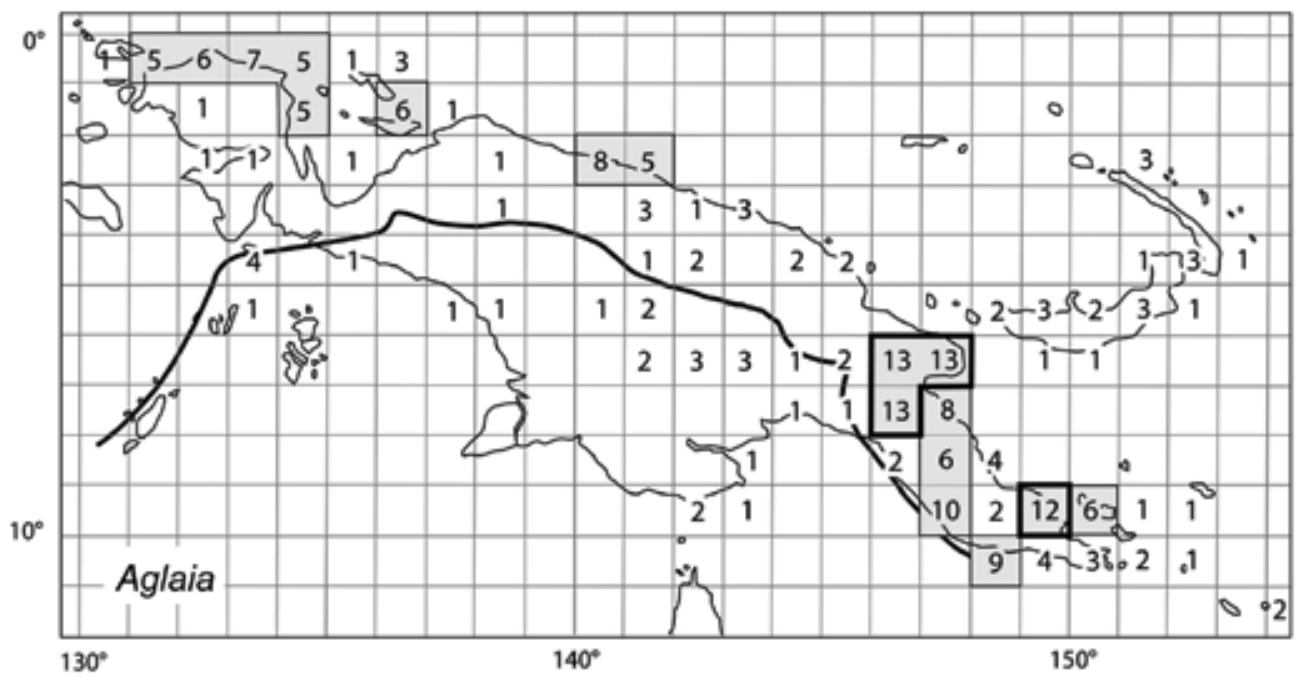

Fig. 42. Species density of Aglaia Lour. in New Guinea, with numbers of species in each $1^{\circ}$ latitude $\times 1^{\circ}$ longitude square (Heads, 2001). Solid line $=$ margin of Australian craton.

Island, and (possibly introduced) Tonga. The great gap between the Philippines and the Santa Cruz islands is filled by a related clade made up of Aglaia parviflora C.DC. and allies in the Moluccas, New Guinea, New Britain, and Solomon Islands. The allopatry is very precise ["A. parviflora is not recorded from the Santa Cruz Islands, while this is the only part of the Solomon Islands where A. saltatorum occurs" (Mabberley et al., 1995)], and this is consistent with an origin of both groups by vicariance.

The next four genera comprise an Australasian group and its sister trans-Atlantic clade, connecting either across the Indian Ocean or Pacific Ocean basins. The whole complex is pantropical.

\section{Synoum A.Juss.}

Distribution. One species on the eastern seaboard of Australia (Cairns to the New South Wales/Victoria border).

Ecology. Trees inhabiting most kinds of rain forests, especially at margins and near the sea; up to $1300 \mathrm{~m}$. 


\section{Anthocarapa Pierre}

Distribution. One or two species in the Philippines (Luzon), Sulawesi, Flores, Sumba, New Guinea, Queensland Solomon Islands, New Caledonia, Vanuatu, and northern Fiji (Rotuma Island; Mabberley, 2013). In NE Australia the species range from Cape York south to Rockingham Bay, and, disjunctly, from SE Queensland to Richmond River, NE New South Wales. Anthocarapa and its sister, Synoum, overlap in eastern Australia around Cairns and Brisbane. The gap in the distribution of Anthocarapa in central Queensland is filled by populations of Synoum.

Ecology. Trees of rain forest, monsoon forest and hill forest; up to $1400 \mathrm{~m}$.

\section{Ruagea H.Karst.}

Distribution. Seven species from Guatemala to Peru, mainly in the Andes. Pennington et al. (1981) recognised five species and cited several doubtful ones, and Palacios (1994) described two new species.

Ecology. Trees and treelets. Lowland tropical rain forest (Peru), montane forest, cloud forest; sea level (rarely, in Amazonian Peru) to $3200 \mathrm{~m}$.

\section{Guarea F.Allam.}

Distribution. A genus of 69 species in tropical America, northwestern Mexico to northern Argentina, including the West Indies (Pennington \& Clarkson, 2013).

Ecology. Nearly all species of Guarea are trees and treelets recorded, at least sometimes, in lowland rain forest below $1000 \mathrm{~m}$ altitude (some exceptions are listed below). Eight species are recorded either in mangrove or other flooded forest. Sixteen species are recorded only in non-flooded, lowland forest, and not on riverbanks. A few are also known in drier areas and at higher altitudes (see below).

Guarea glabra subsp. excelsa of western Mexico to Costa Rica is the only member of the genus recorded from mangrove. It also occurs in tropical deciduous forest (in wet places such as riversides and damp ravines) and in poorly drained savanna.

Eight Guarea taxa occur in periodically flooded forest (Pennington \& Clarkson, 2013, did not record any species from 'swamp forest', but this term is used more in the Old World).

Four species occur in periodically flooded forest and on riverbanks. Of these, Guarea pubescens subsp. pubiflora (A.Juss.) T.D.Penn. has a close relative (G. pubescens (Rich.) A.Juss. subsp. pubescens) in non-flooded forest, while $G$. fissicalyx Harms is closely related to a species of lower montane forest (G. persistens 
W.Palacios). Five species occur in both periodically flooded and non-flooded forest. Three species are not in flooded forest but occur by rivers (on riverbanks or in gallery forest).

In areas with a strongly seasonal climate, as on the Pacific coast of Central America, Guarea species are confined to shady canyons, riversides and other situations with a plentiful supply of ground water. At least eight taxa inhabit drier areas. First, Pennington \& Clarkson (2013) wrote: "In the West Indies a few, such as G. jamaicensis and G. sphenophylla, are found in seasonally dry forest". The other six taxa are in damp ravines and along water courses in drier deciduous and semi-deciduous forest, brejo forest, and cerrado.

Three species are recorded on limestone: Guarea mexicana of Chiapas, Mexico, G. jamaicensis of Jamaica, and G. sphenophylla of Hispaniola (the last two are found in seasonally dry forest).

Guarea cristata T.D.Penn. of western Amazonia is mostly recorded in lowland rain forest on infertile white sand. This is an analogue of the kerangas forest of Malesia. (For notes on the biogeography and evolution of Amazonian flora and fauna on white sand, see Heads, 2012: 194).

Only two species are recorded from secondary vegetation: 1. Guarea silvatica: "Mostly a component of primary lowland rain forest on non-flooded land. Its ability to sucker from cut trunks enables it to persist in secondary regrowth" (Pennington \& Clarkson, 2013); 2. Guarea chiricana: primary and old secondary rain forest, lowland to $1500 \mathrm{~m}$.

Six Guarea species reach $2000 \mathrm{~m}$ altitude. Five of these occur in Central America, and only one is restricted to South America. The upper limit of the genus is represented by Guarea bijuga (Mexico to Ecuador), which ranges from sea level to $2700 \mathrm{~m}$. Guarea luxii (Mexico to E1 Salvador), at (900-)1800-2600 m, is very similar to G. glabra subsp. excelsa of deciduous forest at low elevations.

Notes. The African species that were formerly placed in Guarea have been transferred to Leplaea, Neoguarea (Harms) E.J.M.Koenen \& J.J. de Wilde and Heckeldora Pierre (Koenen \& de Wilde, 2012; Koenen et al., 2015). Most species of Guarea occur in Amazonia, but a substantial number are in Central America, the West Indies and coastal Brazil.

With respect to the overall phylogeny, Pennington \& Clarkson (2013) proposed three main clades: 1. Guarea silvatica C.DC. of the Amazon basin $+G$. anomala T.D. Penn. of SE Brazil; 2. The G. glabra Vahl complex (15 species and subspecies), found mainly in Mexico, Central America and Chocó, with two widespread subspecies extending to the Amazon. This is sister to Clade 1; 3. A large group (57 species), found mainly in South America.

Both species in Clade 1 (Fig. 43) inhabit lowland rain forest. Pennington \& Clarkson (2013) described the two as "ancestral South American species", but clade 1 and 2 are sister to the main South American clade, not ancestral to it. Clades 1 and 2 themselves are largely allopatric (apart from the widespread G. glabra subsp. glabra and G. glabra subsp. microcarpa (C.DC.) T.D.Penn. in Clade 2), consistent with their origin by vicariance. 


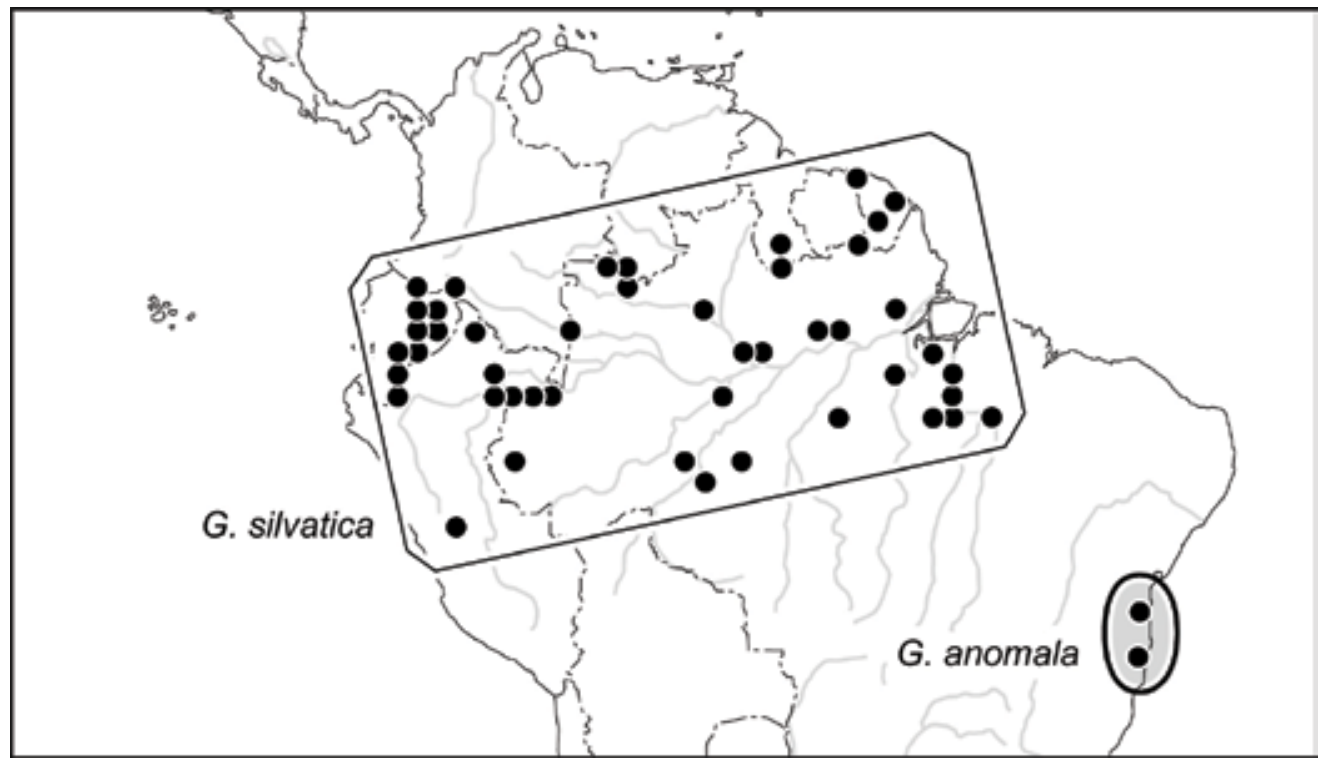

Fig. 43. Distribution of Guarea F.Allam. 'clade 1': Guarea silvatica C.DC. and its sister Guarea anomala T.D.Penn.

The 15 putative members of Clade 2 are mapped in Fig. 44. They comprise six subspecies of Guarea glabra, six other sequenced species, and three species that have not been sequenced, but which are linked with the group morphologically ( $G$. donnell-smithii C.DC., G. constricta Al.Rodr. and G. subsessilifolia Al.Rodr.). The two sequenced subspecies of Guarea glabra did not form a group in the molecular phylogeny, suggesting that the the species is polyphyletic. The Guarea glabra complex as a whole is widespread from Mexico to Brazil, but the taxa show a strong concentration in Mesoamerica (Fig. 44). Only Guarea glabra subsp. glabra (Fig. 44A), the most widespread taxon in Guarea, occurs in Brazil. Guarea glabra susbsp. microcarpa (Fig. 44M) occurs south to Peru. The remaining 13 members are all located west of the Romeral fault system, the boundary in western Colombia between the accreted terranes in the west and continental terrane in the east (Fig. 17). In Cretaceous time, this boundary was the north-western coast of South America. In the Guarea glabra complex, twelve of the 15 taxa, or $80 \%$, occur in Costa Rica/Panama. Of these species, three (Guarea subsessilifolia, G. tonduzii C.DC., G. constricta) are endemic there, and one (G. chiricana) is almost endemic. As discussed already (under Swietenia and Trichilia), the 'landbridge' theory for the biogeography of Costa Rica-Panama might explain diversity there (as the result of overlap), but it does not account for endemism, absence or disjunction.

Pennington \& Clarkson (2013: 202) wrote that within the Guarea glabra complex "There is little genetic or morphological variation between the component species, and their placement at the end of a long branch suggests an ancestral dispersal into Central America and a recent species radiation" (italics added). Nevertheless, the 


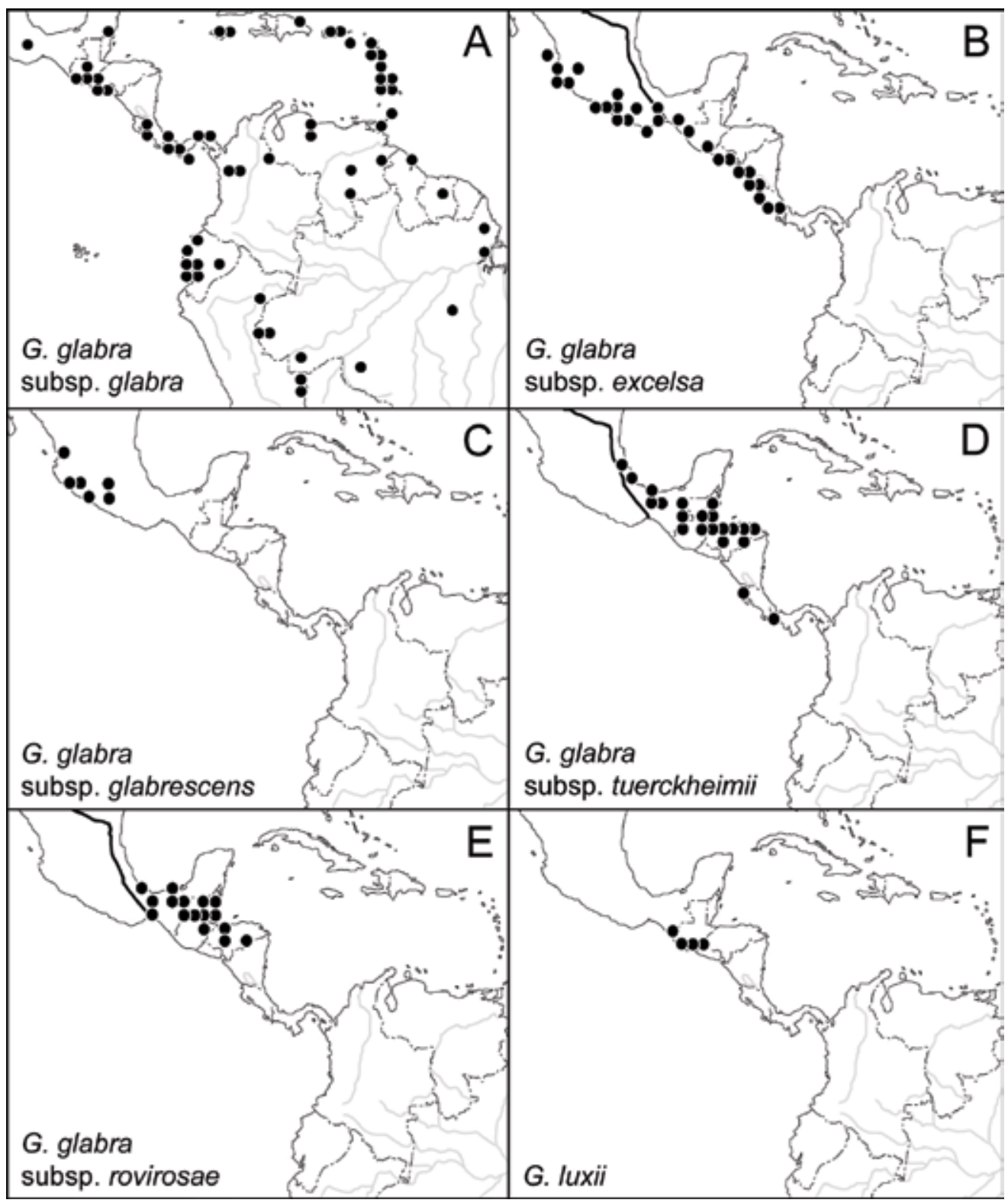

Fig. 44. Distribution of the Guarea glabra complex. Solid line in B, D and E = boundary between accreted terranes in the west and craton in the east. A. Guarea glabra Vahl subsp. glabra. B. Guarea glabra subsp. excelsa (Kunth) T.D.Penn. C. Guarea glabra subsp. glabrescens (Hook. \& Arn.) T.D.Penn. D. Guarea glabra subsp. tuerckheimii (Donn.Sm.) T.D.Penn. E. Guarea glabra subsp. rovirosae (C.DC.) T.D.Penn. F. Guarea luxii C.DC. 


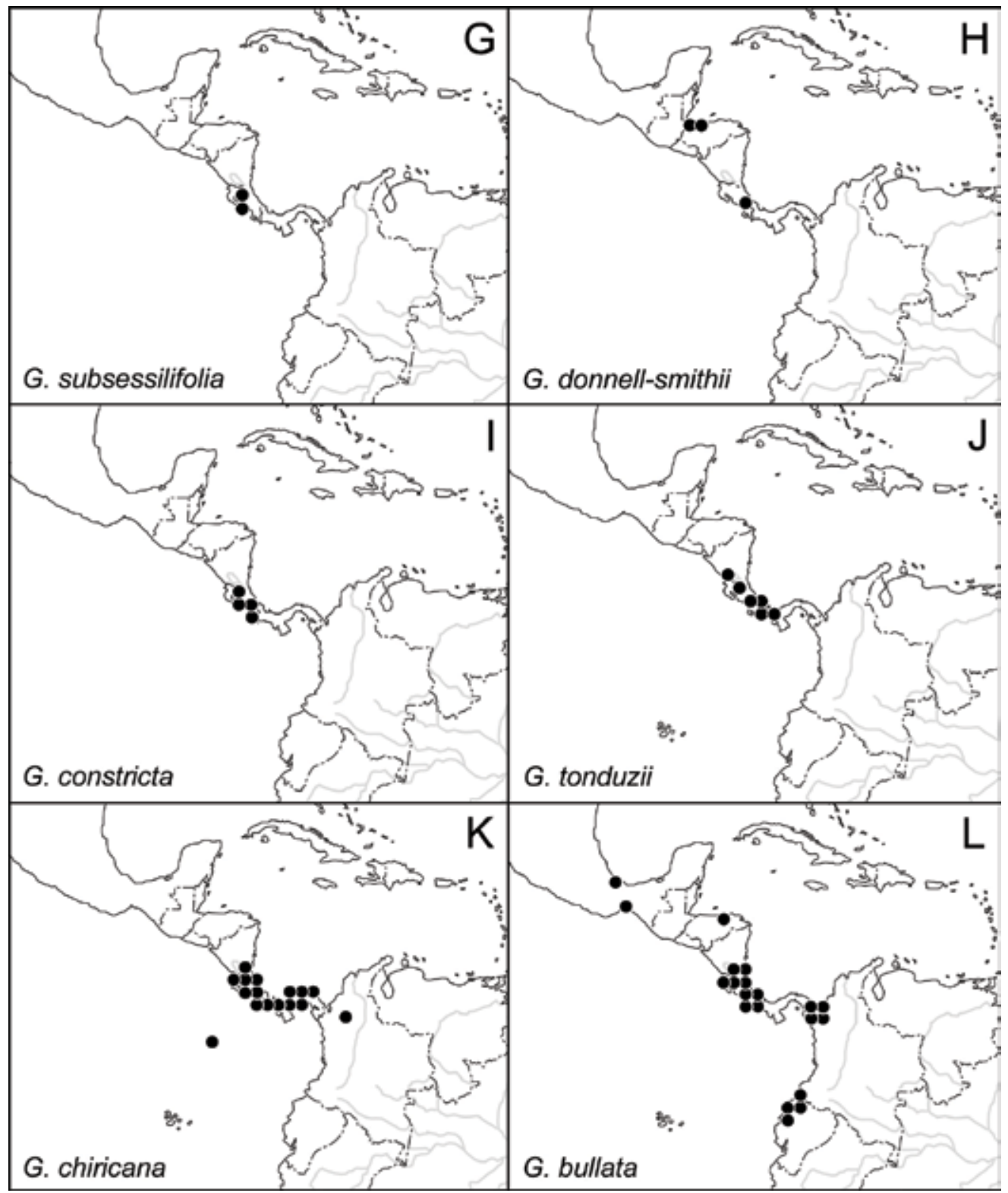

Fig. 44. (Continuation). Distribution of the Guarea glabra complex. G. Guarea subsessilifolia Al.Rodr. H. Guarea donnell-smithii C.DC. I. Guarea constricta Al.Rodr. J. Guarea tonduzii C.DC. K. Guarea chiricana Standl. L. Guarea bullata Radlk. 


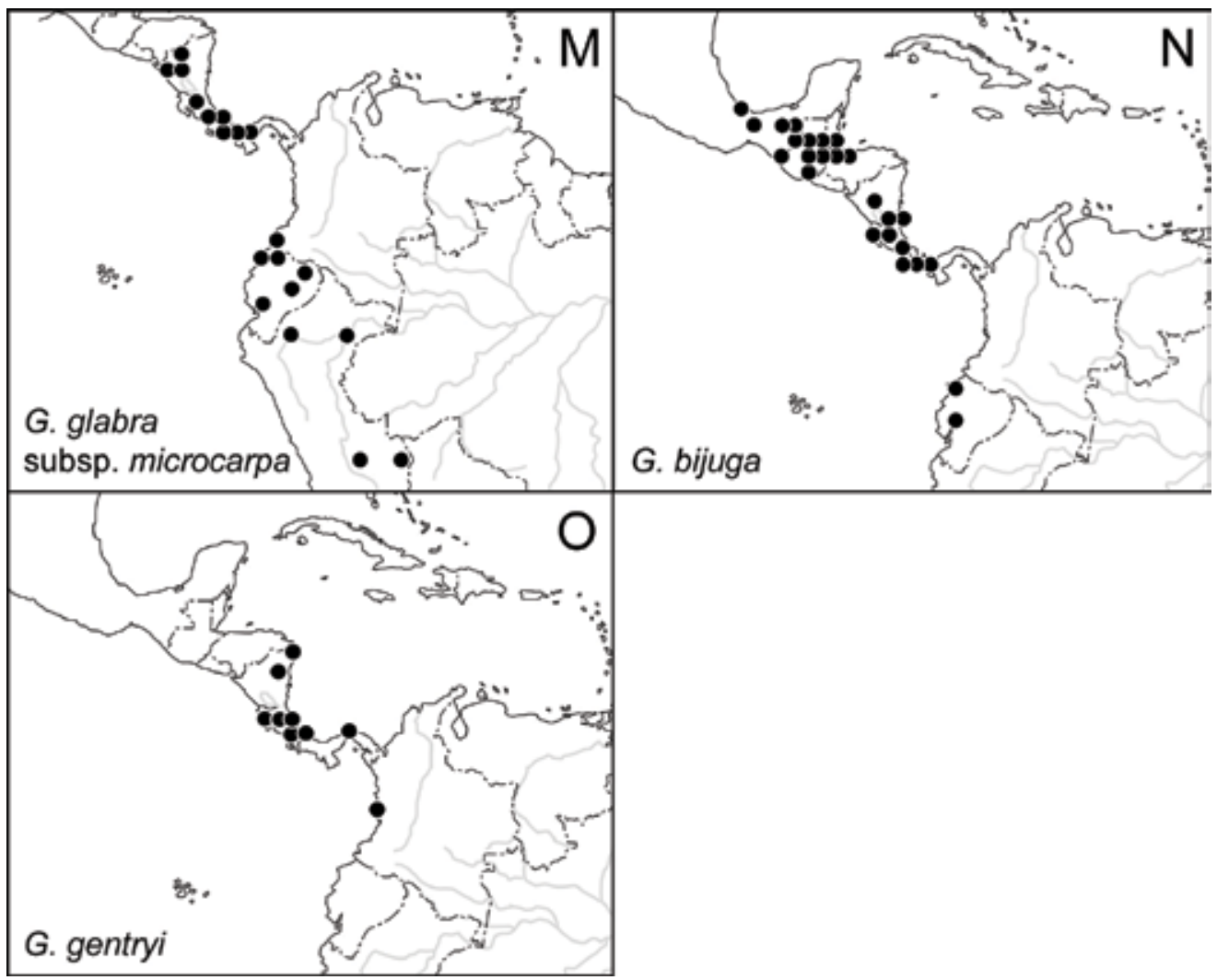

Fig. 44. (Continuation). Distribution of the Guarea glabra complex. M. Guarea glabra subsp. microcarpa (C.DC.) T.D.Penn. N. Guarea bijuga C.DC. O. Guarea gentryi Coronado.

long branch is equally consistent with vicariance. The high level of allopatry between the Guarea glabra complex, mainly in Central America-Chocó, west of the Romeral fault system, and its sister group (G. anomala + G. silvatica, Fig. 43), east of the fault system, also suggests that both groups originated by vicariance, with some subsequent overlap. Most of the overlap involves a single, widespread form of the Guarea glabra complex, C. glabra subsp. glabra, which has probably undergone secondary range expansion. In Mexico two members of the Guarea glabra complex are restricted to the western, accreted terranes (G. glabra subsp. excelsa (Kunth) T.D.Penn., Fig. 44B; and G. glabra subsp. glabrescens (Hook. \& Arn.) T.D.Penn., Fig. 44C) (cf. Swietenia humilis, Fig. 15, and Trichilia americana, Fig. 30A), while three others are restricted to the eastern, cratonic side (G. glabra subsp. tuerckheimii (Donn.Sm.) T.D.Penn., Fig. 44D; G. glabra subsp. rovirosae (C.DC.) T.D.Penn., Fig. 44E; and G. bijuga C.DC., Fig. 44N).

Guarea subsessilifolia (Fig. 44G), G. constricta (Fig. 44I) and G. tonduzii C.DC. (Fig.44J) are restricted to the Costa Rica-Panama sector. Guarea tonduzii forms a clade with Guarea chiricana Standl. (Fig. 44K) and G. bullata Radlk. (Fig. $44 \mathrm{~L})$. The last species is widespread from Mexico to Ecuador, but is disjunct between 
northwestern and southwestern Colombia, across much of Chocó. Similar disjunctions occur in Guarea glabra subsp. microcarpa (Fig. 44M), G. bijuga (Fig. 44N) and, possibly, G. gentryi Coronado (Fig. 44O).

The Guarea glabra complex has a wide ecological range, from mangrove forest (G. glabra subsp. excelsa; Fig. 44B) high into the montane zone. Guarea luxii C.DC. (Fig. 44F) is in high altitude, evergreen cloud forest, at 1800-2600 m., but is very similar to G. glabra subsp. excelsa of tropical deciduous forest at low elevations. Guarea bijuga (Fig. 44N) inhabits wet lowland rain forest, wet montane forest and cloud forest, from sea level to $2700 \mathrm{~m}$. These wide ranges are consistent with rapid, passive uplift of populations during orogeny.

Clade 3, the 'South American' clade of Guarea, consists of 57 species and is predominantly Amazonian, but there are important exceptions. The first is a clade of three species endemic to coastal SE Brazil, between Rio de Janeiro and Bahia: Guarea blanchetii C.DC., G. gracilis T.D.Penn. and G. pendula R.S.Ramalho et al. (Fig. 45). The same centre of endemism was illustrated above in Guarea anomala (Fig. 43) and Trichilia species (Fig. 32).

Another group of non-Amazonian Guarea species in the 'South American clade' is a clade of three species confined to Costa Rica: G. zarceroensis Coronado, $G$. macrocalyx Al.Rodr. and G. tafae-malekui Al.Rodr. (Fig. 46A, B, C) (Guarea tafaemalekui has 3-4 ovules in each ovary locule; this is unique in the subfamily Melioideae but occurs in Cedreloideae).

Pennington \& Clarkson (2013) wrote that the Costa Rican clade "appears to be recently descended from the South American group (according to the short branch lengths) and its ancestors must have dispersed to Central America and then speciated into the three extant species". However, the sister group (Bayesian analysis) of the Costa Rican clade is Guarea subandina W.Palacios of Ecuador and Peru, in wet montane and cloud forest between 2000 and $2400 \mathrm{~m}$ altitude (Fig. 44D). This gives a disjunction from Costa Rica to Ecuador, across Panama and Chocó, repeating the pattern seen in Trichilia pittieri (Fig. 31C). The repetition suggests the disjunction is not the result of individual events of chance dispersal, but has a common cause. This could, in theory, be ecological, but there is no obvious environmental factor. The other explanation is that it reflects tectonic history, and the accretion of oceanic terranes (including island arcs) west of the Romeral fault system could explain the pattern.

Other members of the 'South American clade' that are present in Costa RicaPanama include as many as seven species that are endemic there (Fig. 47). Guarea talamancana Gómez-Laur. \& M.Valerio (Fig. 47A) and G. grossa T.D.Penn. (Fig. 47B) are in Costa Rica on the Caribbean slopes; G. inesiana Al.Rodr. (Fig. 47C), G. aguilarii Al.Rodr. (Fig. 47D) and G. corticosa Al.Rodr. (Fig. 47E) are in Costa Rica on Pacific slopes, and G. hoffmanniana C.DC. (Fig. 47F) and G. rhopalocarpa Radlk. (Fig. 47G) are in Costa Rica and Panama.

Two species in the 'South American clade' are confined to southern Central America and Chocó: Guarea pyriformis T.D.Penn. (Fig. 48A) and G. caulobotrys Cuatrec. (Fig. 48B). Rather than being simply nested in, say, Colombian groups, as dispersal theory might suggest, both have diverse, widespread sisters. 


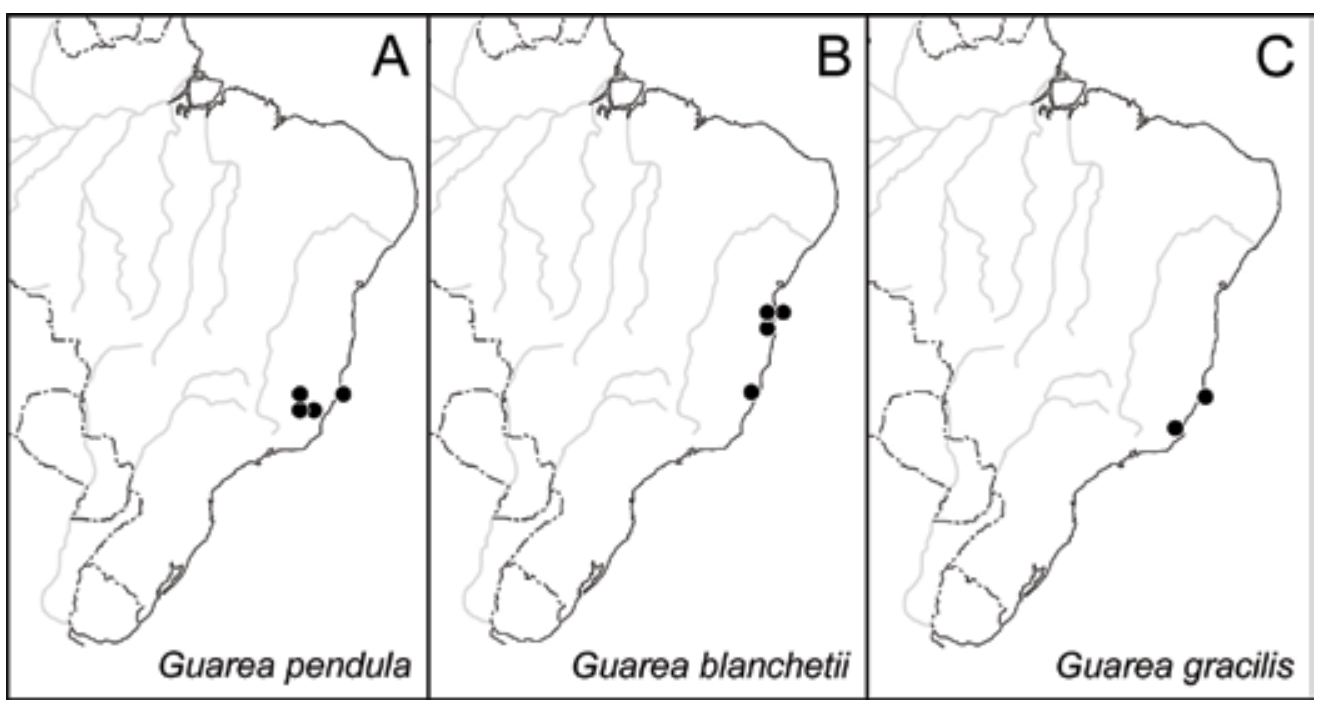

Fig. 45. Distribution of three species of Guarea endemic to SE Brazil. A. Guarea pendula R.S.Ramalho et al. B. Guarea blanchetii C.DC. C. Guarea gracilis T.D.Penn.

Guarea caulobotrys is sister to the rest of the entire South American clade except G. pterorhachis Harms, and G. pyriformis is sister to a widespread clade of five species found from Mexico to SE Brazil.

Four species are endemic to Chocó (Fig. 49): Guarea corrugata Cuatrec., G. reticulatovenosa T.D.Penn., G. polymera Little, and G. cartaguenya. In contrast, two taxa are disjunct between Panama and Ecuador, across Chocó (cf. Trichilia species; Figs. 31 and 32). One is Guarea fistulosa W.Palacios (Fig. 50A), sister to a widespread clade. The other is Guarea pterorhachis subsp. pterorhachis (Figs. 50B), in which the gap is filled by the only other subspecies in the species, subsp. submarginalis T.D.Penn., endemic to Chocó. (Guarea pterorhachis as a whole is sister to the rest of the 'South American' clade). The pattern could, perhaps, be explained by chance 'leapfrog dispersal' from Ecuador to Panama $(\sim 1000 \mathrm{~km})$, or by chance extinction of subsp. pterorhachis in the gap. An alternative, tectonic explanation attributes the pattern to the north-eastward translation of terranes and populations west of the Romeral fault system. Before this process ruptured the populations of subsp. pterorhachis they were adjacent to each other, and subsp. marginalis lay to the south.

Finally, Pennington \& Clarkson (2013) referred to several 'Amazonian' species of Guarea that "now extend into" Panama and Costa Rica (e.g. G. macrophylla Vahl, G. guidonia (L.) Sleumer, and G. grandifolia). However, there is no real reason to consider these as essentially 'Amazonian' species, or that their presence in PanamaCosta Rica is secondary.

Six members of Guarea are present in the West Indies. The first is Guarea glabra subsp. glabra. (Fig. 44A), which is widespread on the mainland, and is also widespread in the Greater Antilles (except Cuba) and Lesser Antilles. In contrast with the other five West Indian forms of Guarea, which are mainly allopatric, this is widespread 


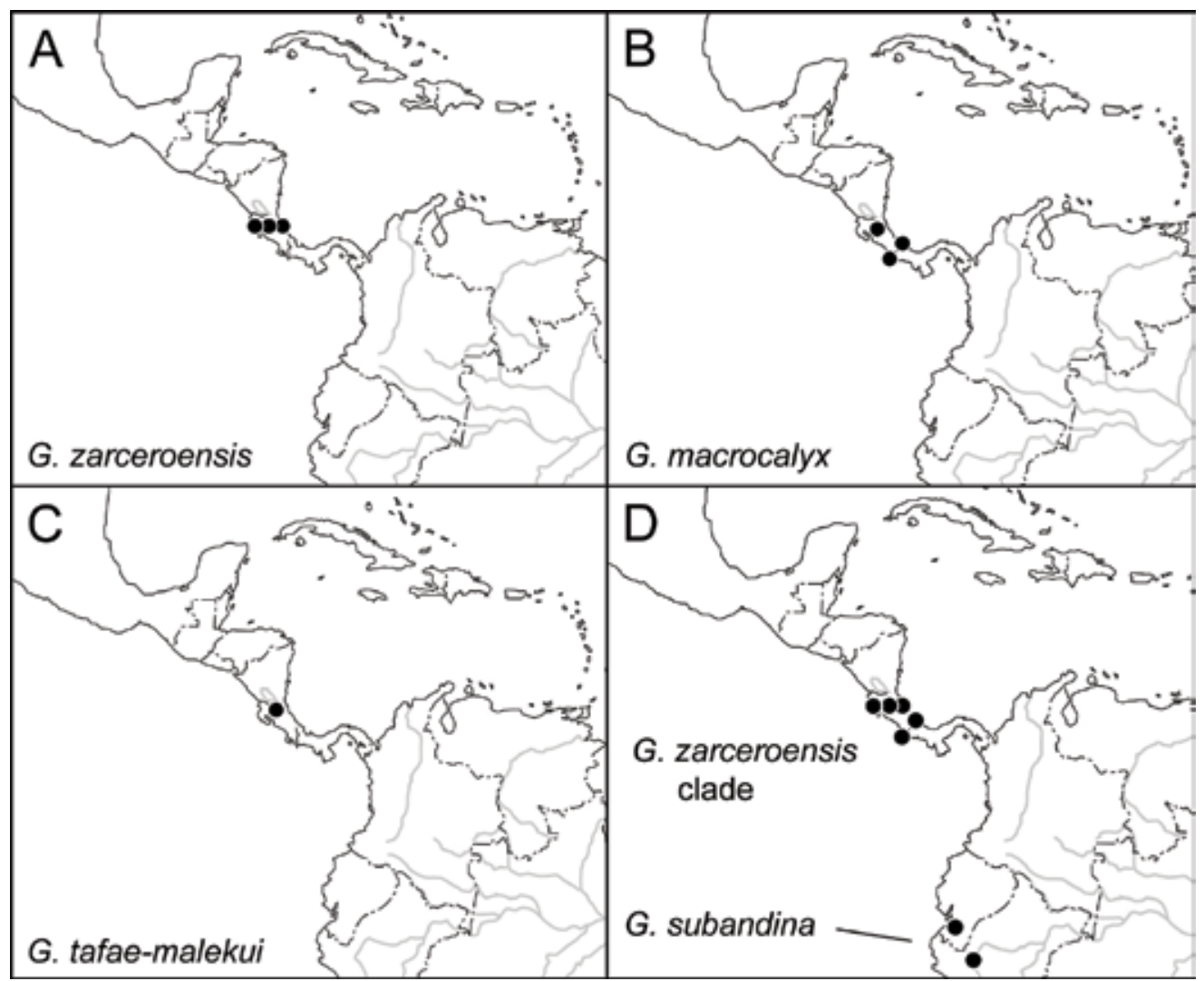

Fig. 46. Distribution of the Guarea zarceroensis group (three species) and its sister, Guarea subandina W.Palacios. A. Guarea zarceroensis Coronado. B. Guarea macrocalyx Al.Rodr. C. Guarea tafae-malekui Al.Rodr. D. The Guarea zarceroensis clade as a whole and Guarea subandina.

in the West Indies and overlaps widely with all the other forms there. This can be explained by range expansion of subsp. glabra. Guarea glabra subsp. glabra is also the only member of the 'glabra complex' that overlaps in Amazonia with the 'South American' clade, again suggesting that it has expanded its range. The five other taxa of Guarea in the West Indies are all allopatric there (except for overlap on Dominica and Martinique); three are also represented on the mainland. This arrangement is consistent with an origin of the distributions by vicariance, followed by overlap on the mainland. The five species are: 1. Guarea kunthiana A.Juss. Widespread on the mainland, also on Dominica and Martinique; 2. Guarea amaicensis Proctor. Endemic to Jamaica (this and the last species form the sister to the the rest of the South American clade); 3. Guarea guidonia. Widespread on the mainland and also in Cuba, Hispaniola (not southwest), and Puerto Rico; 4. Guarea sphenophylla Urb. Endemic to SW Hispaniola; the locality is separated from the rest of Hispaniola and G. guidonia by the Enriquillo fault (movement on this fault caused the 2010 Haiti earthquake); 5. Guarea macrophylla subsp. macrophylla. This has a single record in northern Venezuela (in Yaraquy), and 


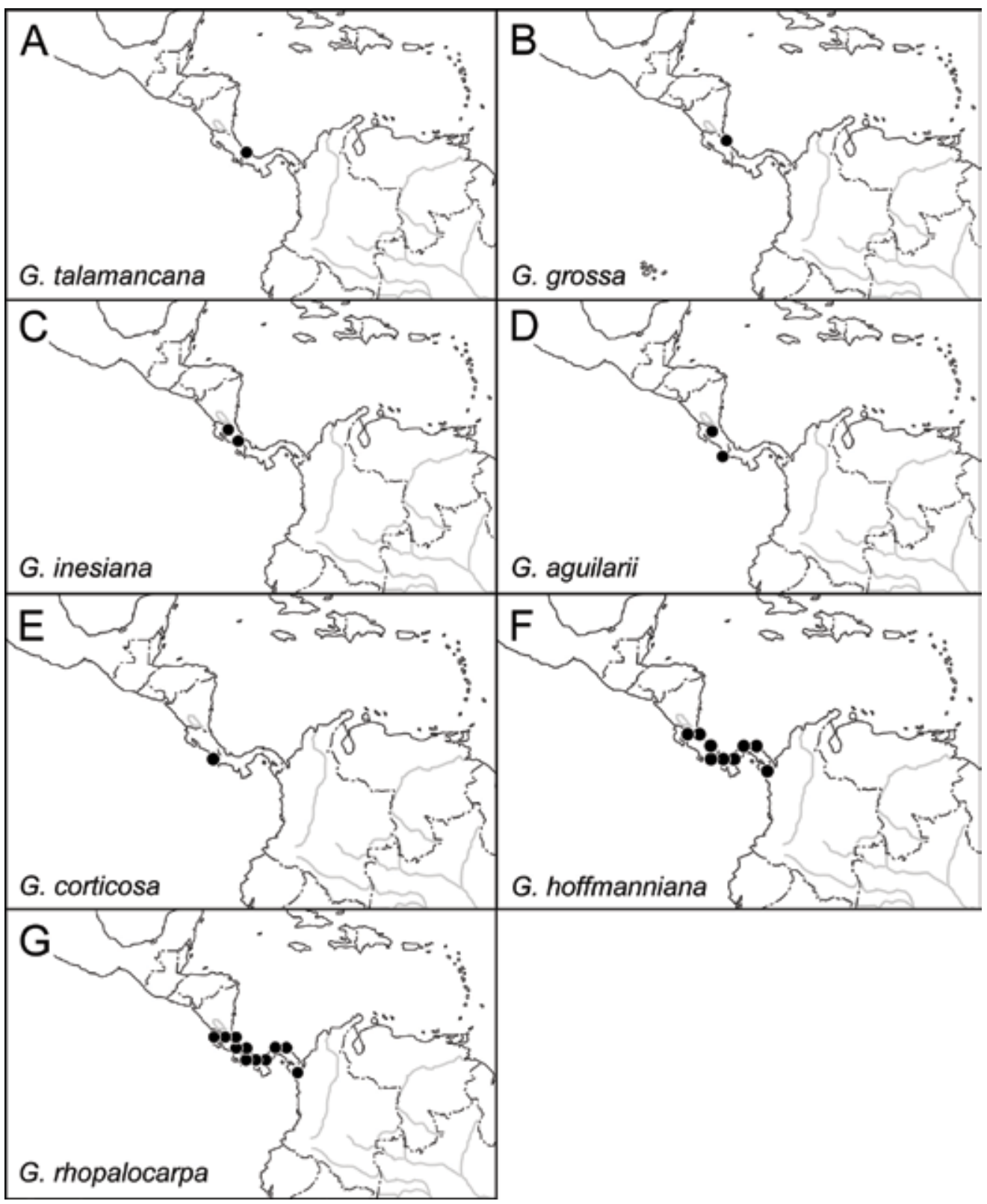

Fig. 47. Distribution of seven Guarea species in the 'South American' clade that are endemic to Costa Rica-Panama. A. Guarea talamancana Gómez-Laur. \& M.Valerio. B. Guarea grossa T.D.Penn. C. Guarea inesiana Al.Rodr. D. Guarea aguilarii Al.Rodr. E. Guarea corticosa Al.Rodr. F. Guarea hoffmanniana C.DC. G. Guarea rhopalocarpa Radlk. 


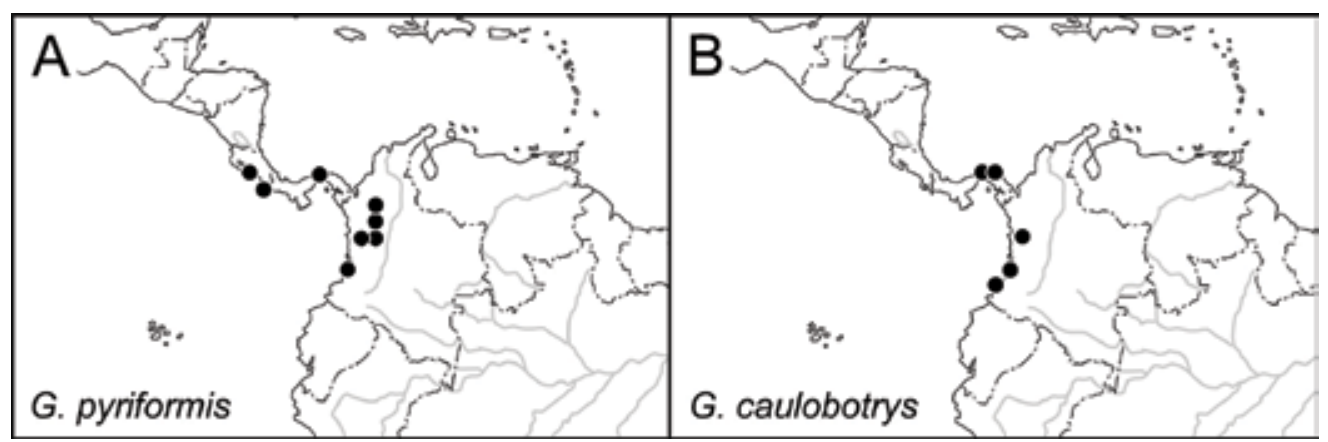

Fig. 48. Distribution of Guarea species endemic to southern Central America and Chocó. A. Guarea pyriformis T.D.Penn. B. Guarea caulobotrys Cuatrec.

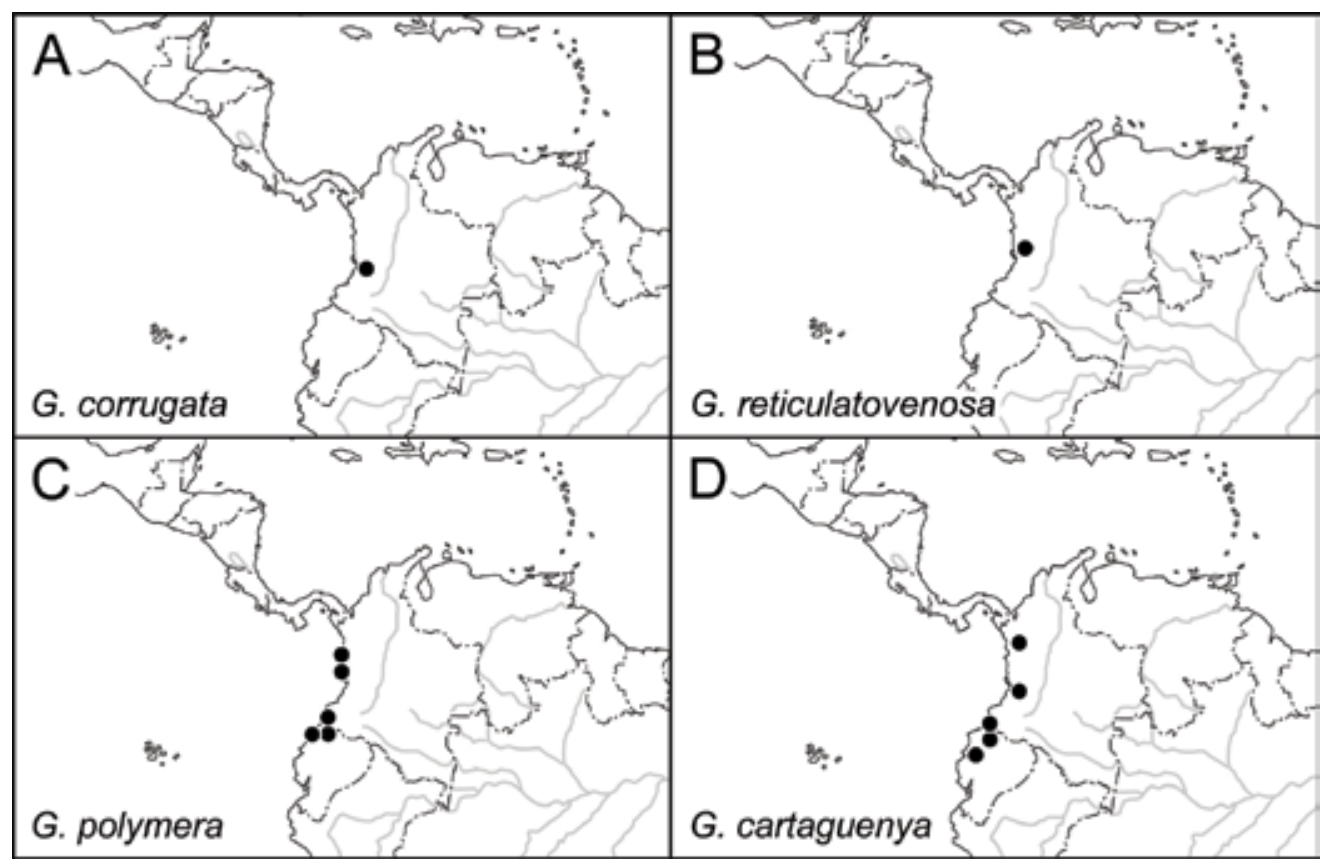

Fig. 49. Distribution of four Guarea species endemic to Chocó, A. Guarea corrugata Cuatrec. B. Guarea reticulatovenosa T.D.Penn. C. Guarea polymera Little. D. Guarea cartaguenya Cuatrec. 


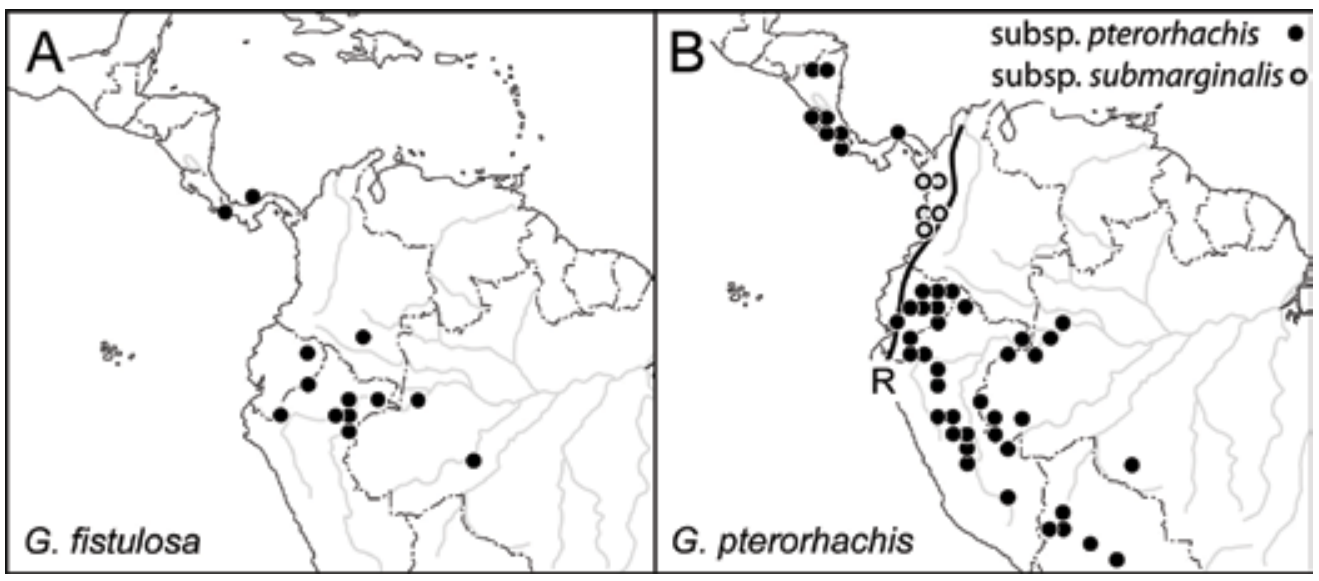

Fig. 50. A. Distribution of Guarea fistulosa W.Palacios. B. Distribution of Guarea pterorhachis Harms.

is also widespread in the Lesser Antilles. The disjunction between Yaracuy and the Lesser Antilles can be explained by strike-slip displacement along the southern margin of the Caribbean (Fig. 17). The species overlaps with Guarea kunthiana on Dominica and Martinique.

The next four genera form a clade (Koenen et al., 2015), although the exact affinities of Neoguarea within the group are not clear.

45. Neoguarea (Harms) E.J.M.Koenen \& J.J. de Wilde

Distribution. One species (Neoguarea glomerulata (Harms) E.J.M.Koenen \& J.J. de Wilde, formerly placed in Guarea) in central Africa (Fig. 51; Koenen \& de Wilde, 2012). The genus ranges from the Benue trough region to the Cuvette Centrale of DRC. Koenen \& de Wilde (2012) observed that it is present on both Bioko and Mount Cameroon, where the related genus Leplaea is notably absent.

Ecology. Treelet or shrub in primary forest and older secondary forest; sea level to $1750 \mathrm{~m}$.

Notes. Different analyses present Neoguarea as sister to Turraeanthus of West and central Africa (Koenen et al., 2015, fig. 1) or to two American genera, Guarea and Ruagea (Koenen \& de Wilde, 2012, figs. S1 \& S2). The latter would not be anomalous, as there is a standard connection between the Gulf of Guinea islands (Neoguarea is on Bioko) and America (Heads, 2015). 


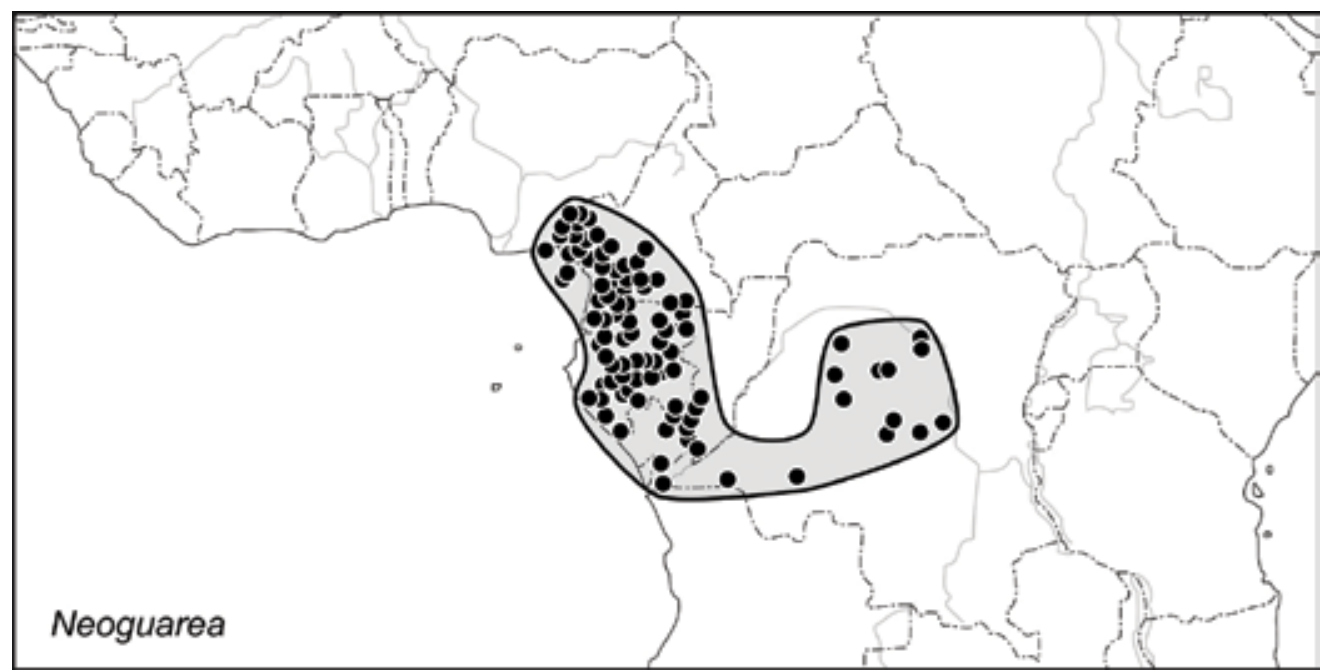

Fig. 51. Distribution of Neoguarea (Harms) E.J.M.Koenen \& J.J. de Wilde.

\section{Turraeanthus Baill.}

Distribution. Three species from West Africa to central Africa (Sierra Leone to Angola and Uganda) (Fig. 52).

Ecology. Trees and treelets in forest. The widespread Turraeanthus africanus (C.DC.) Pellegr. is a tree of evergreen rain forest and deciduous forest, in riparian and poorly drained areas (30-1700 m). It is often gregarious, especially in moist places. The more localised Turraeanthus longipes Baill. (30-700 m) and T. mannii Baill. are both small trees or treelets in forest (African Plant Database, 2019). The last two species are divided at the Cameroon Volcanic Line, with some local overlap in SW Cameroon.

\section{Leplaea Vermoesen}

Distribution. Seven species (Koenen \& de Wilde, 2012) (Fig. 53) (six of the seven species were formerly placed in Guarea) in West and central Africa: Sierra Leone to Uganda. A sterile collection from Tanzania (Morogoro, Uluguru Mountains) is of doubtful identity; Koenen \& de Wilde (2012) treated it under Leplaea cedrata (A.Chev.) E.J.M.Koenen \& J.J. de Wilde. The record needs to be confirmed, but a boundary here, at the Uluguru Mountains, would be standard (see the note under Trichilia). Despite its wide range, Leplaea is absent from Bioko and Mount Cameroon, on the Cameroon Volcanic Line. This area of absence corresponds with a region that, for other groups, is a centre of endemism (see Neoguarea). Leplaea cauliflora E.J.M.Koenen \& J.J. de Wilde and L. mayombensis (Pellegr.) Staner have western limits at the Cameroon Volcanic Line. The major centre of diversity for the genus is in eastern Gabon. 


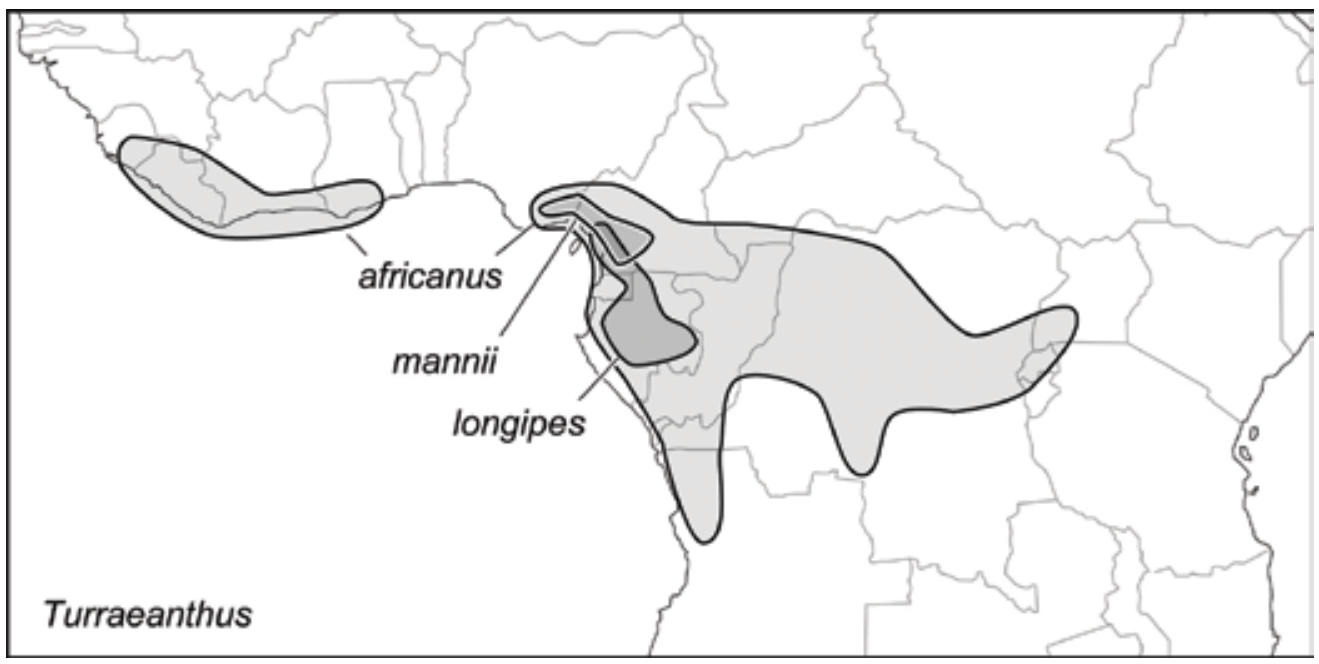

Fig. 52. Distribution of Turraeanthus Baill.

Ecology. Trees, treelets and shrubs. Evergreen rain forest and semi-deciduous forest. Leplaea mangenotiana (Aké Assi \& Lorougnon) E.J.M.Koenen \& J.J. de Wilde is known only from riparian forest. Sea level to $2000 \mathrm{~m}$ (Leplaea mayombensis near the DRC/Uganda border).

\section{Heckeldora Pierre}

Distribution. Seven species in West and central Africa (Fig. 54, based on de Wilde, 2007; Koenen \& de Wilde, 2012). Most diverse in SW Cameroon (4 species) and W Gabon (3 species).

Heckeldora leonensis (Hutch. \& Dalziel) E.J.M.Koenen is sister to the rest of the genus (Koenen et al., 2015), implying a primary break in or around Liberia. There is a large gap in the records between SW Ivory Coast and SE Nigeria, and similar large-scale disjunctions across the Gulf of Guinea occur in many groups. Holmgren et al. (2004: 75-76) mapped 21 woody plant species disjunct between upper and lower Guinea ('continental disjunct' groups), and similar examples from the fauna are discussed elsewhere (Heads, 2015). The disjunction is seen within species and also in many affinities above species level, as in Heckeldora. The gap is usually explained by Pleistocene extirpation in the gap, but it occurs in both high-altitude and low-altitude forms. It is more likely to be related to the disjunction between the Cameroon Volcanic Line and America, and the disjunction in America between the Caribbean part of Venezuela and SE Brazil. It is probably not coincidence that this last disjunction occurs in the only American member of the African clade of Trichilia, $T$. trifolia (Pennington, 2016). 


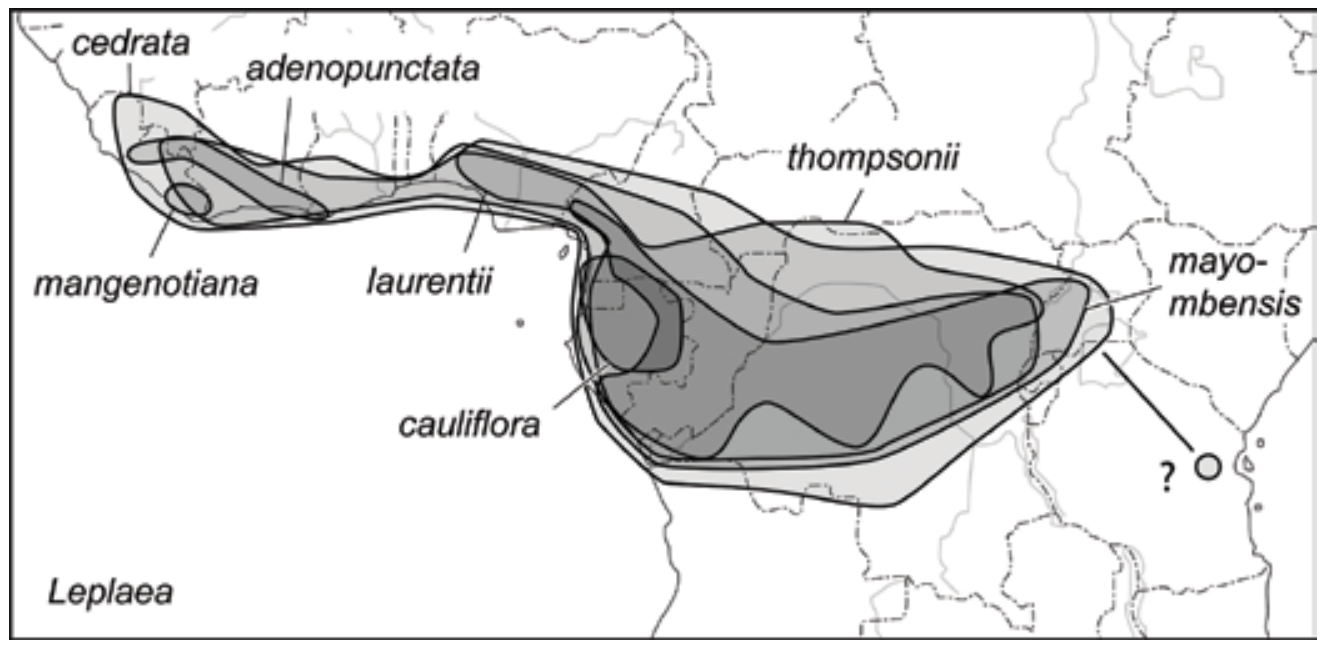

Fig. 53. Distribution of Leplaea Vermoesen.

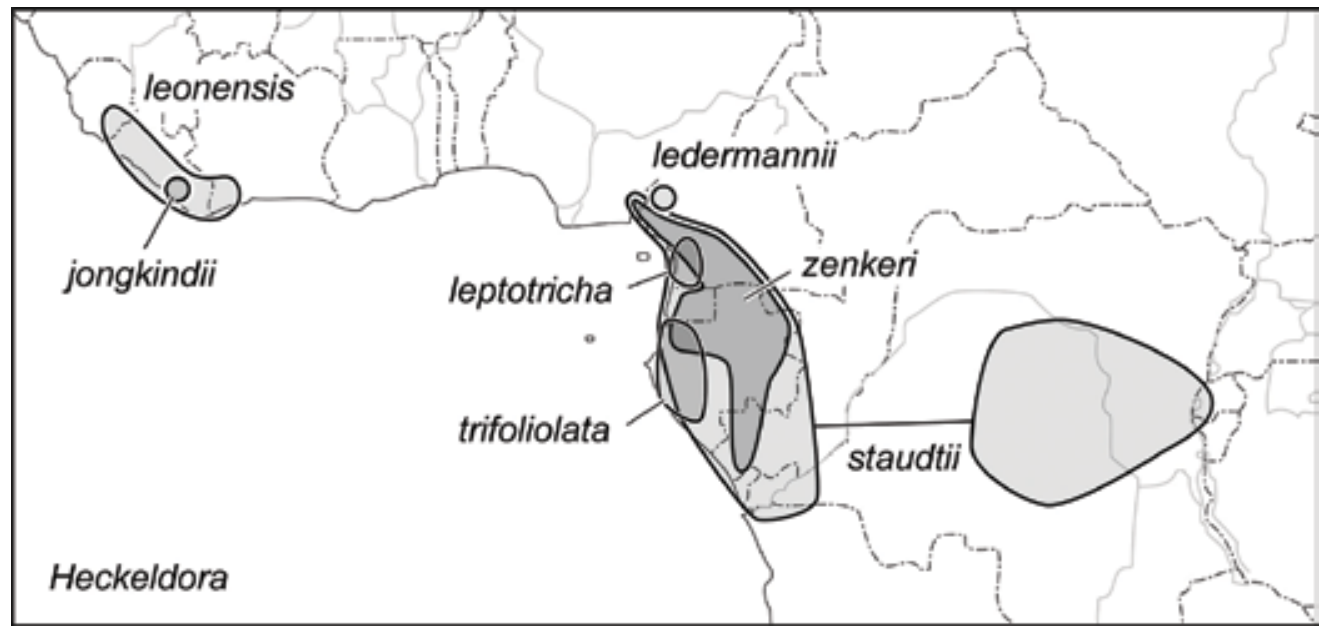

Fig. 54. Distribution of Heckeldora Pierre.

Ecology. Small trees in lowland rain forest, semi-deciduous, riparian, secondary and disturbed forest; on fertile volcanic soil, sand and rocky outcrops; sea level to $1500 \mathrm{~m}$ (Heckeldora ledermannii (Harms) J.J. de Wilde).

\section{Discussion}

Biogeography by revelation

In Entandrophragma, Monthe et al. (2019) wrote that the phylogenetic relationships "reveal multiple rain/dry forest transitions" (italics added). However, this is an 
inference, not an observation, and is based on the questionable assumption that paraphyletic basal grades occupy ecological centres of origin. Likewise, in their study on Aglaia, Grudinski et al. (2014a) wrote, as quoted above, "Only a few biogeographical studies employing phylogenetic methods are available for [Malesian] plants, most of them revealing a predominant west to east dispersal with diversification after the late Miocene..." (italics added). But, again, the studies reached this conclusion only because there were basal, paraphyletic grades in the west, and the claim that biogeographic analyses simply 'reveal' processes that occurred millions of years ago is misleading.

The idea that progress in biogeography is made by 'revelation', rather than the continual proposing and testing of ideas, is becoming popular. Authors are even starting to use the word 'reveal' in the title of their papers (e.g. Yu et al., 2017; Johnson et al., 2017; Lim \& Marshall, 2017; Andersen et al., 2018; Louchart et al., 2018; Kalkman et al., 2018; Appelhans et al., 2018; Price \& Wagner, 2018; Labiszak et al., 2019; Jiang et al., 2019). The idea that the results are revelations indicates how uncritically the authors have accepted the infallibility of the programmes they ran - the ichthyologist Lynne Parenti (pers. comm.) has termed this approach 'plug and play' biogeography. The studies use the same or similar programmes, and so it is not surprising that they 'reveal' the same truth; as Church (1919: 9) wrote a century ago: "The ultra-orthodox botanist may have much in common with an orthodox theologist".

The general model proposed here is presented, not as a revelation, but as a working hypothesis to account for many aspects of biogeography and ecology, including those considered to be anomalous. The standard model of recent radiation does not provide reasoned explanations for many of the patterns in Meliaceae, such as the breaks and disjunctions at the Motagua and Romeral fault systems, at the Cameroon Volcanic Line/Benue Trough, across the tropical Pacific, between the cratonic and accreted parts of New Guinea, at the West Caledonian fault, and many others.

\section{Chronology}

A survey of molecular clock studies on Malesian plants, including the work on Aglaia by Muellner et al. (2008a), stressed that: "All of the studies included used fossils to calibrate molecular evolutionary rates (either directly or secondarily) and thus the inferred ages were minima" (Crayn et al., 2015). However, in practice, fossilcalibrated, minimum clade ages are often treated as maximum ages. This can be done either informally, or in formal Bayesian analyses by imposing suitable priors, stipulating that a clade cannot be much older than its oldest fossil.

By treating the data in this way, molecular clock studies have concluded that the tribes and genera of Meliaceae all originated in (not 'in or before') the Cenozoic, too late to have been affected by the rifting of Gondwana (Koenen et al., 2015). Thus the trans-oceanic affinities must all be explained by chance, trans-oceanic dispersal. Nevertheless, the result depends on interpreting minimum ages as maximum ages, and the accepted clade ages are probably too young. If the fossil-calibrated clade ages are instead treated as minimum ages, as Crayn et al. (2015) argued they should be, the many disjunctions across ocean basins, for example, are consistent with the fossil record, and can be interpreted as the normal results of plate tectonics rather than chance events. 
The standard view on evolutionary chronology was expressed in a recent study: "fossils know best" (Aghová et al., 2018). But it is only possible to know whether or not fossil-based methods are 'best' by comparing them with others. One other method utilises the geography of clades.

The importance of geography is a recurring theme in current molecular studies. Many authors are finding clades that are incongruent with earlier ideas on morphological homologies and classification, but instead show distinct geographic structure, often much more so than in the earlier arrangements (review in Heads, 2014: 56). Geographic distribution has turned out to be the 'character of characters' for molecular phylogeny in general.

This close relationship between geography and phylogeny can be exploited in dating evolution. Since the $19^{\text {th }}$ century, phylogenies have been calibrated with fossils, but an alternative method calibrates the trees with tectonic events that coincide spatially with the molecular clades (Heads, 2012, 2014; De Baets et al., 2016; Landis, 2017). This methodology incorporates fossils and uses these to give minimum clade ages.

Earlier work correlating distributions with tectonics suggested that many groups thought to be Pleistocene are actually Mesozoic (Craw et al., 1999). This was controversial, but fossil-calibrated clock studies continue to push species dates further back. Working on Cedrela, Cavers et al. (2013) wrote: "the once widely supported Pleistocene refuge theory..., has now been modified by models suggesting much older, Neogene (23-2.5 Ma) origins for diversity at the species level and below... The consequence of this shift in perspective is that palaeogeographical drivers such as Andean uplift, Amazonian marine incursions and the formation of the Isthmus of Panama may have played an equal or stronger role in driving diversification than Pleistocene climate fluctuations...". As mentioned above ('Previous models of Meliaceae biogeography'), recent molecular studies have proposed that plant species (such as Gunnera herteri) and animal species (such as petalurid dragonflies and the frog Leiopelma hochstetteri) originated in the Cretaceous. These are fossil-calibrated, minimum ages.

Evolution in form: ancestral polymorphism, and evolution by recombination of ancestral characters

Throughout the $20^{\text {th }}$ century, the ancestor of any group was accepted as a Platonic ideal - a pure, undifferentiated species (or even parent pair) with a very localised distribution and a single habitat type. From this beginning, the group evolved by radiating out into new morphological, geographical, and ecological space.

However, this model fails to account for many aspects of genetics and biogeography. It now appears more likely that the ancestor of a group was already widespread and diverse before the group itself originated and differentiated into its modern components. Inheritance of ancestral polymorphism is now accepted by many geneticists and is termed 'incomplete lineage sorting' (Heads, 2014: 27). Its effects mimic those of hybridism, but the polymorphism dates back to before, not after, the appearance of the modern groups. The existence of ancestral polymorphism means that extant groups may have no new characters, only new combinations of characters; the characters existed in the ancestors and are older than the groups themselves. 
This new model helps explain the situation in many Meliaceae. For example, in Guarea, Pennington \& Clarkson (2013) noted "an absence of unique characters which could be used to define species groups". In their treatment, "All species were defined on the basis of unique combinations of often quantitative characters, without distinct character states". For Meliaceae as a whole, Pennington \& Styles (1975) wrote: "Many of the structures vary independently and because of this, well-defined sets of characters which can be used to delimit genera clearly, are difficult to find... [Uncertainty in generic and tribal delimitation] has been due to the diffuse and often reticulate nature of the variation... Parallel evolutionary trends are numerous... Some genera and most tribes can only be diagnosed by using a combination of several 'differential' characters... There are no absolutely diagnostic characters that can be used to distinguish Chisocheton from Guarea...".

It is suggested here that the ancestors of the main Meliaceae clades were widespread entities that were highly variable in morphology, based in and around mangrove, and able to survive at least a degree of uplift onto dry land. A modern analogue might be Xylocarpus moluccensis sensu lato: a variable form ranging from East Africa to Tonga in mangrove, and also (X. rumphii-type populations) immediately above the mangrove.

\section{'Basal'vs ancestral character states, and the ancestral ecology of Meliaceae in back- mangrove}

It was once thought that 'common is primitive', and so the ancestral Meliaceae would be located in Malesian rain forest. Later, it became accepted that the characters in a 'basal group' were primitive, and so members of subfamily Cedreloideae would be regarded as primitive. However, a basal group is simply a small sister group, and there is no reason why it should be more primitive than its sister. More recently, it has been assumed that the location, morphology or ecology of a paraphyletic basal grade is ancestral. But a phylogeny: a (b (c (d))) does not imply that clade d evolved from a + $\mathrm{b}+\mathrm{c}$; it is just as likely that a, b, c and d all evolved from common ancestor (Fig. 1). For example, it would usually be assumed that the only true mangrove in Meliaceae, Xylocarpus, must be derived from a dry land ancestor, such as its sister genus Carapa. Instead, it is suggested here that both are derived from a third habitat, the backmangrove. In this habitat, trees typical of mangrove, freshwater swamp forest, terra firme rain forest, and secondary forest can often be found growing together in different micro-habitats.

An origin of Meliaceae by the shore explains many aspects of the biogeography, such as the great overlap of clades. It is also consistent with the ecology of its sister group, Simaroubaceae, which includes the following Malesian species (Nooteboom, 1960): 1. Eurycoma longifolia Jack. Beach forest on sandy soil, primary and secondary forest, heath forest, and kerangas - a characteristic silicicolous species frequent at low altitudes; 2. Quassia indica (Gaertn.) Noot. Wet places in lowland forest below 150 $\mathrm{m}$, sometimes in localities that are periodically inundated by fresh or by salt water, for example, on the edge of the mangrove; it is common in north-eastern Borneo in young swamp forest behind the mangrove. 
The significance of secondary, weedy ecology

The old idea of 'undisturbed tropical forest' is oversimplistic (Willis et al., 2004), and the 'weediness' of many rain forest groups has been underestimated. For example, Mabberley (1992: 241) wrote that "Where large gaps are formed in Ugandan rain forests, such light-demanders as the mahoganies (Meliaceae) become conspicuous, so that it has been suggested that the mahogany-rich forests of West Africa are truly secondary".

In America, work on Swietenia macrophylla (Fig. 15B) showed that "under natural conditions this species regenerates in essentially even-aged stands after catastrophic disturbances destroy many or most trees, and, in the case of fires and flooding, saplings and seedlings as well. Adult mahoganies tend to survive these events, and regenerate by shedding seed onto the resulting gaps or clearings" (Snook, 1996).

A study on Swietenia humilis (Fig. 15A) concluded: "Distances of pollen flow more than 10 times greater than previously reported were detected. Our results show that some tropical angiosperm tree species may be much more adaptable and resilient to habitat destruction and fragmentation than previously considered. ... Despite the high level of fragmentation and small size of the subpopulations there was an extensive network of gene exchange over the spatial scale of the study site" (White et al., 2002).

The 'weediness' of many Meliaceae does not imply that their distribution is the result of chance dispersal. Many groups with a weedy, pioneer ecology are local endemics (Heads, 2006). However, this ecology means that they are able to survive, more or less in situ, even under relatively high levels of disturbance.

Does ecology determine distribution, or does distribution determine ecology?

Species survive (or not) in the area they inherit, not in their optimum environment. Niche models are especially valuable, as they show that species distributions do not simply track suitable environment (Heads, 2015). Climate and other environmental factors may affect the physiognomy of the vegetation, but they do not determine the clades that are present, except on a very small scale. For example, very few species (and no Meliaceae) are shared among the lowland tropical rain forests of America, Africa and Asia. Ecological 'anomalies', such as the populations of Trichilia dregeana near sea level at the mouth of the Congo (Fig. 38), Cedrela in subpáramo, or the highest populations of Munronia pinnata at higher, rather than lower, latitudes (in China), all have heuristic value, as they indicate that factors other than current ecology are in play.

\section{Conclusions}

A biogeographic model for Meliaceae must account for the high level of overlap among the clades, which include four, separate pantropical groups, two in each subfamily. Of the 48 genera in Meliaceae, 11 have been recorded in mangrove or back-mangrove, 10 in swamp forest (either periodically or permanently flooded), 22 on limestone, and 22 
in secondary vegetation. Several species are actively invasive weeds. It is suggested that these features occurred in early members of the group, enabling them to undergo massive range expansion (and overlap) during the last great marine transgressions, in the mid-Cretaceous. The dispersal and range expansion that led to the overlap can thus be explained, not by chance, but by geological events. With the regression of the epicontinental seas, many groups were left stranded in the Amazon basin, the Congo basin, central Australia, and elsewhere.

Along with the great overlap, there is also extensive allopatry within the main clades of Meliaceae. Many of the main boundaries coincide with tectonic structures that were active in the Cretaceous. Many of the most important examples occur in Guatemala (Motagua fault system), western Colombia (Romeral fault system), between Pacific and Caribbean Mexico (at the margin between the craton and the terranes accreted in the Cretaceous), in Amazonia (Cretaceous seas), at the Atlantic Ocean basin (rifting), in SE Brazil and Gabon-Angola (rift shoulder uplift), at the Cameroon Volcanic Line and the adjacent Benue Trough in Nigeria, in the Congo basin (Cretaceous seas), in NE India (at the eastern margin of the Indian plate), in New Guinea (at the boundary between the cratonic and allochthonous sectors), between Solomon Islands-Fiji-New Zealand, and Australia-New Guinea (eastward migration of the Pacific arc from Australia into the Pacific), and across the Pacific (subaerial igneous plateaux that formed in the West Pacific and drifted to America).

Boundaries at the Mozambique Channel coincide with a belt of earlier, Jurassic rifting. In three cases, a Madagascar group is sister to (not nested in) a widespread African group. In two cases, a Madagascar group separates before the African and American components in its sister group do.

Aspects of distribution in Costa Rica-Panama (and Colombian Chocó) were examined above in more detail. A 'Great American Biotic Interchange' across a landbridge there might explain the overlap of distributions and the high diversity, but it does not account for the abrupt boundaries, the high endemism, the strange absences, the large-scale disjunctions, the precise correlations of distributions with allochthonous terranes, or the repetition of all of these in many groups with different ecology. These different phenomena, together with the diversity, can all be explained if a large part of the regional biota, rather than forming in situ, was tectonically introduced with the island arcs and other structures that encroached from the Pacific. The Costa RicaPanama region is an important biogeographic centre in its own right; it is not simply a 'bridge' (or a 'barrier' or 'filter') between North and South America.

Although all the genera of Meliaceae (except Schmardaea) are present in the lowlands, five occur at or above $3000 \mathrm{~m}$ altitude, 12 others at or above $2000 \mathrm{~m}$, and 12 others above $1500 \mathrm{~m}$. These records can be explained most simply by continuous, passive uplift of lowland populations through the Cenozoic in the rapidly rising mountains of the Andes and other ranges. The uplift has also led to the differentiation of many upland species and at least one upland genus, Schmardaea of the northern Andes (Fig. 5). 
When the distribution of Meliaceae is analysed into its separate parts, which is a main task of biogeography, it is seen to be made up of completely recognisable, ordinary components. For example, Meliaceae include three trans-Atlantic, five transIndian and three trans-Pacific clades. All three types of distribution also occur in the family's sister group, the Simaroubaceae (see the section 'Global distribution of Meliaceae and allied families'). In fact, all the patterns discussed in this paper are repeated in many other groups, and this indicates that they are not the result of chance events occurring in individual clades, but have a common cause. In theory this could be tectonic or ecological, but it is difficult to see an ecological explanation for most of the patterns described here.

\section{Future work}

Despite groundbreaking studies on the phylogeny of Meliaceae by Koenen et al. (2015) and others, in several clades the topology is still not well resolved. This is true especially in Dysoxylum sensu lato, but also in the position of Soymida and of Neoguarea, and in the phylogeny of the Carapa-Xylocarpus group. In addition, the species delimitation in many genera, even well-studied ones such as Cedrela and Aglaia, is still far from clear.

Ecological information is often very scanty, and for many species (and even genera, such as Naregamia) there is practically no published data. Good altitudinal information (including both upper and lower limits) is often lacking in what are otherwise excellent treatments. For many taxa there is more published information on their phytochemistry than on the most basic aspects of their distribution and ecology. The data tabulated in Fig. 4 is very incomplete, but hopefully it will stimulate further observations in the field and herbarium. Especially desirable would be treatments of the Meliaceae of Madagascar (also India and Angola) with maps, good illustrations and ecological notes. The Dysoxylum problem has been stressed already and needs resolving, and a revision of Turraea would also be of great interest - some of the forms are remarkable.

ACKNOWLEDGEMENTS. This paper is dedicated to David Mabberley on his $70^{\text {th }}$ birthday, in recognition of his colossal contribution. It is a pleasure to thank David for his unfailing support and encouragement over many years. I am very grateful to Alistair Hay for inviting me to contribute to this Festschrift, and for introducing me to the New Guinea Meliaceae when we were colleagues in Bulolo. I also thank Javiera Cisternas, Daleen Maree, John Grehan, Alexey Shipunov, John Steel, Patricio Saldivia and Sandra Turck for their valuable help obtaining literature. Finally, I'm grateful to Amparo Echeverry, Alistair Hay, David Middleton and Wayne Takeuchi for reading the manuscript and suggesting many useful improvements. 


\section{References}

African Plant Database. (2019). (version 3.4.0). Conservatoire et Jardin botaniques de la Ville de Genève, and South African National Biodiversity Institute, Pretoria. http://www. ville-ge.ch/musinfo/bd/cjb/africa/.

Aghová, T., Kimura, Y., Bryja, J., Dobigny, G., Granjon, L. \& Kergoat, G.J. (2018). Fossils know it best: using a new set of fossil calibrations to improve the temporal phylogenetic framework of murid rodents (Rodentia: Muridae). Molec. Phylogen. Evol. 128: 98-111.

Allan, H.H. (1961). Flora of New Zealand, vol. 1. Wellington: Government Printer.

Andersen, M.J., McCullough, J.M., Mauck III, W.M., Smith, B.T. \& Moyle, R.G. (2018). A phylogeny of kingfishers reveals an Indomalayan origin and elevated rates of diversification on oceanic islands. J. Biogeogr. 45: 269-281.

Anderson, C.L., Bremer, K. \& Friis, E.M. (2005). Dating phylogenetically basal eudicots using $r b c L$ sequences and multiple fossil reference points. Amer. J. Bot. 92: 1737-48.

Appelhans, M.S., Reichelt, N., Groppo, M., Paetzold, C. \& Wen, J. (2018). Phylogeny and biogeography of the pantropical genus Zanthoxylum and its closest relatives in the proto-Rutaceae group (Rutaceae). Molec. Phylogen. Evol. 126: 31-44.

Asuk, S.A., Offiong, E.E., Ifebueme, N.M. \& Akpaso, E.O. (2018). Species composition and diversity of mangrove swamp forest in southern Nigeria. Int. J. Avian Wildlife Biol. 3: $166-171$.

Aubréville, A. (1936). La flore forestière de la Côte d'Ivoire. Paris: Larose.

Ávila A., S. \& Flowers, R.W. (2006). Two new species of Choroterpes Eaton (Ephemeroptera: Leptophlebiidae) from Costa Rica. Zootaxa 1245: 59-68.

Bacon, C.D., Velásquez-Puentes, F.J., Hinojosa, L.F., Schwartz, T., Oxelman, B., Pfeil, B., Arroyo, M.T., Wanntorp, L. \& Antonelli, A. (2018). Evolutionary persistence in Gunnera and the contribution of southern plant groups to the tropical Andes biodiversity hotspot. PeerJ 6: e4388.

Baider, C. \& Florens, F.V. (2016). A new and critically endangered species of Turraea (Meliaceae) endemic to the island of Mauritius. Phytotaxa 247: 219-228.

Backer, C.A. \& Van Steenis, C.G.G.J. (1951). Sonneratiaceae. In: Backer, C.A. \& Van Steenis Flora Malesiana, ser. 1, Seed Plants, vol. 4, pp. 280-289. Djakarta: Noordhoff-Kolff N.V.

Banks, H., Feist-Burkhart, S. \& Klitgaard, B. (2006). The unique pollen morphology of Duparquetia (Leguminosae: Caesalpinioideae): developmental evidence of aperture orientation using confocal microscopy. Ann. Bot. 98: 107-115.

Beaulieu, J.M., Tank, D.C., \& Donoghue, M.J. (2013). Southern Hemisphere origin for campanulid angiosperms, with traces of the breakup of Gondwana. BMC Evol. Biol. 13: 80 .

Bromham, L. (2015). Macroevolutionary patterns of salt tolerance in angiosperms. Ann. Bot. 115: 333-341.

Bromham, L. (2019). Six impossible things before breakfast: assumptions, models, and belief in molecular dating. Trends Ecol. Evol. 34: 474-486.

Brown, G. \& Mies, B. (2012). Vegetation ecology of Socotra. Dordrecht: Springer.

Buchs, D.M., Kerr, A.C., Brims, J.C., Zapata-Villada, J.P., Correa-Restrepo, T. \& Rodríguez, G. (2018). Evidence for subaerial development of the Caribbean oceanic plateau in the Late Cretaceous and palaeo-environmental implications. Earth Planetary Sci. Lett. 499: $62-73$. 
Callmander, M.W., Phillipson, P.B. \& Lowry, P.P. (2012). Novelties from the northern mountains complex of Madagascar. III. Two new species of Turraea L. (Meliaceae). Adansonia 34: 93-102.

Carr, L.M., McLenachan, P.A., Waddell, P.J., Gemmell, N.J. \& Penny, D. (2015). Analyses of the mitochondrial genome of Leiopelma hochstetteri argues against the full drowning of New Zealand. J. Biogeogr. 42: 1066-1076.

Cavers, S., Telford, A., Arenal Cruz, F., Pérez Castañeda, A.J., Valencia, R., Navarro, C., Buonamici, A., Lowe, A.J. \& Vendramin, G.G. (2013). Cryptic species and phylogeographical structure in the tree Cedrela odorata L. throughout the Neotropics. J. Biogeogr. 40: 732-746.

Chapman, V.J. (1976). Mangrove vegetation. Vaduz: Cramer.

Cheek, M. (1991). A new species of Turraea (Meliaceae) from Somalia and a note on the species in continental Africa. Kew Bull. 46: 683-690.

Cheek, M. (1996). The identity of Naregamia Wight \& Arn. (Meliaceae). Kew Bull. 51: 716.

Church, A.H. (1919). Thalassiophyta and the subaerial migration. London: Oxford University Press.

Clark, T.P (1990). Studies in the Trichilia-Walsura complex (Meliaceae). Doctoral thesis, University of Oxford.

Clark, T.P. (1994). The species of Walsura and Pseudoclausena genus novum (Meliaceae). Blumea 38: 247-302.

Clarkson, J.J., Pennington, T.D., Chase, M.W., Haynes, G., Engstrand, R., Kaye, M., Michalak, I. \& Muellner-Riehl, A. (2016). Phylogenetic relationships in Trichilia (Meliaceae) based on ribosomal ITS sequences. Phytotaxa 259: 6-17.

Clayton, J.W., Soltis, P.S. \& Soltis, D.E. (2009). Recent long-distance dispersal overshadows ancient biogeographical patterns in a pantropical angiosperm family (Simaroubaceae, Sapindales). Syst. Biol. 58: 395-410.

Colli, L., Stotz, I., Bunge, H.-P., Smethurst, M., Clark, S., Iaffaldano, G., Tassara, A., Guillocheau, F. \& Bianchi, M.C. (2014). Rapid South Atlantic spreading changes and coeval vertical motion in surrounding continents: Evidence for temporal changes of pressure-driven upper mantle flow. Tectonics 32: 1304-1321.

Collinson, M.E. (1983). Fossil plants of the London Clay. London: The Palaeontological Association.

Corner, E.J.H. (1952). Durians and dogma. Indonesian J. Nat. Sci. 5-6: 141-145.

Corner, E.J.H. (1954). The Durian Theory extended - II. The arillate fruit and the compound leaf. Phytomorphology 4: 263-274.

Corner, E.J.H. (1978). The freshwater swamp-forest of south Johore and Singapore. Singapore: Botanic Gardens, Parks and Recreation Department.

Cota-Sánchez, J.H., Reyes-Olivas, A. \& Abreu, D.D. (2011). Vivipary in the cactus family: a reply to Ortega-Baes' et al. evaluation of 25 species from northwestern Argentina. $J$. Arid Environ. 75: 878-880.

Court, A.J. \& Mitchell, N.D. (1988). The germination ecology of Dysoxylum spectabile (Meliaceae). New Zealand J. Bot. 26: 1-6.

Court, A.J. \& Mitchell, N.D. (1989). The growth responses of Dysoxylum spectabile (Meliaceae) to a shaded environment. New Zealand J. Bot. 27: 353-357.

Couvreur, T.L., Niangadouma, R., Sonké, B. \& Sauquet, H. (2015). Sirdavidia, an extraordinary new genus of Annonaceae from Gabon. PhytoKeys 46: 1-19.

Craw, R.C., Grehan, J.R. \& Heads, M.J. (1999). Panbiogeography: Tracking the history of life. New York: Oxford University Press. 
Crayn, D.M., Costion, C. \& Harrington, M.G. (2015). The Sahul-Sunda floristic exchange: dated molecular phylogenies document Cenozoic intercontinental dispersal dynamics. J. Biogeogr. 42: 11-24.

Cuong, N.T., Hoan, D.T. \& Mabberley, D.J. (2014). Munronia petiolata (Meliaceae), a new species from Vietnam. Blumea 59: 139-141.

Czekanski-Moir, J.E. \& Rundell, R.J. (2019). The ecology of nonecological speciation and nonadaptive radiations. Trends Ecol. Evol. 34: 400-415.

Dargie, G.C., Lewis, S.L., Lawson, I.T., Mitchard, E.T.A., Page, S.E., Bocko, Y.E. \& Ifo, S.A. (2017). Age, extent and carbon storage of the central Congo Basin peatland complex. Nature 542: 86-89.

Davies, H.L. (2012). The geology of New Guinea — the cordilleran margin of the Australian continent. Episodes 35: 87-102.

De Baets, K., Antonelli, A. \& Donoghue, P.C.J. (2016). Tectonic blocks and molecular clocks. Philos. Trans., Ser. B. 371: 20160098.

De Wilde, J.J.F.E. (1968). A revision of the species of Trichilia P. Browne (Meliaceae) on the African continent. Meded. Landbouwhogeschool Wageningen 68 (2): 1-207.

De Wilde, J.J.F.E. (2007). A revision of the African genus Heckeldora (Meliaceae). Blumea 52: 179-199.

Denyer, P. \& Baumgartner, P.O. (2006). Emplacement of Jurassic-Lower Cretaceous radiolarites of the Nicoya Complex (Costa Rica). Geol. Acta 4: 203-218.

Ding Hou (1958). Rhizophoraceae. In: Van Steenis, C.G.G.J. (ed.) Flora Malesiana, ser. 1, Seed Plants, vol. 5, pp. 429-493. Djakarta: Noordhoff-Kolff N.V.

Dowling, R.M. \& McDonald, T.J. (1982). Mangrove communities of Queensland. In: Clough, B.F. (ed.) Mangrove ecosystems in Australia: structure, function and management, pp. 79-93. Canberra: Australian Institute of Marine Science/Australian National University Press.

Duretto, M.F., Wilson, P.G. \& Ladiges, P.Y. (2013). Boronia. In: Wilson, A.J.G. (ed.) Flora of Australia, vol. 26, pp. 124-282. Canberra: Australian Biological Resources Study, and Melbourne: CSIRO Publishing.

Earle Smith, C. (1960). A revision of Cedrela (Meliaceae). Fieldiana, Bot. 29: 295-341.

Farnsworth, E. (2000). The ecology and physiology of viviparous and recalcitrant seeds. Annual Rev. Ecol. Syst. 31: 107-138.

Flowers, R.W. \& Ávila A., S. (2006). Biogeographical and ecological notes on the genus Tikuna Savage, Flowers, and Porras (Ephemeroptera: Leptophlebiidae) from Central and South America. Entomol. News 117: 133-138.

Fosberg, F.R. (1974). Miscellaneous notes on the flora of Aldabra and neighbouring islands: III. Kew Bull. 29: 253-266.

Givnish, T.J. (2015). Adaptive radiation versus 'radiation' and 'explosive diversification': why conceptual distinctions are fundamental to understanding evolution. New Phytol. 207: 297-303.

González, C., Urrego, L.E., Martínez, J.I., Polanía, J. \& Yokoyama, Y. (2010). Mangrove dynamics in the southwestern Caribbean since the 'Little Ice Age': a history of human and natural disturbances. The Holocene 20: 849-861.

Grande, L. (2016). Donn Rosen and the perils of paleontology. In: Crother, B.I. \& Parenti, L.R. (eds) Assumptions inhibiting progress in comparative biology, pp. 159-168. Boca Raton, FL: Taylor \& Francis.

Grau, H.R. (2000). Regeneration patterns of Cedrela lilloi (Meliaceae) in northwestern Argentina subtropical montane forests. J. Trop. Ecol. 16: 227-242. 
Griffiths, C.J. (1993). The geological evolution of East Africa. In: Lovett, J.C. \& Wasser, S.K. (eds) Biogeography and ecology of the rain forests of eastern Africa, pp, 9-21. Cambridge: Cambridge University Press.

Griffiths, M.E. (1959). A revision of the African species of Terminalia. Bot. J. Linn. Soc. 55: 818-907.

Grudinski, M., Wanntorp, L., Pannell, C.M. \& Muellner-Riehl, A.N. (2014a). West to east dispersal in a widespread animal-dispersed woody angiosperm genus (Aglaia, Meliaceae) across the Indo-Australian Archipelago. J. Biogeogr. 41: 1149-1159.

Grudinski, M., Pannell, C.M., Chase, M.W., Ahmad, J.A. \& Muellner-Riehl, A.N. (2014b). An evaluation of taxonomic concepts of the widespread plant genus Aglaia and its allies across Wallace's Line (tribe Aglaieae, Meliaceae). Molec. Phylogen. Evol. 73: 65-76.

Guillocheau, F., Chelalou, R., Linol, B., Dauteuil, O., Robin, C., Mvondo, F., Callec, Y. \& Colin, J.P. (2015). Cenozoic landscape evolution in and around the Congo Basin: constraints from sediments and planation surfaces. In: De Wit, M.J., Guillocheau, F. \& De Wit, M.C. (eds) Geology and resource potential of the Congo Basin, pp. 271-313. Berlin: Springer.

Guo, Z., Guo, W., Wu, H., Fang, X., Ng, W.L., Shi, X., Liu, Y., Huang, Z., Li, W., Gan, L. et al. (2018). Differing phylogeographic patterns within the Indo-West Pacific mangrove genus Xylocarpus (Meliaceae). J. Biogeogr. 45: 676-689.

Guppy, H.B. (1906). Observations of a naturalist in the Pacific between 1896 and 1899, vol. II. Plant-dispersal. London: Macmillan.

Hall, R. (2017). Southeast Asia: new views of the geology of the Malay Archipelago. Ann. Rev. Earh Planet. Sci. 45: 331-358.

Hallé, F., Oldeman, R.A.A. \& Tomlinson, P.B. (1978). Tropical trees and forests: An architectural analysis. New York: Springer.

Harms, H. (1940). Meliaceae. In: Engler, A. \& Prantl, K. (eds) Die natürlichen pflanzenfamilien, $2^{\text {nd }}$ edition, vol. 19b, pt. 1, pp. 1-172. Leipzig: W. Engelmann.

Hauenschild, F., Favre, A., Michalak, I. \& Muellner-Riehl, A.N. (2018). The influence of the Gondwanan breakup on the biogeographic history of the ziziphoids (Rhamnaceae). $J$. Biogeogr. 45: 2669-2677.

Hay, A. (1998). The genus Alocasia (Araceae-Colocasieae) in West. Malesia and Sulawesi. Gard. Bull. Singapore 50: 221-334.

Hay, A. \& Mabberley, D.J. (1991). 'Transference of function' and the origin of aroids: their significance in early angiosperm evolution. Bot. Jahrb. Syst. 113: 339-428.

Heads, M. (2001). Regional patterns of biodiversity in New Guinea plants. Bot. J. Linn. Soc. 136: $67-73$.

Heads, M. (2003). Ericaceae in Malesia: vicariance biogeography, terrane tectonics and ecology. Telopea 10: 311-449.

Heads, M. (2006). Seed plants of Fiji: an ecological analysis. Biol. J. Linn. Soc. 89: 407-431.

Heads, M. (2012). Molecular panbiogeography of the tropics. Berkeley, California: University of California Press.

Heads, M. (2014). Biogeography of Australasia: A molecular analysis. Cambridge, UK: Cambridge University Press.

Heads, M. (2015). Biogeography by revelation: investigating a world shaped by miracles. Austral. Syst. Bot. 27: 282-304.

Heads, M. (2016). Pan-biogeografia da América do Sul. In: de Carvalho, C.J.B. \& Almeida, E.A.B. (eds) Biogeografia da América do Sul: Análise de tempo, espaço e forma, pp. 57-103. Rio de Janeiro: Roca. 
Heads, M. (2017). Biogeography and evolution in New Zealand. Boca Raton, FL: Taylor \& Francis.

Heads, M. (2019). Passive uplift of plant and animal populations during mountain-building. Cladistics. https://doi.org/10.1111/cla.12368.

Hemp, A., Zimmermann, R., Remmele, S., Pommer, U., Berauer, B., Hemp, C. \& Fischer, M. (2017). Africa's highest mountain harbours Africa's tallest trees. Biodivers. \& Conservation 26: 103-113.

Hetherington, A.M. (2015). Special issue: Evolutionary plant radiations. New Phytol. 207: 249-479.

Hochmuth, K. \& Gohl, K. (2017). Collision of Manihiki Plateau fragments to accretional margins of northern Andes and Antarctic Peninsula. Tectonics 36: 229-240.

Hochmuth, K., Gohl, K., Uenzelmann-Neben, G. \& Werner, R. (2019) Multiphase magmatic and tectonic evolution of a large igneous plateau: evidence from the crustal structure of the Manihiki Plateau, western Pacific. Tectonophysics 750: 434-457.

Holland, S.M. (2016). The non-uniformity of fossil preservation. Philos. Trans., Soc. B 371 (1699): p.20150130.

Holmgren, M., Poorter, L., \& Siepel, A. (2004). What explains the distribution of rare and endemic West African plants? In: Poorter, L., Bongers, F., Kouamé, F.N. \& Hawthorne, W.D. (eds) Biodiversity of West African forests: an ecological atlas of woody plant species, pp. 73-86. Wallingford, UK: CABI.

Jeffrey, C. (1988). [Review of] The Plant Book. Kew Bull. 43: 722-724.

Jestrow, B., Gutiérrez Amaro, J. \& Francisco-Ortega, J. (2012). Islands within islands: a molecular phylogenetic study of the Leucocroton alliance (Euphorbiaceae) across the Caribbean Islands and within the serpentinite archipelago of Cuba. J. Biogeogr. 39: 452-464.

Jiang, Y., Gao, M, Meng, Y., Wen, J., Ge, X.-J., \& Nie, Z.-L. (2019). The importance of the North Atlantic landbridges and eastern Asia in the post-Boreotropical biogeography of the Northern hemisphere as revealed from the poson ivy genus (Toxicodendron, Anacardiaceae). Molec. Phylogen. Evol. Doi.org/10.1016/j.ympev.2019.106561

Johnson, D.M. \& Murray, N.A. (2018). A revision of Xylopia L. (Annonaceae): the species of tropical Africa. PhytoKeys 97: 1-252.

Johnson, M.A., Clark, J.R., Wagner, W.L. \& Mcdade, L.A. (2017). A molecular phylogeny of the Pacific clade of Cyrtandra (Gesneriaceae) reveals a Fijian origin, recent diversification, and the importance of founder events. Molec. Phylogen. Evol. 116: 30-48.

Kalinganire, A., \& Pinyopusarerk, K. (2000). Chukrasia: biology, cultivation and utilisation. ACIAR Technical Reports [Canberra] No. 49. Canberra: Australian Centre for International Research.

Kalinganire, A., Pinyopusarerk, K. \& Williams, E.R. (2002). Geographic variation in seedling morphology of Chukrasia species. Austral. J. Bot. 50: 319-330.

Kalkman, V.J., Dijkstra, K.-D. B., Dow, R.A., Stokvis, F.R. \& Van Tol, J. (2018). Out of Australia: the Argiolestidae reveal the Melanesian Arc System and East Papua Composite Terrane as possible ancient dispersal routes to the Indo-Australian Archipelago (Odonata: Argiolestidae). Int. J. Odonatol. 21: 114.

Keay, R.W.J. (1958). Meliaceae. In: Hutchinson, J. \& Dalziel, J.M. (eds) Flora of West Tropical Africa, $2^{\text {nd }}$ edition, vol. 1, pp. 697-709. London: Crown Agents for Overseas Governments and Administrations.

Kelly, D.L., Tanner, E.V.J., Kapos, V., Dickinson, T.A., Goodfriend, G.A. \& Fairbairn, P. (1988). Jamaican limestone forests: floristics, structure and environment of three examples along a rainfall gradient. J. Trop. Ecol. 4: 121-156. 
Kenfack, D. (2011a). Resurrection in Carapa (Meliaceae): a reassessment of morphological variation and species boundaries using multivariate methods in a phylogenetic context. Bot. J. Linn. Soc. 165: 186-221.

Kenfack, D. (2011b). A synoptic revision of Carapa (Meliaceae). Harvard Pap. Bot. 16: 171231.

Kilian, N., Hein, P. \& Hubaishan, M.A. (2004). Further notes on the flora of the southern coastal mountains of Yemen. Willdenowia 34: 159-183.

Koecke, A.V., Muellner-Riehl, A.N., Pennington, T.D., Schorr, G. \& Schnitzler, J. (2013). Niche evolution through time and across continents: the story of Neotropical Cedrela (Meliaceae). Amer. J. Bot. 100: 1800-1810.

Köcke, A.V., Muellner-Riehl, A.N., Cáceres, O. \& Pennington, T.D. (2015). Cedrela ngobe (Meliaceae), a new species from Panama and Costa Rica. Edinburgh J. Bot. 72: 225-233.

Koenen, E. (2011). Phylogenetic and biogeographic studies in Guareeae (Meliaceae: Melioideae). Thesis, Wageningen University.

Koenen, E.J. \& de Wilde, J.J. (2012). A taxonomic revision of the reinstated genus Leplaea and the newly recognized genus Neoguarea (Meliaceae, Sapindales): the exclusion of Guarea from Africa. Plant Ecol. Evol. 145: 209-241.

Koenen, E.J., Clarkson, J.J., Pennington, T.D. \& Chatrou, L.W. (2015). Recently evolved diversity and convergent radiations of rainforest mahoganies (Meliaceae) shed new light on the origins of rainforest hyperdiversity. New Phytol. 207: 327-339.

Łabiszak, B., Zaborowska, J. \& Wachowiak, W. (2019). Patterns of mtDNA variation reveal complex evolutionary history of relict and endangered peat bog pine (Pinus uliginosa). AoB PLANTS 11: plz015.

Landis, M.J. (2017). Biogeographic dating of speciation times using paleogeographically informed processes. Syst. Biol. 66: 128-144.

Leroy, J.-F. (1958a). Les Acajous de Madagascar (Khaya et Neobeguea). Compt. Rend. Acad. Sci. Paris 246: 2638-2641. [= Leroy, J.-F. (1958). Contributions à l'étude des forêts de Madagascar. J. Agric. Trop. Bot. Appl. 5: 593-595].

Leroy, J.-F. (1958b). Recherches sur les Meliaceae: sur un genre africano-malgache, le Lepidotrichilia (Harms) J. F. Leroy. Compt. Rend. Acad. Sci. Paris 247: 1025-1027. [= Leroy, J.F. (1958). Contributions à l'étude des forêts de Madagascar II.-Sur un genre africano-malgache: le Lepidotrichilia (Harms)]. J. Agric. Trop. Bot. Appl. 5: 673-675].

Leroy, J.-F. (1958c). Recherches sur les Meliaceae: le Capuronianthus, genre nouveau endémique à Madagascar, type de la tribu des Capuroniantheae trib. nov., sousfamille des Carapoideae subf. nov. Compt. Rend. Acad. Sci. Paris 247: 1374-1376.

Leroy, J.-F. (1958d). Recherches sur les Meliaceae: sur un genre endémique à Madagascar, l'Astrotrichilia (Harms) J. F. Leroy (14 especes). Compt. Rend. Acad. Sci. Paris 247: 1889-1891. [= Leroy, J.-F. (1958). Contributions à l'étude des forêts de Madagascar. IV. Sur un genre endémique de Madagascar: l'Astrotrichilia. J. Agric. Trop. Bot. Appl. 5: 861-862].

Leroy, J.-F. (1964). Contributions à l'étude des forêts de Madagascar. VII. Recherches sur les Meliaceae: le Malleastrum (Baill.) J. F. Ler., genre nouveau endémique de la Grande Ile et des Comores. J. Agric. Trop. Bot. Appl. 11: 127-149.

Leroy, J.-F. (1970). Le genre Neobeguea (Méliacée). J. Agric. Trop. Bot. Appl. 17: 232-233.

Leroy, J.-F. (1976). Essais de taxonomie syncretique. 1. Etude sur les Meliaceae de Madagascar. Adansonia sér. 2, 16: 167-203. 
Leroy, J.-F. (1989). Taxonomie des Meliaceae malgaches: espèces nouvelles du genre Malleastrum (Baillon) J.-F. Leroy. Bull. Mus. Nat.. Hist. Nat., B, 4è sér., Adansonia 11: 397-402.

Leroy, J.-F., \& Lescot, M. (1996). Taxons nouveaux de Trichilieae (Meliaceae-Melioideae) de Madagascar. Bull. Mus. Natl. Hist. Nat., B, 4è série, Adansonia 18: 3-34.

Li, H.T., Yi, T.-S., Gao, L.-M., Ma, P.-F., Zhang, T., Yang, J.-B., Gitzendanner, M.A., Fritsch, P.W., Cai, J. et al. (2019). Origin of angiosperms and the puzzle of the Jurassic gap. Nature Plants 5: 461-470.

Lian, L., Xiang, K.-L., Ortiz, R. del C. \& Wang, W. (2019). A multi-locus phylogeny for the Neotropical Anomospermeae (Menispermaceae): Implications for taxonomy and biogeography. Molec. Phylogen. Evol. 136: 44-52.

Lim, J.Y. \& Marshall, C.R. (2017). The true tempo of evolutionary radiation and decline revealed on the Hawaiian archipelago. Nature 543: 710-713.

Lloyd, F.E. (1902). Vivipary in Podocarpus. Torreya 2: 113-117.

Lomolino, M.V. \& Brown, J.H. (2009). The reticulating phylogeny of island biogeography theory. Quart. Rev. Biol. 84: 357-390.

Londres, M., Schulze, M., Staudhammer, C.L. \& Kainer, K.A. (2017). Population structure and fruit production of Carapa guianensis (Andiroba) in Amazonian floodplain forests: implications for community-based management. Trop. Conservation Sci. 10: p. 1940082917718835 .

Louchart, A., Bastian, F., Baptista, M., Guarino-Vignon, P., Hume, J.P., Jacot-des-Combes, C., Mourer-Chauviré, C., Hänni, C. \& Ollivier, M. (2018). Ancient DNA reveals the origins, colonization histories, and evolutionary pathways of two recently extinct species of giant scops owl from Mauritius and Rodrigues Islands (Mascarene Islands, south-western Indian Ocean). J. Biogeogr. 45: 2678-2689.

Mabberley, D.J. (1979). The species of Chisocheton (Meliaceae). Bull. Brit. Mus. (Nat. Hist.) Bot. 6: 301-386.

Mabberley, D.J. (1988). Meliaceae. In: Morat, P. \& Mackee, H.S. (eds) Flore de la NouvelleCalédonie et Dépendances, vol. 15, pp. 17-89. Paris: Muséum National d'Histoire Naturelle.

Mabberley, D.J. (1992). Tropical rain forest ecology. $2^{\text {nd }}$ edition. New York: Chapman \& Hall. Mabberley, D.J. (1995). Meliaceae. (Aglaia by C.M. Pannell). In: Dassanayake, M.D., Fosberg, F.R. \& Clayton W.A. (eds) A revised handbook to the Flora of Ceylon, vol. 9, pp. 228300. New Delhi: Amerind Publishing.

Mabberley, D.J. (2003). New species of, and other notes on, Chisocheton and Walsura (Meliaceae). Gard. Bull. Singapore 55: 189-200.

Mabberley, D.J. (2007). Meliaceae. In: Soepadmo, E., Saw, L.G., Chung, R.C.K. \& Kiew, R. (eds) Tree flora of Sabah and Sarawak, pp. 17-218. Kuala Lumpur: Forest Research Institute Malaysia, Sabah Forestry Department and Sarawak Forestry Department.

Mabberley, D.J. (2011). Meliaceae. In: Kubitzki, K. (ed.) Flowering Plants. Eudicots, vol. 10, Sapindales, Cucurbitales, Myrtaceae, pp. 185-211. Berlin: Springer.

Mabberley, D.J. (2013). Meliaceae [Aglaia by C.M. Pannell). In: Wilson, A. (ed.) Flora of Australia, vol. 26, pp. 1-42. Canberra: CSIRO Publishing.

Mabberley, D.J. (2017). Mabberley's plant-book: A portable dictionary of plants, $4^{\text {th }}$ edition. Cambridge, UK: Cambridge University Press.

Mabberley, D.J., Pannell, C.M. \& Sing, A.M. (eds) (1995). Meliaceae. Flora Malesiana, ser. 1, Seed Plants, vol. 12, pt. 1. Leiden: Foundation Flora Malesiana.

Mateos, M., Sanjur, O.I. \& Vrijenhoek, R.C. (2002). Historical biogeography of the livebearing fish genus Poeciliopsis (Poeciliidae: Cyprinodontiformes). Evolution 56: 972-984. 
Meijer, W. (1970). Botanical notes on Ceylon trees. I. Soymida febrifuga (Roxb.) Juss. (Meliaceae) indigenous in Ceylon. Ceylon Forest. 9: 95-97.

Monteillet, J. \& Lappartient, J.-R. (1981). Fruits et graines du Crétacé Supérieur des Carrieres de Paki (Senegal). Rev. Palaeobot. Palynol. 34: 331-344.

Monthe, F.K., Migliore, J., Duminil, J., Bouka, G., Demenou, B.B., Doumenge, C., BlancJolivet, C., Ekué, M.R.M. \& Hardy, O.J. (2019). Phylogenetic relationships in two African Cedreloideae tree genera (Meliaceae) reveal multiple rain/dry forest transitions. Perspect. Pl. Ecol. Evol. Syst. 37: 1-10.

Moore, L.B. \& Irwin, J.B. (1978). Oxford book of New Zealand Plants. Auckland: Oxford University Press.

Muellner, A.N. \& Mabberley, D.J. (2008). Phylogenetic position and taxonomic disposition of Turraea breviflora (Meliaceae), a hitherto enigmatic species. Blumea 53: 607-616.

Muellner, A.N., Savolainen, V., Samuel, R. \& Chase, M.W. (2006). The mahogany family 'outof-Africa': divergence time estimation, global biogeographic patterns inferred from $r b c L$ DNA sequences, extant, and fossil distribution of diversity. Molec. Phylogen. Evol. 40: 236-250.

Muellner, A.N., Vassiliades, D.D. \& Renner, S.S. (2007). Placing Biebersteiniaceae, a herbaceous clade of Sapindales, in a temporal and geographic context. Pl. Syst. Evol. 266: 233-252.

Muellner, A.N., Pannell, C.M., Coleman, A. \& Chase, M.W. (2008a). The origin and evolution of Indomalesian, Australasian and Pacific island biotas: insights from Aglaieae (Meliaceae, Sapindales). J. Biogeogr. 35: 1769-1789.

Muellner, A.N., Samuel, R., Chase, M.W., Coleman, A. \& Stuessy, T.F. (2008b). An evaluation of the tribes and of generic relationships in Melioideae (Meliaceae) based on nuclear ITS ribosomal DNA. Taxon 57: 98-106.

Muellner, A.N., Pennington, T.D., Koecke, A.V. \& Renner, S.S. (2010). Biogeography of Cedrela (Meliaceae, Sapindales) in Central and South America. Amer. J. Bot. 97: 511518.

Muellner-Riehl, A.N., Weeks, A., Clayton, J.W., Buerki, S., Nauheimer, L., Chiang, Y.C., Cody, S. \& Pell, S.K. (2016). Molecular phylogenetics and molecular clock dating of Sapindales based on plastid $r b c L$, atpB and trnL-trnF DNA sequences. Taxon 65: 10191036.

Nadkarni, N.M. (1981). Canopy roots: convergent evolution in rainforest nutrient cycles. Science 214: 1023-1024.

Navalón, G., Bright, J.A., Marugán-Lobón, J., \& Rayfield, E.J. (2019). The evolutionary relationship between beak shape, mechanical advantage, and feeding ecology in modern birds. Evolution 73: 422-435.

Navarro, C., Ward, S. \& Hernández, M. (2002). The tree Cedrela odorata (Meliaceae): a morphologically subdivided species in Costa Rica. Revista Biol. Trop. 50: 21-29.

Nei, M. (2013). Mutation-driven evolution. New York: Oxford University Press.

Nooteboom, H.P. (1960). Simaroubaceae. In: Van Steenis, C.G.G.J. (ed.) Flora Malesiana, ser. 1, Seed Plants, vol. 6, pp.193-226. Groningen: Wolters-Noordhoff.

Novick, R.R., Dick, C.W., Lemes, M.R., Navarro, C., Caccone, A. \& Bermingham, E. (2003). Genetic structure of Mesoamerican populations of Big-leaf mahogany (Swietenia macrophylla) inferred from microsatellite analysis. Molec. Ecol. 12: 2885-2893.

Pagel, M.D. \& Meade, A. (2007). BayesTraits. http://www.evolution.reading.ac.uk/BayesTraits. html.

Palacios, W.A. (1994). Especies nuevas de Meliaceae del Ecuador y areas adyacentes. Novon 4: $155-163$. 
Palacios, W.A., Santiana, J. \& Iglesias, J. (2019). A new species of Cedrela (Meliaceae) from the eastern flanks of Ecuador. Phytotaxa 393: 84-88.

Pannell, C.M. (1992). A taxonomic monograph of the genus Aglaia Lour. (Meliaceae). Kew Bull. Add. Series 16. London: HMSO.

Pannell, C.M. (2004). Three new species, two new subspecies and five new combinations at the subspecific level in Aglaia Lour. (Meliaceae). Kew Bull. 59: 87-94.

Pannell, C.M. (2005). Aglaia soepadmoi Pannell (Meliaceae), a new species for Borneo. Gard. Bull. Singapore 57: 183-185.

Pannell, C.M. (2007). Aglaia Lour. In: Soepadmo, E., Saw, L.G., Chung, R.C.K., \& Kiew, R. (eds) Tree flora of Sabah and Sarawak, vol. 6, pp. 24-107. Kuala Lumpur: Forest Research Institute Malaysia, Sabah Forestry Department and Sarawak Forestry Department.

Peng, H., Mabberley, D.J., Pannell, C.M., Edmonds, J.M. \& Bartholomew, B. (2008). Meliaceae. In: Wu, Z.Y., Raven, P.H. \& Hong, D.Y. (eds) Flora of China, vol. 11, pp. 98-131. Beijing: Science Press; and St. Louis: Missouri Botanical Garden.

Pennington, T.D. (1969). Materials for a monograph of the Meliaceae. I. A revision of the genus Vavaea. Blumea 17: 351-366.

Pennington, T.D. (2002). Mahogany carving a future. Biologist [London] 49: 204-208.

Pennington, T.D. (2016). Systematic treatment of American Trichilia (Meliaceae). Phytotaxa 259: $18-162$.

Pennington, T.D. \& Clarkson, J.J. (2013). A revision of Guarea (Meliaceae). Edinburgh J. Bot. 70: $179-362$.

Pennington, T.D. \& Muellner, A.N. (2010). A monograph of Cedrela (Meliaceae). Sherborne, UK: DH Books.

Pennington, T.D. \& Styles, B.T. (1975). A generic monograph of the Meliaceae. Blumea 22: 419-540.

Pennington, T.D., Styles B.T. \& Taylor, D.A.H. (1981). Meliaceae. Flora Neotropica, vol. 28. New York: NYBG Press.

Perdices, A., Bermingham, E., Montilla, A. \& Doadrio, I. (2002). Evolutionary history of the genus Rhamdia (Teleostei: Pimelodidae) in Central America. Molec. Phylogen. Evol. 25: $172-189$.

Pfeil, B.E. \& Crisp, M.D. (2008). The age and biogeography of Citrus and the orange subfamily (Rutaceae: Aurantioideae) in Australasia and New Caledonia. Amer. J. Bot. 95: 16211631.

Philipson, W.R. (1978). Araliaceae: growth forms and shoot morphology. In: Tomlinson, P.B. \& Zimmerman, M. (eds) Tropical trees as living systems, pp. 269-284. Cambridge, UK: Cambridge University Press.

Pigg, K.B., DeVore, M.D., Benedict, J.C. \& Creekmore, R.M.(2014). Fruits of Melia (Meliaceae, Melioideae) from the Middle Miocene Yakima Canyon flora of central Washington State, USA. In: Stevens, W.D., Montiel, O.M., \& Raven P. (eds) Paleobotany and biogeography: A festschrift for Alan Graham in his 80th year, pp. 326-337. Chicago: University of Chicago Press.

Pindell, J.L. \& Kennan, L. (2009). Tectonic evolution of the Gulf of Mexico, Caribbean and northern South America in the mantle reference frame: an update. Geol. Soc. London Special Publ. 328: 1-55.

Potts, A.J. (2017). Catchments catch all in South African coastal lowlands: topography and palaeoclimate restricted gene flow in Nymania capensis (Meliaceae) - a multilocus phylogeographic and distribution modelling approach. PeerJ 5: e2965. 
Prance, G. (1994). A comparison of the efficacy of higher taxa and species numbers in the assessment of biodiversity in the neotropics. Phil. Trans., Ser. B 345: 89-99.

Price, J.P. \& Wagner, W.L. (2018). Origins of the Hawaiian flora: phylogenies and biogeography reveal patterns of long-distance dispersal. J. Syst. Evol. 56: 600-620.

Puentes, D.A. (2005). Flora de la Republica de Cuba. Liechtenstein: A.R. Ganther.

Randrianarivony, T.N., Randriatsivery, M.F., Andriamihajarivo, T.H. \& Callmander, M.W. (2017). Une nouvelle espèce de Turraea (Meliaceae) du Sud-Ouest de Madagascar. Candollea 72: 283-288.

Reid, E.M. \& Chandler, M.E.J. (1933). The London Clay flora. London: British Museum (Natural History).

Ribeiro, A.C. (2006). Tectonic history and the biogeography of the freshwater fishes from the coastal drainages of eastern Brazil: an example of faunal evolution associated with a divergent continental margin. Neotrop. Ichthyol. 4: 225-246.

Richards, P.W., with contributions by Walsh, R.P.D., Baillie, I.C. \& Grieg-Smith, P. (1996). The tropical rainforest. $2^{\text {nd }}$ edition. Cambridge, UK: Cambridge University Press.

Rivas-Torres, G. \& Rivas, M.G. (2018). Allelopathic impacts of the invasive tree Cedrela odorata L. (Meliaceae, Sapindales: Magnoliidae) in the Galapagos flora. In: de Lourdes Torres, M. \& Mena, C.F. (eds) Understanding invasive species in the Galapagos Islands: From the molecular to the landscape, pp. 77-93. Cham, Switzerland: Springer.

Rueangruea, S., Tagane, S., Suddee, S., Tetsana, N., Poopath, M., Nagamasu, H. \& Naiki, A. (2015). Toona calcicola, a new species and Reinwardtiodendron humile, a new record to Thailand. Thai Forest Bull., Bot. 43: 79-86.

Savage, H.M., Flowers, R.W. \& Porras, V. W. (2005) Rediscovery of Choroterpes atramentum in Costa Rica, type species of Tikuna new genus (Ephemeroptera: Leptophlebiidae: Atalophlebiinae), and its role in the 'Great American Interchange'. Zootaxa 932: 1-14. Simpson, G.G. (1953). The major features of evolution. New York: Columbia University Press. Slavenko, A., Feldman, A., Allison, A, Bauer, A.M., Böhm, M., Chirio, L., Colli, G.R., Das, I., Doan, T.M., LeBreton, M. et al. (2019). Global patterns of body size evolution in squamate reptiles are not driven by climate. Global Ecol. Biogeogr. 28: 471-483.

Smith, A.C. (1985). Meliaceae. In: Smith, A.C. (ed.) Flora Vitiensis nova: a new flora of Fiji (spermatophytes only), vol. 3, pp. 527-578. Lawai, Kauai: Pacific Tropical Botanical Garden.

Smith, S.A., Beaulieu, J.M. \& Donoghue, M.J. (2010). An uncorrelated relaxed-clock analysis suggests an earlier origin for flowering plants. Proc. Natl. Acad. Sci. U.S.A. 107: 58975902.

Snook, L.K. (1996). Catastrophic disturbance, logging and the ecology of mahogany (Swietenia macrophylla King): grounds for listing a major tropical timber species in CITES. Bot. J. Linn. Soc. 122: 35-46.

Soepadmo, E. (1972). Fagaceae. In: Van Steenis, C.G.G.J. (ed.) Flora Malesiana, ser. 1, Seed Plants, vol. 7, pp. 265-403. Leyden: Noordhoff.

Soepadmo, E., Saw, L.G., Chung, R.C.K., Wong, K.M. \& Kiew, R. (eds) (1995-2014) Tree flora of Sabah and Sarawak, vols. 1-8. Kuala Lumpur: Forest Research Institute of Malaysia, Sabah Forestry Department and Sarawak Forestry Department.

Soulebeau,A., Aubriot, X., Gaudeul, M., Rouhan, G., Hennequin, S., Haevermans, T., Dubuisson, J.Y. \& Jabbour, F. (2015). The hypothesis of adaptive radiation in evolutionary biology: hard facts about a hazy concept. Organisms Diversity Evol. 15: 747-761.

Staner, P. \& Gilbert, G. (1958). Meliaceae. In: Robyns, W. (ed.) Flore du Congo Belge et du Ruanda-Urundi, vol. 7, pp. 147-213. Bruxelles: Institut National pour l'Étude Agronomique du Congo Belge. 
Stevens, P.F. (2001 onwards). Angiosperm phylogeny website. Version 14, July 2017. www. mobot.org/mobot/research/apweb/welcome.html. Accessed 20 Mar. 2019.

Styles, B.T. \& Bennett, S.T. (1992). Notes on the morphology, chemistry, ecology, conservation status and cytology of Schmardaea microphylla (Meliaceae). Bot. J. Linn. Soc. 108: 359-373.

Styles, B.T. \& White, F. (1991). Meliaceae. In: Polhill, R.M. (ed.) Flora of Tropical East Africa. 68 pp. Rotterdam: Balkema.

Sun, G., Dilcher, D.L., Wang, H. \& Chen, Z. (2011). A eudicot from the Early Cretaceous of China. Nature 471: 625-628.

Takeuchi, W. (2007). Additions to the flora of the Strickland Basin, Papua New Guinea: Hypserpa calcicola (Menispermaceae), a new species from the southern limestone. Harvard Papers Bot. 13: 277-283.

Takeuchi, W. (2008). Additions to the flora of the Strickland Basin, Papua New Guinea: Fittingia paniculata (Myrsinaceae), a new calciphilous species from the southern limestone. Harvard Papers Bot. 13: 267-271.

Takeuchi, W. (2009a). Occurrence records in Papuasian Aglaia (Meliaceae): A. pannelliana and $A$. puberulanthera from the Southern Karst of Papua New Guinea. Harvard Papers Bot. 14: 31-38.

Takeuchi, W. (2009b). Dysoxylum middletonianum (Meliaceae), a distinctive new species from the Southern Fold Mountains of Papua New Guinea. Edinburgh J. Bot. 66: 347-353.

Takeuchi, W. (2010). A new addition to the endemic genus Fittingia (Myrsinaceae) of New Guinea: F. headsiana from the southern limestone, with a synoptical key to the species. Harvard Papers Bot. 15: 37-40.

Takeuchi, W. (2011). Notes on Papuasian Sapindaceae: Harpullia mabberleyana sp. nov., Harpullia rhachiptera and Lepisanthes mixta. Edinburgh J. Bot. 68: 1-9.

Tilney, P.M., Nel, M. \& van Wyk, A.E. (2018). Foliar secretory structures in Melia azedarach (Meliaceae), a widely cultivated and often invasive tree. New Zealand J. Bot. 56: 198215.

Tomlinson, P.B. (1986). The botany of mangroves. Cambridge: Cambridge University Press.

Umhoefer, P.J. (2003). A model for the North America Cordillera in the early Cretaceous: tectonic escape related to arc collion of the Guerrero terrane and a change in North America plate motion. In: Johnson, S.E. Paterson, S.R. Fletcher, J.M. Girty, G.H. Kimbrough, D.L. \& Martín-Barajas, A. (eds) Tectonic evolution of northwestern México and the southwestern USA. Geol. Soc. America Special Paper, vol. 374, pp. 117-134. The Geological Society of America.

Van Balgooy, M.M.J. (1966). Vavaea Bth. Pacific Plant Areas 2. Blumea Suppl. 5: 92-93.

Van Balgooy, M.M.J. (1971). Plant genera of the Pacific as based on a census of phanaerogam genera. Blumea Suppl. 6: 1-222.

Van Steenis, C.G.G.J. (1950). Contributions to the history of botany and exploration in Malaysia. Bull. Jard. Bot. Buitenzorg, ser. 3, vol. 18: 463-471.

Van Steenis, C.G.G.J. (1958). Rhizophoraceae: ecology. In: Van Steenis, C.G.G.J. (ed.) Flora Malesiana, ser. 1, Seed Plants, vol. 5, pp. 429-444. Djakarta: Noordhoff-Kolff N.V.

Van Steenis, C.G.G.J. (1981). Rheophytes of the world: an account of the flood-resistant flowering plants and ferns and the theory of autonomous evolution. Rockville, MD: Sijthoff and Noordhoff.

Ware, J.L., Beatty, C.D., Sánchez Herrera, M., Valley, S.A., Johnson, J.T., Kerst, C., May, M.L. \& Theischinger, G. (2014). The petaltail dragonflies (Odonata: Petaluridae): Mesozoic 
habitat specialists that survive to the modern day. J. Biogeogr. 41: 1291-1300.

Weber, M.B.I., Cardona, A., Paniagua, F., Cordani, U., Sepúlveda, L. \& Wilson, R. (2009). The Cabo de la Vela Mafic-Ultramafic Complex, Northeastern Colombian Caribbean region: a record of multistage evolution of a Late Cretaceous intra-oceanic arc. Geol. Soc. London Special Publ. 328: 549-568.

White, F. (1986). The taxonomy, chorology and reproductive biology of southern African Meliaceae and Ptaeroxylaceae. Bothalia 16: 143-168.

White, F. \& Styles, B.T. (1963). Meliaceae. In: Exell, A.W., Fernandes, A. \& Wild, H. (eds) Flora Zambesiaca, vol. 2, pp. 285-319. London, UK: Crown Agents.

White, F. \& Styles, B.T. (1986). Meliaceae. In: Leistner, O.A. (ed.) Flora of Southern Africa, vol. 18, pp. 39-61. Pretoria, South Africa: Botanical Research Institute, Department of Ariculture and Water Supply.

White, G.M., Boshier, D.H. \& Powell, W. (2002). Increased pollen flow counteracts fragmentation in a tropical dry forest: an example from Swietenia humilis Zuccarini. Proc. Natl. Acad. Sci. U.S.A. 99: 2038-2042.

Whitmore, T.C. (1984). The tropical rain forests of the Far East, $2^{\text {nd }}$ edition. Oxford: Oxford University Press.

Willis, K.J., Gillson, L. \& Brncic, T.M. (2004). How “virgin” is virgin rainforest? Science 304: 402-403.

Wongprasert, T., Phengklai, C. \& Boonthavikoon, T. (2011). Synoptic account of the Meliaceae of Thailand. Thai Forest Bull., Bot. 39: 210-266.

WWF (World Wildlife Fund) (2019). Eastern Africa: central Tanzania extending into Kenya. https://www.worldwildlife.org/ecoregions/at0109.

Yakusu, E.K., Monthe, F.S., Bourland, N., Hardy, O.J., Louppe, D., Lokanda, F.B.M., Hubau, W., Muhongya, J.-M.K., Bulcke, J.V. van, Acker, J. van et. al. (2018). Le genre Entandrophragma (Meliaceae): taxonomie et écologie d'arbres africains d'intérêt économique (synthèse bibliographique). Biotechnol. Agron. Soc. Environm. 22: 113127.

Yu, X.Q., Gao, L.M., Soltis, D.E., Soltis, P.S., Yang, J.B., Fang, L., Yang, S.X. \& Li, D.Z. (2017). Insights into the historical assembly of East Asian subtropical evergreen broadleaved forests revealed by the temporal history of the tea family. New Phytol. 215: 1235-1248. 
